University of Louisville

ThinkIR: The University of Louisville's Institutional Repository

Electronic Theses and Dissertations

$12-2004$

\title{
Cases of university faculty conceptions and practices of teaching, assessment and action research.
}

Carol Dianne Raubenheimer 1959-

University of Louisville

Follow this and additional works at: https://ir.library.louisville.edu/etd

\section{Recommended Citation}

Raubenheimer, Carol Dianne 1959-, "Cases of university faculty conceptions and practices of teaching, assessment and action research." (2004). Electronic Theses and Dissertations. Paper 1185.

https://doi.org/10.18297/etd/1185

This Doctoral Dissertation is brought to you for free and open access by ThinkIR: The University of Louisville's Institutional Repository. It has been accepted for inclusion in Electronic Theses and Dissertations by an authorized administrator of ThinkIR: The University of Louisville's Institutional Repository. This title appears here courtesy of the author, who has retained all other copyrights. For more information, please contact thinkir@louisville.edu. 


\title{
CASES OF UNIVERSITY FACULTY CONCEPTIONS AND PRACTICES OF
}

TEACHING, ASSESSMENT AND ACTION RESEARCH

$$
\text { By }
$$

Carol Dianne Raubenheimer

B.Sc. University of Natal, South Africa

B.Sc. (Honours) University of Natal, South Africa

M.Sc. University of Natal, South Africa

Advanced Diploma in Adult Education, University of Natal, South Africa

M.Ed. University of Natal, South Africa

\author{
A Dissertation \\ Submitted to the Faculty of the \\ Graduate School of the University of Louisville \\ in Partial Fulfillment of the Requirements \\ for the Degree of
}

Doctor of Philosophy

College of Education and Human Development

University of Louisville

Louisville, Kentucky

In Cooperation with Western Kentucky University

December 2004 
Copyright 2004 by Carol Dianne Raubenheimer

All rights reserved 
By

Carol Dianne Raubenheimer

B.Sc. University of Natal, South Africa, 1979

B.Sc. (Honours) University of Natal, South Africa, 1980

M.Sc. University of Natal, South Africa, 1986

Advanced Diploma in Adult Education, 1991

M.Ed. University of Natal, South Africa, 1996

A Dissertation Approved on

23 August, 2004

By the following Dissertation Committee:

Dr. Joseph Petrosko: Chairperson

Dr. Thomas Reio: Co-Chairperson

Dr. Jeanne Fienne

Dr. Andrew Kemp

Dr. Sharon Spall 


\section{DEDICATION}

This dissertation is dedicated to my late mother,

Alice Sylvia Ashington,

who always encouraged my studies and

who believed it important for women to educate themselves. 


\section{ACKNOWLEDGEMENTS}

I wish to thank Dr. Joseph Petrosko and Dr. Thomas Reio for taking over this dissertation in mid-stream after the resignation of my initial advisor, Dr. Sandra Mathison, who I also thank for her early involvement. Particularly, I thank Dr. Reio for dealing with day-to-day items and for positive and friendly assistance in the lonely journey of dissertation writing. I would also like to thank all of the other committee members who have provided feedback and support over the last few years. Thank you to Steven, my husband, for ongoing involvement and providing a listening ear to many frustrations regarding this work. Additionally, I thank my former colleagues, Sr. Sharon Sullivan $(\mathrm{PhD})$ and Dr. Robert Pierce for their interest in the work and helping me to maintain the writing momentum.

This work was supported in part by the NASA Opportunities for Visionary Academics (NOVA) (a higher education faculty development program) funded by the National Aeronautic and Space Administration (NASA). The views expressed are those of the authors. 


\begin{abstract}
CASES OF HIGHER EDUCATION FACULTY CONCEPTIONS AND PRACTICES OF TEACHING, ASSESSMENT AND ACTION RESEARCH
\end{abstract}

Dianne Raubenheimer

August, 2004

Conceptions of teaching and learning held by faculty in higher education broadly reflect two dominant approaches, those that are teacher-focused and content oriented, and those that are student-focused and learner oriented (Entwistle, Skinner, Entwistle \& Orr, 2000). Conceptions of teaching may be reflected in the pedagogical choices and practices of instructors, but this has not been well established at college level. Thus, an examination of such conceptions may advance the understanding of good teaching at the college level (Fernandez-Balboa \& Stiehl, 1995). Using a case study approach this research (a) examined conceptions of teaching and learning, assessment, and action research held by selected science faculty in higher education involved in NOVA (NASA Opportunities for Visionary Academics) funded courses, and (b) explores the relationship among conceptions and their practices.

The dissertation is divided into six chapters. Chapter One provides a rationale and conceptual framework for the study, which is embedded in (a) research on the scholarship of teaching and learning (SOTL), (b) research on faculty conceptions, 
epistemological assumptions and approaches to teaching, learning and assessment, (c) research on faculty conceptions of research and action research practices, and (d) research on faculty professional development. Chapter Two is a review of the literature relating to these four areas of research and educational development.

Chapter Three outlines the research methodology employed. A case study approach was selected because there have been few studies of faculty conceptions and practices, particularly in depth case studies that examine the relationship among conceptions and associated practices.

Chapter Four and Five present the results of the study. In Chapter Four, five detailed individual case narratives are presented, one for each of the five professors who participated in the research. The study participants ratified these as a member check to validate the findings. Chapter Five is a cross-case analysis of emerging themes and issues and reflects both common trends, as well as differences, among the cases. The cross-case analysis is related to the research questions for the study. The results show that in general conceptions of teaching and assessment are associated with practices of these phenomena. However, there are a number of interesting anomalies relating to the less well-known phenomenon of action research, and these are explored more fully.

Chapter Six links the research findings with the relevant literature and draws on Bandura's social cognitive theory as an explanatory construct. Particularly, it is important to note that environmental conditions act as a third factor in reciprocal relationships with personal factors (including conceptions) and behavior (teaching practices). 


\section{TABLE OF CONTENTS}

\section{PAGE}

ACKNOWLEDGEMENTS iv

ABSTRACT

LIST OF TABLES

$\mathrm{V}$

LIST OF FIGURES

$\mathrm{x}$ vii

INTRODUCTION

Rationale for this Research Area 2

$\begin{array}{ll}\text { Conceptual Framework } & 6\end{array}$

Conceptions of the Scholarship of Teaching and 7

Learning

Conceptions of Teaching, Learning and Assessnnent 8

Conceptions of Research and Action Research 10

Faculty Development 11

$\begin{array}{ll}\text { Context of the Study } & 13\end{array}$

$\begin{array}{ll}\text { Purpose } & 15\end{array}$

Research Questions 16

$\begin{array}{ll}\text { LITERATURE REVIEW } & 17\end{array}$

Teacher Preparation in Science and Mathematics 18

The scholarship of teaching and learning in higher education 26

Effective teaching in higher education $\quad 40$

Conceptions of Teaching, Learning, Assessment and Research 48 
Conceptions of Teaching and Learning 48

Conceptions of Assessment $\quad 61$

$\begin{array}{ll}\text { Conceptions of Research } & 70\end{array}$

$\begin{array}{ll}\text { Action Research } & 74\end{array}$

Action research in NOVA $\quad 86$

Professional Development of Faculty 90

$\begin{array}{ll}\text { Summary } & 101\end{array}$

$\begin{array}{lr}\text { METHODOLOGY } & 103\end{array}$

$\begin{array}{ll}\text { Key terms } & 104\end{array}$

$\begin{array}{ll}\text { Research Design } & 105\end{array}$

Rationale for case study approach 106

$\begin{array}{ll}\text { Participants } & 110\end{array}$

$\begin{array}{ll}\text { Selection of sites and participants } & 110\end{array}$

$\begin{array}{ll}\text { Data collection and analysis } & 113\end{array}$

$\begin{array}{ll}\text { Case records } & 115\end{array}$

$\begin{array}{ll}\text { Site visits } & 115\end{array}$

$\begin{array}{ll}\text { Faculty interviews } & 116\end{array}$

$\begin{array}{ll}\text { Artifacts } & 119\end{array}$

$\begin{array}{ll}\text { Classroom observations } & 120\end{array}$

$\begin{array}{ll}\text { Student interviews } & 121\end{array}$

Survey Instruments $\quad 121$

$\begin{array}{ll}\text { Case study narrative } & 123\end{array}$

$\begin{array}{ll}\text { Cross-case analysis } & 124\end{array}$ 
Reliability and validity

Dealing with reliability

Dealing with validity

Evaluating case reports

Ethical considerations

Limitations

Introducing the five professors

Kenneth Lane

Teaching and Learning: Conceptions

Teaching and Learning: Practices

Comparison of Conceptions and Practices

Assessment: Conceptions

Assessment: Practices

Comparison of Conceptions and Practices

Action Research: Conceptions

Action Research: Practices

Comparison of Conceptions and Practices

Conclusion

John Walton

Teaching and Learning: Conceptions

Teaching and Learning: Practices

Comparison of Conceptions and Practices 
Assessment: Conceptions

Assessment: Practices

Comparison of Conceptions and Practices

Action Research: Conceptions

Action Research: Practices

Comparison of Conceptions and Practices

Conclusion

Bruce Stevenson

Teaching and Lcarning: Conceptions

Teaching and Learning: Practices

Comparison of Conceptions and Practices

Assessment: Conceptions

Assessment: Practices

Comparison of Conceptions and Practices

Action Research: Conceptions

Action Research: Practices

Comparison of Conceptions and Practices

Conclusion

Todd Andrews

Teaching and Learning: Conceptions

Teaching and Learning: Practices

Comparison of Conceptions and Practices 
Assessment: Practices

Comparison of Conceptions and Practices

Action Research: Conceptions

Action Research: Practices

Comparison of Conceptions and Practices

Conclusion

William Rogers

Teaching and Learning: Conceptions

Teaching and Learning: Practices

Comparison of Conceptions and Practices

Assessment: Conceptions

Assessment: Practices

Comparison of Conceptions and Practices

Action Research: Conceptions

Action Research: Practices 256

Comparison of Conceptions and Practices

Conclusion

Summary

Faculty conceptions and practices

Conceptions: Teaching and Learning

Practices: Teaching and Learning 
Summary of Cross-case Themes

Conceptions: Assessment

Practices: Assessment

Comparison of Conceptions and Practices: Assessment

Summary of cross-case themes 288

Conceptions: Action Research 289

Practices: Action Research 295

Comparison of Conceptions and Practices: Action 299

Research

Summary of cross-case themes

Theories of action and theories-in use

Scholarship of teaching and learning in practice

Summary

Faculty conceptions and practices: Teaching and learning

Faculty conceptions and practices: Assessment

Faculty conceptions: Action research

Conceptual change

Social learning theory as a model for changing concepts

and practices

Implications for faculty development initiatives

Recommendations for future study 


\section{REFERENCES}

APPENDICES

Appendix A: Introductory email

Appendix B: Faculty interview questions

Appendix C: Esteem classroom observation instrument

Appendix D: Student interview questions

Appendix E: Approaches to teaching inventory

Appendix F: Modified STEBI B instrument

Appendix G: Esteem assessment of classroom learning

in science inventory

Appendix $\mathrm{H}$ : Subject informed consent form

CURRICULUM VITAE 


\section{LIST OF TABLES}

\section{TABLE}

PAGE

1. Multidimensional Model of Scholarship of Teaching

2. A Summary of Teaching Orientations and Belief

Dimensions (after Samuelowicz \& Bain, 2001)

3. A Summary of Assessment Orientations and Belief

Dimensions (after Samuelowicz \& Bain, 2002)

4. Sources and Method of Data Collection and Analysis 114

5. The Professors and the Courses Taught

6. A Comparison of the Properties and Associated Dimensions of

Teaching and Learning that are Espoused and Practiced: Dr. Lane

7. A Comparison of the Properties and Associated Dimensions of

Assessment that are Espoused and Practiced: Dr. Lane

8. A Comparison of the Properties and Associated Dimensions of

Action Research that are Espoused and Practiced: Dr. Lane

9. A Comparison of the Properties and Associated Dimensions of

Teaching and Learning that are Espoused and Practiced: Dr. Walton

10. A Comparison of the Properties and Associated Dimensions of

Assessment that are Espoused and Practiced Dr. Walton

11. A Comparison of the Properties and Associated Dimensions of Action Research that are Espoused and Practiced: Dr. Walton 
12. A Comparison of the Properties and Associated Dimensions of

Teaching and Learning that are Espoused and Practiced: Dr. Stevenson

13. A Comparison of the Properties and Associated Dimensions of 200 Assessment that are Espoused and Practiced Dr. Stevenson

14. A Comparison of the Properties and Associated Dimensions of 206 Action Research that are Espoused and Practiced: Dr. Stevenson

15. A Comparison of the Properties and Associated Dimensions of Teaching and Learning that are Espoused and Practiced: Dr. Andrews

16. A Comparison of the Properties and Associated Dimensions of 228 Assessment that are Espoused and Practiced Dr. Andrews

17. A Comparison of the Properties and Associated Dimensions of 234 Action Research that are Espoused and Practiced: Dr. Andrews

18. A Comparison of the Properties and Associated Dimensions of Teaching and Learning that are Espoused and Practiced: Dr. Rogers

19. A Comparison of the Properties and Associated Dimensions of Assessment that are Espoused and Practiced Dr. Rogers

20. A Comparison of the Properties and Associated Dimensions of Action Research that are Espoused and Practiced: Dr. Rogers

21. A Comparison of the Properties of Teaching Espoused by Different Professors

22. A Comparison of the Properties of Teaching Practiced by Different Professors

23. A Comparison of the properties of teaching Espoused and 
Practiced by different Professors

24. A Comparison of the Properties of Assessment Espoused by Different 281 Professors

25. A Comparison of the Properties of Assessment Practiced by Different 286 Professors

26. A Comparison of the Conceptions and Practices of Assessment of Different Professors

27. A Comparison of the Properties of Action Research Espoused by 290 Different Professors

28. A Comparison of the Properties of Action Research Practiced by 295 Different Professors

29. A Comparison of the Conceptions and Practices of Action Research 299 of Different professors

30. Multidimensional Model of Scholarship of Teaching

31. Analysis of the Scholarship of Teaching of Five Professors 


\section{LIST OF FIGURES}

FIGURES

PAGE

1. Intersection of Overlapping Concepts 7

2. A Model of the Scholarship of Teaching 30

3. .Fox's Dimensions of Teaching 49

4. Relationship among Different Traditions in the Study of Practice 78

5. ATI scores for Dr. Lane 140

6. Results of the Esteem Observation Instrument for Dr. Lane 144

7. Results of the Assessment of Classroom Learning in Science Inventory 150 for Dr. Lane

8. Star Diagram for Action Research Practices of Dr. Lane 155

9. ATI Scores for Dr. Walton 163

10. Results of the Esteem Observation Instrument for Dr. Walton. 164

11. Results of the Assessment of Classroom Learning in Science Inventory 172 for Dr. Walton.

12. Star Diagram for Action Research Practices of Dr. Walton 180

13. ATI Scores for Dr. Stevenson 190

14. Results of the Esteem Observation Instrument for Dr. Stevenson 192

15. Results of the Assessment of Classroom Learning in Science Inventory 199 for Dr. Stevenson 
16. Star Diagram for Action Research Practices of Dr. Stevenson 
17. ATI Scores for Dr. Andrews 215

18. Results of the Esteem Observation Instrument for Dr. Andrews. 218

19. Results of the Assessment of Classroom Learning in Science Inventory 227 for Dr. Andrews

20. Star Diagram for Action Research Practices of Dr. Andrews 231

21. ATI Scores for Dr. Rogers 242

22. Results of the Esteem Observation Instrument for Dr. Rogers. 244

23. Results of the Assessment of Classroom Learning in Science Inventory 252 for Dr. Rogers

24. Star Diagram for Action Research Practices of Dr. Rogers 256

25. Intersection of Teaching Strategy and Teaching Intention 264

26. Intersection of Knowledge Orientation and Assessment Strategy 280

27. Intersection of Outcome Focus and Research Strategy 289

28. Schematization of the Relations between Three Classes of Determinants 332 in Triadic Reciprocal Causation 


\section{CHAPTER 1}

\section{INTRODUCTION}

In 1990, Ernest Boyer opened the debate about the role of faculty in higher education in the U.S. by publishing Scholarship reconsidered: Priorities of the professoriate (Boyer, 1990). He was concerned about an overemphasis on research and publications at the expense of teaching and learning in institutions of higher education. He called for teaching to be recognized as a scholarly activity and began developing mechanisms for appraising faculty work. Since then, there have been several definitions for and research on the scholarship of teaching and learning (SOTL).

Areola, Theall and Aleamoni (2003), extending Boyer's work, suggested that there are several core activities associated with the professoriate and presented a model that represents the complexity of the work of the professor, dividing the profession into the "base profession" and the "meta-profession". The "base profession" is the faculty member's area of content expertise, methods of keeping abreast in his/her field, and the clinical and research skills appropriate to that field. The "meta-profession" consists of the broad range of skills and the ways in which the role of all professors is the same, and includes the skills associated with teaching.

This dissertation aims to explore how science faculty at a range of institutions in the U.S. conceptualize and implement their work in instructional design, delivery, assessment and action research and is therefore embedded in the research on the scholarship of teaching and learning (SOTL). 
In summarizing the Educational Research Information Center (ERIC) trends on teaching and learning for 1999-2000 Kezar (2002a) noted four themes that have continued from the late 1990s. These are (a) active learning, (b) assessment or student outcomes, (c) diversity, and (d) integrating technology, with the technology theme being dominant. The active learning theme promotes the use of teaching strategies that engage students in the learning process, such as through debates and dialogue, collaborative learning groups, service learning and learning communities. She added that while the literature used to be dominated by administrative and policy issues, this has given way to a greater concern for teaching and learning. This may reflect a "desire to move towards conceptualizing teaching as scholarship" (p. 1) as opposed to teaching as craft.

In terms of trends in faculty related issues, Kezar (2002b) wrote that most of the literature dealt with service conditions, such as role definition, workload, preparation, and stress. She added, "teaching and service remain areas not well understood or documented" (p. 1) although there was a move towards recognizing classroom research as a method for "creating teaching and learning communities with the shared goal of understanding learning well enough to improve it” (p. 6). So, research on teaching as scholarship is still a developing field of study in the U.S.

Kember (1997) suggested that there is a continuum of conceptions held by faculty about teaching, with the existence of an intermediate category as faculty transition from teacher-focused conceptions towards more participative and student-centered approaches. While there is some evidence for this intermediate category (Fox, 1983: Trigwell, Prosser \& Taylor, 1994; van Driel, Verloop, van Werven \& Dekkers, 1997), this has yet to be 
confirmed. Samuelowicz and Bain (2001) showed that a transition category did not exist in a study of 39 academics in 8 disciplines, but in contrast that a broad separation existed between the two dominant approaches to teaching. Kember (1997) also called for more research on the relationship between categories and the way in which conceptions may change over time. This current study may contribute to the discussion about a transition category. Additionally, a review of relevant literature revealed that there have been few comparable studies on faculty conceptions undertaken in the U.S. and this was confirmed by personal communication with Professors Trigwell, Biggs, Bain and Samuelowicz. This study is timely in the context of the U.S.A.

Effective and diverse student assessment practices include authentic assessment and regular feedback to students and are aimed at enhancing student learning (Angelo \& Cross, 1993). However, classroom assessment practices in higher education are often not congruent with current research-based conceptions of the acquisition of knowledge and skills (Samuelowicz \& Bain, 2002). If conceptions about teaching are linked to conceptions of assessment (Samuelowicz \& Bain, 2002), restructuring the way in which faculty undertake assessment is contingent upon restructuring underlying beliefs about teaching and learning. The literature review did not reveal any U.S. studies on faculty conceptions of assessment, indicating that this is a priority area. Additionally, this study will contribute to an increased understanding of the relationship among conceptions of different aspects of practice (teaching, assessment and action research).

One of the goals of higher education is to provide students with opportunities to learn, gain mastery and understanding of new subject matter. But, it has been established that faculty do not always consider how their own views of teaching and learning impact 
instruction, assessment and student learning (Samuelowicz \& Bain, 2002), and yet there are consequences for student learning that result from different styles of teaching and assessment. Student learning is linked to the style adopted by the instructor, with a deep approach to teaching promoting a deep approach to learning, and a surface approach to teaching fostering a surface approach to learning (Prosser \& Trigwell, 1999). Deep approaches lead to greater conceptual understanding and mastery of the structure of the discipline, while surface approaches promote rote learning.

Most students experience teacher-centered education in higher education in the U.S. (Edgerton, 1997) suggesting that they are more likely to be engaging in surface learning. With the move in the U.S. to providing more content courses to future education majors (U.S. Department of Education, 2002), it is increasingly important that university faculty teaching content courses utilize effective teaching strategies, so that future teachers have good pedagogical practices modeled for them, and so they develop solid conceptual understanding in science. This research will contribute to understanding how content specialists understand the teaching and learning process and what factors enable a shift to more student centered approaches.

Bruner (1996) called the ideas that teachers bring to the teaching and learning situation "folk pedagogy" and added that,

In theorizing about the practice of education in the classroom (or any other setting, for that matter), you had better take into account the folk theories that those engaged in teaching and learning already have. For any innovations that you, as a "proper" pedagogical theorist, may wish to introduce will have to 
compete with, replace, or otherwise modify the folk theories that already guide both teachers and pupils. (p. 46)

Despite such comments, little of the research on teacher's beliefs has entered the field of instructional design and professional development (Moallem \& Earle, 1998). Professional development initiatives tend to proceed on the basis of providing information as opposed to challenging and changing underlying assumptions associated with practices. The uptake of innovation is impacted by faculty beliefs and faculty development initiatives need to take into account the differing perspectives, if they are to be successful (Ho, 1998). The results obtained from this study will be made available to the NOVA (NASA Opportunities for Visionary Academics) facilitators for use in the design of future leadership development conferences and faculty development activities, thereby contributing to an improved faculty development initiative.

Action research has been used extensively as a tool for higher education faculty development in other contexts, such as the University of Hong Kong and in Australia (Kember, 2000), but there have been few reports of its use in universities in the U.S. (Bondy \& Ross, 1998; Ross \& Bondy, 1996). Although action research has been widely applied in school settings in the U.S., one cannot assume that the approach will automatically transfer to the higher education context, and be well received and perceived as a valid tool for facilitating educational change.

Approaches to research typically reflect the disciplinary procedures within which faculty were trained (Huber, 1999), and this may be a factor for consideration in the implementation of action research projects, where the nature and assumptions implicit in action research are foreign to science professors. An analysis of the action research 
proposals of 53 Universities in the NOVA program revealed that the majority of the action research projects were in the initial stages of conceptualization (Raubenheimer, 2003). For instance, little attention was given to instrumentation and methods of data analysis. Most proposals adopted traditional approaches to research rooted in an empirical analytical paradigm where pre-test and post-test designs were dominant, with the focus on student performance rather than faculty roles. This initial work highlights the importance of examining faculty conceptions and approaches to action research. If it is to become accepted as a valid approach for professional development, geared to understanding and changing practices, then it is important to identify faculty conceptions about action research and the value they derive from the outcome of such research initiatives.

Particularly, the literature revealed few studies examining the relationship between different conceptions and between conceptions and practices. There is evidence that conceptions about teaching are directly related to teaching practices (Bain 2000; Hativa , 2001; Quinlan, 1996, 1999a, 1999b; Trigwell \& Prosser, 1996a), but more research into this aspect has been called for. Particularly, there is a need for in depth case studies to explore these issues (Bain, 2000; Quinlan, 1996, 1999a, 1999b; Samuelowicz, 1999).

\section{Conceptual Framework}

There are four main conceptual areas framing this study, (a) research on the scholarship of teaching and learning (SOTL) and faculty conceptions of its meaning, (b) research on faculty conceptions, epistemological assumptions and approaches to teaching, learning and assessment, (c) research on faculty conceptions of research and 
action research practices, and (d) research on faculty professional development. This section provides an overview of research in each area. These are represented below as three intersecting circles, with the focus of this study being primarily on the intersection of $\mathrm{A}$ and $\mathrm{B}$, but with consideration of the implications for the scholarship of teaching and learning and for professional development. It is suggested that professional development is located at the intersection of the three circles because successful professional development initiatives need to take account of these other issues.

A



C

\section{B}

Figure 1. Intersection of Overlapping Concepts.

Conceptions of the Scholarship of Teaching and Learning (SOTL)

In the past decade in the U.S., much consideration has been given to the notion of the scholarship of teaching and learning (SOTL) in higher education (Hutchings \& Schulman, 1999; Schulman 1999). There are several definitions for the scholarship of teaching and learning, but essentially all refer to a greater consideration for how faculty should teach in order to improve student outcomes, how such efforts should be evaluated, 
reported and used for promotion and tenure purposes (Boyer, 1990; Glassick, Huber \& Maeeroff, 1997).

Trigwell, Martin, Benjamin and Prosser (2000) identified five different categories which represent the different ways in which faculty think about teaching scholarship. These were (a) knowledge of the literature related to teaching, (b) improving teaching by reading the literature, (c) improving student learning by investigating one's own teaching, (d) improving student learning using discipline specific literature and knowledge, and (e) investigating and communicating the results of one's own teaching and student learning within the discipline. The categories, from (a) through (e), were ranked as a hierarchy from lower order to higher order conceptions. Thus, a more holistic approach to the scholarship of teaching requires a faculty member to use literature to focus on important issues, to conduct research in his/her own teaching and student outcomes, and to report the findings to the academic community.

\section{Conceptions of Teaching, Learning and Assessment}

Conceptions of teaching and learning held by faculty in higher education broadly reflect two dominant approaches, those that are teacher-focused and content oriented, and those that are student-focused and learner oriented (Entwistle, Skinner, Entwistle \& Orr, 2000). These authors also related conceptions to underpinning epistemological assumptions, with a teacher-focused approach reflecting a dualistic perspective and the student-centered approach reflecting a relativistic position. This categorization follows the work of Perry (cited in Hofer \& Pintrich, 1997), who described a sequence of nine positions, clustered into four dominant ways of knowing in college students, namely, (a) dualism, (b) multiplicity, (c) relativism, and (d) commitment with relativism. As learners 
move through this continuum, they move from an absolutist, right and wrong view of the world, to a view that embraces the contextual relevance of knowledge and the role of values in knowledge construction. Dualism embraces "received knowledge", while commitment with relativism is "constructed knowledge" (Hofer \& Pintrich, 1997, p. 92).

Kember (1997) suggested that the categories of conceptions of teaching and learning are not hierarchically ordered, but a sequenced set of categories, where faculty may move from one conception to another over time, but do not retain the characteristics of their former stance. The "teacher-student interaction" category was considered a transition category between teacher-centered approaches and student-centered approaches. He believed that change was likely to be slow and difficult to effect, "indicative of conceptual change akin to that described in the literature on science concepts" (p. 263), where the resistance of concepts to change has been reported.

Two distinctly different categories of conceptions imply that it might be difficult to shift faculty from one epistemological position to another through faculty development programs, because the two positions are in opposition to each other. In contrast, a continuum of conceptions implies a smoother transition process. Sawyer (1999) also noted that beliefs implicit in the conceptions may be tacit and not openly articulated, making it difficult to bring about change unless they are made explicit.

Samuelowicz and Bain (2002) further showed that conceptions of teaching were linked to faculty conceptions of assessment, with teacher-centered instructors viewing the purpose of assessment as the "reproduction of knowledge" or the "application of knowledge", while student centered faculty were concerned with "assessing student's ability to integrate, transform and use knowledge purposefully" (p. 190). Thus, 
conceptions of teaching are reflected in the pedagogical choices and practices of instructors. An examination of such conceptions may advance the understanding of good teaching at the college level (Fernandez-Balboa \& Stiehl, 1995).

\section{Conceptions of Research and Action Research}

Brew (2001) noted that, "American literature has neglected to consider different conceptions of research held by academics" (p. 272), adding that the ways in which faculty conceptualize the scholarship of teaching are also likely to be related to the ways in which they view research. Examining faculty conceptions of research, she identified four variations, (a) a domino conception in which research was seen as the process of putting together separate elements for problem solving, (b) a layer conception, where research was considered the process of discovering underlying meanings, (c) a trading conception, where research was considered as a market place for the exchange of products, and (d) the journey conception, with research seen as a personal process of discovery and transformation. Different researchers may embrace one or more of these views, but there does not appear to be a continuum of categories, as suggested by Kember (1997) with conceptions of teaching and learning.

Action research is a method for education practitioners to systematically and selfconsciously research classroom actions and outcomes, with the intention of improving their own practice. It begins with the practitioner generating a question about an aspect of his/her action and developing a systematic plan of action for gathering and analyzing data. This might include data collection through self or peer observation, interviews and questionnaires with learners and other participants. Action research is an iterative process involving successive cycles of question generation, planning, action, observation, and 
reflection (Hopkins, 1993). It focuses on action in a particular context with the purpose of improving practice in the future. No literature was found on faculty conceptions of action research, although previous published research with university faculty (Kember, 1998, 2000; Zuber-Skerritt, 1992a, 1992b) has validated the effectiveness of action research as a professional development strategy to develop expertise in teaching. The absence of literature on conceptions of action research opens an area for research.

There have been many calls for classroom-based research to be undertaken by practitioners in higher education in the U.S. (Cross \& Angelo, 1989; Cross, 1998). Cross (1998) noted that that few college teachers know enough about the teaching and learning process, other than through their own experiences, and added that classroom research can contribute to an understanding of teaching and learning processes. While the notion of classroom-based research is relatively new, Bondy and Ross (1998) noted "it fits in with the tradition of action research which has a long history within the educational community" (p. 231), but that it has not been widely applied in higher education in the U.S. This was confirmed by Krockover, Adams, Eichinger, Nakhleh and Shepardson (2001), implying that action research is an emergent area in higher education in the U.S. Faculty Professional Development

Borko and Putnam (1995) working out of a cognitive psychological perspective for the professional development of teachers described the essential knowledge base of teaching as (a) "general pedagogical knowledge", (b) "subject-matter knowledge", and (c) "pedagogical content knowledge" (p. 60). Faculty in higher education are likely to have sound subject-matter knowledge because they teach in the area in which they were schooled. However, they are less likely to have general pedagogical knowledge or 
pedagogical content knowledge, because they have not been trained in pedagogy (Hativa, 2002). They base their general pedagogical knowledge and pedagogical content knowledge on personal experience, trial and error and personal opinion. Borko and Putnam (1995) concluded that

Successful professional development efforts are those that help teachers to acquire or develop new ways of thinking about learning, learners, and subject matter, thus constructing a professional knowledge base that will enable them to teach students in more powerful and meaningful ways. (p. 60)

Most faculty development initiatives in higher education have been skills-based, attempting to increase the repertoire of an instructor's available teaching strategies (Ho, 1998). In contrast, Ho (2000) provided a faculty development model grounded in theories of conceptual change. The model is based on the assumption that to change teaching, it is first necessary to change conceptions. The model is akin to the constructivist conceptual change model developed for restructuring scientific concepts among learners (Driver \& Oldham, 1986). Ho (2000) demonstrated that her conceptual change model was effective in changing the conceptual framework and teaching styles of about two-thirds of participants in the program. Those who did not change their conceptions also did not change their approaches to teaching (Ho, 2000).

Aryris and Schon (1974) noted that "integrating thought with action effectively has plagued philosophers, frustrated social scientists, and eluded professional practitioners for years" (p. 3) and that thought and personal theories do not always match action. They proposed the concepts of theories of action and theories-in-use. A theory of action is the explanation and theoretical knowledge that individuals articulate for dealing 
with practical problems. It is the "espoused theory for that situation" (p. 7) that is supposed to guide a particular behavior or response. In contrast, the theory-in-use is the actual theory that governs action. These authors noted that the two concepts might not be congruent with each other. For instance, a stated theory of action might not be reflected in the associated actions undertaken, resulting in internal inconsistency between thought and action.

In the context of this study, theories of action will be the conception of teaching, learning, assessment and action research that faculty espouse, while the theories-in-use will be evident in actual approaches to teaching, assessment and research. Aryris and Schon (1974) added that the focal point of professional development should be on infusing the various theories of action into a coherent theory of practice. While there is an assumed link between conception and practice, this has not been well studied in higher education (Samuelowicz, 1999).

\section{Context of the Study}

The National Aeronautics and Space Admininistration (NASA) is the U.S. agency responsible for space exploration. NASA Opportunities for Visionary Academics (NOVA) is a NASA-funded program aimed at improving science and mathematics education at Universities across the U.S. by introducing innovative science and mathematics courses for pre-service teachers. The national network consists of more than 80 Universities in 37 states. Courses are housed in a number of different academic units, $61 \%$ in science departments, $9 \%$ in mathematics departments, $22 \%$ in science education or education departments, $1 \%$ in engineering units, $1 \%$ in technology units, $1 \%$ cross listed (interdisciplinary) and 5\% unspecified (Sunal, Kallam, McKinnon, Raubenheimer, Gardner, MacAllistair, et al., 2003). 
In the U.S. teacher preparation in the content area in science is typically undertaken by science professors teaching introductory courses, while science pedagogy is taught by education faculty in methods classes (Carr, 2002). This often leads to a false dichotomy between content knowledge and teaching skills. To address this, NOVA promotes interaction between science and education faculty by involving a team of three faculty members (one from education, one from science, and an administrator) in an initial professional development workshop on trends and approaches in science education, including a focus on inquiry and student-centered approaches to teaching in the content area.

Beginning in 1998, faculty that requested funding from NOVA for implementing new courses were required to develop an action research component in their proposal. The education faculty member on the NOVA team usually took on the role of assisting science faculty in developing action research plans for improving teaching, student learning, and course design. Once funded, the team implements the new science or math course, gathers research data, and submits a final report that includes the results of the action research project.

Each year, follow-up leadership development conferences are held for ongoing faculty development, communication of action research findings and to make available additional professional development and funding opportunities. This context provides an ideal situation for research into issues relating to change and innovation in higher education because of the range of institutions and faculty members involved in the initiative and the database of materials that has been accumulated and housed at the Science Teaching and Learning Center at the University of Alabama, Tuscaloosa. 
NOVA represents an example of a program promoting faculty engagement in alternative teaching and learning practices. Another initiative geared to promoting discourse around teaching in higher education is the American Association for Higher Education (AAHE) Teaching Academy Campus Program, which is one part of the Carnegie Academy for the Scholarship in Teaching and Learning (CASTL) (AAHE, 2002a). The latter program focuses on developing research on teaching and learning across disciplines and on how to assess and document this work, particularly for inclusion in tenure review processes. One difference between the two is that NOVA requires a faculty team to work collaboratively, whilst CASTL worked with individuals nominated to be fulltime research fellows for the period of a year. Thus, NOVA provides a contrasting context for research. While some research has been undertaken in the NOVA program, this will be the first to explore faculty conceptions of teaching and learning, assessment and action research.

\section{Purpose}

The purpose of this research is:

- To examine conceptions of teaching and learning, assessment and action research held by science faculty involved in NOVA funded courses.

- To explore the relationship among these conceptions and actual practices of teaching and learning, assessment and action research.

- To consider the role of action research in faculty development and conceptual change in the context of the NOVA program.

- To consider whether such practices constitute the scholarship of teaching and learning as compared to the literature definitions. 


\section{Research questions}

The research questions follow on from the purpose statements.

- How do science faculty involved in NOVA courses conceptualize teaching, learning, assessment and action research?

- What approaches to teaching, assessment and action research do these faculty employ?

- How do theories of action (conceptions) relate to theories-in-use (practices)?

- Does practice constitute the scholarship of teaching and learning, in relationship to the literature definitions? 


\section{CHAPTER 2}

\section{LITERATURE REVIEW}

This chapter examines literature relevant to the research study, by firstly considering the challenges and context in which science and mathematics teacher educators work in the U.S. Thereafter research on and theories about the scholarship of teaching and learning (SOTL) are reviewed to provide an overview of definitions and the ways in which teaching scholarship is considered in academic settings. The third section considers the nature of effective teaching in higher education and the reciprocal role it plays in student learning. The fourth section examines the literature on faculty conceptions of teaching and learning, assessment and research. Faculty conceptions are often considered important determinants of practice and the relationship between conceptions and practice is explored. Finally, the chapter reviews literature relevant to effective faculty development initiatives.

The literature search was conducted using a systematic approach using the OCLC FirstSearch Database at Brescia University and University of Louisville, keeping a record of keywords, subjects and authors searched by date. Keywords and subjects included higher education, conceptions, beliefs, professors, academics, professional development, assessment, teaching and learning, action research, and epistemology. Access to databases included WorldCat, ERIC, ArticleFirst, Proceedings, Dissertation Abstracts, and Education Abstracts. Articles and books were sourced through interlibrary loan if they were not available in the library or online. Specific articles were located using the 
reference section in articles acquired, particularly review articles and those directly relevant to the topics under consideration.

\section{Teacher Preparation in Science and Mathematics}

This section considers issues relevant to initial teacher preparation in the content areas by science and mathematics professors. A broad picture of the educational scene is painted by exploring research on science and mathematics education, national educational policies, and other factors impacting the effectiveness of initial teacher preparation.

The United States of America is faced with an ongoing shortage of teachers and administrators in $\mathrm{K}-12$ schools, with early retirement, routine retirement, reduced class size and increased student enrollment positively affecting the demand for teachers (American Association for Employment in Education [AAEE], 2001). While the demand may be high, several factors are actually diminishing the supply of new teachers to the workforce, including school violence, poor working conditions and low salaries. For six years in a row, no area had reported a considerable surplus of teachers (AAEE, 2001).

In addition to general teacher shortages, the supply of science and mathematics teachers remains a concern across the nation, with an estimated 240,00 middle and high school science and mathematics teachers being needed by 2011 , representing nearly $70 \%$ new teachers (National Commission on Mathematics and Science Teaching for the $21^{\text {st }}$ Century, 2001). The National Science Teachers Association (NSTA) reported that in $2000,48 \%$ of middle schools and $61 \%$ of high schools already had difficulty in finding qualified science teachers (NSTA, 2000). Clearly, the problems will be exacerbated over the next ten years. NSTA (2000) cited a number of reasons for this state, including high 
teacher turnover due to job dissatisfaction, lack of administrative support and poor salaries. Also, many teachers teach out of their area of certification, almost half of the current teachers are inexperienced, and more than $20 \%$ are not certified (National Commission on Mathematics and Science Teaching for the $21^{\text {st }}$ Century, 2001).

The Commission called for high quality teaching, which necessitates that teachers (a) have a deep knowledge of the discipline, (b) use effective teaching strategies, (c) are certified, (d) focus on student learning, and (e) ensure that inquiry methods are at the heart of science teaching, and problem solving at the heart of mathematics education. However, since the 1960s the number of science course that elementary school teachers are required to take has actually declined (National Association of Colleges, 1996). The National Commission on Mathematics and Science Teaching added that teaching in science and mathematics classes in the US has largely remained unchanged despite the vast number of reform efforts introduced since the 1960s, although Tobias (1991a) previously noted that the reason for the failure of many reform efforts was an emphasis on quick fixes over long-term sustainable change. Yager (1992) also contended that many of the same mistakes still plague the newer reform efforts, such as an over-emphasis on content and course coverage, teacher proofing the curriculum, and a reliance on the development of new materials and texts. He argued that teachers are pivotal to successful curriculum reform efforts and that teachers need to internalize new goals for teaching science for meaningful change to occur. Historically the purpose of science education was on preparing students for subsequent grades, but new goals should emphasize student involvement in using science to solve problems in their own lives and communities. 
These issues have raised increasing concern over the last decade about the quality of teachers prepared by higher education institutions, resulting in the production of a number of reports by the National Science Foundation (NSF, 1996) and the National Research Council (NRC). These reports called for new and revised university curricula, improved pedagogical approaches, subject relevance and greater student participation in course activities (NSF, 1996; NRC, 1997; NRC, 1999, NRC, 2001). The NRC (NRC 1999, 2001) challenged universities to form partnerships with local school districts, and particularly to collaborate across departments in the university to improve science education provision. Interdisciplinary courses and faculty development programs were identified as ways to contribute to improved science and mathematics teacher preparation.

Adding to this, the Association for the Education of Teachers of Science (AETS) (1999) noted that most teacher educators and professors are not adequately prepared for teaching, and developed a set of standards for the preparation of science faculty in higher education, as well as for school-based mentors and personnel providing professional development for teachers. These standards "should provide a clearly defined framework for the knowledge, skills, experiences, attitudes, and habits of mind essential for the successful science teacher educator" (p. 1). They advocated that programs preparing doctoral science education candidates need to align their programs to the following six standards: (a) knowledge of science, not just in one area, but across several science disciplines, (b) science pedagogy, including inquiry based teaching, use of the learning cycle, the role of science and technology in society (STS), and in pedagogical content knowledge (PCK), (c) curriculum, instruction, assessment, and reflective classroom 
teaching, (d) research on learning, cognition, and conceptual change (e) research and scholarly activity through research based projects, conference presentations and publications, and (f) professional development activities, including the co-teaching of methods classes and attendance of in-service workshops. To achieve this, AETS suggested that programs should be developed to train graduates wishing to enter higher education, and should include teaming graduate students with effective professors to mentor and model good teaching. They also advocated providing training for teaching assistants, engaging graduate students in action research processes, and evaluating graduate teaching using the standards outlined.

Science and mathematics teachers are typically prepared in their respective content areas by professors in those disciplines, while methods courses are taught separately by education faculty (Carr, 2002), often developing a schism between content and methods. This is incongruent with the notion of developing pedagogical content knowledge, the knowledge of how to teach specific content within the disciplines (Schulman, 1986). Many of the content professors have little knowledge of how humans think and learn, and little practical teaching experience (Daly, 1994), using lecture as the dominant method of instruction and traditional styles of assessment such as multiple choice, short and answer and grading on the curve (Goubeaud, 2004). Duggan-Haas (1998) highlighted the two different cultures prevailing in science classes versus teacher education classes, drawing the distinction between the underpinning philosophies of science versus education as "(1) 'weeding out' vs nurturing, (2) meritocractic vs democratic, and (3) masculine vs feminine" (p. 3). 
High attrition rates from the sciences in many university courses can be attributed to poor teaching methods, quick-paced didactic instruction, narrow skills-testing on examinations, the absence of an overview of material to be covered, and insufficient opportunities for student participation (Tobias, 1991b; Seymour, 1995). In particular, this resulted in the high dropout of female students from the sciences because their expectations of faculty and instruction were not met (Seymour, 1995). The 2002 National Survey of Student Engagement (NSSE, 2000) showed that students at liberal arts and general colleges are more actively involved in their learning, while students in doctorate granting universities are least involved suggesting that a "teaching as telling" instructional style prevails, even in the senior year.

Additionally, many teacher educators "do not practice what they preach" because they do not adopt teaching styles that demonstrate the expectations of future teachers (Reynolds, McCullough, Bendixen-Noe \& Morrow, 1994, p. 28). This means that many future science and mathematics teachers do not witness good instruction in their college courses, and consequently have a hard time conceptualizing inquiry-based science, because they did not experience it as learners (Reiff, 2002). With the thrust from the Department of Education (US Department of Education, 2002) for more content courses over pedagogical courses, it is increasingly important that future teachers have good teaching modeled for them by the content specialists, so they develop solid conceptual understanding in science and mathematics, as well as experience effective pedagogical practices. Approaches to teaching, attitudes and confidence are influenced by the teacher's own experiences as learners of science (Mulholland \& Wallace, 1996) and so teachers tend to teach as they have been taught (Cross, 1996, Guziec \& Lawson, 2004). 
Because they have not had good teaching modeled for them, this means poor teaching methods infiltrate into schools.

Poor teacher quality is attributed as a major cause in the poor performance by U.S. children in international and national science and mathematics tests. For instance, the U.S. has performed poorly on international standardized tests in mathematics and science, such as the Third International Mathematics and Science Survey (TIMSS), where of 20 nations assessed in advanced mathematics and physics, none scored significantly lower than the USA in mathematics and only one scored lower in physics (National Commission on Mathematics and Science Teaching for the $21^{\text {st }}$ Century, 2001). Similarly, the National Assessment of Educational Progress for 1996 showed that less than one third of all US students in grades 4, 8 and 12 performed at or above proficiency in mathematics and science, with more than a third scoring below basic competence in these subjects (National Commission on Mathematics and Science Teaching for the $21^{\text {st }}$ Century, 2001).

Experiences of badly taught science courses during college years creates a cycle of school teachers entering the work force who do not like science and who do not teach it effectively, leading to students who enter university with the same attitudes, and who continue to experience poor instruction. This creates a continuous cycle of negativity that needs to be broken. For this reason there have been a number of national initiatives to highlight the problems in science and mathematics education, and to make recommendations for improvement in initial teacher preparation and ongoing professional development. 
Such concerns for improving science and mathematics education resulted in the National Committee on Science Education Standards and Assessment (NRC, 1996) and the National Council for Teachers of Mathematics (NCTM, 1991) preparing standards for teaching of these subjects at school level and for initial teacher preparation. Science education should specifically adopt an inquiry-based approach to teaching (NSF, 2000), with a shift away from an accumulation of knowledge to "science as a way of thinking and an attitude of mind" (p. 14). Similarly, mathematics education was seen as a shift towards reasoning, evidence as verification, problem solving and "connecting mathematics, its ideas, and its applications - away from treating mathematics as a body of isolated concepts and procedures" (p. 3).

Additionally, the National Council for the Accreditation of Teacher Education (NCATE) has developed standards for accrediting educational institutions that prepare teachers, including standards for assessing content, pedagogical and professional knowledge, and the skills and dispositions needed to help students to learn (NCATE, 2002). Such standards provide guidelines and benchmarks for institutions preparing teachers. These efforts are geared to breaking the cycle of poor instruction that leads to poor teaching by future teachers.

There are many examples showing that when elementary education majors have good instruction modeled for them, they become more effective teachers. For instance, Bell, Toti, McNall and Tai (2004) found that when preservice teachers were taught about the nature of science using a process-skills based approach, they were likely to implement lessons on the nature of science during their induction year, and into post-induction years. The authors noted that most research on the nature of science has shown that "teachers 
typically fail to develop desired understandings of the nature of science from their subject matter or teacher education coursework" (p22). They attributed their success to a strong emphasis on the nature of science during course work and modeling of effective lessons on the topic.

When preservice elementary teachers are provided with a supportive environment in which they are encouraged to make explicit, examine and restructure their concepts, they are likely to build more appropriate conceptual schema about science concepts, and to restructure their beliefs about teaching science (Mulholland \& Wallace, 1996). Concepts need to be gradually built and introduced using concrete examples. Having cognitive restructuring processing modeled for teachers in turn enables them to use the same processes with their future students, thus "breaking the cycle" (p. 17). New teachers are able to adapt the knowledge and skills they learned at university to their own teaching situations, provided they were taught effectively (Mulholland \& Wallace, 1999).

Similarly, Guziec and Lawson (2004) showed that preservice teachers are more interested in teaching science if they have good instruction modeled for them during their science content courses. Guziec and Lawson (2004) noted that the development of courses that are more appropriate for elementary education majors require "instructors to attempt a different teaching style from how they were taught and have been teaching" (p. 40).

Innovative courses that challenge the dominant practices in science teaching at the college level are urgently needed if there is to be an improvement of teaching at school level, and if the cycle of poor science teaching is to be broken. This is the challenge for 
initial teacher preparation in science and mathematics, and is the context within which the NASA Opportunities for Visionary Academics (NOVA) program works.

The scholarship of teaching and learning in higher education

In this section, consideration is given to the different ways in which the scholarship of teaching (SOTL) is conceptualized and defined. Different authors present different views and frameworks for SOTL and these different perspectives are important for determining whether particular educational practices can be considered scholarly. The relationship of SOTL to disciplinary inquiry is also highlighted.

There are many definitions of what constitutes the scholarship of teaching in universities and the terms tend to be used interchangeably. Experts agree that there is a lack of "broadly acceptable definitions for the scholarship of teaching, scholarly teaching, excellence in teaching, expert teacher, and research on teaching and learning" (Kreber, 2002a, p. 161). This can be attributed to faculty members hold differing conceptions about the value and purposes of the scholarship of teaching and learning (Brew, 1999a).

The roots of the concept can be traced back to 1928 in the inaugural address of the fifth president of the University of Chicago, Robert Maynard Hutchins. He recognized that most $\mathrm{PhD}$ students ultimately became teachers but that they were not prepared for this role (American Association for Higher Education, 2002b). He suggested they

must be in touch with the most recent and most successful movements in undergraduate education, of which he now learns officially little or nothing. How should he learn about them? Not in my opinion by doing practice teaching upon the helpless undergraduate. Rather he should learn about them through seeing 
experiments carried on in undergraduate work by the members of the department in which he is studying for the degree. (p. 2)

This suggested that university faculty should engage in research on teaching and learning within their disciplines and doctoral graduates should learn from these activities.

More recently the discussion about the nature of the scholarship of teaching in higher education can be traced to Boyer's seminal work, Scholarship reconsidered: Priorities of the professoriate (Boyer, 1990), published when he was President of the Carnegie Foundation for Teaching and Learning. In it he outlined four components that are key to what it means to be a scholar: (a) the scholarship of discovery, geared to inquiry for the sake of producing new knowledge, (b) the scholarship of integration, focusing on integrating new knowledge into a larger picture, (c) the scholarship of application, emphasizing the value and use of knowledge, and (d) the scholarship of teaching, involving the dissemination of knowledge as a communal act. He was driven by the belief that an excessive focus on research productivity had created an imbalance in the work of academics in favor of research, but that there should be a balance between these four components in the life of scholars. Most university professors held the belief that they would not get tenure without prolific research publications, and viewed teaching as subordinate to research (Daly, 1994).

Healey (2000) later noted that all four forms of Boyer's scholarship could be applied to the scholarship of teaching as "discovery research into the nature of learning and teaching; integration of material from several disciplines to understand what is going on in the classroom; application of what is known about how students learn to the learning-teaching process; and teaching" (p. 171). This approach emphasizes 
commonalities between the four forms of scholarship and their application to teaching, rather than seeing them as separate entities. Theall and Centra (2001) agreed that all four aspects apply to the scholarship of teaching and learning, and that the person who demonstrates the scholarship of teaching, then, embodies all the forms of scholarship and directs them toward the goal of creating future scholars and arming them with the necessary skills and habits of thought and action that maintain the ongoing cycle of learning and teaching and teaching and learning. (p. 42)

Boyer's publication fueled debate and played a major role in universities across the country reconsidering the way in which they evaluate and reward the work of faculty. Soon after its publication, questions began to be raised about how scholarship should be assessed and there was a call for standards and procedures for measuring faculty performance (Boyer, 1996). Particular facets for which assessment criteria and procedures were needed included personal and professional qualities, faculty performance, and service in professional capacities. This is particularly relevant today because the Carnegie Classifications of university research activities is being revised, to be completed by 2005 , and will include indicators of teaching and service (Atkinson, 2001). Boyer envisioned the development of standards and suggested that the four forms of scholarship, (a) discovery, (b) integration, (c) application, and (d) teaching be placed horizontally on a grid and measured against 6 standards listed vertically. The six standards were "clear goals, appropriate procedures, adequate resources, effective communication, significant results, and careful thought and self-critique"(p. 135). 
This concern for assessment standards, criteria and methods led to a follow up publication by the Carnegie Foundation for the Advancement of Teaching and Learning, Scholarship assessed: Evaluation of the professoriate (Glassick, Huber and Maeeroff, 1997). In it the authors gave more detail of the six standards suggested by Boyer (1996), listing a set of questions that might be used to assess whether the standards had been achieved. They argued that new ways of documenting scholarly activity that go beyond just the written text and that use multiple sources of data were needed. In particular, they recommended the use of portfolios to document the four aspects of scholarship, with evidence including students' test scores, products of teaching, course materials, research on one's own teaching, and videotapes of classroom sessions. The six standards were suggested as the basis for evaluating such portfolios, where portfolios were not exhaustive, but dynamic and aimed at showing that the standards had been met. Boileau (1993) added that the portfolio should increase dialogue on teaching by creating opportunities for discourse among stakeholders, thus acting as a way of legitimizing "teaching conversations and evaluation" (p. 8).

The six criteria produced by Boyer (1996) and Glassick, Huber and Maeeroff (1997) apply to all forms of scholarship, while Kreber and Cranton (2000) produced a set of criteria and indicators that can specifically be applied to formative and summative assessment of what Kreber (1999) called "teaching scholarship". Kreber (2000a) showed that the work of faculty goes beyond just production and includes a multiplicity of skills and tasks. Many of these did not culminate in products, but were still perceived by professors as important in enhancing their scholarship. The three knowledge domains for "teaching scholarship" identified by Kreber and Cranton (2000) are (a) instructional 
knowledge, which is the knowledge that teachers need to teach in the area of instruction, (b) pedagogical knowledge, which refers to what is known about how students learn, and (c) curricular knowledge, which refers to the goals, purposes and rationale of a course of study. Within these domains they added three categories of reflection, (a) content reflection, (b) process reflection, and (c) premise reflection, making a total of nine types of reflection on teaching scholarship. This is replicated in Figure 2.

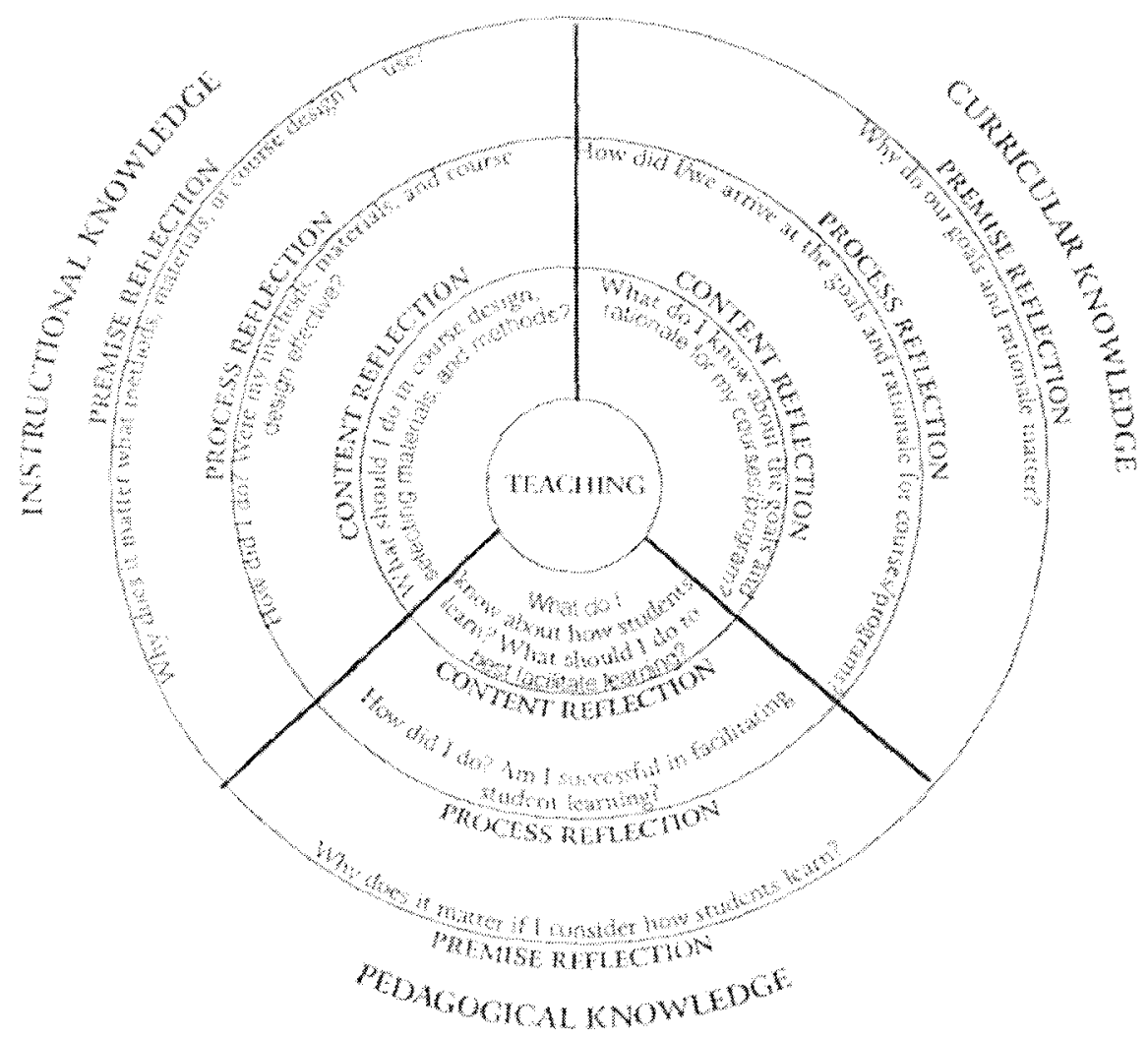

Figure 2. A Model of the Scholarship of Teaching.

From Exploring the scholarship of teaching, by C. Kreber \& P.A.Cranton, 2000, Journal of Higher Education, 71, 476-495.

Indicators were developed for these nine types of reflection performance (Kreber, 1999; Kreber \& Cranton, 2000). The indicators cover both outputs (products) and 
processes of faculty work because Kreber (2000a) considered it important to take into account all the various facets of academic work. In this way they differ from the criteria established by the Carnegie Foundation, which focused only on outputs (Boyer, 1996; Glassick, Huber and Maeeroff, 1997). Richlin (2001) suggested that Kreber and Cranton (2000) "compound, rather than simplify, the definition of the scholarship of teaching" (p. 58) and argued that they were more concerned with scholarly teaching, rather than the scholarship of teaching.

Richlin (2001) distinguished between scholarly teaching and the scholarship of teaching and learning, with the latter being embedded in the broader term of scholarly teaching. She held that scholarly teaching is geared to improving teaching, and that while it adopts a formal, systematic research process, is not geared to public communication and often remains a private activity. In contrast, the scholarship of teaching requires publication and dissemination of the results of one's work. Similarly, Hutchings and Schulman (1999) argued that teaching excellence, in which faculty strive to be good teachers, is the responsibility of all educators, while the scholarship of teaching has four additional criteria, that (a) it becomes public, (b) is open to critical review and evaluation, (c) is in a form that members of the education community can use and build on, and (d) is geared to raising questions for investigation. In this way the products of the scholarship of teaching result in peer-reviewed information that "becomes part of the knowledge based of teaching and learning in higher education” (p. 58) (Richlin, 2001). Kreber (2002b) suggested that both terms have merit and that comparisons of one another are counterproductive, because they each contribute to debates about improving teaching. 
Trigwell, Martin, Benjamin and Prosser (2000) also viewed public communication of results as part of the scholarship of teaching and learning. Working in Australia they conducted a study to establish how faculty members, who recently completed a faculty development program on teaching and learning in higher education, understood the scholarship of teaching. Five different categories were identified which represented the different ways in which faculty think about teaching scholarship. These were (a) knowledge of the literature related to teaching, (b) improving teaching by reading the literature, (c) improving student learning by investigating one's own teaching, (d) improving student learning using discipline specific literature and knowledge, and (e) investigating and communicating the results of one's own teaching and student learning within the discipline. The categories, from (a) through (e), were ranked as a hierarchy from lower order to higher order conceptions. Thus, a more holistic approach to the scholarship of teaching requires a faculty member to use literature to focus on important issues, to conduct research in his/her own teaching and student outcomes, and to report the findings to the academic community.

Based on this work, the authors developed a model for the development of scholarship in teaching, which is essentially a rubric for levels of engagement on four dimensions, namely the informed dimension, the reflection dimension, the communication dimension and the conception dimension. This is replicated in Table 1. Using this model, faculty who are less involved in the scholarship of teaching are located at the top of the table and tend to use informal theory to drive their practice. They tend to be more teacher-focused than student-focused. In contrast, faculty who are more engaged in the scholarship of teaching are located at the bottom of the table, and use literature to 
guide their thinking, are concerned to involve students in the learning process, engage in reflective practice and classroom research, and communicate their findings to others.

Clearly, it is also possible for faculty to be located at different levels between these two points and at different levels on the four dimensions.

Table 1

Multidimensional Model of Scholarship of Teaching

\begin{tabular}{|l|l|l|l|}
\hline Informed dimension & $\begin{array}{l}\text { Reflection } \\
\text { dimension }\end{array}$ & $\begin{array}{l}\text { Communication } \\
\text { dimension }\end{array}$ & $\begin{array}{l}\text { Conception } \\
\text { dimension }\end{array}$ \\
\hline $\begin{array}{l}\text { Uses informal } \\
\text { theories of teaching } \\
\text { and learning }\end{array}$ & $\begin{array}{l}\text { Effectively none or } \\
\text { unfocused reflection }\end{array}$ & None & $\begin{array}{l}\text { Sees teaching in a } \\
\text { teacher-focused } \\
\text { way }\end{array}$ \\
\hline $\begin{array}{l}\text { Engages with the } \\
\text { literature of } \\
\text { teaching and } \\
\text { learning generally }\end{array}$ & - & $\begin{array}{l}\text { Communicates with } \\
\text { departmental/faculty } \\
\text { peers (tea room, } \\
\text { conversations, } \\
\text { department seminars) }\end{array}$ & - \\
\hline $\begin{array}{l}\text { Engages with the } \\
\text { literature, } \\
\text { particularly the } \\
\text { discipline literature }\end{array}$ & Reflection-in-action & $\begin{array}{l}\text { Reports work at local } \\
\text { and national } \\
\text { conferences }\end{array}$ & - \\
\hline $\begin{array}{l}\text { Conducts action } \\
\text { research, has } \\
\text { synoptic capacity, } \\
\text { and pedagogic } \\
\text { content knowledge }\end{array}$ & $\begin{array}{l}\text { Reflection focused } \\
\text { on asking what do I } \\
\text { need to know about } \\
\text { here, and how will I } \\
\text { find out about it? }\end{array}$ & $\begin{array}{l}\text { Publishes in } \\
\text { international } \\
\text { scholarly journals }\end{array}$ & $\begin{array}{l}\text { Sees teaching in a } \\
\text { student-focused } \\
\text { way }\end{array}$ \\
\hline
\end{tabular}

Note. - No information was provided for these cells. From Scholarship of teaching: A model, by K. Trigwell, E. Martin, J. Benjamin \& M. Prosser, 2000, Higher Education Research and Development, 19, p. 163.

More recently, Areola, Theall and Aleamoni (2003), extending Boyer's work, suggested that there are several core activities associated with the work of professors and presented a complex web-based model that represents the diversity of the work of the professor. They divided the work of professors into the "base profession" and the "meta- 
profession". The "base profession" is the faculty member's area of content expertise, methods of keeping abreast in his/her field, and the clinical and research skills appropriate to that field. The "meta-profession" constitutes of a set of broad skills and areas of expertise that are important for all professors, for instance, technical writing, public speaking, course management, instructional design, delivery and assessment, epistemological beliefs, and knowledge of learning theory and human development. It includes the specific skills associated with the scholarship of teaching and learning (SOTL), which they consider to be a special category of the broader term, scholarship. From this they created a set of matrices of "meta profession" skills for (a) teaching, (b) scholarly/creative activities, (c) service, and (d) SOTL. These matrices can be used as a framework for research into scholarship or for faculty development and evaluation.

In 1998 the Carnegie Foundation for the Advancement of Teaching and Learning consolidated a working definition, "The scholarship of teaching is problem posing about an issue of teaching or learning, study of the problem through methods appropriate to disciplinary epistemologies, application of results to practice, communication of results, self-reflection, and peer review" (The Carnegie Foundation for the Advancement of Teaching and Learning, as cited in Silva, 1999, p. 2). This definition recognized differences in the approach to researching teaching and learning rooted in particular disciplines.

Huber (1999) provided examples of how scholars researching their own teaching usually begin with the research models and methods they use for research questions within their respective disciplines. In part this is a reflection of what they consider to be "normal procedures in their discipline" (p. 6) and a desire for the research to be accepted as 
scholarly amongst peers. Cross (1998) concurred that research on teaching be undertaken within the disciplines because faculty within a particular discipline "share a value system with respect to teaching goals that is distinctly disciple-related and significantly different from that of colleagues in other disciplines" (p. 8). This means that there will be differences in the ways in which faculty undertake teaching and research within different disciplines. It will also impact their willingness to accept new approaches to teaching and conducting research because their epistemologies are discipline specific.

Working out of the discipline of geography, Healey (2000) advocated that research into the scholarship of teaching be located within the discipline in which it develops because "for most academic staff their primary allegiance is to their subject or profession" (p. 173). He added that his would contribute to enhancing the status of discipline-based pedagogic research given that currently few discipline specialists publish research on the nature of teaching, learning and assessment in their subjects. A central concern in this process is the development of pedagogical content knowledge (PCK) (Paulsen, 2001), which requires the integration of content knowledge and pedagogical knowledge to create a "special synthesis and unique relation of the two" (p. 20).

Paulsen (2001) suggested four ways that scholars can develop pedagogical content knowledge, by (a) teaching and reflecting on experiences, (b) participating in faculty development and evaluation, (c) engaging in graduate training programs, and (d) conducting classroom research. The outcome is discipline specific knowledge of how and why students learn, and what teaching strategies are effective in enhancing learning. Kreber (2000a) agreed that learning about one's discipline and learning about teaching are intertwined. However, Weston and McAline (2000) contended that teaching is generally 
isolated from the mainstream work of the disciplines, and that this means that the scholarship of teaching is also seen as a separate activity. The challenge then is to integrate the scholarship of teaching into the disciplines, and Weston and McAline (2000) offered a continuum of professional development activities to make this possible.

Eight case studies of Carnegie fellows are described by Hutchings (2000) in Opening lines: Approaches to the scholarship of teaching and learning, a Carnegie Foundation Publication. The disciplines covered by the cases include humanities, social sciences, natural sciences, business and interdisciplinary studies. A set of common topics and themes emerged from the various cases and these were developed as section heading in the final version of each case. Each of the authors described the process of formulating a question, strategies considered for data collection, how choices were made, what worked and did not work, and what advice would be given to faculty considering or newly involved in considering the scholarship of teaching and learning. Opening lines goes some way to creating common ground and parallels across disciplines.

Several issues are identified in the cases, such as how faculty can "admit" to having a problem in teaching. Traditionally this is viewed as a contradiction in terms because it may seem like an "accusation" (p. 3), such that a dichotomy between terminal remediation and ongoing investigation has developed (Bass, 1999). However, problem posing and making problems public is central to a deeper understanding of processes involved in teaching and learning. This openness to investigating problems in teaching is central to investigations revolving around the scholarship of teaching and learning.

From the cases, Hutchings (2000) generated a taxonomy of four types of research question: (a) "what works" (the relative effectiveness of different approaches), (b) "what 
is" (the characteristic features of a given approach), (c) "visions of the possible" (where teaching and learning should be), and (d) formulating new conceptual frameworks for shaping thought about practice. She noted that the latter are under-represented in the literature. Hutchings added that the categories are not mutually exclusive and that indeed, there may be a fifth type, that of "a lot of playing around" (p. 5).

In her cross-case analysis she noted that there is "no single best method or approach for conducting the scholarship of teaching and learning" (p. 1). However, she suggested three criteria for defining the scholarship of teaching and learning: (a) that teaching is deeply embedded in the discipline, (b) that it is an aspect of practice, and (c) that it is characterized by a transformational agenda. Hutchings (2000) noted one additional factor, that the cases "document the power of methodological conversation and collaboration across fields" (p. 7). At first this may appear to be a contradiction to the criterion of operating out of the particular discipline, but instead should be viewed as an extension to the specific discipline-related methodology to include the multiple approaches to research advocated by Keller (1998). Huber (1999) contended that the "placement of the scholarship of teaching and learning in the larger world of knowledge production is very much up for grabs right now" (p. 8) and that it is an "open question whether this work will end up looking like "normal" academic science or not" (p. 9).

That the scholarship of teaching and learning be situated within the disciplines should be considered as a starting point for interdisciplinary debates and the development of new theories (Huber and Morreale, 2001). Carter (2001) pointed out that the scholarship and teaching movement in the US is multidisciplinary in nature because it includes a range of disciplines and that this can extend to true interdisciplinary dialogue, with the purpose 
of creating new knowledge that "no single discipline on its own could have created" (p. 3). To achieve this she suggests that interdisciplinary "spaces", real and virtual, need to be actively created and supported. One way for interdisciplinary co-operation presents itself in classroom research (Carter, 2001), and through the development of PCK, as individuals integrate their discipline specific content knowledge with pedagogical knowledge derived from traditional educational research (Paulsen, 2001). This may or may not include the collaboration with others in other disciplines, but is interdisciplinary in that different disciplines are being called upon to understand context.

Kreber (2000b) showed that most faculty perceived that they learn best about their discipline and about teaching when they collaborated with others. But, most of them also contended that collaborative work was not as highly rated by the academy, as were singleauthored works. She appealed for more recognition to be given to collaborative research and teaching. Creating communities of inquiry, where collaborators examine difficult issues in particular situations is another way to foster interdisciplinary scholarship (Larson, 2000). Recognition of the importance of local context may necessitate a shift from "a predominantly logico-scientific mode of knowing in favor of an interpretive or narrative way of knowing" (Larson, 2000) and develop a greater respect amongst the community of inquirers for different research methods and for methodological pluralism (Huber \& Morreale, 2001). This may necessitate paradigm dialogues, which are "conversations between researchers, scientists and other scholars who have different paradigmatical engagements or preferences" (Smaling, 2000, p. 51).

Silva (1999) is critical of the Carnegie Foundation definition because their focus is only on research on teaching or learning, which she feels is too narrow. She added that 
scholarship should not be seen just as a science, but also be viewed as an art, involving passion for one's work, commitment to students, critical thought, engagement of students in critical thinking processes and ethical consideration. This is a move toward a broader definition of scholarship that attempts to move beyond the technical to a more personally constructed approach. Similarly, Kreber (2000a) called for a new definition of scholarship and argued that the term scholarship of teaching was too loose when first introduced by Boyer, but that it now has become too exclusive by focusing on pedagogical content knowledge, research into teaching and learning, and traditional peer review, and that this is preventing faculty with a different perspective from engaging in the discourse. She maintained that the scholarship of teaching rests on faculty philosophies of teaching and should represent the congruence between theory and practice. This is akin to merging theories of action into a coherent theory of practice, as proposed by Argyris and Schön (1974).

Clearly, there are a number of different definitions and approaches to the scholarship of teaching and learning, ranging from a more specific focus on researching classroom practice and the communication of research findings (Trigwell, Martin, Benjamin \& Prosser, 2000), to broader views where teaching is viewed as an art and not just a science (Silva, 1999). All the authors surveyed agreed that new teaching and research methods are needed in higher education to improve the processes of teaching and learning and to enhance student learning. Approaches to the scholarship of teaching and learning need to be grounded in the research on teaching and theories about effective educational practice (Healey, 2000; Huber, 1999). Because faculty tend to operate out of the discipline within which they are trained, interdisciplinary teams may be valuable for 
exchanges on alternative research methods and for moving faculty to consider new ways of teaching and researching their actions.

The dominance of the traditional empirical view of research may gain ascendance unless alternative modes can generate acceptable findings and conclusions (Huber, 1999). However, classroom research does not readily lend itself to the traditional paradigm because it is extremely difficult to control and manipulate variables and to deal with issues such as sample size and representativeness (Huber, 1999). So, alternative, more qualitative approaches are often needed to answer particular questions (Keller, 1998). Interdisciplinary teams may be one way in which deeper debates about methods for inquiry and pathways for validating knowledge constructs can occur (Carter, 2001).

NOVA has a contribution to make in understanding the scholarship of teaching and learning in the US because the program explicitly advocates the use of classroom research as a means of establishing the effectiveness of instruction and student outcomes in NOVA funded courses. There is a clear focus on student-centered approaches and a concern for improved student learning. Also, interdisciplinary teams are formed that include a faculty member from science or mathematics, a member from education and an administrator. Additionally, NOVA provides a context in which faculty can demonstrate the scholarship of teaching and learning by reporting and publishing findings at Leadership Development Conferences, other national conferences and through NOVA initiated publications. Thus, NOVA is an ideal context for exploring faculty conceptions of and approaches to the scholarship of teaching and learning. 


\section{Effective teaching in higher education}

It is important to examine what is meant by effective instruction if one is to examine the relationship between concepts about teaching and learning, and associated teaching practices. This section explores some of the theories and related approaches to effective instruction in higher education, and considers the impact of different teaching approaches on student outcomes. The epistemological assumptions of both teachers and learners is an important dimension.

Effective teaching involves enabling students to develop a deep understanding of the materials they are studying. This can be achieved through a variety of thoughtdemanding tasks (Levin \& Nolan, 2000), including having students explain concepts in their own words, making predictions, doing drawings, finding exemplars in new contexts and applying concepts to new situations (Brandt, 1992). In part this requires a move away from an emphasis on breadth of content, to more in depth studies of specific concepts and their relationships. Atkin and Helms (1993) coined the phrase "less is more" in this context (p. 5). Zuber-Skerritt (1992a) concurred, stating

So far we have arrived at the position that the most appropriate mode of learning and teaching in higher education is that of the alternative paradigm which may be characterized by learner-centered, problem-oriented, interdisciplinary, processcentered, and using an open, critical approach. (p. 147)

Ramsden (1992) developed six key principles for effective teaching in higher education, (a) clear explanation of complex subject matter, (b) careful consideration of students, (c) clear goals for intellectual challenge, (d) appropriate assessment and feedback, (e) active student engagement, independence and control, and (f) ability to 
learn from students. Hativa (2001) found that different instructors achieved excellence in different ways, but that clarity of presentation and a positive classroom environment were the two most important characteristics identified by exemplary teachers and their students.

Shulman (1986) described three domains of knowledge for teachers, including those in higher education. These are (a) subject matter knowledge, the knowledge of the subject content being taught, (b) general pedagogical knowledge, the knowledge and ability to use pedagogies that are not subject specific, and (c) pedagogical content knowledge (PCK), the specific knowledge and strategies to teach in the discipline. PCK includes knowledge of common student misconceptions, useful analogies and ways to represent specific concepts. Hativa and Goodyear (2002) added four other domains, (a) knowledge of learners, (b) knowledge of learning, (c) knowledge of educational goals, and (d) knowledge of self. All seven domains can be considered necessary for effective teaching in higher education.

Studies of student learning in higher education in the US have tended to focus on learning-oriented behaviors and their relationship to grade and performance-oriented behaviors (Cross \& Steadman, 1996). In contrast, there is a rich body of research by scholars in the United Kingdom and Australia that have concentrated on studying deep and surface approaches to learning by students (Prosser \& Trigwell, 1999). A surface approach is characterized by an attempt by learners to reproduce information, a concern for grades and course requirements, and is characterized by minimal mental effort. In contrast, a deep approach relies on relating new information to existing knowledge, the 
application of new information to new contexts and on the creation of meaning (Cross \& Steadman, 1996).

There is a clear relationship between teaching strategies and student learning, with students adopting deep approaches in classrooms that are more student-centered (Prosser \& Trigwell, 1999). Students with a deep approach to learning and a solid initial grasp of subject matter tended to be more successful than students with poor initial conceptual development who used a deep approach, or groups that used a shallow approach to learning (Prosser, Trigwell, Hazel \& Waterhouse, 2000). For instance, Kember, Charlesworth, Davies, McKay and Stott (1997) examined student approaches to learning in three courses redesigned to promote a deep approach to learning, at a university in Hong Kong. Their results showed that when students are engaged in integrating theory and practice and in reflecting on learning, they are more likely to develop a deep approach. To achieve these effects, instructors must move away from lecture-based teaching to more participative approaches that include real-life applications of learning. In comparison, traditional courses using traditional approaches lead to a decline in deep approaches to learning (Kember, Charlesworth, Davies, McKay \& Stott, 1997).

An increase in conceptual understanding can be affected in student-centered classrooms. Smelcer (2000) found that there was an increase in college students' understanding of science concepts and processes in an integrated science course (funded by NOVA) when engaged in hands-on, participatory tasks. However, she also found that students with greater initial conceptual knowledge made fewer overall gains if expectation levels were set for the weaker students. 
It is generally accepted that collaborative learning groups enhance student learning and that students' learning decreases significantly in a lecture setting after 15-18 minutes (Centra, 1993). When adopting participatory approaches to teaching, the structure of groups needs to be taken into consideration. With this in mind, Adams, Brissenden, Lindell, Slater and Wallace (2002) considered gender differences in collaborative learning groups and found that males in general were more likely to be disengaged during group work than were females, and that females in male dominated groups adopted similar patterns of inattention. In contrast, females in single gender groups or groups with an equal gender composition spent much less time disengaged. Classrooms need to be structured to take account of such environmental factors, to maximize the performance of all students.

Students' epistemological assumptions and approaches to learning are also important factors that impact cognitive restructuring (Prosser, Walker \& Millar, 1996). These authors found a contradiction that most students realized that physics is concerned with understanding the physical world, but did not approach their learning in this way. Most made no attempt to relate their learning to real world experiences. They had epistemologies rooted in a traditional view of science and adopted less sophisticated conceptions of the nature of the discipline when studying. The authors noted that it is important for instructors to understand student conceptions about the particular discipline and to teach in ways that challenge these. They provided two examples of how they used "buzz groups" during lectures to challenge students to consider alternative views. Firstly, students were forced into the realization that different people hold different conceptions about particular concepts in physics, such as force. Then they were challenged to 
confront the fact that different students study in different ways. In both these instances students had to confront their own constructions and compare them to others. This can be a powerful strategy to help in restructuring beliefs about learning and the nature of knowledge.

Students' initial perceptions of the discipline when they enter into a field of study also affect the way in which they study. If they perceive a discipline to be factually based, they may adopt a surface approach to learning. The way in which courses and programs are presented (in lectures and on paper) may further frame students' epistemological assumptions, by supporting or challenging particular positions (Prosser, Trigwell, Hazel \& Waterhouse, 2000; Sheppard \& Gilbert, 1991).

Marton and Saljo (1997) described five qualitatively different epistemological positions held by students: (a) a quantitative increase in knowledge, (b) memorization, (c) the acquisition of facts and methods for subsequent utilization, (d) the abstraction of meaning, and (e) an interpretive process aimed at understanding reality. Students' approaches to learning, whether deep or surface, are related to these epistemological positions (Prosser \& Trigwell, 1999) with the first three positions reflecting surface approaches. The ability to relate the subject matter to real world contexts is important for effective learning, reflecting students' epistemological assumptions about the relevance of learning and a deep approach to learning. Students with relative epistemological assumptions tend to be more successful (Prosser, Walker \& Millar, 1996; Sheppard \& Gilbert, 1991).

Clearly, the manner in which university teachers teach has implications for student outcomes, including the way in which students learn. Prosser and Trigwell 
(1999) summarized these themes by providing a model for understanding teaching and learning in higher education. The model offers a way to understand variations in student learning outcomes based on (a) the actual learning situation, (b) the students' prior experiences, (c) the student's perceptions of the learning context, and (d) the student's approaches to learning. All factors interact to determine the quality of the learning outcomes. The authors suggested that, "When looked at from this theoretical perspective, a major task of teaching is to ascertain the perceptions students have of their learning situations, and work towards developing learning and teaching contexts which students experience in similar ways to that which the teacher designs" (p. 25). Teaching and learning are reciprocal processes.

NOVA workshops, attended by all teams applying for funding, provide science and mathematics faculty with information and exemplars of innovative instruction strategies and effective teaching methods, specifically for teaching future teachers. This includes promoting learner-centered, inquiry-based approaches to teaching. Much of the workshop content is drawn from the National Science Foundation (NSF, 1996) and the National Research Council (NRC). These reports called for new and revised university curricula, improved pedagogical approaches, subject relevance and greater student participation in course activities (NSF, 1996; NRC, 1997; NRC, 1999, NRC, 2001).

The NOVA workshops provide a summary of constructivist learning theories (Sunal, 1999), and also advocate a cognitive restructuring approach in which it is important to identify and work with the existing conceptions and misconceptions of the learner (Driver \& Oldham, 1986). Learners play a prominent part in the process of formulating their own knowledge. The learning cycle, consisting of three phases 
(exploration, concept invention and concept application), is presented as one strategy to engage students in examining and restructuring their thinking and conceptual framework(s) (Karplus, 1977). During the exploration phase students' attention is focused on a phenomenon being investigated and they are forced to make public and confront existing ideas. During the concept invention phase, students engage in activities that challenge existing ideas, and they are required to discuss, clarify, and invent new terms and concepts to explain the phenomena observed. This facilitates the process of assimilation or accommodation of new knowledge. In the application phase they apply the new knowledge to new contexts and real world situation (Karplus, 1977).

These models are intended to provide the science and mathematics professors attending NOVA workshops with theoretical models for restructuring their own courses and teaching styles. Proposals are evaluated against these criteria.

Conceptions of Teaching, Learning, Assessment and Research

This section explores a number of related areas of research, that of faculty conceptions (or beliefs) about different aspects of practice, namely conceptions of teaching and learning, conceptions of assessment, and conceptions of research. Different categories of conception are presented and factors that may facilitate conceptual change are examined. It is a commonly held belief that faculty conceptions impact their practice, although there are very few studies and literature to support this claim (Samuelowicz, 1999). Thus, an examination of conceptions and their relationship to practices is an important aspect of this literature review. 


\section{Conceptions of Teaching and Learning}

Fox (1983) presented four theories of teaching based on faculty definitions of teaching, two of which he called simple theories of teaching, namely (a) knowledge transfer (transfer theory), and (b) shaping students to a predetermined mold (shaping theory); and two he called developed theories, namely (c) exploratory or traveling through a subject (traveling theory), and (d) a developmental process (growing theory). These theories are related to attitudes about student learning along two continua or dimensions, one contrasting an emphasis on subject content to a focus on student change, and the other contrasting teacher initiated teaching with student initiated learning. This is summarized in Figure 3. These theories were offered as a means of resolving misunderstandings among teachers and between teachers and students.

A fifth 'building theory' also emerged as a hybrid of simple and more developed theories. This may reflect an intermediate or transition category, with academics' theories evolving through practice and experience, although Samuelowicz (1999) suggested that his schema might be too simplistic. 
Student content focus

C -Traveling Theory

D - Growing Theory
A - Transfer Theory

B - Shaping Theory Teacher initiated

Student Initiated

E - Building theory Teacher initiated

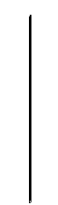

Student change focus

Figure 3. Fox's Dimensions of Teaching. From The disjunction between lecturers' conceptions of teaching and their claimed educational practice, by K. Murray \& R. MacDonald, 1997, Higher Education, 33, p. 334.

In a study that aimed to identify university teacher's intentions associated with particular teaching strategies, Trigwell, Prosser and Taylor (1994) conducted a phenomenographical study of 24 first year physics and chemistry science educators from two universities in Australia. Conceptions of teaching were based on beliefs about teaching purpose (intentions) and teaching strategies. A combination of four intentions and three strategies resulted in five distinct approaches to teaching emerging from the data, (a) a teacher-focused strategy with the intention of transmitting information to students, (b) a teacher-focused strategy with the intention that students acquire the concepts of the discipline, (c) a teacher-student interaction strategy with the intention that students acquire the concepts of the discipline, (d) a student-focused strategy aimed at students developing their conceptions, and (e) a student-focused strategy aimed at 
students changing their conceptions. This study represented another way of understanding and representing conceptions held by university instructors about teaching. The teacher-student interaction strategy (Trigwell, Prosser \& Taylor, 1994) also represented an intermediate category in a hierarchy from less to more sophisticated conceptions, suggesting that, in time, faculty transition across the different categories. Other evidence for a movement across categories over time comes from McAlpine and Weston (2002) who suggested that improvement in teaching is a developmental process that is facilitated by reflection on beliefs about teaching and learning. The longitudinal case presented by Entwistle and Walker (2002) also illustrated how one teacher's conceptions shifted from being teacher-centered to student-centered over time, indicating a developmental process that moved through several phases.

In a synthesis of the literature on faculty conceptions of teaching and learning Kember (1997) conducted a review of thirteen articles, including his own (Gow \& Kember, 1993; Kember \& Gow, 1994), about the conceptions of teaching held by university academics. The original studies came from a number of countries, including Australia, Hong Kong, the United Kingdom, Canada and China, with the majority of studies originating in Australia. All of the studies used qualitative approaches and interviews "under an open naturalistic framework" ( $\mathrm{p} 258)$ in which no preconceived hypotheses were formulated, but in which categories emerged from the data.

Kember (1997) noted that there were many different terms used, including orientations, beliefs, conceptions, approaches and intentions, with conception of teaching being the most common. Belief was synonymous with conception, while orientation was broader encompassing several conceptions. Teaching approach included motive and 
strategy. Despite the differences, all of the papers articulated conceptions and Kember (1997) constructed a matrix of the categories for each study, representing them on a continuum from teacher-centered/content-oriented to student-centered/learner-oriented. There was "a high degree of commonality in the categories" (p 259), showing consistency across studies.

Five dominant categories emerged: (a) imparting information, (b) transmitting structured knowledge, (c) teacher-student interaction, (d) facilitating understanding, and (e) conceptual change. To distinguish between categories, most of the different authors used key characteristics, called dimensions, evident in each category, although factor analysis was also used in two studies to confirm the qualitatively derived categories. The common dimensions used across studies were the implicit views of the teacher, teaching, students, content, and knowledge. The differences in these dimensions helped to separate out differing categories and showed that the earlier studies presented in this review (Fox, 1983; Trigwell, Prosser \& Taylor, 1994), which only used two dimensions, were somewhat limited because there are several more possible dimensions for identifying orientations.

Kember (1997) suggested that the categories are not hierarchically ordered, but a sequenced set of categories, where faculty may move from one conception to another over time, but do not retain the characteristics of their former stance. The "teacherstudent interaction" category was considered a transition stage between teacher-centered approaches and student-centered approaches. Evidence for this transition group was also found by van Driel, Verloop, van Werven and Dekkers (1997) who described a studentdirecting category, where students are engaged in a variety of activities orchestrated and 
controlled by the teacher. Kember (1997) believed that change from one conception to another was likely to be slow and difficult to effect, "indicative of conceptual change akin to that described in the literature on science concepts" ( $\mathrm{p} 263)$, where the resistance of concepts to change has been reported.

Kember (1997) observed that categories tended to be described as distinct from each other suggesting well-defined boundaries between them, when in fact the evidence suggests otherwise. It seems that categories are more fluid, rather than a set of discrete entities. Similarly, Hassard (1993) questioned whether paradigms are hermetically sealed entities as had been suggested by Kuhn (1970) when he wrote of paradigm shifts in the natural sciences. Instead Hassard suggested that paradigms are porous and can be mediated. Kember reflected that Each academic's conceptions of teaching will have formed through some complex amalgam of influences such as experiences as a student, departmental and institutional ethos, conceptions of the discipline and even the nature of the classroom. As teaching is central to the role of academics, conceptions of teaching tend to become subsumed into the subconscious. It therefore takes a major perspective transformation to change them. (p 271)

Essentially, changing approaches to teaching entails a paradigm shift, with an accompanying change in epistemology. Such changes have major implications for changing pedagogical practices because unless underlying conceptual frameworks change, classroom practices will not change (Raubenheimer, 1994). Kember (1997) called for more research on the relationship between categories and the way in which conceptions may change over time. Hofer and Pintrich (1997) noted that there is little 
empirical evidence for what fosters epistemological development or change, although many suggestions have been made for promoting such progression, usually involving cognitive conflict and restructuring.

As an extension to an earlier study (Samuelowicz \& Bain, 1992), Samuelowicz and Bain (2001) conducted semi-structured interviews with 39 academics in eight disciplines from three universities in Australia. The purpose was to examine beliefs about teaching, about knowledge, student learning and the relationship between teaching and learning, but with several modifications to the earlier study. They used a three phase grounded analysis, with the first step being to establish categories of orientation to teaching and learning using the constant comparative method. Seven orientations (called conceptions in their previous study) were identified.

The second step in the process involved comparing and contrasting orientations to identify the different belief dimensions, of which nine emerged. The final step was to code all the belief dimensions with an $\mathrm{A}, \mathrm{A} / \mathrm{b}, \mathrm{B} / \mathrm{a}$ or $\mathrm{B}$. The $\mathrm{A}$ represented a more teaching centered orientation, the $\mathrm{A} / \mathrm{b}$ a teaching centered orientation but with aspects of a learning emphasis, the $\mathrm{B} / \mathrm{a}$ reflected a learning centered orientation but with aspects of a teaching emphasis and the B consisted of a learning centered orientation. Once this was done, the 7 orientations were placed in order from those with the most A's on the left hand side and those with the most B's on the right hand side, with all nine dimensions listed. This resulted in a matrix of 7 orientations by 9 dimensions, a total of 63 possible cells. The seven orientations and nine dimensions are summarized in Table 2. 
Table 2

A Summary of Orientations and Belief Dimensions (after Samuelowicz \& Bain, 2001)

\begin{tabular}{|c|c|c|c|c|c|c|c|}
\hline & \multicolumn{4}{|c|}{ Teaching-centered orientations } & \multicolumn{3}{|c|}{ Learning-centered orientation } \\
\hline Dimension & $\begin{array}{l}\text { Imparting } \\
\text { knowledge }\end{array}$ & $\begin{array}{l}\text { Transmitting } \\
\text { structured } \\
\text { knowledge }\end{array}$ & $\begin{array}{l}\text { Providing and } \\
\text { facilitating } \\
\text { understanding }\end{array}$ & $\begin{array}{l}\text { Helping } \\
\text { students } \\
\text { develop } \\
\text { expertise }\end{array}$ & $\begin{array}{l}\text { Preventing } \\
\text { misunder- } \\
\text { standings }\end{array}$ & $\begin{array}{l}\text { Negotiating } \\
\text { understanding }\end{array}$ & $\begin{array}{l}\text { Encouraging } \\
\text { knowledge } \\
\text { creation }\end{array}$ \\
\hline $\begin{array}{l}\text { Desired } \\
\text { learning } \\
\text { outcomes }\end{array}$ & A & $\mathrm{A} / \mathrm{b}$ & $\mathrm{A} / \mathrm{b}$ & B & B & B & B \\
\hline $\begin{array}{l}\text { Expected use } \\
\text { of knowledge }\end{array}$ & A & $\mathrm{A} / \mathrm{b}$ & $\mathrm{A} / \mathrm{b}$ & $\mathrm{B}$ & B & $\mathrm{B}$ & B \\
\hline $\begin{array}{l}\text { Responsibility } \\
\text { for organizing } \\
\text { or } \\
\text { transforming } \\
\text { knowledge }\end{array}$ & $\mathrm{A}$ & $\mathrm{A}$ & $\mathrm{A} / \mathrm{b}$ & $\mathrm{B} / \mathrm{a}$ & $\mathrm{B}$ & B & $\mathrm{B}$ \\
\hline $\begin{array}{l}\text { Nature of } \\
\text { knowledge }\end{array}$ & $\mathrm{A}$ & $\bar{A}$ & $\mathrm{~A}$ & $\mathrm{~B}$ & $\mathrm{~B}$ & B & $\mathrm{B}$ \\
\hline $\begin{array}{l}\text { Student's } \\
\text { existing } \\
\text { conceptions }\end{array}$ & $\mathrm{A}$ & $\mathrm{A}$ & $\mathrm{A}$ & A & $\mathrm{B} / \mathrm{a}$ & $\mathrm{B}$ & $\mathrm{B}$ \\
\hline $\begin{array}{l}\text { Teacher- } \\
\text { students } \\
\text { interaction }\end{array}$ & $\mathrm{A}$ & $\mathrm{A} / \mathrm{b}$ & $\mathrm{B} / \mathrm{a}$ & $\bar{B}$ & B & B & $\mathrm{B}$ \\
\hline $\begin{array}{l}\text { Control of } \\
\text { content }\end{array}$ & A & A & A & A & A & A & B \\
\hline $\begin{array}{l}\text { Professional } \\
\text { development }\end{array}$ & $\mathrm{A}$ & $\mathrm{A}$ & $\mathrm{A}$ & $\mathrm{B}$ & $\mathrm{B}$ & $\mathrm{B}$ & $\mathrm{B}$ \\
\hline $\begin{array}{l}\text { Interest } \\
\text { motivation }\end{array}$ & $\mathrm{A}$ & $\mathrm{A}$ & $\bar{A}$ & B & $\mathrm{B}$ & $\mathrm{B}$ & $\mathrm{B}$ \\
\hline
\end{tabular}

From Revisiting academics' beliefs about teaching and learning, by K. Samuelowicz \& J.

D. Bain, 2001, Higher Education, 41, p.306-307.

Each faculty member was located within one orientation and coded $\mathrm{A}, \mathrm{A} / \mathrm{b}, \mathrm{B} / \mathrm{a}$ or B for each of the 9 dimensions, providing a specific profile for each participant. Different disciplines tended to be distributed across the orientations suggesting that orientations were not specific to one particular area of study. These authors also provided detailed case descriptions of faculty within each orientation. 
Analysis of the data was extended by allocating a number, one through four, to each of the qualitative codes of $\mathrm{A}, \mathrm{Ab}, \mathrm{Ba}$ and $\mathrm{B}$, thereby retaining the rank order from lower to higher conception of teaching. These data were subject to a cluster analysis using Ward's method to compute Euclidean distances between data, thereby providing a quantitative analysis of the relationship between and among different orientations.

Results showed that three of the orientations were clustered close together, and that all three have a focus on teacher-centered approaches. The orientations included in this group are those of "imparting information", "transmitting structured knowledge", and "providing and facilitating understanding". The remaining four orientations, "helping develop expertise", "preventing misunderstandings", "negotiating understanding", and "encouraging knowledge creation" were clustered into a second group. These two major groupings were distinctive, with no intermediate cluster category, suggesting that the orientations are either teacher centered or learner centered. Undergraduate professors never expressed the orientation of "encouraging knowledge creation", suggesting that they did not believe students were capable of conducting original research and generating new knowledge. While not all graduate professors expressed this orientation, it was only ever expressed at that level (Samuelowicz \& Bain, 2001).

The findings from this study were compared to the findings from the 1992 study (Samuelowicz \& Bain, 1992). In relationship to the 1992 study, the 2001 study (Samuelowicz \& Bain, 2001) revealed 7 orientations and 9 belief dimensions, while the 1992 study had revealed 5 orientations and 5 belief dimensions. All 5 original orientations from the 1992 study reappeared, but two divided to form two additional categories. Four of the belief dimensions reappeared, one split into two and an additional 
3 emerged. These results indicated a consistency in categories over time, with additional subdivisions being identified because of the more in depth nature of the 2001 study. Thus, the new data provided a deeper insight into faculty conceptions and provided more detailed descriptors for orientations and belief dimensions.

The 2001 data (Samuelowicz \& Bain, 2001) were also contrasted to the literature surveyed and this showed that seven of the dimensions had identical counterparts in other studies, but not all other studies. Two beliefs, teacher-student interaction and students' personal/professional development have analogies in other studies, but not exact comparisons. Thus, there are parallels to previous studies, even though different methods were used, including empirical analysis, general qualitative analysis, content analysis, constant comparative analysis and phenomenography, thereby making comparisons across studies and categories difficult (Murray \& MacDonald, 1997).

There was no evidence in the Samuelowicz and Bain study (Samuelowicz \& Bain, 2001) for a transition grouping as claimed by Kember (1997). The implication of this for faculty development is significant because if there is no transitional category, it will prove difficult to move people out of the particular paradigm in which they are located. It may not be possible to move faculty located within group one to a group two position. It may only be possible to encourage faculty within the second group to consider higher order orientations simply because they are more disposed to change than those located in the first group. Radloff (2002) found that 23 technical college teachers' beliefs underwent little change during a two-year teacher education program, with conceptions of learning as "applying information" still predominating at the end of the period (p. 278). There was a decrease in the view that learning was only about absorbing information, but learner- 
centered purposes, such as (a) understanding concepts, (b) broadening and deepening knowledge, and (c) learning as a process to become a lifelong learner, did not increase. This suggests that these teachers did not move out of their existing view of learning, although these college teachers did report changes in their personal approaches to learning and classroom teaching. Further research is needed on the relationship between faculty views and their uptake of innovation and ideas presented in faculty development programs.

Broadly speaking, conceptions of teaching and learning held by faculty in higher education reflect a dichotomy with two dominant approaches, those that are teacherfocused and content-oriented, and those that are student-focused and learner-oriented (Entwistle, Skinner, Entwistle \& Orr, 2000). Teacher-focused strategies are concerned with knowledge transmission by imparting knowledge through lecture and video, while a student-focused approach is concerned with facilitating learning, through problem solving, interactive teaching and student motivation (Kember \& Gow, 1994). These two positions can be compared to the two ends of the spectrum in epistemological positions, as summarized by Hofer and Pintrich (1997), from a view of knowledge as absolutist on one end of the continuum, to a view that embraces contextual relativism on the other end.

There is a relationship between conception of teaching and conception of student learning. Teachers in the teacher-focus group are more concerned with a "surface" approach to learning, while teachers in the student-focused group are more concerned with a "deep" approach to learning (Trigwell \& Prosser, 1996a). As already noted in the previous section, the teacher's epistemological position can impact the epistemological position adopted by the learner (Hofer \& Pintrich, 1997). So for instance, in a large scale 
survey of Engineering faculty, Colbeck, Cabrero and Marine (2000) found the use of collaborative group design projects was positively associated with the goal of teaching teamwork and lifelong learning, while the use of traditional methods was associated with the goal of teaching the 'fundamentals' of the discipline.

Teachers who perceive their role as facilitators of learning are more likely to accommodate different learning styles and engage in remediation of the weaknesses of their students (Kember, Kwan \& Ledesma, 2001). Similarly, teachers who are more student-focused and concerned with conceptual change have a view of knowledge as being constructed and select objects and processes of study that are more relational and focus on student's knowledge (Martin, Prosser, Trigwell, Ramsden \& Benjamin, 2000). In contrast, unclear teaching leads to low student understanding of material presented, with a lack of pedagogical knowledge contributing to poor teaching (Hativa, 1998). Saroyan and Amundsen (2001) summed this up saying, "the lower the pedagogical competence, the more fragmented the view of teaching and learning" (p. 345).

Furthermore, the approach to teaching is also linked to job satisfaction, with university teachers who adopt student-centered approaches tending to be more positive about their teaching environment, about the control they have over what and how they teach and about the value of their teaching within the department. Transmission mode teachers, in comparison, tend to be less satisfied about their role as instructors (Trigwell \& Prosser, 1996b).

While Trigwell and Prosser (1996a) found a direct relationship between teaching strategy used and conception of teaching espoused, Murray and MacDonald (1997) discovered that there were several faculty who had inconsistent conceptions of their role 
as teachers. Hativa (2001) also discovered that, while there was a relationship between beliefs and effective instruction of exemplary university teachers, it was "far from perfect" (p. 727). Samuelowicz and Bain (1992) referred to this disjunction between stated conception and actual approach as "one of the mysteries of higher education" ( $\mathrm{p}$. 110 ) and called more research to examine the relationship between personal theories and practices (Samuelowicz, 1999, Samuelowicz \& Bain, 2001).

Murray and MacDonald (1997) suggested three possible reasons for this state, (a) that conceptions are context specific, where certain situations work against implementation of the associated strategy, (b) that this can be explained by a difference between theory of action and theory-in-use and (Argyris \& Schon, 1974), and (c) that there is a need for more faculty development to "help staff challenge or operationalize their perceived role" (p. 346). Research is also needed on the relationship between views of the discipline and teaching practices, because while these have been fairly well established among math and science teachers, "beliefs about discipline have not been identified and researched in higher education" (Samuelowicz, 1999, p 25).

Quinlan (1999a, 1999b) and Bain (2000) advocated the use of case studies to more fully explore the relationship between conceptions and practices. Bain (2000) presented the case of two academics employing mathematical modeling in their teaching and shows how beliefs about teaching and learning, about the discipline, about what should be learned and what methods and activities should be used, are intimately associated with the practices they adopt. One perceived mathematics as a social construction and a way of formulating and solving problems. She selected tasks that encouraged students to draw on their existing knowledge in answering questions and in 
relating them to real world situations. The other saw mathematics as a structured discipline with his role being to model the deep structure for students. This meant teaching students the rules to find an underlying simplicity.

Similarly, Quinlan (1999a) examined the conceptions and practices of seven faculty members in an engineering department, and then presented two cases in detail to highlight how the differences in conception underpinned different goals for students and choices of instructional strategies. Faculty members who are design oriented see divergent thinking and the skills of synthesis as important learning goals for students. In contrast, those who are more scientifically oriented value analysis of structured problems and traditional laboratory sessions. These faculty found that students had difficulty in applying knowledge to new contexts. Quinlan (1999a) concluded that the dichotomy in beliefs and approaches reflects a larger debate within the field of engineering, that of "design versus analysis" (p. 18), with each rooted in its own historical and philosophical position of the nature of the discipline. She found a similar trend when examining faculty conceptions and approaches to the discipline of history (1999b).

The research presented in this section shows that faculty hold personally constructed conceptions about teaching (Fox, 1983; Trigwell, Prosser \& Taylor 1994; Trigwell \& Prosser, 1996a; Samuelowcs \& Bain, 1992, 2001), that tends to match the way in which they teach (Trigwell \& Prosser, 1996a), and that the way in which they teach impacts the way in which students learn (Trigwell \& Prosser, 1996a). Teachers who intend to transfer knowledge adopt teacher-focused strategies, while those who intend to bring about conceptual change adopt student-centered strategies. Students in teacherfocused classrooms tend to adopt surface approaches to learning, while those in student- 
centered classrooms adopt deep approaches to learning. University teachers who adopt student-centered approaches also tend to be more positive about their teaching environment and the value of their teaching (Trigwell \& Prosser, 1996a).

Faculty may be able to move conceptions over time, although there are conflicting views about a transition grouping, with Samuelowicz \& Bain (2001) finding no evidence for this. There is also some evidence that conceptions about teaching are directly related to teaching practices (Bain 2000; Hativa, 2001, Quinlan, 1999; Trigwell \& Prosser, 1996a), but more research into this aspect has been called for.

Within the NOVA program there are likely to be a range of different conceptions about teaching and learning, but there has been no research undertaken on this. The research study reported here contributes to an understanding of the ways in which science and mathematics faculty think about teaching and learning in their disciplines, and in the ways in which such conceptions may change over time. Furthermore Samuelowicz (1999) also wrote that, "given the shared assumption that teaching practices are associated with explicit or implicit conceptualizations of teaching and their importance to the improvement in the quality of teaching and learning, surprisingly few studies have investigated this relationship in higher education" (p. 14). This research will endeavor to examine how some faculty conceptualize teaching and explore their practices associated with these ideas.

Conceptions of Assessment

Rowntree (1987, as cited in Sambell \& McDowell, 1998) stated that, "if we wish to discover the truth about an educational system, we must look to its assessment procedures" ( $\mathrm{p}$ 1). This is because views about the nature of knowledge, the purpose of 
teaching and the role of assessment are integrally linked (Ramsden, 1992). For instance, in Meeting the highly qualified teacher challenge: The Secretary's Annual Report on teacher quality (US Department of Education, 2002), the Department of Education stated that "By focusing its definition of "highly qualified" teachers on preparation in content, as opposed to components such as pedagogy or teaching practicums, it expresses its opinion of what matters most" (p. 6). This sent a clear message that Congress and the US Department of Education views content preparation as more important than pedagogical training and this is reflected in the emphasis on standardized tests as exit procedures (US Department of Education, 2000). This is a traditional view of assessment, that of high stakes accountability testing (Shepard, 2000). Similarly, classroom assessment is linked to curriculum intentions, although there is frequently dissonance between instructional practices and assessment, where instructional practices may be rooted in constructivist theories, but assessment in the traditional paradigm (Shepard, 2000).

Effective assessment includes both formative and summative practices (Burke, 1999). Summative assessment techniques are those intended to provide a grade for individual students (Angelo \& Cross, 1993) and include tests, performance tasks, rubrics, observation checklists, interviews or conferences, learning logs and journals, and portfolios (Burke, 1999).

Angelo and Cross (1993) coined the term "classroom assessment" (p. xiii) for formative assessment and noted that it is distinct from student evaluation. There are several purposes for classroom assessment: (a) to obtain feedback on effectiveness of and student satisfaction with classroom activities and teaching, (b) to enhance teaching, (c) to track student learning, (d) to improve student learning, and (e) increase communication 
and collaboration between instructor and students (Steadman, 1998). The intention of classroom assessment is to provide information on "what, how much, and how well students are learning" (Angelo \& Cross, 1993, p. 5) so that faculty can adapt their teaching towards enhanced student learning. There are many classroom assessment techniques or CATs that can be used to in higher education to assess (a) course-related knowledge and skills, for instance by employing preconception checks, minute papers, word journals and concept maps, (b) learner attitudes, values and self-awareness, using approaches such as classroom opinion polls, self-confidence surveys, skills checklists, and self-assessments of learning styles, and (c) learner reactions to instruction, including the use of teacher designed feedback forms, quality circles and assignment assessments (Angelo \& Cross, 1993). These authors provided a detailed description of these and many other CATs for higher education.

Richlin (1998) identified four stages of concern as new graduate teaching assistants embark on becoming instructors. These are (a) the pre-stage in which assistants do not really see themselves as a teacher (or they 'just know' they will be a good teacher), (b) stage 1, where they are not sure they are good enough to do it right, (c) stage 2 , where there is a concern for whether student learning is being facilitated, and (d) stage 3 , where assistants see themselves as partners with the students. Their views of assessment in each stage reflect these concerns. During a practicum for teaching assistants, Richlin (1998) assigns each assistant three CATs to use during the semester to help them move beyond their "teaching as survival" concerns (p. 81) and to develop their teaching effectiveness and efficacy. This approach has proved effective, with assistants moving toward more student-centered approaches, showing more concern for student 
learning. Furthermore, by the end of the semester, the teaching assistants, who were initially resistant, valued these classroom assessment strategies.

Steadman (1998) found that classroom assessment was valued by instructors at three community colleges because it provided a way to "tune in to student voices" ( $p$. 26), thereby leading to improved student involvement in learning. It also brought faculty with similar interests together to discuss teaching, and provided a systematic way to reflect on and change teaching practices. Negative comments about the use of CATs were that it is time consuming and that faculty have to deal with negative feedback, which they may not always consider valid (Stead, 1998). The main factor contributing to the adoption and continued use of CATs was that faculty found it intrinsically rewarding. CATs can also be successfully modified and implemented across different disciplines (Eisenbach, Golich \& Curry, 1998).

Ramsden (1992) suggested that a transmission view of knowledge is accompanied by a view of assessment "as an activity that should test how much has been added" (p. 184) and asserted that this view is not uncommon in higher education. He called for assessment to match the emerging paradigm of teaching, to be used to diagnose misunderstandings and make better judgments about student outcomes. Wilson and Wineburg (1993) showed that the investigation of schoolteacher's assessment practices revealed underlying differences in teacher attitudes and pedagogical knowledge, although such studies of teachers and academics are limited (Samuelowicz, 1999). Identifying this gap, Samuelowicz and Bain (2002) qualitatively examined the orientations to assessment of 20 academics from five disciplines at three Universities in Australia by conducting semi-structured interviews with participants. An orientation was defined as a "coherent 
pattern of beliefs inferred from, and grounded in academics' assessment practices and their explanations of those practices" ( $p$ 176). Responses were probed to ensure a full and accurate description of the characteristic beliefs underlying assessment practices. Six orientations to assessment emerged, (a) reproducing bits of knowledge, (b) reproducing structured knowledge, (c) applying structured knowledge, (c) organizing subject knowledge, (e) transforming discipline knowledge, and (f) transforming conceptions of the discipline/world.

In the second phase of analysis, the orientations were compared and contrasted to determine the major differences in implicit beliefs, resulting in six belief dimensions. The six dimensions were (a) nature and structure of knowledge, (b) degree of integration of knowledge, (c) degree of transformation of knowledge, (d) differences between good and poor answers, (e) role of assessment in teaching and learning, (f) use of feedback gained from assessment. This resulted in an overall framework, which is a matrix containing 36 cells, 6 orientations $\times 6$ dimensions, which categorized assessment practice on a gradation from knowledge reproduction to knowledge reconstruction/transformation. The final step was to code all the belief dimensions with an $\mathrm{A}, \mathrm{A} / \mathrm{b}, \mathrm{B} / \mathrm{a}$ or $\mathrm{B}$. The $\mathrm{A}$ represented a more teaching centered orientation, the $\mathrm{A} / \mathrm{b}$ a teaching centered orientation but with aspects of a learning emphasis, the $\mathrm{B} / \mathrm{a}$ reflected a learning centered orientation but with aspects of a teaching emphasis and the B consisted of a learning centered orientation. This is replicated in Table 3. 
Table 3

A Summary of Orientations and Belief Dimensions (after Samuelowicz \& Bain, 2002)

\begin{tabular}{|c|c|c|c|c|c|c|}
\hline \multirow[b]{2}{*}{ Orientation } & \multicolumn{6}{|c|}{ Belief Dimensions } \\
\hline & $\begin{array}{l}\text { role of } \\
\text { assessment }\end{array}$ & $\begin{array}{l}\text { nature and } \\
\text { structure of } \\
\text { knowledge }\end{array}$ & $\begin{array}{l}\text { degree of } \\
\text { integration } \\
\text { of } \\
\text { knowledge }\end{array}$ & $\begin{array}{l}\text { degree of } \\
\text { transformation } \\
\text { of knowledge }\end{array}$ & $\begin{array}{l}\text { differences } \\
\text { between } \\
\text { good and } \\
\text { poor } \\
\text { answers }\end{array}$ & $\begin{array}{l}\text { use of } \\
\text { feedback } \\
\text { gained } \\
\text { from } \\
\text { assessment }\end{array}$ \\
\hline $\begin{array}{l}\text { 1. Reproducing bits } \\
\text { of knowledge }\end{array}$ & $\mathrm{A}$ & $\mathrm{A}$ & $\mathrm{A}$ & $\mathrm{A}$ & $\mathrm{A}$ & $\mathrm{A}$ \\
\hline $\begin{array}{l}\text { 2. Reproducing } \\
\text { structured } \\
\text { knowledge }\end{array}$ & $\mathrm{A} / \mathrm{b}$ & $\mathrm{A} / \mathrm{b}$ & A & $\mathrm{A} / \mathrm{b}$ & $\mathrm{A}$ & $\mathrm{A}$ \\
\hline $\begin{array}{l}\text { 3. Applying } \\
\text { structured } \\
\text { knowledge }\end{array}$ & $\mathrm{A} / \mathrm{b}$ & $\mathrm{A} / \mathrm{b}$ & $\mathrm{A} / \mathrm{b}$ & $\mathrm{B}$ & $\mathrm{A} / \mathrm{b}$ & $\mathrm{A} / \mathrm{b}$ \\
\hline $\begin{array}{l}\text { 4. Organizing } \\
\text { subject knowledge }\end{array}$ & B & $\mathrm{A} / \mathrm{b}$ & B & B & $\mathrm{A} / \mathrm{b}$ & $\mathrm{A} / \mathrm{b}$ \\
\hline $\begin{array}{l}\text { 5. Transforming } \\
\text { discipline } \\
\text { knowledge } \\
\end{array}$ & B & B & B & B & B & $\mathrm{B} / \mathrm{a}$ \\
\hline $\begin{array}{l}\text { 6. Transforming } \\
\text { conceptions of the } \\
\text { discipline/world }\end{array}$ & B & B & B & B & B & B \\
\hline
\end{tabular}

From Identifying academics' orientation to assessment practice, by K. Samuelowicz \&

J. D. Bain, 2002, Higher Education, 43, p.184-185.

Samuelowicz and Bain (2002) described each of the 36 cells, and then further reduced the orientations to assessment into three dominant groupings, being "reproduction of knowledge" which contains predominantly A scores (first two orientations in the above table), "application of knowledge" with A/b scores (third orientation in table), and the "transformational value of knowledge" with mostly B scores (last three orientations in the table). Each faculty member was coded as either $\mathrm{A}, \mathrm{A} / \mathrm{b}$ or B and allocated a score. Finally, using Spearman's rank correlation they found that there was a significant correlation between views of assessment and views of learning established in the related study of the same sample of faculty (Samuelowicz \& Bain, 2001). 
The data presented by Samuelowicz and Bain (2002) provides a systematic analysis of the beliefs of faculty as related to assessment and shows that the manner in which assessment is undertaken relates to beliefs about teaching and learning. Thus, restructuring the way in which faculty undertake assessment is contingent upon restructuring underlying beliefs about teaching and learning. Understanding the stage in which an instructor is located helps in building programs to support faculty development (Richlin, 1998). This is a major challenge for professional development initiatives.

Assessment practices can be powerful instruments shaping student learning (Samuelowicz, 1999). Students also hold conceptions about the purposes or assessment and the intentions of their instructors. Sambell and McDowell (1998) illuminated student perceptions of the purpose of innovative or alternative forms of assessment and explored students' beliefs about the underlying hidden messages or hidden curriculum in such assessment practices. Thirteen case studies of courses using innovative assessment practices were undertaken at a university in the United Kingdom. Case studies covered a range of courses with different assessment practices, including oral presentations, research projects, peer assessment, group projects, open book exams, poster presentations, simulations, portfolios and personal profiles.

Results were presented at two levels, at the level of overall student perceptions and then at the level of individual interpretations. Three major themes emerged from the analysis of the whole data set. First, students felt motivated to work in different ways because of the different assessment practices. Second, they felt that the new approach to assessment fostered a different relationship between students and faculty. Third, students 
identified that the alternative assessment was located in a different view of what learning was.

When data from individual students were probed, some contradictory points of view emerged. For instance, one instructor saw multiple-choice tests as a way to prevent swotting for exams and as a way to ensure breadth of coverage. In contrast students held different perspectives, with some seeing the multiple-choice test as a way to ensure they learned all the foundational concepts, while others saw it as a way to force them to work harder, to catch them out, or as a mechanism for accountability. Similarly, the case of a course that developed student profiles as a means to provide individualized feedback to students, for them to track their own performance, created different perceptions amongst students. Some saw the individual meetings with faculty, during which learning profiles were constructed, as a way to provide academic support and guidance. Others saw it as a way for the instructors to tell them what they should know or be doing, as a way to check up on them, or as a way to find out how they were performing in relationship to others. The results showed that at the general level students understand the explanations offered by their instructors about alternative forms of assessment, but that these are further subject to personal interpretations. Personal constructs are a consequence of self-interest, experiences and contextual factors.

Not only do faculty members hold personal conceptions about the nature and purpose of teaching, learning and assessment, students hold similar conceptions and for common understanding, mutual negotiation of intent is necessary. This means that innovative assessment practices need to be made explicit to students, but that even when this is done, individuals may still have different interpretations of purpose. 
In summary, faculty hold personal conceptions of assessment that are consistent with their beliefs about teaching and learning. To change faculty conceptions about assessment, beliefs about teaching and learning are likely to also need restructuring (Samuelowicz \& Bain, 2002). Furthermore, their constructs about the purposes and value of assessment are likely to be different to those held by students and open dialogue and negotiation are needed to reach consensus (Sambell \&McDowell, 1998).

During NOVA workshops, faculty are also provided with information and examples of alternative assessment including the use of performance tasks and rubrics, portfolios, thinking maps, writing prompts and student self-evaluation strategies (Johnston, 1999). Several journal articles were provided as resources for faculty to use in designing their own assessment processes for new courses.

Raubenheimer $(2003,2004)$ found that most of the action research plans $(74 \%)$, produced by a sample of college professors, indicated intent to use some form of alternative assessment. The range of techniques suggested for student assessment was wide and included journals, on-line tasks, performance tasks, rubrics, observation, interview, concept maps, quick writes, journals, portfolios, discussion groups, self evaluation, peer review, and logs of class activities. However, there was insufficient discussion on how these techniques would be used to gather data, and how that data would be analyzed. This indicated that more work is needed to establish faculty conceptions of the purposes and value of assessment and to contrast this with associated practices. 


\section{Conceptions of Research}

Typically, the differences in the way in which research is approached by different researchers is attributed to disciplinary differences (Huber, 1999). However, Becher (1989, cited in Brew, 2001) showed that the disciplines "do not provide the primary way in which people think of their research" (p. 272), but that there is a complex set of factors that contribute to academic's ideas about research. For instance, they differ in the extent to which their external environment and personal concerns affect their perceptions of research. Similarly, Rowland (1996) in a study of heads of department at a British university found that the relationship between disciplinary base and accompanying view of research was not fixed.

Brew (2001) highlighted that empirical work on faculty conception of research is hard to find and suggested that in the context of the US, the focus on the notion of scholarship to encompass the full range of academic work, has meant that "the American literature has neglected to consider different conceptions of research held by academics" (p. 273). Identifying this general gap in the literature, Brew (2001) conducted a phenomenographical study to examine Australian university researcher's conceptions of research. Four variations, were identified: (a) a domino conception in which research was seen as a series of separate entities with the intention of putting together these separate elements for problem solving (one solution can lead to others), (b) a layer conception, where research was considered the process of discovering underlying meanings implicit in data gathered, (c) a trading conception, where research was considered as a market place for the exchange of products, like publications and social networks, and usually for 
personal recognition or reward, and (d) the journey conception, with research seen as a personal process of discovery and transformation.

She also discovered that some researchers were associated principally with only one category, while others spanned across two or three categories. None of the faculty surveyed spanned across all four. Thus, a researcher may shift views depending on the purpose of the research being undertaken. Brew (2001) further contended that the four conceptions did not form a hierarchy or continuum of categories with one category subordinate to others. Instead she noted that while phenomenographers studying children's ideas found hierarchical arrangements in conceptions to be typical, this is not necessarily a precondition for phenomenographical research findings.

In the US, however, the way in which research is conducted is strongly influenced by the dominant paradigm, that of technical rationality (Schon, 1995, Keller, 1998). An initial analysis of 53 action research proposals and projects in the NOVA program (Raubenheimer, 2003, 2004) showed that most of these science and mathematics faculty were generally operating out of the research paradigm typical of the natural sciences, where quantitative methods and analyses, using pre-test and post-test data, were dominant. There were few qualitative approaches to research employed and faculty typically investigated students' knowledge, skills and attitudes, rather than investigating their own instruction and classroom environment.

Harwood, Reiff, and Phillipson (2002) hypothesized that "implementing inquirybased teaching into the classroom and practicing a school science that more closely resembles scientists' scientific endeavors hinges on developing a common understanding and language around the issues of scientific inquiry and inquiry based-instruction" (p. 3). 
They added that the difficulty is that it is not clear what the conceptions are that scientists hold about the nature of scientific inquiry. In a grounded theory approach, interviews were conducted with 53 scientists in nine departments at a US university, to probe conceptions on this topic. Results indicated that conceptions were very similar across departments, with all perceiving scientific inquiry as process, grounded in two key ideas, that scientific knowledge builds and extends prior knowledge, and that it changes over time. Again these findings suggest that science educators at university level are rooted in a traditional paradigm, and it could be hypothesized that their views and approaches to teaching would be linked to this framework.

Rowland (1996) hypothesized a direct relationship between approach to teaching and research. He interviewed heads of department and found they believed that the relationship between teaching and research was much closer in interactional settings. In a lecture dominated classroom, where students asked few questions, there was little spinoff for the instructor's personal area of research. In contrast, in project and discussion based classrooms, where students were encouraged to challenge and raise questions, there were outcomes that were potentially significant to the instructor's personal research interest. Here it was suggested that effective teaching leads to new insights and research possibilities within the discipline.

The meta-analysis done by Hattie and Marsh (1996) of 58 studies on the relationship between research and teaching shows that there is a vast body of literature on the topic. These studies considered whether a strong research agenda in the discipline improved teaching effectiveness. Brew and Boud (1995) noted that one of the problems with such studies was the uncontested and narrow way in which the terms 'research' and 
'teaching' were used. They called for more studies that explored teaching and research processes, rather than just their products. Additionally, seldom did the research examine the effect of teaching on research, as was done by Rowland (1996), indicating that research is considered more important in higher education institutions. From their analysis, Hattie and Marsh (1996) concluded that research productivity does not enhance teaching and that, similarly, research productivity does not detract from being a good teacher. "We must conclude that the common belief that research and teaching are inextricably entwined is an enduring myth" (p. 530). They suggested that the myth is kept alive by the academy to justify the emphasis on research, especially for tenure and review processes. These studies did not explore the relationship between conceptions of research and teaching practices.

Instead of more studies on the relationship between research and teaching, Hattie and Marsh (1996) called for research to be undertaken into (a) the relationship between research and faculty orientation to teaching, (b) between research and faculty conceptions of learning, and (c) into the categories of conceptions about teaching. Brew (2001) similarly called for more research that matches conceptions of research to conceptions of teaching, to "open up a more sophisticated discussion of the relationship" (p. 273) because both sets of conceptions are rooted in personally held theories about the nature of knowledge and inquiry (Brew, 1999b).

Hirsch (2000) advocated the use of Schon's notion of reflection-in-action and reflection on knowing (Schon, 1995), as well as action research, as mechanisms to bridge the gap between theory and practice. In this review of literature, no studies were located that examined faculty conceptions of classroom research or of action research. But, if 
science and mathematics faculty are to be encouraged to employ classroom research techniques outside of the paradigm with which they are familiar, it is essential to consider their assumptions about the nature of knowledge production and its relationship to teaching, and the role of action research in influencing teaching practices. This doctoral research study will go some way to entering into this discussion by examining faculty conceptions of the relationship between teaching, learning, assessment and action research.

\section{Action Research}

The role of action research in higher education is presented after an overview of the nature of action research is made. Different approaches to action research and their underlying assumptions are explored as a framework for the analysis of action research projects.

Action research was first conceptualized by Lewin, added to by Kolb with his concept of the experiential learning model, and further extended by Carr and Kemmis (1986) and other authors (Zuber-Skerritt, 1992a, 1992b). For instance, Stenhouse (1975) developed the notion of teacher-as-researcher, an extended professional taking responsibility for testing personal theories about curriculum research and development in their own teaching practice. Schön (1983) added that the reflective practitioner "reflects on the understandings which have been implicit in his action, understandings which he surfaces, criticizes, restructures, and embodies in further action" (p.50). However, reflection on action is not enough but needs to be "coupled with a self-critical and critical perspective of the teaching practice and its wider context" (Zuber-Skerritt, 1992b, p. 26). Thus, action research must lead to improved practice and change in the particular context. 
Carr and Kemmis (1986) made a significant contribution to understanding and implementing action research. They envisioned the following steps in the process: (a) analyzing the problem, (b) planning strategies and interventions to remedy the problem, (c) evaluation of the course of action, (d) reflection on the results, and (e) repetition(s) of the cycle. In summary, action research is an iterative process involving successive cycles of question generation, planning, action, observation, and reflection, with the latter being termed the four moments of action research (Hopkins, 1993; Zuber-Skerritt, 1992b).

It is a qualitative research technique (Denezin \& Lincoln, 2000), using methods including observation, field notes, interviews, questionnaires, sociometry, archival data (e.g. documents), artifacts, and self-reporting (e.g. journal entries) (Hopkins, 1993; Mills, 2000). The basic assumption is that people learn and create new knowledge out of personal experiences through reflection, then formulate abstract conceptions and generalizations. These are then applied to new contexts and situations (Zuber-Skerritt, 1992b). Action research then is about developing an understanding of praxis, the dialectical relationship between formal theory and the theories generated in a particular context (Hadfield \& Bennett, 1995). “Action research projects are always case studies" (Hermes, 1999, p. 203) because they focus on local context and action, and thus any generalizations relate only to that situation.

Zuber-Skerrit (1992a) described several criteria for action research. It is "Critical (and self-critical) collaborative enquiry by Reflective practitioners being Accountable and making the results of their enquiry public, Self-evaluating their practice and engaged in Participative problem-solving and continuing professional development" (p. 15). He termed this the CRASP model of action research. Kember (1998) later distilled a set of 
characteristics from various authors representing the major typologies of action research. Accordingly, action research: (a) is concerned with social practice, (b) is participative, (c) has participants selecting the focus, (d) has as its purpose the improvement of practice, (e) is a cyclical process, (f) involves rigorous systematic inquiry, and (g) is reflective. "Perhaps the clearest distinction between action research and other modes lies in the attitude to changes to what is being researched. Other paradigms tend to avoid perturbing the subject of their research" (Kember, 1998, p. 52).

After Habermas, Carr and Kemmis (1986) categorized action research projects as serving one of three knowledge-constitutive interests (a) technical, (b) practical, or (c) emancipatory. The technical interest is concerned with improving efficiency and effectiveness in educational practice by gathering empirical data to test hypotheses and make generalizations. The practitioner is not the main researcher, but participants are coopted into the process by an outside 'expert' (Zuber-Skerritt, 1992b). Industrial action research, which has a tendency to be "technicist and co-optive", fits into this category (Kemmis \& McTaggart, 2000, p. 570).

The practical interest is driven by the need to generate meaning, understand practice and interpret reality through reflection and consensus. This often involves a practitioner and researcher cooperating together to identif problems, causes and interventions (Zuber-Skerrit, 1992a). Classroom action research, in which "primary concern is given to teachers' self-understanding and judgments," has a practical emphasis (Kemmis \& McTaggart, 2000, p. 569).

The emancipatory perspective focuses on identifying myths, assumptions, constraints and the relationship between value, interest and myth. Collaboration between 
stakeholders and the process moderator means that responsibility is shared equally among participants. Action versus description is central and solutions are political, consciousness raising and geared to the transformation of society. Critical action research and participatory action research are located within this interest. There is a commitment to social analysis and change, through the process of reflection. Critical action research arose because of dissatisfaction with classroom action research, which does not take a "broad view of the relationship between education and social change" (Kemmis \& McTaggart, 2000, p. 569). Similarly, participatory action research arose though the "resistance to conventional research practices that were perceived by particular kinds of participants as acts of colonization" (p. 572). Respectively, these three interests correspond to an empirical analytical paradigm, a social sciences paradigm and a critical sciences paradigm (Popkewitz, 1984).

Kemmis and McTaggart (2000) identified five different approaches to inquiry about practice and created a matrix to categorize epistemological assumptions and associated methodological approaches. The matrix identifies two dichotomies that have divided research approaches; the first division is between those approaches that see human action as either (a) individualistic, or (b) as a social product; and the second division conceives of research phenomena as either (a) objective, or (b) subjective. These are respectively placed on the $\mathrm{x}$ and $\mathrm{y}$-axis of the matrix. A fifth category is a reflexivedialectical position that includes all elements. The matrix is replicated in Figure 4. This classification shows that the method used depends upon the underlying view of practice and the particular epistemological assumptions. 
Different researchers into practice emphasize different aspects of practice in their investigations and rely on different research methods and techniques that seem appropriate in the study of practice viewed from the particular perspective they adopt. That is, different methodological perspectives in research on practice are related to different epistemological perspectives on the nature of practice. (p. 580)

\begin{tabular}{|c|c|c|c|}
\hline $\begin{array}{r}\text { Focus } \\
\text { Perspective }\end{array}$ & The individual & The social & $\begin{array}{l}\text { Both: Reflexive-dialectical } \\
\text { view of individual-social } \\
\text { relations and connections }\end{array}$ \\
\hline Objective & $\begin{array}{l}\text { (1) Practice as individual } \\
\text { behavior: Quantitative, } \\
\text { correlational-experimental } \\
\text { methods. Psychometric and } \\
\text { observational techniques, tests, } \\
\text { interaction schedules. }\end{array}$ & $\begin{array}{l}\text { (2) Practice as social and systems } \\
\text { behavior: Quantitative, correlational- } \\
\text { experimental methods. Observational } \\
\text { techniques, sociometrics, systems } \\
\text { analysis, social ecology. }\end{array}$ & \\
\hline Subjective & $\begin{array}{l}\text { (3) Practice as intentional action: } \\
\text { Qualitative, interpretive methods. } \\
\text { Clinical analysis, interview, } \\
\text { questionnaire, diaries, journals, } \\
\text { self-report, introspection. }\end{array}$ & $\begin{array}{l}\text { (4) Practice as socially structured, } \\
\text { shaped by discourses and tradition: } \\
\text { Qualitative, interpretive, historical } \\
\text { methods, discourse analysis, } \\
\text { document analysis. }\end{array}$ & \\
\hline $\begin{array}{l}\text { Both: } \\
\text { Reflective- } \\
\text { dialectical view } \\
\text { of subjective- } \\
\text { objective relation } \\
\text { and connections }\end{array}$ & & & $\begin{array}{l}\text { (5) Practice as socially and } \\
\text { historically constituted by } \\
\text { human agency and social } \\
\text { action: Critical methods, } \\
\text { dialectical analysis } \\
\text { (Multiple methods) }\end{array}$ \\
\hline
\end{tabular}

Figure 4. Relationship among Different Traditions in the Study of Practice. From Participatory Action Research, by S. Kemmis \& R. McTaggart, 2000, in N.K. Denezin \& Y. Lincoln (Eds.), A Handbook of Qualitative Research, (2 ${ }^{\text {nd }}$ ed.), p. 581, Thousand Oaks, CA: Sage Publications, Inc. 
They further extended their analysis by relating the different positions to the three knowledge constitutive interests already described. The objective orientation serves the technical interest, the subjective orientation serves the practical interest, and the reflexivedialectical orientation serves the critical-emancipatory interest. This means that based on the design and methods used in different action research studies it is possible to categorize action research projects into one of these three forms of action research.

Also, the conceptions of action research held by practitioners are likely to be different within each paradigm. Rearick and Feldman (1999) used the three knowledge constitutive interests or orientations (technical, practical, emancipatory) as one dimension in a framework for analyzing books on action research written by teacher educators. They included two additional dimensions in the framework, the purposes of action research represented and the types of reflective processes used. Purposes of action research were divided into the categories of personal, professional and political; and types of reflective processes into autobiographical, collaborative or communal, again reflecting the three orientations. The construction of "star diagrams" (p. 338), provided a way to represent the relationship among the dimensions and hence the orientation adopted by different authors. This framework can be used "to examine others' practice of action research" (p. 347). A similar consideration of the approaches and perspectives of academics may lead to a better understanding of how change can occur in higher education teaching.

Zuber-Skerritt (1992a, 1992b) held that action research is particularly relevant for higher education because it focuses on improving teaching and professionalism in universities and colleges by focusing on the pedagogical aspects of higher education. There are numerous examples of higher education faculty researching their own action, 
together with others, particularly in Australia, Hong Kong and the United Kingdom (Burchell, 2000; Conway, Kember, Sivan \& Wu, 1994; Hadfield \& Bennett, 1995; Kember, 1998, 2000; Kember, Lam, Yan, Yum \& Liu, 1999; Zoller, 1999; Zuber-Skerritt, 1992a, 1992b). Action research is acknowledged as a powerful way to examine preconceptions, bring about curriculum change, improve instructional design and implementation, and enhance faculty development (Zuber-Skerritt, 1992a, 1992b; Kember, 1998, 2000). For instance, action research was used to monitor the implementation of new courses at the Hong Kong Polytechnic (Conway, Kember, Sivan \& Wu, 1994) and indicated the value of faculty working together to implement new pedagogies. The successful implementation of action research projects requires a supportive environment and the active collaboration of various stakeholders (Bondy \& Ross, 1998). Time and the perceptions of administrators and students can be "roadblocks" to the process.

The role of facilitator or consultant is central to effective implementation of action research projects (Zuber-Skerritt, 1992b), where the consultant's role is not one of providing information and advice, but "to help them to create this knowledge themselves through experience, self-reflection and critical debate with others" (p. 106). Fedock, Zambo and Cobern (1996) showed how change in instruction occurred at a community college with the assistance of an outside mentor, who facilitated the change process in a way that fostered the exchange of ideas, mutual trust and openness. The facilitator can balance different demands implied by action research, although the facilitator's style and role definition may positively or negatively impact the process (Burchell, 2000), and determine if the approach is technical, practical or emancipatory (Kember \& Gow, 1992). 
Kember $(1998,2000)$ described the role of "critical friend" in the Action Learning Project, an inter-institutional project involving eight institutions in Hong Kong. Within the project there were a number of coordinators who worked with ten to twelve teams in the role of "critical friend". Their role included that of (a) "rapport builder", (b) "coffee maker" (ongoing facilitator'), (c) "mirror", (d) teaching consultant (e) evaluation and research advisor, (f) writing consultant and (g) match maker (putting people in touch with others). The critical friend is effective in enabling faculty to rethink the way they do things based on sound evidence (Kember \& McKay, 1996). However, there were a number of tensions associated with the role, such as how to avoid imposing ideas, how to engage all members of a group, and how to manage different interests, perspectives and personalities, so as to prevent any one person from dominating (Kember \& Gow, 1992). In the context of the US, Schön (1995) concluded that Boyer's challenge to develop the scholarship of teaching requires a new epistemology for universities. "Like other organizations, education institutions have epistemologies. They hold conceptions of what counts as legitimate knowledge and how you know what you claim to know" (p. 27). He called for a new epistemology that requires "knowing in action" and "reflection in action", and added that this is what social psychologist, Kurt Lewin meant by action research. "The new scholarship implies action research. The new categories of scholarship activity must take the form of action research" (p. 30). Schön added that if teaching is to be seen as scholarship, then the practice of teaching must give rise to new forms of knowledge that include the application to social contexts and social action. He argued for a move away from the technical rationality that is prevalent in universities across the USA. While he was calling for a new paradigm for educational research in higher education he 
noted that there is likely to be a long and difficult battle with the epistemology evident in the dominant paradigm.

Keller (1998) concurred that the research on and in American institutions of higher education has been dominated by "methodological monism" (p. 267) where the scientific method has predominated over other approaches. He argued for more research in higher education using other methods of enquiry, particularly pluralistic approaches. Kezar (2000a) agreed that the critique of research in higher education points at the need to bridge the gap between research and practice, and like Schön (1995) suggested that action research provides one way to achieve this, with faculty conducting research on their own teaching.

Action research has not been widely applied in higher education in the US, except for some teacher education programs, (Bondy \& Ross, 1998; Ross \& Bondy, 1996), including with beginning and experienced science teachers (Feldman \& Capobianco, 2000), and in local school-university collaborations (Bertram \& Easley, 2000). In part this is because, historically, scholarship has been synonymous with research publications and quantitative research (Kreber, 2000a), and there has not been a focus on improved teaching practice for tenure and promotion review (Boyer, 1990), which could include feedback from action research. Thus, there are fewer examples of action research in the content area disciplines (Bondy \& Ross, 1998). Despite this, Krockover, Adams, Eichinger, Nakhleh and Shepardson (2001), working out of Purdue University, concluded that, "efforts to implement action-research models in higher education settings, though limited in number, support our belief that action research is an effective means of reforming teaching of introductory college and university science" (p. 317). 
Conducting classroom research has been advocated for many years as a mechanism for contributing to the scholarship of teaching in higher education in the US (Cross \& Angelo, 1989; Cross, 1998; Paulsen, 1999). Classroom research is essentially equivalent to action research (Bondy \& Ross, 1998) with the purpose being to improve teaching and learning, which means that the cycle from question formulation to changing teaching practice must be completed (Cross, 1998). Research results are relevant to immediate practice. The difference between this approach and traditional research is that it does not end with data analysis, but leads to the generation of new questions and new action (Cross, 1998). In essence, this is action research, although it can be argued, using Figure 4, that classroom research serves only in the practical interest.

Using the Delphi technique, a team of experts on the scholarship of teaching and learning in higher education agreed that action research and classroom research are not well understood in the US (Kreber, 2001a; Paulsen, 2001), although they concurred that an understanding of classroom research is crucial to the practice of the scholarship of teaching and learning. "People practicing the scholarship of teaching need to have assessment, evaluation, and research skills. They need to be able to conduct classroom research and document the process of teaching and learning and student progress" (Paulsen, 2001, p. 27). The relationship between the literature on action research, classroom research and the scholarship of teaching also is not clear (Kreber, 200la).

Paulsen (2001) asserted that one of the main reasons why classroom research has not been widely applied is because of a confusion surrounding the terms classroom assessment and classroom research. He added that the primary advocates of both approaches, namely Cross and Angelo (1993), have used the terms interchangeably, 
"thereby training faculty and faculty developers everywhere to think of classroom research, in a somewhat narrow sense, as referring to the use of a set of classroom assessment techniques (CATs)" (p. 21). Cross (1998) has since made it clear that the two are separate processes, with classroom research being geared to understanding how students learn and how professors might enhance this process. Classroom research should be integrated with research and theories of learning (Cross \& Steadman, 1996) and should not be an add-on activity but embedded in regular class sessions, engaging students as collaborators in the process (Cross, 1998). Classroom assessment techniques represent a range of strategies for assessing student outcomes, and can be used as one component in action research (Cross \& Steadman, 1996).

Because action research is a qualitative approach, it is foreign to many scholars who are more familiar and at ease with quantitative methods. Schön (1995) described the case of a professor at MIT who had developed two new computer-aided instruction programs. The paradox that developed was that the professor, who had the opportunity to research the impact of his programs on student learning, was not able to develop a suitable research question. He might have investigated student opinions about the software, how they were using it, what it meant to them and why they preferred one program above the other. Although the professor documented the process of developing the computer programs, the Academic Council did not consider the work to be high-quality research and he did not get tenure. Schön concluded that this was a classic case where "not only was the institutional system so dedicated to technical rationality that it could not recognize the legitimacy of a particular version of action research, but the faculty member in question could not generate that research" (p. 33). He concluded that introducing and legitimizing 
action research may prove equally difficult with other scholars in the disciplines who would be undertaking such research. This shows that there can be no talk about the scholarship of teaching "unless we change the rules that govern what counts both as legitimate knowledge and as appropriately rigorous research into teaching and learning" (p. 34).

Few college teachers know enough about the learning process, other than through their own experiences, but classroom research can contribute to an understanding of teaching and learning processes (Cross, 1998). The cases described in Hutchings (2000) include examples of faculty undertaking classroom research and raising issues about the process. For instance, Jacobs (2000) grappled with several issues about data analysis, including decisions about how to manage the overwhelming amount of data that such studies generate, the challenge to reduce the data to meaningful interpretations, whether the data were ready to be reported, the need to integrate the findings with the literature, and whether the conclusions were robust enough for publication.

These are very important considerations for faculty wanting to undertake qualitative research into their own action. To resolve his immediate dilemma of what to do with the data, he decided to write mini reports on each of the areas of evidence as soon as there was enough data analyzed to draw tentative conclusions (Jacobs, 2000). This means that in the future these reports can form the basis of comparison with other data as it becomes available or is analyzed. While Jacobs has not explicitly adopted an action research approach, many of the elements are in place. He acknowledged, "It seems like every time I start to draw a conclusion I come up with another question that I'd like to answer first" (p. 48). This is typical of the cyclical nature of action research. He has also 
used a number of sources of data and methods for gathering data, and this too is a characteristic of action research. So, there may be more cases of action research, but implemented under the name of classroom research or classroom assessment.

In summary, action research can contribute to reform in curriculum and instruction in higher education, although the limited number of action research reports and publications in higher education in the US shows that this is an area in which more research is needed. One of the main purposes of NOVA is to encourage faculty to adopt new approaches to teaching and assessment, and to the evaluation of their work. NOVA promotes a cognitive apprenticeship approach, which involves people changing roles from teacher to learner within an action research model, involving cycles of planning, action, observation and shared reflection (Sunal, Hodges, Sunal, Whitaker, Freeman, and Edwards, 2001). This allows the teacher-learner to review the adequacy of traditional approaches and to make changes. Ownership of change is a central concept. Thus, NOVA has attempted to provide an alternative research framework to the dominant paradigm, and to bridge the gap between research and practice by promoting research on classroom action. This program provides a rich context for exploring faculty conceptions of and approaches to action research in the science and mathematics disciplines.

\section{Action research in NOVA}

A review of some prior research on action research within NOVA is presented in this section.

The NOVA program requires an action research component in proposals, before funding is provided for the development of new courses. To date 92 institutions have been funded and since 1998 all generated action research proposals and submitted reports of 
their actions, including reflections on the implications of the results for future action. An initial examination of action research projects in the NOVA program was conducted on the action research proposals of 53 NOVA funded institutions using rubrics to score proposals and content analysis to deductively code proposals (Raubenheimer, 2003, 2004). Similarly content analysis was undertaken on the abstracts of papers presented at the 2001 and 2002 NOVA Leadership Development Conferences and descriptions of some exemplary action research projects provided. The action research data were supplemented by site visit data made to 20 of the participating institutions.

Results indicated that in the first stage of proposal development, most institutions were still in early stages of developing action research plans because the majority of proposals were categorized within the apprentice-proficient range. Only a quarter of the institutions had clear and well-developed action research proposals that provided a comprehensive framework for meaningful data collection and analysis. The documentary analysis of the 53 proposals revealed that most were weak on the proposed data analysis component, with 39 proposals (74\%) making no mention about data analysis or simply stating that data would "be analyzed" or "compared" to other groups. Forty-one percent of institutions did not devise actual research questions or hypotheses, although in almost all cases these could be inferred. Many institutions (57\%) did not specify the type of instruments that would be used to collect data, making broad statements about methods of data collection, such as by survey or questionnaire. More faculty development is needed on methods of data collection and analysis, particularly involving qualitative methods of inquiry. 
All 56 action research proposals reviewed reflected the desire to move away from traditional lecture approaches to more interactive methods to enhance student learning. Action research conceptions were well articulated in 31 of these proposals and the cyclical nature of change is clearly reflected, showing a general understanding of the role of action research. The research questions or research purposes suggested in the proposals focused on the enhancement of student content knowledge, process skills, attitudes and/or student teaching efficacy and these purposes were specifically stated in 50 proposals, showing explicit concern for enhancing student learning. However, there were few proposals (19\%) where faculty proposed actually researching their own teaching. Such research might include particular approaches to teaching, classroom relationships, issues relating to classroom climate, the personal constructs of faculty and their impact on teaching, or the value of different approaches to assessment.

Action research involves cycles of planning, acting, observing and reflecting, but the action research projects in general did not meet this criterion because there is little evidence of more than one cycle being undertaken, even amongst the exemplary research projects presented at leadership development conferences. It is clear that faculty need more input, time and support in order to focus on themselves as the unit of analysis and to extend their efforts to ongoing cycles action.

Most of the institutions proposed quantitative approaches, with twenty-eight institutions (53\%) advocating the use of pre-test and posttest scores of student knowledge, skills and attitudes. Another quantitative approach commonly advocated was that of experimental and control groups ( $30 \%$ of institutions), in some cases in a true quasiexperimental design or combined with a pretest post-test design. Kember and McKay 
(1997) noted that the use of control groups is unusual in action research groups, but this was the dominant conception of research design in the NOVA action research projects.

The quantitative approaches were usually to be combined with additional qualitative techniques ( $66 \%$ of institutions), as advocated by the education faculty team member, and were designed to elicit more in-depth data, to provide a deeper understanding about teaching and learning. The range of techniques suggested for student assessment was wide and includes journals, on-line tasks, performance tasks, rubrics, observation, interview, concept maps, quick writes, journals, portfolios, discussion groups, self evaluation, peer review, and logs of class activities. This is an impressive array of qualitative techniques, which professors in science and mathematics disciplines have embraced. These alternative approaches provide valuable ways to assess student's content and conceptual knowledge, skills and attitudes, but there was insufficient discussion on how these would be used to gather data, how that data would be analyzed and used to improve instruction. Indeed, the use of new assessment techniques did not form a focus in any of the action research proposals.

Of 16 action research papers presented at the NOVA Leadership Development Conferences, 13 described improvement in students' science or math content knowledge, improved attitudes to the subject, enhanced process skills and improved instructor teaching efficacy. While these proposals were included in the documentary analysis of all 53 NOVA proposals, a content analysis of the presentations has not been undertaken, indicating a need for additional analysis of the action research results and outcomes of these projects. 
Using the framework established by Kemmis and McTaggart (2000, see p. 77), the data shows that the action research projects in NOVA are primarily technical in nature, with only a few reflecting practical concerns. Overall, there is little evidence for emancipatory agendas. This suggest that science and mathematics educators in the NOVA program are strongly located in a traditional empirical-analytical paradigm (Pokewitz, 1984) and that it may be hard for them to move outside of this domain and to accept new methods of inquiry. The paradoxical case described by Schön (1995) of the professor who had the opportunity to research the impact of computer aided instruction on student learning, but who was not able to develop a suitable research question, is relevant here. Similarly, science and mathematics professors may not be able to generate questions that are relevant to teaching and assessment practices, focusing instead on learners.

Action research has the potential to transform practice but it is apparent that more work is needed in the NOVA project to encourage and support faculty to examine their own teaching and assessment practices within an action research mode that utilizes the pluralistic, multidisciplinary research methods as suggested by Keller (1998). Additional professional development within the NOVA Leadership Development Conferences might focus on supporting these activities. An examination of underlying conceptions of action research, and their relationship to teaching, learning and assessment may provide useful information to facilitate this process.

\section{Professional Development of Faculty}

In this section some effective professional development practices are highlighted, particularly in considering ways to bring about a restructuring of faculty conceptions. 
Recommendations for faculty development towards the scholarship of teaching, based on Kreber (2001b), are explored.

There are many role functions for higher education faculty, including keeping abreast of developments in the specific discipline, research, writing and publishing articles, grant writing, attending and presenting at conferences, community service activities, advising and grading students, and formal instruction (Areola, Theall, \& Aleamoni, 2003; Kreber, 2000c). More experienced faculty tend to be better able to integrate teaching with research and service activities (Kreber, 2000c). However, most higher education faculty undergo little preparation for these roles, particularly for teaching. Typically there is no pre-service training in teaching and so faculty in the disciplines are less likely to have developed pedagogical knowledge and pedagogical content knowledge (Hativa, 2002). To address this, faculty development, if offered at all, is usually done through in-service programs (Zuber-Skerritt, 1992a), which typically have been skills based (Ho, 1998). Webb (1992) noted that most of these efforts have been located in a positivist paradigm, with a "simplistic delivery system view of education" (Kember \& McKay, 1994, p. 531).

Weaker teachers are generally less willing to engage in the process of selfimprovement, feeling threatened by such activities (Zuber-Skerritt, 1992a). In a Delphi study, experts acknowledged that the lack of formal training and resistance to efforts to improve pedagogical knowledge remain an "unresolved issue" for the scholarship of teaching and learning (Kreber, 2001b, p. 79). Kreber (2001b) made five recommendations for faculty development towards the scholarship of teaching. 
First, she suggested that there is a need to, "introduce faculty wide collaborative action research programs in which professors and faculty developers explore teaching and learning in the discipline" (Kreber, 2001b, p. 81). Action research as an effective means of faculty development, as has already been argued (see previous section) (Kember, 1998, 2000; Kember \& Gow, 1992; ; Kember \& McKay, 1994; Zuber-Skerritt, 1992a, 1992b). For instance, Kember \& McKay (1994) showed the power of action research as a mechanism to bring faculty together, to engage in discourse around course structure and delivery. Prior to the introduction of a new degree program and accompanying action research process, most of the faculty had not tried new methods of teaching or assessment and so the project was successful in enhancing student learning as well as in the professional development of the faculty.

Second, Kreber (2001b) suggested that faculty "contract for and focus on the scholarship of teaching for a given number of years" and that institutions "allow for sabbaticals to be dedicated to the scholarship of teaching" (p. 83). The case studies outlined by the Carnegie Foundation for Teaching and Learning, involving faculty fellowships and sabbaticals have demonstrated the success of this second recommendation. These cases are representative of many different issues in education across disciplines (Hutchings, 2000).

The third recommendation by Kreber (2001b) was that faculty development be based on educational theory and research. It is important to examine teaching practices through a combination of reflection and an articulated theory and knowledge base (Entwistle, Skinner, Entwistle, \& Odd, 2000). Two theories about the nature of change within individuals are relevant to the discussion in this section: (a) the notion of theories 
of action and theories-in-use, described by Aryris and Schon (1974), and (b) the theory of conceptual change (Ho, 1998; Posner, Strike, Hewson \& Gertzog, 1982).

Zuber-Skerritt, (1992b, p. 30) noted that, "Even though academics may publicly commit themselves to the progressive ideas discussed above, in actual practice they often retreat to a traditional approach which in turn makes students adopt that approach". This comment relates to the notion that theories of action, or espoused theories, do not always concur with theories-in-use, the theories people actually use to guide action. "Theoriesin-use tend to be tacit structures" and "contain assumptions about self, others and environment - these assumptions constitute a microcosm of science in everyday" (Argyris \& Schon, 1974, p. 30) and represent the values, unconscious beliefs and underlying rationale that govern behavior.

Theories-in-use can be inferred from observed behavior (Hativa \& Goodyear, 2002), such as acts of teaching. They added that, "teachers' practical knowledge explains their part of the rationale underlying teaching practice that is tacit and only implicitly known to the teachers" (p. 348). This knowledge is developed through trial and error, usually without reflection and reference to educational theory. "As a consequence from the non-systematic way it develops, teachers' practical knowledge is deeply embedded in their beliefs, values, understandings and attitudes" (p. 349).

Argyris and Schon (1974) argued that the process of improving professional effectiveness involves the examination and rebuilding of one's theories of action, and considering their relationship to theories-in-use. This may occur in a linear way, through an incremental process of building new knowledge upon the old. They called this modelone or single-loop learning, where new learning conforms to the basic principles of the 
old theories (Ho, 2000). Model-one values tend to be concerned with rationality, effectiveness, the exclusion of others, defining goals in private, and the desire to control and manipulate the environment (Argyris \& Schon, 1974). Most faculty development in higher education has been oriented toward this model, adding new teaching techniques without examining fundamental assumptions about teaching and learning (Ho, 1998). Essentially, this is akin to the Piagetian notion of assimilation, the incorporation of new ideas into existing schemata, without restructuring of the schema.

Change in behavior, however, often requires a fundamental re-examination of the underlying beliefs, values and assumptions that underpin action. Argyris and Schon (1974) called this double-loop learning because it necessitates the examination of old ways of thinking and doing, and the building of new theories of action, and new theoriesin-use. This usually occurs through dilemmas that arise and present contradictions to assumed beliefs. They identified four types of dilemma, (a) dilemmas of incongruity, which arise because on an increasing incongruity between espoused theory and theoriesin-use, (b) dilemmas of inconsistency when coexisting beliefs and values within the theory-in-use become incompatible, (c) dilemmas of effectiveness, when it becomes increasingly hard to achieve established goals, and (d) dilemmas of value when an individual begins to dislike the behaviors that the theories-in-use created (Argyris \& Schon, 1974). As people are exposed to such dilemmas, they are forced to reconsider their assumptions and their thinking.

Essentially, double-loop learning involves confrontation, to achieve transformation. This is synonymous with Piaget's accommodation, where existing 
schemata need to be restructured to accommodate new information. Ho (2000) concluded that

In the process of theory transitions, professionals need to become aware of their own theories-of-action, to admit the sources of dilemmas, and actually to value the confrontation. The confrontation will then create tension to resolve the dilemmas, thus leading to changes in the espoused theory or theory-in-use. (p. 32) So, faculty members have deeply held beliefs and assumptions that impact how they teach and assess and until their theories of action and practice are made conscious, change will not occur. Aryris and Schon's theories "attempt to explain the process of change: how does the change happen?" (Ho, 1998, p. 33). Opportunities to surface the old and incorporate the new are needed. Thus, the challenge for the professional developer, critical friend or educational consultant is to move faculty into double-loop learning.

The theory of conceptual change, originally developed as a means of dealing with alternative conceptions in science (Posner, Strike, Hewson \& Gertzog, 1982), details the conditions needed for effecting conceptual change about teaching and learning (Ho, 1998). There are four conditions for conceptual change proposed by Posner, Strike, Hewson and Gertzog (1982): (a) that there must be "dissatisfaction with existing conceptions" (p. 220) leading the learner to considering alternatives, (b) that a new conception must be intelligible, (c) that a new conception must appear plausible by making sense, and (d) that the new conception should be fruitful, explaining more than the old conception was able to do. Ho (1998) noted that the conceptual change model has 
one particular feature in common with the theory of second-loop learning, that it requires the confrontation of existing ideas. Ho (1998) emphasized that

In the context of conceptual change in staff development the confrontation could have two origins. One, as suggested by Argyris and Schon, is the mismatch between the espoused conception of teaching and actual teaching practices; another, as implied by Posner et al., is the unsatisfying nature of the existing conception of teaching. (p. 34)

Ho (1998) used this to derive a model for a faculty development program aimed at changing faculty conceptions about teaching and learning. Within ten activities spanning four sessions, participating faculty are taken through the stages designed to:

1. engage participants in active reflection and critical analysis of their espoused conceptions of teaching and their actual practices;

2. confront participants with the inconsistencies that might exist between their espoused conceptions of teaching and their actual teaching practices, and the inconsistencies that might exist between their aspirations and their current conceptions;

3. instill in participants an awareness of the need to resolve these inconsistencies;

4. expose participants to alternative conceptions of teaching held among tertiary teachers;

5. facilitate participants' understanding of the factors that are more conducive to effective and deep learning for their students, and those that are more likely to induce surface learning; 
6. facilitate participants' formulation of conceptions of teaching alternative to the one they are holding and which are more conducive to deep learning; and

7. engage participants in planning changes for their teaching so as to encourage them to build up a commitment to change.

Ho (2000) established that eighty-six percent of the participants in this type of development program found it useful (Ho, 2000), although only two-thirds underwent a conceptual change. However, all those who did experience a change in conception also improved their teaching practices $(\mathrm{Ho}, 1998)$. The faculty who did not change their concepts also did not change practices. Overall, faculty found the processes of "selfawareness" and "exposure to alternative conceptions" ( $76 \%$ respectively) to be more valuable than the "confrontation process" (48\%) (Ho, 2000, p. 29). The latter was attributed to many participants being uncomfortable confronting inconsistencies between their espoused conceptions and their actual practices, and Ho (2000) added that "several participants found it difficult to buy into the idea at all" (p. 34). Exposure to alternative concepts, while generally well received, also yielded statements about the lack of relevance of these new ideas, with some faculty remaining skeptical and defensive, even when shown case studies relevant to their discipline. This supports evidence of the resilience of conceptions to change, although the three strategies used in combination did achieve the desired results among many of the faculty (Ho, 2000).

Other models of faculty development draw on the research on the scholarship of teaching and learning already described in this chapter. Based on their research on the scholarship of teaching and learning Trigwell, Martin, Benjamin, and Prosser, (2000) developed materials for a professional development program known as the Australian 
Scholarship of Teaching Project (1999). This provides faculty development on teaching and learning at four Australian Universities. This project aims to (a) develop and support scholarly practice amongst university professors and (b) to communicate their findings amongst the higher education community. The project developed two modules with study guides, one module focused on the practice of scholarly teaching (aimed at experiencing variation in the conception, informed and reflection dimensions) and the second focused on the communication of that scholarly teaching practice (experiencing variation in the reflection and communication dimensions) (Australian Scholarship of Teaching Project, 1999). No results on the success of this model were found, although all the materials are available on-line.

Similarly, Weston and McAline (2000) proposed a continuum of professional development in three phases: (a) phase one, growth in teaching, (b) phase two, dialogue with colleagues about teaching and learning, and (c) phase 3 , growth in scholarship of teaching. In phase one faculty reflect on their own teaching and their students' learning to develop personal knowledge and understanding. In phase two, they share their knowledge by mentoring others, participating in various formal and informal structures focusing on teaching and learning, and organizing events to involve others in the critical dialogue. The emphasis is on forming a community with other interested persons. In phase three, faculty formalize the process by securing funds, conducting research, reading relevant literature, presenting and publishing their work. The mentoring role continues as they support others to research their teaching. While they acknowledge that an individual can move through these phases on their own, a faculty developer working collegially with university professors can be crucial to initiating interest and accelerating movement 
through the process (Weston \& McAline, 2000). Research on the effectiveness of this approach was not described by the authors.

Reading groups, "town hall" meetings and professional seminars are also effective mechanisms for this cognitive restructuring process (Kezar, 2001). This is consistent with Kreber's fourth recommendation, that faculty be encouraged to read discipline specific articles on teaching, and form reading circles to discuss these. This would include research on how college students learn, and how university practitioners can engage in classroom research (Paulsen, 1999). Kreber (2001b) also suggested team teaching as a way to stimulate discussion and reflection to improve practice. Kezar (2001), however, noted that there is a paucity of research in this area because most universities are not learning organizations and also because the shift is mostly a "philosophical change" within individuals and so is difficult to research empirically.

Kreber's fifth suggestion was that courses on learning to teach in higher education should be developed that model the scholarship of teaching (Kreber, 2001b) because courses that model the scholarship of teaching can be effective at increasing the scholarship and teaching of participants, namely current and future educators in higher education (Kreber, 1999). This is consistent with the call by the Association for Education of Teachers in Science (AETS, 1991) for the improved preparation of teacher educators through the use of standards in preparing higher education faculty, as well as school-based mentors and personnel providing in-service education.

In addition to the five points raised by Kreber (2001b) in the Delphi study, it is also important to consider the organizational context within which individual change occurs (Zuber-Skerritt, 1992b). Successful faculty development programs can only occur 
with adequate institutional support (Camblin \& Steger, 2000). Aleamoni (1997)

recommended that faculty development should be linked to faculty assessment, with institutional commitment to "a comprehensive instructional evaluation scheme and a subsequent comprehensive instructional development program" (p. 36). It is within enabling, rather than coercive organizational settings, that faculty development is most effective (Chopp, Frost \& Jean, 2001). Interdisciplinary teams, peer mentoring and collaboration amongst various stakeholders are important ingredients (Harnish \& Wild, 1994; Quinlan \& Åkerlind, 2000; Wilhelm, Craig, Glover, Allen \& Huffman, 2000). The NOVA professional development model follows a traditional approach, offering workshops on current research findings in science and mathematics education and on the NASA themes (strategic enterprises) that should be integrated into new courses. To become involved in NOVA activities, an interdisciplinary team of three faculty members (one from education, one from science or mathematics, and an administrator) attends an initial 3-day training workshop. Thereafter they develop a grant proposal, which is submitted to NOVA for funding consideration. Beginning in 1998, as a regular part of the NOVA Phase I workshops, action (practitioner) research forms one component of professional development process. Once funded, the team implements the new science or math course, gathers research data, and submits a final report that includes the results of the action research. Each year, follow-up leadership development conferences are held for ongoing faculty development and additional funding and project opportunities.

The education faculty member on the NOVA team is expected to take on the role of assisting science and mathematics faculty members in the development and use of 
action research plans in improving teaching, student learning, and course design. While NOVA members are available to answer questions, nobody works directly with each institution, in situ, as a consultant or critical friend. The extent to which faculty have shifted their conceptions of teaching and learning, assessment and the role of action research, through the NOVA model, needs investigation.

A group of research fellows (including myself), trained in the use of a particular set of protocols, have conducted site visits to institutions across the country. Data gathered includes interviews with all team members, interviews with students in NOVA courses, as well as an observation of a lesson. Classroom field notes were written and sessions rated using the ESTEEM instrument (Burry-Stock \& Oxford, 1994), while faculty rated their self-efficacy as teachers using a modified Science Teacher Efficacy Belief Instrument. (STEBI B) (Enochs \& Riggs, 1990). Other materials, such as syllabuses, action research proposals, reports and conference papers have also been collected. All of these data are housed at the Science Teaching and Learning Center at the University of Alabama and will be used in this study in combination with new data that needs to be gathered.

\section{Summary}

This review has shown that there is a need for further research into faculty conceptions of teaching and learning, assessment and action research in the US. The relationship between these conceptions and practices needs further exploration, to establish if there is any correspondence between beliefs and actions, or to account for incongruencies where they exist.

Action research has the potential to transform practices and conceptual frameworks through processes of professional development that involve interdisciplinary teams 
inquiring into aspects of teaching and learning. The extent to which it achieves this purposes needs further exploration. This current study sets out to examine these aspects and to consider if practices of selected NOVA faculty constitute the scholarship of teaching and learning. 


\section{CHAPTER 3}

\section{METHODOLOGY}

This research is grounded in an interpretive perspective in that it considers how people in natural settings attempt to make sense of the world around them and how they interpret phenomena. The socially constructed nature of reality is accepted because different people experience and interpret experiences in different ways (Denzin \& Lincoln, 2000). This is the basis of constructivism, which has as its central tenant that learners actively construct their own understanding based on personal experiences, prior conceptions, language usage and enculturation (Driver, 1992). It is assumed that this applies to the way in which university professors build their knowledge about teaching, learning, assessment and research.

Another of the assumptions in this study is that behavior is influenced by beliefs (Bandura, 1986) and is therefore instrumental in the way in which faculty undertake their work. It has already been shown that conceptions impact the selection of teaching and assessment strategies (Prosser \& Trigwell, 1999; Samuelowicz \& Bain, 2002). These conceptions are also likely to be reflected in the ways that curriculum documents are used to support their teaching, the assessment tasks used with students (Hofer \& Pintrich, 1998; Robinson \& Leamon, 1999) and in their action research proposals and reports. This study aims to explore the extent to which these assumptions are valid.

This chapter explains the methods to be used in carrying out this study. While the study is essentially qualitative in nature, some quantitative data were gathered to support 
the findings of the qualitative analysis. The intention was not to use quantitative data to test the qualitative findings, but because both provide different types of data on the same subjects and "each form of data is useful for both verification and generation of theory" (Glaser \& Strauss, 1967, p. 18).

\section{Key terms}

The terms conceptions, beliefs, dimensions, orientations and approaches have often been used interchangeably or inconsistently in the literature (Pajares, 1992). Kember (1997) in reviewing the literature provides clarification on these different terms and these were used in this research.

Conceptions are abstract representations with specific meanings attached to particular phenomena (Kember, 1997). We form conceptions of virtually every aspect of our world and these mediate the way in which we interpret and respond to situations. "A conception is always the experience of something" (Marton, 1988, p. 181). Marton (1988) identified three main foci of research on conceptions. First there is a rich body of research on outcomes of learning and approaches adopted by learners (see deep and surface approaches referred to in chapter 2). Second, much of the research has focused on the qualitatively different ideas students hold about the content of various disciplines, such as in science, and whether the ideas represent the accepted view or alternative conceptions (also referred to as misconceptions). The third line of research emphasizes how people conceive of various aspects of their every day world. This is where research on faculty conceptions of various aspects of their practice fits in.

Belief is considered synonymous with the definition of conception because beliefs are also built out of our experiences of the world around us (Kember, 1997). However, 
the term is less commonly used in the literature on higher education although frequently in the literature on schoolteachers' beliefs (Calderhead, 1996; Pajares, 1992). These beliefs may also be called belief dimensions (Samuelowicz \& Bain, 1992, 2001, 2002). Nespor (1987), again describing teacher's beliefs noted that beliefs are organized into systems that include the relationship between different beliefs.

Orientation encompasses more than one conception and is thus a "broader level of categorization" in which the main category (orientation) has several subordinate categories derived from several conceptions (Kember, 1997, $\mathrm{p} 257$ ). This relates to systems described above.

Approaches, either teaching or learning approaches, are strategies for achieving particular goals, and involve intention and motive (Kember, 1997).

Knowledge may be either tacit or explicit. Tacit knowledge is knowledge drawn from experiences and it therefore personal, context specific and often difficult to formulate or transfer. Explicit knowledge is formalized, easily codified and therefore easy to communicate and transfer (Carlson, 2002).

\section{Research Design}

Good qualitative design requires the use of a set of procedures that are "simultaneously open-ended and rigorous" (Janesick, 2000, p. 379). While there are elements that are predetermined, the researcher must be open to new and emergent ideas as the research progresses. Design must fit the purpose of the study, which in this instance is to explore conceptions held by faculty and associated practices, and so careful consideration must be given to methods that will elicit sufficient data to answer the research questions. 
Other research studies examining faculty conceptions have utilized a range of different research designs and methods, including phenomenography (e.g. Trigwell, Prosser \& Taylor, 1994; Trigwell \& Prosser, 1996a, 1996b), content analysis (e.g. Kember \& Gow, 1994; Murray \& MacDonald, 1997), personal construct theory and Kelly's repertory grid method (e.g. Kreber, 2000b), grounded theory and the constant comparative method (e.g. Samuelowicz \& Bain, 1992, 2001), and case studies (Bain, 2000; Quinlan, 1996, 1999a, 1999b). Quinlan (1996, 1999a, 1999b) utilized multiple methods of data collection and analysis, including a general pattern-matching analytic technique to analyze interview data. In addition, based on their qualitative work, Prosser and Trigwell (1999) used several different inventories to empirically examine relationships between academic's conceptions and student's approaches to study (see Trigwell \& Prosser, 1996a; Trigwell, Prosser \& Waterhouse, 1999). All of these methods have yielded valuable data and insights on the relationship between conceptions and approaches to teaching and learning. Rationale for case study approach

Marton and Svensson (1979) drew the distinction between explanation versus understanding as the purpose for studies on conceptions, with generalized studies being concerned with explanations and causal relations, while contextualized studies are concerned with understanding. "Understanding on the other hand, is a question of interpretation in terms of a pattern or a complex of meanings and has been connected with conceptions of the intentionality of human acts" (Marton \&Svensson, 1979, p. 481). This is the ultimate aim in this research. For this reason, case study methodology is the design selected. 
"Researchers have turned to case study in the face of the difficulties which have been encountered in attempting to apply a classical scientific paradigm of research to problems in which human behavior, action or intention play a large part"' (Stenhouse, 1987, p. 212). Case studies are intensive, holistic descriptions and analysis of a single unit or bounded system (Merriam, 1998). They provide a means of examining specific instances but illuminating a general problem. Case study research requires the thick description of the complexities of a situation, and is concerned with the study of the particular (Stake, 2000).

Case study is not a methodological choice, but a choice of what is to be studied. By whatever methods, we choose to study the case. We could study it analytically or holistically, entirely by repeated measures of hermeneutically, organically or culturally and by mixed methods - but we concentrate, at least for the time being, on the case. (Stake, 2000, p. 435)

Stake (2000) also advocates that case studies are organized around a limited number of research questions, thereby providing a clear focus.

Case studies allow for the use of multiple sources of data, methods of collection and analysis (Glaser \& Strauss, 1967; Merriam, 1998). Both qualitative and quantitative data can be used to add to the richness of the case. The value of multiple methods lies in obtaining a "richer, more complete pictures of the phenomena being investigated" (Dinham, 2002, p. 331). This lies in contrast to the traditional view that multiple methods increase the validity and reliability of findings, which assumes that there is some reality to be "discovered" (p. 331). Rather, multiple methods increase the richness of available 
data and the thickness of description and may "tap different domains of knowing" (Mathison, 1988, p. 14).

The process of gathering several types of data from several sources and using several different methods is termed triangulation (Hopkins, 1993; Janesick, 2000). The purpose of triangulation is "to reduce the likelihood of misinterpretation" by obtaining different perspectives and interpretations (Stake, 2000, p. 443). Triangulation is used to secure an in-depth understanding of the phenomena under investigation and adds rigor, breadth, complexity, richness and depth (Merriam, 1998). The four common methods of triangulation are (a) data triangulation, in which a variety of data sources are used, (b) investigator triangulation, involving several different researchers, (c) theory triangulation, involving the use of multiple perspectives to interpret data, and (d) methodological triangulation, in which multiple methods are used (Jansesick, 2000). This research used both data triangulation and methodological triangulation.

While triangulation is generally viewed as a method to enhance validity and establish reliability (Dinham, 2002), Mathison (1988) contended that it frequently "results in divergent, inconsistent and contradictory evidence that must be rendered sensible by the researcher" (p. 13). So, triangulation often does not lead to increased validity (in the traditional sense), but to exposing inconsistencies and contradictions. This was anticipated in this study where relationships between conceptions and practices are being explored, and where inconsistencies might be exhibited, therefore needing further exploration and plausible explanations.

Case studies can provide in depth information on factors impacting the way in which university teachers undertake their teaching. For instance, Entwistle and Walker 
(2002) provided a case study of the shifts in conceptions in one university teacher over time and Hativa $(1998,2002)$ identified factors contributing to the poor performance of two professors. Burroughs-Lange used a case study approach to examine faculty conceptions of the nature of learning, views about students, knowledge in their field and views about responsibility towards students. Hammich (1994) examined four cases of teaching assistants to track changes in conceptions of teaching after they were taught specific pedagogical strategies.

Cases are also are a way to integrate findings on conceptions and practices because it is possible to explore relationships in depth. For instance, Brickhouse (1990) and Smith and Neale (1989) examined cases of school teacher's beliefs and accompanying practices and identified a coupling between the these aspects. However, in higher education there have been few case studies considering the link between conceptual frameworks and associated practices (Samuelowicz, 1999). While, Ballantyne, Bain and Packer, 1997) presented the narrative accounts of 44 expert teachers in higher education, they did not provide within or cross-case analyses.

However, some authors have attempted to link conceptions with associated practices. Quinlan (1996, 1999a, 1999b) and Bain (2000) demonstrated that a close relationship does exist in the cases they studied. Both used an internal relatedness method to related conceptions and practices (Samuelowicz, 1999) where "in research using contextualized descriptions, the main results are the meaning of related categories and the character of the relations existing between them" (Marton \& Svensson, 1979, p. 479). In contextual cases, the meaning of the data are "based on the comparison of the meaning of the main categories and interrelations" (p. 479). Quinlan (1996, 1999a, 1999b) further 
examined cross-case issues and found that conceptions were associated with a particular view of the discipline, but noted that there are few other studies examining beliefs about the discipline and associated practices in higher education. So, case studies provide a powerful method for telling the stories of academics and for examining the diversity of factors that impact their practices.

Several cases were selected for this research. Yin (1994) calls this a holistic, multiple case design. It is holistic because there is only one unit of analysis, the individual faculty member in each case, and multiple because there are several cases. Stake (2000) refers to a number of cases in a study as a "collective case study" where the cases are chosen because "understanding them will lead to better understanding, perhaps better theorizing, about a still larger collection of cases" (p. 436). The intention was to use the individual cases to better understand the nature of the relationship between conceptions of teaching and learning, assessment and action research, and the actual practices of these by science and mathematics processors; and then to make comparisons across cases. Once this was done, the relationship of the findings to the larger population of NOVA courses was reflected on.

\section{Participants}

\section{Selection of sites and participants}

In selecting case study participants it is necessary to define the boundaries for the case or the criteria that make it a single unit of study (Merriam, 1998). In this research, the individual case is the faculty member teaching a newly developed, NOVA-funded, science course for non-science majors, specifically education majors. In some instances, 
two faculty team teach the course and this meant that there were two cases within the same context.

Purposeful sampling was used to select the cases in the study (Patton, 1987, 1990). Purposeful sampling ensures the selection of information-rich cases for in depth study, those that one can learn most from (Patton, 1990). It is a process of "building in variety and acknowledging opportunities for intensive study" (Stake, 2000, p. 446). There are several different ways of selecting a purposeful sample, including (a) typical sampling (reflects average position), (b) unique sampling (reflects atypical cases), (c) maximum variation (shows the most diversity of opinions and contexts), (d) snowball or chain reaction sampling (asking participants to recommend others), and (e) theoretical sampling (the ongoing generation of samples based on prior findings and emerging theories) (Merriam, 1998). In this study maximum variation was used to select the sample so that comparisons of similarities and differences between cases can be maximized (Glaser \& Strauss, 1967). This results in "important shared patterns that cut across cases and derive their significance from having emerged out of heterogeneity" Patton, 1990, p. 172).

It is important to generate a set of criteria for choosing participants. This should include a list of attributes from which is possible to then locate units that match the list. This is called criterion-based selection (Merriam, 1998). The criteria for selection of cases for this study are defined below:

- Site visits have been conducted by a NOVA research fellow and that all necessary documents were housed in the database at the Science Teaching and Learning 
Center, University of Alabama, Tuscaloosa. To date approximately 25 site visits have been conducted to NOVA funded institutions.

- Preference was given to site visits conducted by the author of this dissertation so that she could draw upon personal experiences.

- For (c) and (d) below, preference was given to sites that have presented action research projects at one of the NOVA Leadership Development Conferences (LDC) in 2001, 2002 or 2003. The first time the action research projects were presented was in 2001. I attended all action research presentations at the LDCs.

- Based on data housed in the Science Teaching and Learning Center, University of Alabama, suggestions from other NOVA research fellows and on personal observations, cases selected reflected maximum variation and interesting cases along the following continua, (a) teacher-centered/teacher-directed versus student centered classrooms, (b) quantitative versus qualitative action research projects, (c) action research projects focusing on student outcomes versus those interested in faculty teaching processes, (d) team taught versus an individual teacher, and (e) evidence of disjunction between theory of action and theory-in-use versus coherence in theories.

Initially eight cases were included in the study. Data was collected for all eight cases, although one case withdrew because of health problems after the first interview. During the process of transcribing the interviews and generating tentative codes it became clear that there was duplication of data among the cases. At that point it was decided that fewer cases would reach saturation and cover the criteria described above. 
This resulted in five cases being selected, with some cases meeting more than one criterion.

The first case reflected a teacher-directed instructor focusing on students assimilating new knowledge. The second case represented a student-centered classroom in which students are active participants, and a case with a qualitative action research project that examines teaching. The third case reflected a quantitative action research project focusing on student outcomes. The fourth and fifth cases reflected a quantitative action research project focusing on teaching. These latter two cases also represented a team taught course.

By emailing selected faculty who meet these criteria and outlining requirements for participation (e.g. interviews, completion of inventories, submission of syllabi and test items), access and entry to sites was negotiated and agreements with participants established, including informed consent forms (see appendix A for introductory email). All of those faculty invited ultimately agreed to participate in the research.

\section{Data collection and analysis}

Data were gathered on conceptions and practices of teaching and learning, assessment and action research. Data came from several sources, including faculty, students, solicited documents and other data from the existing database housed at the Science Teaching and Learning Center, University of Alabama, Tuscaloosa. Several methods were used to obtain data including interview, survey inventories and mining of documents. A summary of the data sources, methods of collection and methods of analysis are shown in Table 4. 
Analysis was simultaneous with data collection and included coding data for emerging patterns and themes. An explanation of each data source and procedures for analysis follows after Table 4.

Table 4

Sources and Method of Data Collection and Analysis

\begin{tabular}{|l|l|l|}
\hline Topic & $\begin{array}{l}\text { Source and method of data } \\
\text { collection }\end{array}$ & Analysis \\
\hline $\begin{array}{l}\text { Teaching and } \\
\text { learning }\end{array}$ & $\begin{array}{l}\text { Conceptions } \\
\text { Interviews (science/math faculty) } \\
\text { STEBI (Science teacher efficacy } \\
\text { belief instrument) }\end{array}$ & $\begin{array}{l}\text { Conceptions } \\
\text { Data coding, explanation } \\
\text { building } \\
\text { Descriptive statistics of } \\
\text { subscales } \\
\text { Descriptive statistics of } \\
\text { subscales }\end{array}$ \\
& $\begin{array}{l}\text { ATI (Approach to teaching inventory) } \\
\text { ESTEEM - observation instrument }\end{array}$ & $\begin{array}{l}\text { Practices } \\
\text { Descriptive statistics of } \\
\text { subscales } \\
\text { Data coding, explanation } \\
\text { building }\end{array}$ \\
& $\begin{array}{l}\text { Syllabuses } \\
\text { Field notes } \\
\text { Student interview transcripts }\end{array}$ & $\begin{array}{l}\text { Conceptions } \\
\text { Data coding, explanation } \\
\text { building }\end{array}$ \\
& $\begin{array}{l}\text { Conceptions } \\
\text { Interviews (science/math faculty) }\end{array}$ & $\begin{array}{l}\text { Practices } \\
\text { Data coding, explanation } \\
\text { building } \\
\text { Descriptive statistics of } \\
\text { subscales }\end{array}$ \\
\hline Assessment & $\begin{array}{l}\text { Conceptions } \\
\text { Data coding, explanation } \\
\text { building }\end{array}$ \\
& $\begin{array}{l}\text { Practices } \\
\text { Syllabuses } \\
\text { Test items } \\
\text { ACLSI (Assessment of classroom } \\
\text { learning in science inventory) }\end{array}$ & $\begin{array}{l}\text { Conceptions } \\
\text { Interviews (science/math faculty) }\end{array}$ \\
& $\begin{array}{l}\text { Practices } \\
\text { Data coding, explanation } \\
\text { building; "Star diagrams" } \\
\text { AR reports and presentations }\end{array}$ & \\
\hline $\begin{array}{l}\text { Action } \\
\text { research }\end{array}$ & & \\
& & \\
& &
\end{tabular}




\section{Case records}

A case record for each case was compiled utilizing all the data that were collected as outlined in Table 4. This record represents a condensation of the raw case in an edited form, to make the raw data "manageable and accessible" (Patton, 1987, p. 149). Within the case record, there is information from the various sources and different instruments used. It is a way of keeping all the data for the case study in one place. It "is the data of the study organized so the researcher can locate specific data during intensive analysis" (Merriam, 1998, p. 194). Alternatively, it may be called the case study database.

The data collection and analysis procedures are outlined in the next sections. Once the individual case study analysis was done, within-case analysis was also undertaken to compare the different constructions and practices across cases.

Site visits

In October 2001, six NOVA research fellows (including myself) were trained in the use of a series of protocols while conducting a joint site visit to Kansas State University. Thereafter each research fellow has conducted a number of visits to participating NOVA institutions. Site visit data included information about the context in which the cases are located, (including type and size of university, course details, student numbers), interviews with NOVA team members, interviews with students in NOVA courses, at least one classroom observation, and where appropriate, a laboratory session observation. Data included transcripts, completed observation instruments, self-assessment inventories, field notes and a summary report of findings. The data for each site visit is housed in the Science Teaching and Learning Center, University of Alabama, Tuscaloosa, and was used to situate the cases. 
Interviews are a way to gain access to "feelings, thoughts and intentions", aspects that cannot be accessed through direct observation (Patton, 2002). Semi-structured, openended interviews were conducted, with the researcher being reflective and probing as needed (Patton, 2002). The interviewer's task is "first and foremost to gather data, not change people" (Patton, 1990, p. 354).

Because the cases being investigated may include sites from as far a field as Idaho, California, Tennessee, and Florida, further field visits were not be possible. Thus, the choice was for interviews to be conducted either telephonically or electronically. One of the benefits of face-to-face interviews is that the researcher can gain valuable information through non-verbal cues and establish a rapport with the interviewee (Rubin \& Rubin, 1995), although Persichitte, Young and Tharp (1996) found that the opposite is also true, that electronic interviewers are unable to interrupt or give evaluative cues to interviewee responses. While neither telephonic nor electronic means will facilitate reading of nonverbal cues, but both make possible the establishment of a relationship. An added advantage of electronic interviewing is that the need for transcription is eliminated and the respondent has more control over the tone, style and content of their responses (Persichitte, Young \& Tharp, 1996).

The electronic interview process was piloted with a work colleague at Brescia University and found to be too lengthy to use for all interviews. The pilot, in which only the first set of questions about teaching and learning were posed, took over two and a half hours to complete. It was felt this was too much time to expect participants to contribute because a one-hour to 90-minute interview is optimum (Seidman, 1998; Yin, 1994). So, it 
was decided that three separate interviews would be set with each faculty member participating in the study, one on teaching and learning, one on assessment and a third on action research. All interviews on teaching and learning were done telephonically because it was the longest of the interviews and could be completed in a one and a half hour period, using the telephone. This also helped to create a rapport with the participants.

Thereafter, the interviewees were given the option for the second and third interview to be done electronically, via email. In practice, only one participant selected this method, with the other four preferring to be interviewed telephonically. The interview sessions were all scheduled telephonically, to further consolidate the relationship, and to ensure that the scheduled times were recorded by both parties. All telephonic interviews were recorded, with the permission of the participant, and the tapes transcribed verbatim. For the two electronic interviews, the responses were consolidated into one transcript. All transcripts were returned to the interviewee for a member check. At this point the researcher also raised questions of clarification as necessary. The interview protocol and questions are contained in Appendix B. The categories of questions generated were derived from the review of the literature, keeping the research questions in mind.

Once the interviews were fully transcribed an open coding process was used to begin analyzing the data (Strauss \& Corbin, 1998). All transcripts were read at least twice (Bogdan \& Biklen, 2003), line by line (Charmaz, 2000), noting comments, observations and queries in the margin, and generating a list of different items that emerged (Merriam, 1998). Similar items were grouped together by comparing lists within and between transcripts, thereby generating a tentative list of categories (Miles \& Huberman, 1994). Other tentative categories were also drawn from the literature as presented in chapter two 
and the researcher was open to inductively developing more codes over time (Miles \& Huberman, 1994).

Categories have a life of their own and are abstractions derived from the data, not data themselves (Charmaz, 2000, Glaser \& Strauss, 1967). Categories should be given names that reflect the purpose of the research. They should be exhaustive (able to place all data in a category), mutually exclusive (fit into only one category), sensitizing (reflect the sense of the data) and be conceptually congruent (at the same level of abstraction) (Merriam, 1998). While each case was given consideration in its own right, cross-case analysis had already begun because ultimately the same codes were used to code all faculty interviews on each conception area.

Once there was a set of tentative codes, a codebook was developed that has a detailed description of each code, with inclusion and exclusion criteria, and exemplars of each category (Ryan \& Bernard, 2000). These codes were assigned to units of data by reworking through the transcripts again (Miles \& Huberman, 1994) and coded using the computer program HyperResearch, which allows for sections of transcripts to be allocated a code(s). A unit of data is a bracketed chunk of data (word, phrase, sentence or paragraph) from field notes, observations, transcripts and other documents (Bogdan \& Biklen, 2003).

A retrieval system is essential for maintaining the data (Merriam, 1998; Miles \& Huberman, 1994) and so HyperResearch was used as the software for data coding, storage, report generation, cross-referencing and retrieval. In this way all data relating to one case and to any particular category is in the same place and can easily be accessed. A master copy of the original data was kept in all instances in a database. 
Throughout this process, the researcher kept a running record of thoughts, initial impressions and emerging categories in a journal. Memos record the relationships among themes (Strauss \& Corbin, 1998) and are "the intermediate step between coding and the first draft of the analysis" (Charmaz, 2000, p. 517). Memos provide a way for the researcher to trace their own thinking, to explore the relationship among codes, and record the stages of analysis. Charmaz (2000) calls it developing a "dual self", indicating the dialectic nature of the process (p. 517). Memos for this research were kept in a handwritten journal.

By the time codes have been developed, a lot of interpretive analysis has occurred. Coding is data reduction. "Coding is analysis" (Miles \& Huberman, 1994, p. 56) and is refined as the researcher goes along. The researcher is constantly moving back and forth between deductive and inductive modes. It is an iterative process of data collection, data reduction, data display and drawing conclusions (Miles \& Huberman, 1994). The researcher begins to explore patterns in the data, usually represented around four summarizers, (a) themes, (b) causes/explanations, (c) relationships among people, and (d) emerging constructs (Miles \& Huberman, 1994).

\section{Artifacts}

Curriculum documents reflect the relationship among structure, process and content and provide valuable insight into intention and strategies selected for instruction (Robinson \& Leamon, 1999). They also reflect underpinning epistemological assumptions (Hofer \& Pintrich, 1998). Analysis of such documents therefore provides evidence of the particular emphases and orientations of different instructors (Robinson \& Leamon, 1999). Each faculty member participating in the study was requested to make available a copy of 
the syllabus and assessment items for the course. Copies of action research proposals and project reports were obtained from the database at the Science Teaching and Learning Center, University of Alabama.

Artifacts, including syllabuses, action research documents and assessment items were scanned into HyperResearch and a data file created with multiple sources for each individual, thus allowing conceptual frameworks to be built within and across cases. This means that these data were analyzed together with other data in the case record as already described. Similarly, the field notes and reports written by NOVA research fellows were inductively analyzed and coded for emergent themes.

The use of quantitative data is one way to methodologically triangulate data (Patton, 2002). Action research documents were analyzed using "star diagrams" (Rearick \& Feldman, 1999). Star diagrams are a method to represent the relationship among three dimensions of action research, namely (a) theoretical orientation (technical, practical or emancipatory), (b) purposes (professional understanding, personal growth or political empowerment), and (c) types of reflection (autobiographical, collaborative or communal). They help to "locate the primary foci of the example of action research" (Rearick \& Feldman, 1999, p. 338).

\section{Classroom observations}

Classroom field notes written by NOVA research fellows are housed in the database at the Science Teaching and Learning Center at the University of Alabama. These were accessed and analyzed in the same way as faculty interviews and artifacts, with codes emerging from the data. 
NOVA research fellows conducting classroom visits complete the Expert Science Teaching Educational Evaluation Model (ESTEEM) Classroom Observation Rubric (Burry-Stock, 1995; Burry-Stock \& Oxford, 1994) (see appendix C). The observation instrument is a five point analytical scoring rubric that focuses on four dimensions (called variables) of teaching: (a) facilitating the learning process from a constructivist perspective, (b) content-specific pedagogy, (c) context-specific pedagogy, and (d) content-knowledge. There are several scoring items for each dimension, with a total of 18 items in the observation instrument. Within each dimension these items are totaled and converted into a percentage, and then represented graphically, providing an overall indication of the teacher's competency level. The reliability figures for the instrument are reported by Burry-Stock and Oxford (1994) and acceptable. Each case study faculty member received scores on the four dimensions, as well as an overall effectiveness score and these scores were obtained from the NOVA database.

\section{Student interviews}

Transcripts of interviews with NOVA course students (see appendix D for interview questions) are housed in the database at the Science Teaching and Learning Center at the University of Alabama. These were obtained and analyzed in the same way as other data in the case record, with codes emerging from the data.

\section{Survey Instruments}

Additional data were gathered using a set of different surveys to triangulate and provide further insight into the findings from the qualitative data (Patton, 2002). These were used to help confirm conceptions and to establish relationships between different conceptions. 
The Approaches to Teaching Inventory (ATI) (Trigwell \& Prosser, 1996a, in press), derived from qualitative data, aims to quantify the way in which university professors conceive of their teaching. The inventory consists of four subscales, (a) information transmission subscale, (b) conceptual change subscale, (c) teacher-focused subscale, (d) student-focused strategy subscale (see appendix E). Trigwell and Prosser (1999) claim a close relationship between teaching intention and strategy selected, the ATI is one way to establish this relationship. Reliability data from some recent studies using the ATI have been reported and are acceptable (Trigwell \& Prosser, in press). Data collected using the ATI were contrasted with the data collected during interviews.

A modified version of the Science Teaching Efficacy Belief Instrument (STEBI) (Form B) (Enochs \& Riggs, 1990), completed by NOVA case study faculty and available in the database, was used (see Appendix F). The STEBI B was developed for use with preservice elementary education teachers (Enochs \& Riggs, 1990) and was modified by NOVA for use with university instructors. STEBI B measures the constructs of selfefficacy on two sub-scales: (a) personal science teaching efficacy, and (b) science teaching outcome expectancy. There are 25 items on the instrument, with values between 1 and 5 , so that the total score possible is 125 , and reliability measures are reported by Enochs and Riggs (1990). Data from this source were related to faculty conceptions of their teaching abilities.

To survey faculty perceptions of their abilities to use different assessment procedures, a modified version of the Expert Science Teaching Educational Evaluation Model (ESTEEM) Assessment of Classroom Learning in Science Inventory (ACLSI) was completed by all participants (Burry-Stock, 1995) (see appendix G). There are 57 items, 
representing seven categories, to which individuals responds on a scale of zero (not skilled) to five (highly skilled) (Burry-Stock, 1995). This instrument was adapted for the science classroom from the Grading Practices Assessment Inventory for mathematics classrooms, with a Cronbach's alpha reliability coefficient of 0.98 .

\section{Case study narrative}

With-in case analysis was conducted using the processes described in the preceding sections, by examining codes emerging from the various data sources, and searching for patterns and relationships, particularly among conceptions, and between conceptions and practices. In this way, patterns and relationships within the individual cases gradually took shape.

To assist with that process, for each case, summary reports were generated using a HyperResearch feature. In this process, all instances of a particular code were gathered from across the data sources and collated into a report for that code associated with that particular case. This was done for all codes in both conceptions and practices in each of the areas of study, namely (a) teaching and learning, (b) assessment, and (c) action research, for each case. Using these reports as the chain of evidence, the case study narratives were written. Summary matrices (Miles \& Huberman, 1994) that compared the properties associated with conceptions and with practices were prepared for each of the three areas under investigation, for each case. These helped with the analysis of the relationship between conceptions and practices. Each case narrative was sent to the research participants as a member check for comments and concerns.

These narratives are analytic, interpretative and evaluative accounts of the context and each case study stands alone allowing the reader to "understand the case holistically" 
(Patton, 1987, p. 148). The intention is to move from description to explanation (Miles \& Huberman, 1994). Assertions and naturalistic generalizations about the case were developed in the case study narratives (Stake, 2000), particularly about the relationship between conceptions and practices.

Cross-case analysis

By consideration of the themes across cases, common issues between cases were highlighted, and differences noted. This process began as interview transcripts were coded and analysed. The matrices developed during single case analysis were valuable, as were other matrices and visual devices, in displaying and make comparisons of data across sites (Miles \& Huberman, 1994). This process was rather like overlaying transparencies to identify how themes are linked to each other and to build abstractions across cases. In cross-case analysis the intention is, if possible, to "build a general explanation that fits each of the cases" (Merriam, 1998, p. 195). The purpose is to “deepen understanding and explanation" (Miles \& Huberman, 1994, p. 173). At this point it was important to keep the research questions in mind, so that there was a move towards addressing the purposes of the study and consolidating theory.

\section{Reliability and validity}

Lincoln and Guba (1986) articulated criteria for judging the processes used in naturalistic inquiry, namely trustworthiness and authenticity. Within each of these, subcategories of criteria were identified in relationship to their counterparts in the traditional research paradigm, as indicated in the following sentences in brackets. Trustworthiness criteria establish the rigor of a qualitative investigation and include methods to demonstrate (a) credibility (internal validity), (b) transferability (external 
validity), (c) dependability (reliability), and (d) confirmability (objectivity) of the findings.

Dealing with reliability

Authenticity refers to balancing the different constructions and values inherent in a qualitative study, those between different participants and between participants and the researcher. In part this is achieved through acknowledging the researcher's personal theoretical biases, and presenting a full interpretation of the context under investigation (Merriam, 1998). Researcher reflexivity is central to the process, reflecting on the relationship between the researcher's personal theories and the interpretations of observations or findings (Lincoln \& Guba, 1990). Adequate engagement in data collection, including representing discrepant views is essential. This is an ongoing process as the research proceeds.

Methodological triangulation using multiple methods of data collection is a method to achieve reliability (Merriam, 1998) and this was done through the use of both qualitative and quantitative techniques already described. This also helps with construct validity because multiple sources "provide multiple measures of the same phenomenon" (Yin, 1994, p. 92).

One of the inherent problems of dissertation research is that the researcher is working on an independent and original research project. This means that there are unlikely to be other researchers against whom coder reliability can be checked. To overcome this dilemma in this study two interviews were recoded three months apart and the reliability figures calculated. This was done to achieve intra-coder reliability (Miles \& Huberman, 1994). For the first interview, the intra-coder reliability was $87 \%$. Further 
analysis of the disagreements or items not coded in both interviews increased this to $100 \%$, with each of them being considered relevant to the particular category. The intracoder reliability for the second interview was $83 \%$, although after further analysis of the disagreements or non-coded items increased this to $98 \%$. Only one item was deemed incorrectly coded. These are acceptable reliability figures (Miles \& Huberman, 1994).

Another method for achieving reliability in a qualitative study is to develop an audit trail, which comprises a detailed account of how data were collected and analyzed. This was achieved through the development of a reflective journal referred to in an earlier section. In these, memos included a detailed account of how data were collected, the manner in which data were coded and how interpretations and decisions were made (Merriam, 1998). Reliability was also achieved through establishing a case study database, both in hard copy and on computer, in which all the evidence for each case is housed and directly accessible (Yin, 1994). In effect this constitutes the case record.

In writing the case study report it is also crucial to maintain "a chain of evidence" to further the reliability (Yin, 1994, p. 98). The chain of evidence allows a reader of the case to follow the manner in which conclusions were drawn from the data available. That is, sufficient evidence must be provided to justify the conclusions that the researcher arrives at. This includes "citing specific documents, interviews or observations" (p. 99) and was undertaken in this research.

Dealing with validity

Credibility (internal validity) is the concern for how well findings match reality and can be established in several ways. Two strategies advocated by Lincoln and Guba (1986) were used to establish credibility. First, data triangulation was employed, 
gathering data from a number of sources, thereby converging multiple sources of data onto the case unit (Yin, 1994). Second, member checks were conducted by sending the interview transcripts and case study narratives back to participating faculty for their reaction, verification and alternative constructions. Participants expressed satisfaction with the records and interpretations made.

Transferability (external validity) was achieved through the thick descriptions (Lincoln \& Guba, 1986) contained in the narrative case records, so that other readers can identify with the cases. Also, the use of a multi-case, multi-site design that maximizes variation also contributes to external validity, because it allows "the results to be applied by readers to a greater range of other situations" (Merriam, 1998, p. 212), that is the broader NOVA context.

\section{Evaluating case reports}

To judge the quality case reports, Lincoln and Guba (1990) suggested that alternative criteria, relevant to the naturalistic paradigm of inquiry, should be developed and applied. These are (a) resonance, (b) rhetorical, (c) empowerment and (d) applicability criteria. These criteria were referred to as a guide as the final case study narratives are written and as a sounding board for assessing and editing the quality of the cases.

Resonance refers to the extent to which there is agreement between the theoretical position adopted by the researcher and the representation in the report. "A portion of the case study ought to be given over to consideration of conscious reflexivity" with the researcher reflecting on the process of constructing meaning (Lincoln \& Guba, 1990, p. 54). Rhetorical criteria refer to the extent to which the case study is well written and 
organized. It should be well crafted and clear, displaying "elegance", "creativity" and "courage" (p. 56). The report should be open and honest, representing the researcher's independent construction of the situation. Empowerment criteria refer to the manner in which the report galvanizes readers into action and raises consciousness by suggesting possible courses of action, rather than ending just with "suggestions for further research" (p. 57). Finally, applicability criteria are those aspects of the report that allow the reader to identify with the case and draw comparisons and parallels to their own situation. Again, this is done through "thick description" (p. 57), providing a basis for those reading the case to identify with or to re-examine their own assumptions and beliefs about a phenomenon. This was included in this research process.

\section{Ethical considerations}

Because case studies are intensive explorations of context, it is crucial that ethical guidelines are established prior to negotiating entry. "Qualitative researchers are guests in the private spaces of the world. Their manners should be good and their code of ethics strict" (Stake, 2000, p. 447).

The educational case study usually involves some invasion of privacy and so careful consideration must be given to protecting the participants (Merriam, 1998). In this study, the informed consent of all participants was elicited and confidentiality of the cases assured (see appendix H). Each participant was asked to create a pseudonym and this, or a modification assigned by the researcher, was used throughout the study. No references were made to the name of the institution or department in which the participants work. Permission was also obtained to use data already collected by other NOVA research fellows because such consent cannot be assumed (Merriam, 1998). 
Another ethical consideration revolves around the power of the researcher because data can be interpreted and presented in a manner that reflects the researcher's biases (Merriam, 1998). Thus, the researcher has power over the data. The openness of the researcher to hear different voices and different interpretations is important. Sending interview transcripts, the draft case record and narrative case study to the participants for ratification is an important way to address these ethical issues (Stake, 2000). In the event of conflicting perceptions or opinions between the researcher and participants that remain unresolved, both views should be reported in the final case study, although this was not necessary in this research.

The required CITI training was undertaken and all human subjects review requirements of the University of Louisville were met.

\section{Limitations}

Limitations to a study may be both intentional and unintentional. An intentional limitation is the use of data from an existing database. In most of the cases the field notes, student interviews and classroom observation data was already available, and so was not gathered at the same time that the faculty interviews were conducted. Some of these data were gathered after the site visits were conducted. Because there is a difference in temporal collection of data it is conceivable that faculty conceptions may have shifted by the time that interviews occur. The dates on which data were collected were noted in the case record as one possible variable.

Different NOVA research fellows have been responsible for the collection of data and this is a further limitation with respect to the field notes and classroom observation rubric. All research fellows were trained together by NOVA staff to use the various 
protocols in an attempt to address this issue, although inter-coder reliability was not established, and so there may be differences in the way in which different observers coded classroom observations and in the type of field observations made. Even though student interview data were direct transcriptions, different interviewers conducted the interviews and there could be some differences in emphasis.

Other unintentional limitations may have arisen as the study was conducted. 


\section{CHAPTER 4}

\section{THE CASES}

The purpose of this chapter is to provide detailed case study narratives for each of the five professors involved in the study. Each professor represents one case. The intention is to provide sufficient description of each case to be able to move towards explanation (Miles \& Huberman, 1994), which is the purpose of the next chapter, where cross case analysis is undertaken.

As data were coded, properties that describe the phenomena of teaching and learning; of assessment; and of action research emerged or were drawn from the literature. Properties describe the characteristics of phenomena being investigated. In the text these properties are highlighted by using bold text. Thus, each case is written around these properties and their associated dimensions, that is, the variants associated with the phenomena and arising from the various data sources. Because the narratives emerge from the data, the narratives are analytic, interpretative and evaluative accounts with the intention that the reader, "understand the case holistically" (Patton, 1987, p. 148).

Original quotations made by the professors, as well as segments from documents analyzed, are used as supporting evidence of conceptions and practices. The analysis of conceptions was derived primarily from interview data, the self-report STEBI B instrument (Science Teacher Efficacy Belief Instrument), the self-report ATI (Approaches to Teaching Inventory) survey, the self-survey ratings on the Assessment of Classroom Learning in Science Inventory (ACLSI), and the action research proposal. The 
analysis of practices is derived from the interview data, the course syllabus, an observation of a teaching session by a NOVA research fellow, site visit data including student interviews, assessment items and action research reports and presentations.

In using interview data to support practices, it is important that the data does not indicate intention, but reflects actual practices. For this reason, Kember and Kwan (2002) criticized Trigwell and Prosser, saying that, "unless the evidence for categorizing conceptions and approaches came from discrete parts of the transcripts, which is not specified in the paper, the claim to have established a conception/approach relationship should be treated with a degree of skepticism" (p. 222). For this reason, care has been taken to use the interview data to support practices only where there is clear evidence that these are not just intentions, but include examples and other detail to support the claim.

\section{Introducing the five professors}

All the professors in the study teach a science discipline (either physical science, earth science or biology) at a university or college in the U.S. All have participated in implementing a NOVA grant to improve instruction at their university. All are male. The range in teaching experience is from four years to over 30 years experience. One common characteristic of all courses is that they have a relatively small number of students enrolled (maximum of 35), although several of the professors expressed that they were trying to reduce the number of students further by either capping the course, or by introducing another section. Also, all courses are for education or non-science majors.

All institutions are at least 4 -year institutions, with some granting doctorates. The institutions range in size from a small private 4 -year college with only 700 students to a large state institution with 12,000 students. Table 5 summarizes the professor's teaching 
experience, the Carnegie classification of the institutions, and characteristics of their particular NOVA course.

Table 5:

The Professors and the Courses Taught

\begin{tabular}{|l|l|l|l|l|l|l|}
\hline Professor & Institution type & $\begin{array}{l}\text { Years } \\
\text { teaching } \\
\text { (full } \\
\text { time) }\end{array}$ & Course Topic(s) & $\begin{array}{l}\text { Course } \\
\text { level }\end{array}$ & $\begin{array}{l}\text { Class } \\
\text { size } \\
\text { (max) }\end{array}$ & $\begin{array}{l}\text { Requirement } \\
\text { or elective }\end{array}$ \\
\hline $\begin{array}{l}\text { Kenneth } \\
\text { Lane }\end{array}$ & $\begin{array}{l}\text { Small, private, } \\
\text { Baccalaureate } \\
\text { College, HBCU }\end{array}$ & 15 & Physical science & 100 & 30 & Requirement \\
\hline $\begin{array}{l}\text { John } \\
\text { Walton }\end{array}$ & $\begin{array}{l}\text { Small, private, } \\
\text { Master's College and } \\
\text { University II }\end{array}$ & +30 & Physical science & 200 & 35 & Requirement \\
\hline $\begin{array}{l}\text { Bruce } \\
\text { Stevenson }\end{array}$ & $\begin{array}{l}\text { Large, state } \\
\text { Doctoral/Research } \\
\text { University, } \\
\text { Extensive }\end{array}$ & 10 & Earth science & 300 & 20 & Elective \\
\hline $\begin{array}{l}\text { William } \\
\text { Rogers }\end{array}$ & $\begin{array}{l}\text { Small, private, } \\
\text { Baccalaureate } \\
\text { College-General }\end{array}$ & $\begin{array}{l}36(25 \text { yrs } \\
\text { high } \\
\text { school })\end{array}$ & $\begin{array}{l}\text { Biology and } \\
\text { physical science }\end{array}$ & 200 & 20 & Requirement \\
\hline $\begin{array}{l}\text { Todd } \\
\text { Andrews }\end{array}$ & $\begin{array}{l}\text { Small, private, } \\
\text { Baccalaureate } \\
\text { College-General }\end{array}$ & 4 & $\begin{array}{l}\text { Biology and } \\
\text { physical science }\end{array}$ & 200 & 20 & Requirement \\
\hline
\end{tabular}

${ }^{\circ}$ indicate courses that were team taught by two professors 


\section{Kenneth Lane}

This case was chosen to represent the more traditional teacher-centered/studentdirecting instructor with a focus on information transmission.

Dr. Kenneth Lane teaches a 100 level physical science course for non-science and education majors. The class meets twice a week in a regular classroom with desks set out in rows, with one student per desk. There is no associated laboratory section for the course. There is a core text for the course and selected chapters are covered over the semester, typically one chapter per week. English is not Dr. Lane's first language. Teaching and Learning: Conceptions

Dr. Lane's teaching goal is to impart his knowledge to students, saying that, "I want to share my knowledge with you guys and I hope you take it". "I am happy where I am right now, just to share what I know with all the people". He repeatedly stated that he is satisfied as long as students learned something from his class. "The push of teaching is that they learn and ah, if they learn, ah, whatever amount of material I am giving them and they get something out of it, I be more than happy." He also hopes that they will be able to relate the information learned to current events outside of the classroom.

He believes that an important role for the instructor is to make it easier for students to learn the content, saying, "if there is no frustration in their learning, I think they going to learn more or they will try to learn more from you". "I am just leading them to what we're trying to find". So, he tries to find different ways to explain phenomena in simple terms keeping in mind "to whom you going to deliver that information". He has a strong concern for engaging the learners in the process so that they are not afraid of the material being covered. He wants to try to encourage all the students in his class to learn. 
He does this by trying to create a relaxed classroom atmosphere and by eliciting what they do and don't know so that he can use that as the basis for further teaching, focusing on what they do not know. "I just dig information from them so that they can find what they did right and what they did wrong".

The NOVA grant was used to purchase Calculator-Based Laboratory ${ }^{\mathrm{TM}}\left(\mathrm{CBL}^{\mathrm{TM}}\right)$ calculators and these are used for students to calculate equation-based problems. This is seen as a major teaching innovation. The instructor states that he has shifted instruction from being just lecture based, to using a problem-based approach after the calculators were introduced (teaching strategy). This problem based approach refers specifically to the use of equations to solve mathematical problems.

Students are allocated a chapter to read a week ahead of time. "I have to tell them what we're going to be talking about and doing next session." They are expected to keep note of questions that arise through their reading. Typically, the instructor states that he will provide a lecture-based summary of the chapter content, and then open the class up for discussion. "Yeah, that's my strategy, especially to facilitate, first of all to give them something to think about in terms of what we're doing the next time in the classroom, and once they do that to come to me, and, which means that I know they have done it, and from there I'm trying to get things out. Trying to dig from them and see what they know and what we can do from that". He does the probing by "asking a bunch of questions related to the topic. Ah, did you think of ah, ah, lets say, did you think of changing the temperature, did you think of changing the equation". If students don't understand something he tries to find another way to explain the material and refers to this as an alternative teaching strategy. Thereafter students are assigned exercises from the end of the 
particular chapter in the textbook to work through. They must figure out which formula to use and calculate the solution using the $\mathrm{CBL}^{\mathrm{TM}}$ calculators. "Instead of me sit, getting the calculator and then doing it, I want them to use their own weight and distance, put in their own calculator and tell me". The students are allowed to work with other students and the instructor circulates around the classroom, assisting as necessary (learning interaction). Essentially the control of learning is teacher directed, with students participating in assigned tasks.

His view of knowledge is a body of information to be learned, with only one possible correct answer in science, saying, "Ah well, in a science it is ah, really mathematically there is only one answer to it". Knowledge is seen as absolute, although it might be applied in different ways, in different disciplines, "knowledge is knowledge, ah, and the application that is different". Knowledge is seen as being built progressively. Any knowledge is valuable in its own right, with learning viewed as a "lifetime commitment" by making connections across disciplines. "I would like to be ah, not an expert on everything, but at least knowledgeable".

The textbook is the main source of knowledge for students who are expected to read assigned chapters each week prior to class lectures and discussions. While he sees that there is only one correct answer to any problem, Dr. Lane does not want to be the sole source of solutions in the classroom. "So, I am trying to just make sure that I'm not the only one giving them the answers. I want them to find the answers themselves, while I am trying to lead them to that". He also encourages student to read newspapers and magazine articles about science, to gather information from the Internet and to watch science related TV programs so that "they learn all this thing and they link it to what we study". 
Apart from the use of knowledge to solve mathematical problems, he sees a broader goal for acquiring knowledge. Students may ask what the value of a particular class is, but he feels that all knowledge can be applied at some point in life. "You might, you might ask why do I take class, what do I take? I am not going to use it. Now, you, you never say that because yes, you will use it one day without you knowing that you using it". Thus, he tries to make connections to real world contexts, "that there is a link, not only these ah, textbook thing, but also in the real life".

He selects course content and a textbook by deciding what the basic concepts are that students need to learn in order to have a good general knowledge for that particular course. "This is the basic they have to know. They know this, and ah, and once I have finished the basic, then the left out will, will fit any time". "So, if it is that important then I include it, if it is not that important I can just highlight it in passing it through. But, not emphasizing it quite often". However, he acknowledges that sometimes there is content that is left out that later he feels was so important that it should have been included.

Dr. Lane's pedagogical knowledge and desire to teach has developed through a role model and a mentor. In graduate school he took a class in teaching methodology and that had impacted his thinking about teaching. That instructor "made the atmosphere very relaxing and inducing", and this course made him realize that there are different ways of teaching and explaining phenomena. One group assignment required course participants to present a lesson in which "we were trying to deliver the ah, the ah, trying to explain what we learned in science" to their non-science peers. He also had a mentor in graduate school who had worked for a long time in industry and who had returned to teaching. This 
person impacted him because he stated that "money is nothing, but knowledge is everything", "and that influenced me to, to, to be teaching".

He shares his teaching ideas with colleagues through informal discussions, for instance at coffee breaks. "We share information, especially when you have ah, when three or two people teach the same, the same class in different sections".

Teaching effectiveness is gauged by students' involvement in class, saying, "Um, $50-60 \%$ ah, you know success rate is not bad. Yeah, you don't get all of it, but you still can manage to get more". Exams and tests are another measure of success, to see how students comprehend the subject matter. "And then say they did quite well, so that's another way of evaluating your methodology". Finally, when students state that they have learned something, "whatever, whatever small it is", he considers that another indicator of success.

Four major constraints to teaching and student learning were cited. These were (a) time available to cover the content, (b) student interest and motivation ("Those mixed group, ah, some have some, you know, interest to learn and some don't"), (c) availability of resources ("Sometimes I don't have that, and I can see that oh, I can teach this using this model, and I can then make them see it, but if I don't have that particular tools to use, and then I'll be talking and just giving them a talk, but they can't see"), and (d) a lack of student ability in mathematics. If he identifies a weak student he tries to remediate this by talking to them "on how to work harder" and finding connections that interest them. However, often the really poor students "really don't care" and do not try to apply themselves (student motivation). Having calculators purchased with the NOVA grant funds has assisted him in implementing some hands-on activities. Other basic equipment and chemicals are also available. 
Dr. Lane found it hard to describe the impact he has on student learning, saying, "Oh, ah, well, I can't, that's, that's a question that the students should, should answer really". "I don't know how it is going to affect them until maybe they, they finish or they talk about it, or they apply it. That is the only way I can tell that yes they did learn, that my teaching influenced their learning. Ah, but, it is, it is a, difficult to know that". He went on to say that he thought that the way the instructor presents material is a key factor in whether there is an impact on student learning, that an instructor should not intimidate students, but rather "just make them, make them feel at home. That will influence what, what they learn".

Students are responsible for reading the material ahead of class and to stay abreast of the work for the class. He expects them to keep a record of "what they don't understand, and when they come back to me, and then I'm going to talk about it". Students are also expected to participate in class in activities, like doing calculations, as directed. "They are the ones to basically to learn", with him orienting them in the right direction.

On the self-report STEBI B, Dr. Lane scored (a) 65 (out of 70) on the personal science teaching efficacy subscale, and (b) 44 (out of 55) on the science teaching outcome expectancy subscale. Thus, he has high personal efficacy about teaching and about teaching outcomes and the impact on students. The latter aspect, however, was not reflected in his interview, where he could not clearly articulate how he would impact student learning outcomes. He felt that it would be better to ask the students. Thus, the high STEBI outcome efficacy result is not consistent with the interview data. 
On the Approaches to Teaching Inventory (ATI) Dr. Lane reports himself as having a strong information transmission focus, conceptual change focus and student focused orientation (see Figure 5). He considers himself much less teacher focused.



ITI $=$ Information transmission intention TFS $=$ teacher focused strategy $\mathrm{CCI}=$ conceptual change intention $\mathrm{SFS}=$ student focused strategy

ITTF $=$ information transmission and teacher focused $\mathrm{CCSF}=$ conceptual change and student focused

Figure 5. ATI Scores for Dr. Lane

The information transmission focus is consistent with the interview data already presented, but there is less evidence for a conceptual change focus. No mention is made of conceptual development or conceptual change processes, other than that "I am trying to have student to learn these because they are very important concepts" and that "we discuss about it, and introduce the concept and why we're going to do that" and "once you understand this concept, why you have to use this equation, and then we can go to that equation". While he is interested to find out student's existing knowledge on topics, and then to teach from that basis, concepts are not seen as being mediated, but as facts to learn. No mention is made of associated strategies for conceptual change, such as accommodation, scaffolding, the learning cycle or cognitive restructuring. Essentially, the teaching strategies and goals are oriented to enhancing understanding through assimilation of new knowledge and application by solving equation based problems. So, while conceptual change may be a goal, there is less evidence to support this in practice. 
Similarly, there is less evidence for a strong orientation towards student-focused strategies, where the dominant method of student engagement is through reading the text, classroom discussions and calculator usage. Thus, the perception of student engagement also appears to be greater than is actually present.

Teaching and Learning: Practices

The goals for the course as listed in the syllabus are for students to be able to "discuss" and "understand" basic physical and chemical principles. This involves explanation and description of phenomena and their properties. The syllabus lists the content to be covered each week (view of knowledge). Typically a new chapter in the textbook is dealt with each week. Thus, content is selected based on what is in the textbook, with students sequentially working through the chapters in the order presented in the book.

The syllabus is strict in terms of what is allowed and not allowed in the classroom, which phrases like "Students who make excessive noise or try to disturb others will be asked to leave the classroom, all students must adhere to the dress code, no caps are allowed in the classroom, no smoking, food, drinks, or gum chewing will be allowed, and students should pay full attention to lectures, take notes, participate in class, sit upright and maintain a professional learning posture" (classroom atmosphere).

There is no associated laboratory section for the course, although the instructor claims that the students do about five to seven experiments in the same classroom during the semester. Typically these involve a demonstration by the instructor, such as him doing a titration, followed by students being provided with some data, which they must 
then plug into the $\mathrm{CBL}^{\mathrm{TM}}$ calculator to calculate an equation or to create a graph. Students do not handle much equipment other than the calculators.

The observation of teaching by this writer concurred with the instructor's description of his teaching strategies. There was a short lecture on the use of calculators, followed by students plugging numbers into the calculator to find out how it works. The session was teacher centered, although the instructor was highly energetic and enthusiastic about the lesson, attempting to engage students in a more interactive way through question and answer. The students worked individually with their calculators and there was no cooperative learning.

The purpose of the lesson was not clear and was not stated. It seemed to be to let students play with the graphing calculators, with the instructor giving instructions like "take your time, you want to enjoy this lesson" and "explore and see what happens when you change the numbers". The instructor circulated around the classroom looking at what students had done, making comments.

Towards the end of the lesson, students were asked to think about what factors affect temperature changes, and to gather data that could be plugged into the calculators. There was no specification of what data should be gathered. Right at the end of the lesson there was a reference to graphing the data for temperature against time, and that students should do this on their own for homework, although the calculators were turned in at the end of the lesson. As a last minute point he asked students what factors might cause temperature to rise, and students responded with ideas such as the temperature of the room, the number of people in the room, the shape of the container, and the size of the original ice block. It was only during the subsequent interview with the instructor that I 
discovered that students had previously conducted a mini-lab in class regarding the temperature of melting ice, and they were being requested to graph this data. To an outsider the lesson did not flow and there was little internal coherence.

Interviews with students confirmed the approach stated by Dr. Lane. First the students stated that they are expected to read a chapter from the textbook, and then raise questions for class discussion. They stated that they did not do any laboratory activities, excepting for some "mini-labs" in the same classroom, such as taking temperature. They said they learned by having problem solving examples modeled for them, and then doing their own problems. A common method involved the use of the $\mathrm{CBL}^{\mathrm{TM}}$ calculators, where they had to graph various data presented. The subject was similar to the material covered in high school, but the college course was more work and more challenging. They noted that Dr. Lane is very patient, makes the subject easier for them by giving them problems they can solve, encourages them to be positive about science, and is always available for assistance.

Factors that facilitated implementation of the course were the funding from NOVA, which allowed for calculators to be bought, and administrative support. The latter involved allowing students to register for either the 'new' course or the traditional version, based on how the course fit with student's schedules.

Using the Esteem observation instrument, Dr. Lane was rated by this NOVA research fellow and the results are presented in Figure 6. 


\section{ESTEEM Observation Scores}



Category

Figure 6. Results of the Esteem Observation Instrument for Dr. Lane

He scored $50 \%$ for content knowledge (use of exemplars, balance between depth and comprehensiveness, coherence of science experiences, and accuracy of content) and $53.3 \%$ for content pedagogy, which includes the use of different teaching methods, higher order thinking skills, promoting conceptual understanding and integration of content and processes. For facilitating learning (motivating learners, student engagement in activities and experiences) he scored a $68 \%$ (role of instructor). Scores of $35 \%-69 \%$ are considered “competent” (Burry-Stock, 1995). He scored 73.3\% for context pedagogy, which is defined as fluid control of teacher and student interactions. Scores of $70-85 \%$ are considered "proficient".

From the interview conducted during the site visit, the overall emphasis in the course is evidently on bookwork (source of knowledge), with minimal activity based approaches, investigations or even experiments being undertaken. The approach espoused was that of problem solving, and the definition of this was clearly solving mathematical equations (teaching strategies). There is no explicit mention of dealing with different learning styles, but based on the preferred teaching strategies, Dr. Lane is essentially 
catering to logical-mathematical (problem solving of equations) and linguistic learning styles (reading and discussions), with some limited kinesthetic application through calculator usage.

Comparison of Conceptions and Practice: Teaching and Learning

In comparing conceptions and practices, it is necessary to contrast the data from the different sources, as outlined in the previous two sections. Here the conceptions of teaching and learning reflect views across classes, while the practices refer specifically to the NOVA class. Table 6 summarizes the properties and associated dimensions for both conceptions and practices of teaching and learning. 
Table 6

A Comparison of the Properties and Associated Dimensions of Teaching and Learning

that are Espoused and Practiced: Dr. Lane

\begin{tabular}{|c|c|c|}
\hline Properties & Conceptions & Practice \\
\hline Teaching goals & $\begin{array}{l}\text { Imparting content knowledge, } \\
\text { simplifying material, leading } \\
\text { students to the answers }\end{array}$ & $\begin{array}{l}\text { Explaining and describing } \\
\text { phenomena, using calculators }\end{array}$ \\
\hline Role of instructor & $\begin{array}{l}\text { Direct student learning, make } \\
\text { subject matter easier, reduce } \\
\text { frustration }\end{array}$ & $\begin{array}{l}\text { Impart knowledge, engage } \\
\text { students, direct discussion }\end{array}$ \\
\hline Teaching strategy & $\begin{array}{l}\text { Pre-readings, mini-lecture, } \\
\text { question and answer, probing, } \\
\text { solving problems and } \\
\text { equations, use of } \mathrm{CBL}^{\mathrm{TM}} \text {, some } \\
\text { demonstrations }\end{array}$ & $\begin{array}{l}\text { Pre-readings, mini-lecture, } \\
\text { question and answer, probing } \\
\text { solving problems and } \\
\text { equations, use of } \mathrm{CBL}^{\mathrm{TM}} \text {, some } \\
\text { demonstrations }\end{array}$ \\
\hline View of knowledge & $\begin{array}{l}\text { Set of information to be } \\
\text { learned, valuable in its own } \\
\text { right, connected across } \\
\text { disciplines, one correct answer }\end{array}$ & List of material to be covered \\
\hline Use of knowledge & $\begin{array}{l}\text { Apply to life situations, has } \\
\text { different applications } \\
\text { according to discipline }\end{array}$ & $\begin{array}{l}\text { Solving calculation-based } \\
\text { problems }\end{array}$ \\
\hline Source of knowledge & $\begin{array}{l}\text { Teacher, textbook, other } \\
\text { students, TV and mass media }\end{array}$ & Textbook, teacher \\
\hline Selection of content & $\begin{array}{l}\text { Cover the basic building } \\
\text { blocks, current information }\end{array}$ & $\begin{array}{l}\text { Sequentially working through } \\
\text { the textbook }\end{array}$ \\
\hline $\begin{array}{l}\text { Pedagogical } \\
\text { knowledge } \\
\text { development }\end{array}$ & $\begin{array}{l}\text { Mentors, graduate seminar } \\
\text { course on teaching }\end{array}$ & No evidence \\
\hline $\begin{array}{l}\text { Sharing teaching } \\
\text { ideas }\end{array}$ & $\begin{array}{l}\text { Informal discussions with } \\
\text { colleagues }\end{array}$ & $\begin{array}{l}\text { Informal discussions with } \\
\text { colleagues }\end{array}$ \\
\hline $\begin{array}{l}\text { Teaching } \\
\text { effectiveness }\end{array}$ & $\begin{array}{l}\text { Participation, test scores, } \\
\text { student testimonials }\end{array}$ & No evidence \\
\hline $\begin{array}{l}\text { Constraints to } \\
\text { teaching }\end{array}$ & Time, resources & No evidence \\
\hline $\begin{array}{l}\text { Factors facilitating } \\
\text { implementation }\end{array}$ & Calculators & $\begin{array}{l}\text { NOVA funding, calculators, } \\
\text { administrator support }\end{array}$ \\
\hline Learning interaction & $\begin{array}{l}\text { Teacher-student, some } \\
\text { student-student }\end{array}$ & $\begin{array}{l}\text { Teacher-student, student- } \\
\text { teacher }\end{array}$ \\
\hline Learning control & Teacher directing students & Teacher directing students \\
\hline
\end{tabular}


Table 9 (continued)

\begin{tabular}{|l|l|l|}
\hline Properties & Conceptions & Practice \\
\hline Learning styles & No evidence & $\begin{array}{l}\text { Mathematical, linguistic and } \\
\text { some kinesthetic }\end{array}$ \\
\hline $\begin{array}{l}\text { Impact on student } \\
\text { learning }\end{array}$ & Uncertain of outcomes & $\begin{array}{l}\text { Making the subject easier to } \\
\text { learn }\end{array}$ \\
\hline $\begin{array}{l}\text { Constraints to } \\
\text { student learning }\end{array}$ & $\begin{array}{l}\text { Student interest and } \\
\text { motivation, mathematical } \\
\text { ability }\end{array}$ & No evidence \\
\hline $\begin{array}{l}\text { Student } \\
\text { responsibilities }\end{array}$ & $\begin{array}{l}\text { Do pre-readings, raising } \\
\text { questions for discussion }\end{array}$ & $\begin{array}{l}\text { Do pre-readings, raising } \\
\text { questions for discussion }\end{array}$ \\
\hline
\end{tabular}

In comparing the conceptions of teaching and learning to practices, there is consistency in the overall findings, where conceptions are comparable to practices. However, in his self-assessment, he sees himself as more student centered than is evidenced from his descriptions of and observations of his practice.

\section{Assessment: Conceptions}

The primary purpose of assessment described by Dr. Lane is to establish if students have learned the material covered during the semester, saying "The role of assessment is basically to ah, find out what has been given to students if they know, ah what you taught them". He also sees assessment as a means of assessing their problem solving skills. He is interested to establish if his methods of teaching were effective, saying "the two major things I learn from them, its basically I assess their understanding of what, ah, I've told them, at the same time it give me ah, a feedback on if the method I used explained that".

His preferred strategies for assessing students include using tests and pop quizzes. "Let's say two days or a week after that, I will assess them by giving them a quiz or a test just to find out if they understood ah, the principles I gave them". He likes to provide 
weekly book assignments on the chapter they are working on. He states that he focuses on problem solving, which involves the use of formulae to solve word problems. Sometimes he also gives them "lets say a paper to write on what I just talked about". He believes that the more students participate, the more they learn, so includes a participation grade, too.

Pop quizzes are done almost every week (periodicity), to cover the chapter they are working on, while exams are done at midterm and the end of semester because that is the college's policy. The pop quizzes are used as "an incentive to keep studying constantly" because students never know when they will be implemented.

He considers that feedback is intended to provide students with the correct answers, and to show them how their problem solving can be improved. Sometimes, if there is an opinion, "I can write some comment on it, so we can discuss them through".

Dr. Lane says the data obtained is used for two purposes: (a) to monitor student understanding of the content, and (b) to assess his own teaching. It is to "assess their understanding of what ah, I've told them" and "either change your method of ah, teaching or just modify what you, you teach". The latter suggest that he might either modify his teaching method or modify the content he teaches. By changing teaching method he means explaining the content in a different manner, saying "If they don't understand it, so I can modify and try to tell them a different way over the same thing".

He believes that in science there is one correct answer to problems saying, "in science there is only one answer, however, there's no opinion. We don't go through the opinion" (knowledge focus). However, he is happy for students to use different ways to find an answer. "You can make it long way or can make it short way, but as long as we get to the same answer, that's alright, but we teach them to think, ah make short or long 
answer, but we have to come up with the same result". He discourages rote memorization by saying that, "um, I tell them the only way you can ah, understand the formula is to practice it. The more you practice it, the more you use it and exercise it, the more you will know". So, he believes that understanding comes through repeated practice.

He encourages students to show all their work so that they can be given a grade, even if they do not get the final correct answer (grading implementation). "You might make a mistake in between, but you know, so I tell you where you made a mistake. That's how I do it." He says he allocates a grade for all work that students do.

He does not tell students what to study for upcoming tests, but prefers that students ask questions, saying to them, "Do you have any problem, somewhere that you don't understand and we can work some exercise". "I prefer them to be involved instead of me telling, teaching them again (assessment preparation).

\section{Assessment: Practices}

As outlined in the syllabus, Dr. Lane establishes a student's final grade as follows (strategies); (a) attendance and class participation - 20\%, (b) labs and homework assignments - 30\%, (c) mid-term exam - 20\%, (d) pop quizzes -10\%, and (e) final exam $20 \%$. The mid-term and final exams are college wide requirements. The pop quizzes are implemented without prior warning. The attendance and participation grade is essentially an attendance grade, with students getting no points for 8 or more days missed, with a sliding scale up to 20 points for zero missed days (grade implementation). He does not give a grade for actual classroom interaction, just physical presence at the lesson.

Weekly assignments are typically assigned from the section at the end of the relevant chapter in the textbook. The midterm exam contained 20 questions, of which 14 
were multiple-choice questions, two were true/false and four were calculations

(strategies). A list of equations was provided. The point allocation for each question was not indicated. The final exam assesses all the course material covered for the semester (periodicity).

He provides feedback by writing comments on papers and by discussing answers in class. "I give the feedback also in terms of writing or I can go to classroom, and then say OK, ah, you have the papers, OK, lets just find out what we did right and what we did wrong and how, which way's the best way to do it" (knowledge focus).

The self-survey ratings on the Assessment of Classroom Learning in Science Inventory (ACLSI) for Dr. Lane are relatively high overall. The ACLSI assesses the use of a diversity of different strategies and purposes. All scores were above $85 \%$ and therefore considered to be expert (Burry-Stock, 1995).

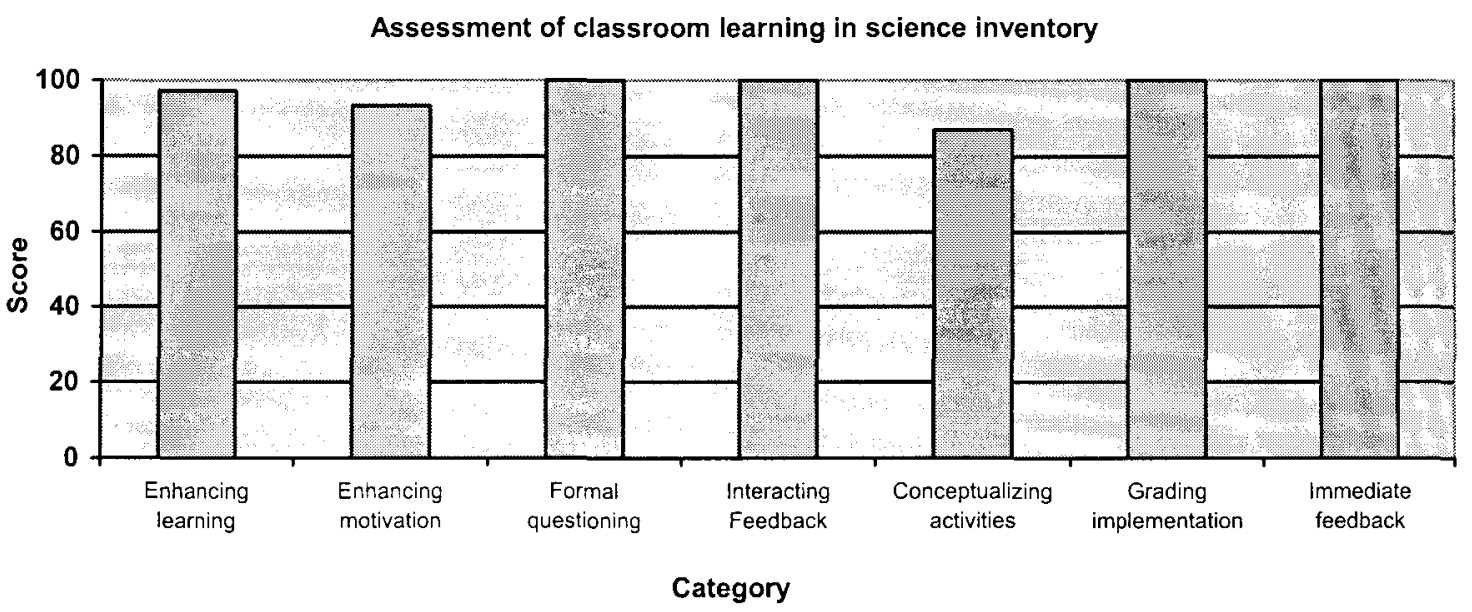

Figure 7. Results of the Assessment of Classroom Learning in Science Inventory for Dr. Lane.

To score a high score on the different subscales, a teacher would have to be using a variety of different strategies for a range of different purposes. For instance, the formal 
questioning category focuses on the use of traditional tests, grades and quizzes, and Dr. Lane rated himself at $100 \%$ for this category.

The conceptualizing activities category includes the use of concept maps, laboratory reports, and computer projects for student assessment. Dr. Lane scored $87 \%$ on this category, but there is no evidence in his syllabus or from the interview data that he included these tasks in his range of assessment strategies. Similarly, for the enhancing motivation category, which includes the use of portfolios, science fairs, individual and group presentations, he scored a $93.3 \%$ and yet there is no evidence from the data of these assessment strategies being used to enhance motivation. Similarly, he scored $100 \%$ on the immediate feedback category, which includes the use of hands-on activities for informal feedback, and yet only 5 to 7 hands-on tasks are conducted each semester. This suggests that Dr. Lane rated himself higher on several of the ACLSI subscales than is suggested by his practices.

Comparison of Conceptions and Practices: Assessment

In comparing conceptions and practices, it is necessary to contrast the data from the different sources, as outlined in the previous two sections. Table 7 summarizes the properties and associated dimensions for both conceptions and practices of assessment. 
Table 7

A Comparison of the Properties and Associated Dimensions of Assessment Espoused and Practiced: Dr. Lane

\begin{tabular}{|c|c|c|}
\hline Properties & Conceptions & Practice \\
\hline $\begin{array}{l}\text { Purpose of } \\
\text { assessment }\end{array}$ & $\begin{array}{l}\text { Assess student knowledge } \\
\text { of content, problem solving } \\
\text { skills }\end{array}$ & $\begin{array}{l}\text { Calculations and factual } \\
\text { information }\end{array}$ \\
\hline Strategies & $\begin{array}{l}\text { Weekly assignments, tests, } \\
\text { quizzes, some written } \\
\text { assignments, attendance } \\
\text { and participation }\end{array}$ & $\begin{array}{l}\text { Weekly assignments, tests } \\
\text { (true/false, multiple choice, } \\
\text { calculations), quizzes, attendance } \\
\text { only }\end{array}$ \\
\hline Periodicity & $\begin{array}{l}\text { Weekly textbook } \\
\text { assignments, pop quizzes, } \\
\text { midterm and final exam }\end{array}$ & $\begin{array}{l}\text { Weekly textbook assignments, } \\
\text { pop quizzes, midterm and final } \\
\text { exam }\end{array}$ \\
\hline Interaction feedback & $\begin{array}{l}\text { Provide correct answers, } \\
\text { improve problem solving, } \\
\text { discuss opinions }\end{array}$ & $\begin{array}{l}\text { Provide comments on tests, } \\
\text { classroom discussions }\end{array}$ \\
\hline Use of data & $\begin{array}{l}\text { Monitor student learning, } \\
\text { modify teaching, modify } \\
\text { content }\end{array}$ & No evidence \\
\hline $\begin{array}{l}\text { Assessment } \\
\text { preparation }\end{array}$ & $\begin{array}{l}\text { Review of material } \\
\text { requested by students }\end{array}$ & $\begin{array}{l}\text { Review of material requested by } \\
\text { students }\end{array}$ \\
\hline Knowledge focus & $\begin{array}{l}\text { One correct answer, correct } \\
\text { method, understanding and } \\
\text { applying formulae }\end{array}$ & $\begin{array}{l}\text { One correct answer, correct } \\
\text { method, understanding and } \\
\text { applying formulae }\end{array}$ \\
\hline $\begin{array}{l}\text { Relationship to } \\
\text { teaching and learning }\end{array}$ & $\begin{array}{l}\text { Change method of teaching } \\
\text { or way of conveying } \\
\text { information, if necessary }\end{array}$ & No evidence \\
\hline $\begin{array}{l}\text { Grading } \\
\text { implementation }\end{array}$ & $\begin{array}{l}\text { Allocate grade for work } \\
\text { shown and all tasks }\end{array}$ & $\begin{array}{l}\text { Allocate grade for all tasks, and } \\
\text { final grade }\end{array}$ \\
\hline
\end{tabular}

Evidence for conceptions and practices indicate a consistency between these aspects. However, the self-report ratings appear higher than are indicated by the data collected.

Action Research: Conceptions

The originator of the NOVA course and action research project left the college and Dr. Lane was expected to assume responsibility for teaching the course, and for 
implementing the action research project. However, he did not continue with the action research project due to lack of time and because "I didn't know exactly what was his motive". He received no support from the education team member in trying to implement the original research design.

The original project was conceived of having an experimental and a control group, with one group being taught physical science using the newly acquired $\mathrm{CBL}^{\mathrm{TM}}$ calculators, and the other group being taught without using calculators. Students would randomly self -select which course they wanted to participate in, based on their schedules (research design). Dr. Lane was satisfied with this design.

Dr. Lane has used the original NOVA action research proposal to begin conceptualizing another action research project for his chemistry class, focusing on what he calls green chemistry. He plans to have one group working on regular wet chemistry experiments together with $\mathrm{CBL}^{\mathrm{TM}}$ calculators, and another group using the green chemistry approach in which they use microwaves and other readily available materials to do the same experiments. He wants to see which method works best, but has not yet generated any questions but considers that a common test might reveal which approach is best based on student results (instrumentation). Action research is viewed as a one-off process that can be used to generate research findings in a short period of time (iteration).

Dr. Lane could not articulate a general purpose for action research, returning continually to the specifics of his planned project, which was to test the value of one experimental method over another. He considered the purpose to be personal, not relative to broader professional or political issues. Because he is concerned with 
improving efficiency and effectiveness of an educational practice by gathering empirical data to compare control and experimental groups, the interest reflected in his description is essentially technical in nature.

He plans to share his findings with local high schools and also to make presentations at conferences (use of data). He anticipates that the findings will also be used to make changes to other classes that are currently being taught, saying, "what I am anticipating is for me, is basically changing, I am going to be changing most of the experiments that we going to be doing, now changing all the experiments to be on the green side of chemistry", indicating that he is anticipating better results from the group of students using the new methodology. This reflection is essentially autobiographical because it is done by only one individual and does not consider the broader context.

The star diagram (Rearick \& Feldman, 1999) in Figure 8 shows that the primary foci of the conceived action research project reflects a technical interest, autobiographical reflection, and personal purpose. 


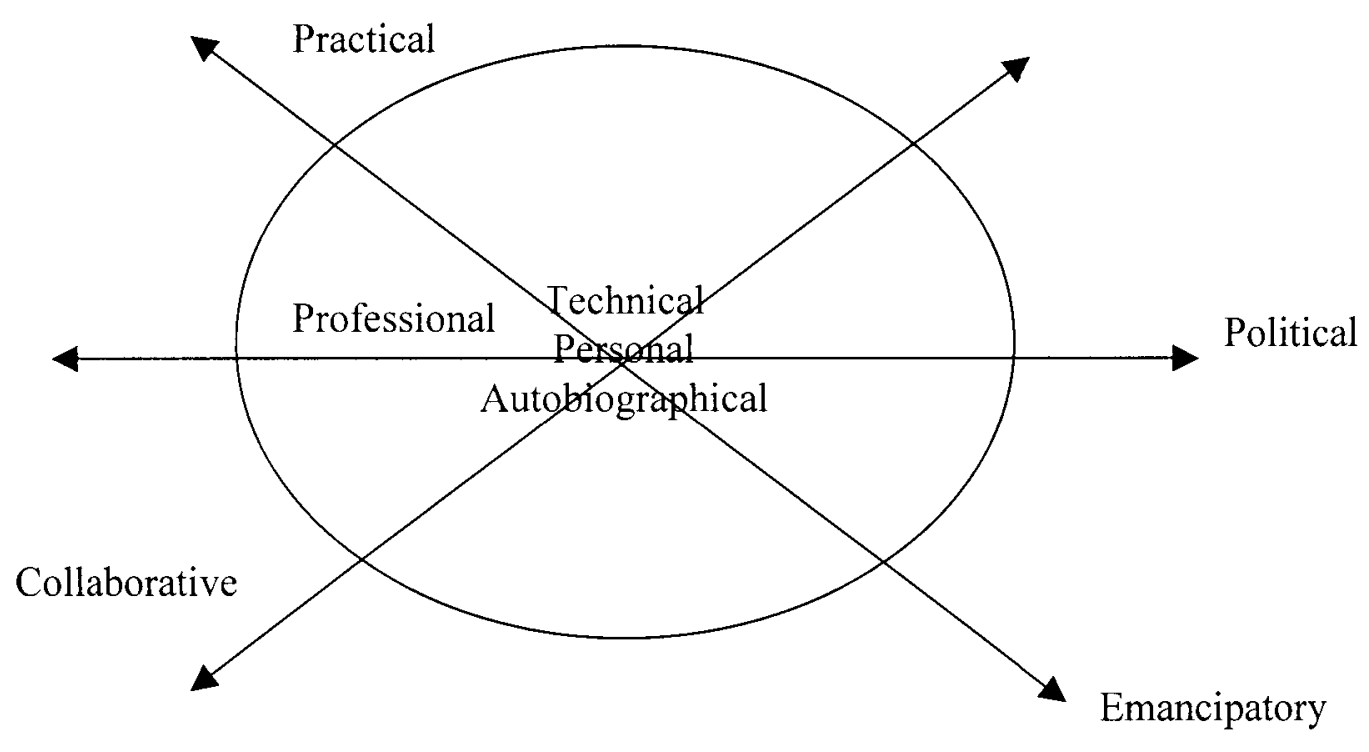

Figure 8. Star Diagram for Action Research Practices of Dr. Lane

Action Research: Practices

He has not yet implemented an action research project.

Comparison of Conceptions and Practices: Action Research

In comparing conceptions and practices, it is necessary to contrast the data from different sources. Table 8 summarizes the properties and associated dimensions for both conceptions and practices of action research. 
Table 8

A Comparison of the Properties and Associated Dimensions of Action Research that are Espoused and Practiced: Dr. Lane

\begin{tabular}{|c|c|c|}
\hline Properties & Conceptions & Practice \\
\hline $\begin{array}{l}\text { Conceptualization } \\
\text { and support }\end{array}$ & $\begin{array}{l}\text { Replication of the previous } \\
\text { study, no support from others } \\
\text { envisioned }\end{array}$ & $\begin{array}{l}\text { No project implemented yet, no } \\
\text { external support }\end{array}$ \\
\hline Focus & $\begin{array}{l}\text { Student outcomes in the } \\
\text { experimental design }\end{array}$ & \\
\hline Research design & Experiment and control groups & \\
\hline Instrumentation & A common test for both groups & \\
\hline $\begin{array}{l}\text { Knowledge } \\
\text { orientation }\end{array}$ & Quantitative, gather factual data & \\
\hline Interest & Technical & \\
\hline Purpose & $\begin{array}{l}\text { Personal purposes, establish the } \\
\text { value of a particular } \\
\text { scientific/laboratory method }\end{array}$ & \\
\hline Reflection & $\begin{array}{l}\text { Autobiographical, use the new } \\
\text { experimental method }\end{array}$ & \\
\hline Use of results & $\begin{array}{l}\text { Advocate the use of new } \\
\text { laboratory methods in other } \\
\text { courses }\end{array}$ & \\
\hline Iteration & One off process & \\
\hline
\end{tabular}

It is not possible to compare conceptions and practices because Dr. Lane has not implemented an action research project.

\section{Conclusion}

Dr. Lane holds an objective view in all three areas researched, focusing on imparting knowledge to learners who are expected to assimilate that knowledge. The metaphor that characterizes this instructor's views is 'teacher as knowledge imparter, student as assimilator'. Overall, there is a consistency among his conceptions and his practices of teaching and learning, assessment, and action research. Any inconsistency 
presents itself in his self-perception and self-rating on the various instruments used, where he generally rates himself higher than evidence suggests is true of his practices.

\section{John Walton}

This case was selected as an example of student centered learning, with the instructor serving as guide and facilitator. It also represents a qualitative approach to action research focusing on instruction.

John Walton is a semi-retired science professor who has been teaching for more than 30 years. He works part time, teaching one course each semester, including the level 200 NOVA course, which uses the theme of the international space station to teach about physical science processes (getting to the space station), life processes (living on the space station), earth processes (looking back to earth from the station) and space science (looking outwards from the station). There is no text for the course with students being required to obtain and read material from a variety of sources.

The course is an integrated laboratory and lecture course, meeting three times a week for 65 minutes and once a week for one and a half hours. Typically the 65 -minute sessions involve a short introductory lecture by the instructor followed by a variety of activities, while the one and a half hour session is devoted entirely to inquiry-based investigations. The course was originally team-taught together with another science faculty member, but now Dr. Walton is solely responsible for teaching the class.

\section{Teaching and learning: Conceptions}

Dr. Walton's primary goal of teaching is for students to learn new subject material through experimentation, "we want them to learn the methodology of science", "and not just through facts or through any wisdom I'd impart, but through hands-on learning 
through experimenting"'. They have to be able to devise experiments, gather data and interpret findings. He also wants students to be able to apply knowledge to everyday life and real world situations. An additional intention is for students to incorporate the teaching ideas and approaches from the course into their future classrooms, and more broadly for them to "have a way of learning that will transfer to the whole of life". He hopes that students are never again be content to just have material "dumped on them" to rote memorize (impact on students). He hopes they will "have a way of learning that will transfer to the whole of life".

His preferred method of instruction is "hands-on learning through experimenting". "Instead of learning something and then going in the lab to verify it, you learn something by doing the lab". At first he starts with a "cookbook" approach so that students have the process modeled for them and thus learn what is expected. Eventually he reaches the stage where he can pose a problem or a question, "and have them as a group talk it over for a few minutes, and then come to some way to test or investigate". He also uses group projects in which students participate in researching and presenting topics to the class. This leads to further discussion and the presentation of content based on student questions and things they do not understand.

His sees his role is to outline the purpose of the lesson and present introductory material to students. Thereafter, he assigns tasks to students and likes to "wander around with my ears open, and ah, just make suggestions and ask questions". He prefers to start with investigations or activity-based tasks so students "can experience whatever concept we're talking about" and finds that from this they generate a lot of good questions. "So, I guess my part would be a facilitator, a guider, someone who comes alongside them and 
talks to them and asks the questions." "I don't intervene and say, no this won't work." His analogy for a good teacher is that of an athletic coach, because "coaches are prepared, coaches make sure that every student they have, every player, understands the, the play or the way that it should happen. And the coaches make them redo, and redo, and redo a skill until they get it."

His pedagogical knowledge primarily developed through trial and error over the years. He also learned from negative role models, teachers who were "the last one in the door, no greeting, just turn around and start writing on the board, no chance for questions, the first one out the door. See you tomorrow," "while we closed up our books". Even at that point he had wondered, "why we didn't do more experiments in science and why we didn't do some of them before hand, and then talk about what happened".

As a major influence for developing his teaching he goes back to the analogy of being a coach, saying that he was a successful tennis coach, "I developed kids by drilling them and drilling them, and helping them with their homework. Making sure they did it, and showed them how to do it, and then they experienced it. And you know, I said man, there's some connection here." While teaching a graduate science course for teachers he used a more activity-based approach and found that the teachers loved it and wished they had been taught that way at the undergraduate level. That stimulated him to start to integrate new ideas into his other science classes. He realized that he had lost some students using the traditional lecture method, which he had thought was necessary because they needed some "minimal amount [of content] because some of these guys were pre-med and they had to have a rigorous course". So, he began integrating hands-on activities into all his classes and found that those "who were gonna be doctors and go on and be $\mathrm{PhD}$ 
scientists and stuff, they thrived under that kind of experience too". This reinforced him to continue integrating new approaches into his teaching and now feels he could not teach any other way.

He has not been able to share his teaching ideas much at the current university because he is not a full time faculty member. However, the other team member who used to team-teach the course is dean of science and has shared their successes with others in the department and made a presentation to one of the NOVA LDC meetings. When Dr. Walton was a fulltime faculty member he says several other instructors had become excited by his ideas.

The main source of information about his effectiveness as a teacher comes directly from student feedback during "so what sessions" held at the end of a particular unit, as well as from student evaluations at the end of semester. He has also received several positive anecdotal comments about the course from others on campus, even the husband and wife team that operate the girl's dorm. He believes that this has increased student interest and enrollment in the course because "word of mouth around the campus is that this is a fun course and that it's, it's ah, a neat way to learn". Additionally, follow-up by the team member in the education department has shown that new teachers who took the course are using the ideas during teaching sessions at local schools.

Major constraints to teaching were cited as: (a) material and equipment, and (b) the increasing demand for the course which had increased student enrollment to more than 30 students, making group work more difficult to manage. Factors that have facilitated implementation of the course are the fact that: (a) it is for education majors, which means that content can be selected from a variety of disciplines rather than having to focus on 
facts in one subject, (b) that being part-time he has plenty of time to prepare for class, and (c) that there was freedom over the choice of testing methods, and that exams could be done away with, and (d) the supportive NOVA team that included the dean of science.

Dr. Walton draws from Greek philosophy and distinguishes three different types of knowledge, namely: (a) factual knowledge, including definitions and formulae, and categories and lists of information, (b) the wisdom and understanding to use and apply the factual knowledge, and (c) experiential knowledge that is acquired by doing. The Greeks believed that the highest way is through experience and he endorses this position, quoting one philosopher who said, "Let no-one in at my door who hasn't experienced this".

In the classroom context he does not want to be the only source of knowledge saying that "I have to get away from the authoritarian position of, I'm the professor now, I know, you don't know, you listen to me". He believes in drawing from different disciplines and integrating them into a thematic unit, in this case the international space station. "In this particular course you never run out of material to do because it's so broad". Knowledge should be used to generate and test new ideas and theories, so that students generate their own understanding through experience. "We're gonna learn to experience, in fact that's the best way to learn."

The course designers decided on a thematic approach, using the international space station as the focus. All course content is oriented around this theme, meaning that it is interdisciplinary and includes physical science, earth science, life science and space science. The instructor teaches some basic concepts, such as Kepler's laws and Newton's laws, with students selecting additional topics to research and present (learning control). As a consequence of giving students some control over content, he does not feel that he 
has to be solely responsible for "design and questions and activities in the class", but puts more responsibility on the students to be participants in the process (learning interaction).

While he tries to build a rapport with students, for instance by inviting the groups to his house for pizza, he feels that students are limited by their perception that he is the one who has the final decision over their grade. So while "toward the end of the year there is less of it, I don't know that I ever totally get away from it". Their experiences of education in other contexts are a major constraint to their own and future learning, because they find it hard to transcend to a new approach. An additional constraint to student learning is when students work in groups, where they "feel a little reluctant to pass on what they know because they feel a little competitive". Students do not feel comfortable with everyone getting the same grade for a group assignment. He counters this by saying that in the real world you have to learn to work in teams and to take joint responsibility for outcomes. Expectations of a required amount of content and poor mathematical ability are other constraints to student learning.

On the self-report STEBI B, Dr. Walton scored (a) 61 (out of 70) on the personal science teaching efficacy subscale, and (b) 41 (out of 55) on the science teaching outcome expectancy subscale. Both subscales are relatively high, indicating that he has high personal teaching efficacy as well as strong efficacy that he impacts student learning.

On the Approaches to Teaching Inventory (ATI) Dr. Walton reports himself as having a strong conceptual change focus and student focused orientation (see Figure 9). He considers himself much less concerned with information transmission and less teacher focused. This is consistent with the interview data already presented, where his concern is 
for students to learn application of information rather than just the facts, and where he states that his preferred method is that of hands-on activities and presentations by students. He is concerned that students demonstrate their own understanding. Evidence from the interview also supports the student-focused categorization, where he sees himself as a coach of student learning, rather than as directing their learning. His concern for changing student conceptions is also evident in his description of practices, where he uses on-line quizzes as a diagnostic tool to identify student's preconceptions. Through discussion and hands-on activities, he attempts to change any misconceptions over time (see section on assessment).



ITI $=$ Information transmission intention $\mathrm{TFS}=$ teacher focused strategy $\mathrm{CCI}=$ conceptual change intention $\mathrm{SFS}=$ student focused strategy ITTF $=$ information transmission and teacher focused $\mathrm{CCSF}=$ conceptual change and student focused

Figure 9. ATI Scores for Dr. Walton

\section{Teaching and learning: Practices}

The syllabus states that the course is designed to "model a frame of mind that investigates, experiments, and evaluates while developing an appreciation for discovery" (teaching goals). "In this course we will learn general foundations of science, which include gravity, energy and requirements for life, integrated into a framework of current 
scientific endeavors" using the context of the International Space Station (selection of content). While there is a concern for learning basic content, the knowledge focus of the course is on using scientific processes, with students collecting, manipulating and presenting data.

The syllabus states that instruction will be varied between "traditional lecture, demonstrations, discussions and videos. The majority of time will be spent with hands-on experimentation" including doing some of the actual experiments that were done on the international space station (teaching strategies). Methods of instruction were intended to "ease the transitions from student learners to science educators in the elementary environment". In other words, students should learn pedagogy through seeing it modeled in their own learning (teaching goal).

Using the Esteem observation instrument, Dr. Walton was rated by this NOVA research fellow and the results are presented in Figure 10.

\section{ESTEEM Observation Scores}

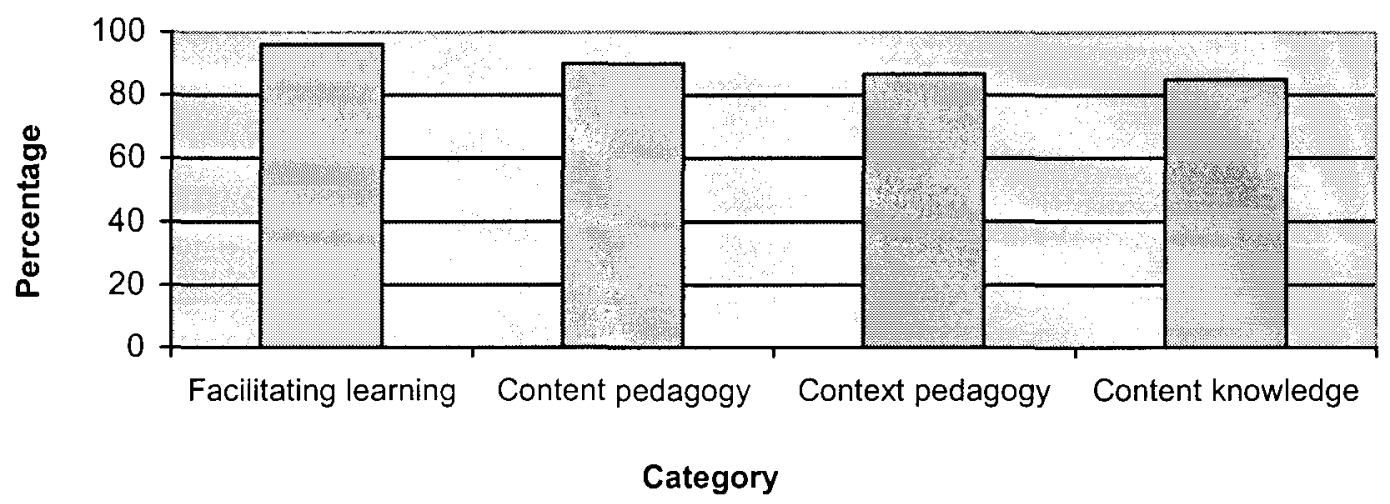

Figure 10. Results of the Esteem Observation Instrument for Dr. Walton.

He scored more than $85 \%$ on all categories, with scores of greater than $85 \%$ considered "expert" (Burry-Stock, 1995). For facilitating learning (motivating learners, 
student engagement in activities and experiences) (role of instructor) he scored a 96\%, for content pedagogy he scored $90 \%$ (use of different teaching methods, higher order thinking skills, promoting conceptual understanding and integration of content and processes), for context pedagogy he scored $86.7 \%$ (fluid control of teacher and student interactions), and for content knowledge he scored $85 \%$ (use of exemplars, balance between depth and comprehensiveness, coherence of science experiences, and accuracy of content).

When the observation was undertaken, there were two instructors in the classroom and there was some resulting disorganization as to who was responsible for what component of instruction. Similarly, students were not sure how well the two instructors communicated before the class as sometimes they would contradict each other, and students were not sure who to listen to. During the interview the instructor agreed that sometimes "we were a little disorganized and Jim would say, well tomorrow we're going to do our presentations, and I would say wait a minute, we said next week". He went further to claim that sometimes they deliberately conflicted and disagreed about subject matter to challenge the students to think for themselves.

Observations were conducted of both the lecture session and the laboratory session, and in both the students were fully engaged in the class activities. Students presented their own projects to the rest of the group in the lecture session and then watched a video. In the laboratory session, students worked on an investigation about the focal length of lenses and also observed sunspots through a telescope. The instructor worked with groups to guide and challenge their learning. Students were active and there was good teacher-student interaction. 
In general, students were very positive about the course, and were keen to come to class (teaching effectiveness). They appreciated the range of teaching methods and multimedia used. They noted that they did lots of hands-on activities during traditional lecture sessions as well as during the afternoon laboratory sessions.

They felt that the course was very different to their other science and mathematics courses, which tend to be lecture and test based. Thus, some found it hard to go from the "freedom" of the class to more structured classes in other subjects, like mathematics (constraints to learning). Because of the more positive experiences the students had in the class, they felt more prepared for their future professions as elementary education teachers, saying "it made me want to teach science in the classroom more" and "I think I will come away from the class with a lot of helpful materials". One student went as far as to say that he may have chosen education as his major if he had "been taught well earlier" using this different, discovery approach. In science at school he had "just learned facts", while this approach was more interesting and engaging because "they are making a scientist out of you".

Because Dr. Walton shows preference for instruction that involves students in hands-on investigations and experiments, he is geared toward kinesthetic learners (learning styles). Additionally, the orientation towards group tasks means that there is a strong interpersonal dynamic. Ability to use mathematics is also an element.

He sees students as being responsible for what they need to learn by being open minded to changing their ideas and constructs, to participate in their group and to "get to the place where they can ask each other questions and come to some, formulate some 
hypothesis that's testable". The observation of group presentations by this researcher showed that students met their responsibilities as assigned.

A strong team, consisting of science and education faculty, facilitated implementation of the NOVA course. The dean of science team-taught the course with Dr. Walton for the first two years and has maintained interest and support for the course. An additional factor was the funding and credibility that was brought to the project by being associated with NASA. Those who were initially resistant were persuaded to accept the implementation of the course, with the dean of science saying to them "if NASA has approved the course, why can't you".

Comparison of Conceptions and Practices: Teaching and Learning

In comparing conceptions and practices, it is necessary to contrast the data from the different sources, as outlined in the previous two sections. Here the conceptions of teaching and learning reflect views across classes, while the practices refer specifically to the NOVA class. Table 9 summarizes the properties and associated dimensions for both conceptions and practices of teaching and learning. 
Table 9

A Comparison of the Properties and Associated Dimensions of Teaching and Learning that are Espoused and Practiced: Dr. Walton

\begin{tabular}{|c|c|c|}
\hline Properties & Conceptions & Practice \\
\hline Teaching goals & $\begin{array}{l}\text { Acquiring new knowledge } \\
\text { through experimentation and } \\
\text { application, lifelong learning. } \\
\text { Modeling teaching }\end{array}$ & $\begin{array}{l}\text { Develop a frame of mind by } \\
\text { investigation, } \\
\text { experimentation, and } \\
\text { discovery. Modeling teaching }\end{array}$ \\
\hline Role of instructor & $\begin{array}{l}\text { Coach, facilitator, } \\
\text { challenging and asking } \\
\text { questions. }\end{array}$ & $\begin{array}{l}\text { Organizer and facilitator, } \\
\text { challenging and asking } \\
\text { questions. }\end{array}$ \\
\hline Teaching strategy & $\begin{array}{l}\text { Hands-on experimenting, } \\
\text { group work and } \\
\text { presentations }\end{array}$ & $\begin{array}{l}\text { Hands-on experimenting, } \\
\text { group work and presentations, } \\
\text { multimedia }\end{array}$ \\
\hline View of knowledge & $\begin{array}{l}\text { Facts, wisdom and } \\
\text { understanding, experiential } \\
\text { knowledge }\end{array}$ & $\begin{array}{l}\text { Basic facts, scientific } \\
\text { processes }\end{array}$ \\
\hline Use of knowledge & Generate and test theories & Generate and test theories \\
\hline Source of knowledge & $\begin{array}{l}\text { Different disciplines of } \\
\text { science, experience, beyond } \\
\text { the professor }\end{array}$ & $\begin{array}{l}\text { Different disciplines of } \\
\text { science, experience, beyond } \\
\text { the professor }\end{array}$ \\
\hline Selection of content & $\begin{array}{l}\text { Themat } \\
\text { interdis }\end{array}$ & $\begin{array}{l}\text { Thematic and } \\
\text { interdisciplinary }\end{array}$ \\
\hline $\begin{array}{l}\text { Pedagogical } \\
\text { knowledge } \\
\text { development }\end{array}$ & $\begin{array}{l}\text { Negative role models, trial } \\
\text { and error, positive feedback } \\
\text { on new methods }\end{array}$ & No evidence \\
\hline $\begin{array}{l}\text { Sharing teaching } \\
\text { ideas }\end{array}$ & $\begin{array}{l}\text { Limited because not full time } \\
\text { faculty member }\end{array}$ & $\begin{array}{l}\text { Limited because not full time } \\
\text { faculty member. Other team } \\
\text { members have presented } \\
\text { findings }\end{array}$ \\
\hline $\begin{array}{l}\text { Teaching } \\
\text { effectiveness }\end{array}$ & $\begin{array}{l}\text { Student feedback, anecdotal } \\
\text { reports, student use of ideas } \\
\text { in classrooms }\end{array}$ & Positive student comments \\
\hline $\begin{array}{l}\text { Constraints to } \\
\text { teaching }\end{array}$ & $\begin{array}{l}\text { Materials, demand for the } \\
\text { course }\end{array}$ & No evidence \\
\hline $\begin{array}{l}\text { Factors facilitating } \\
\text { implementation }\end{array}$ & $\begin{array}{l}\text { Interdisciplinary nature, time } \\
\text { for preparation, support of } \\
\text { team members, including } \\
\text { dean of sciences }\end{array}$ & $\begin{array}{l}\text { Interdisciplinary nature, time } \\
\text { for preparation, support of } \\
\text { team members, including } \\
\text { dean of sciences, NASA } \\
\text { affiliation }\end{array}$ \\
\hline
\end{tabular}


Table 9 (continued)

\begin{tabular}{|l|l|l|}
\hline Properties & Conceptions & Practice \\
\hline Learning interaction & $\begin{array}{l}\text { Two way process, student } \\
\text { engagement, some student } \\
\text { reticence because of grading }\end{array}$ & $\begin{array}{l}\text { Two way process, student } \\
\text { engagement }\end{array}$ \\
\hline Learning control & Two way process & Two way process \\
\hline Learning styles & No evidence & $\begin{array}{l}\text { Kinesthetic, interpersonal, } \\
\text { logico-mathematical }\end{array}$ \\
\hline $\begin{array}{l}\text { Impact on student } \\
\text { learning }\end{array}$ & $\begin{array}{l}\text { Life-long learners able to } \\
\text { critique teaching approaches }\end{array}$ & $\begin{array}{l}\text { More positive view of science } \\
\text { and confidence in ability to } \\
\text { teach }\end{array}$ \\
\hline $\begin{array}{l}\text { Constraints to } \\
\text { student learning }\end{array}$ & $\begin{array}{l}\text { Prior experiences of learning } \\
\text { in other classes, mathematics }\end{array}$ & $\begin{array}{l}\text { Transitioning between } \\
\text { different styles of instruction }\end{array}$ \\
\hline $\begin{array}{l}\text { Student } \\
\text { responsibilities }\end{array}$ & $\begin{array}{l}\text { Open minded and willing to } \\
\text { change, participate in groups, } \\
\text { raise questions and challenge } \\
\text { others }\end{array}$ & $\begin{array}{l}\text { Participate in groups, raise } \\
\text { questions and challenge } \\
\text { others }\end{array}$ \\
\hline
\end{tabular}

Overall there is consistency between conceptions and practices.

\section{Assessment: Conceptions}

The purpose of assessment is to establish if students have "assimilated and learned the subject matter and then can reproduce it in a presentation". "Basically I think its to measure what the students have learned". Through student presentations of material he is able to establish how much they understand. "The presentations we do ah, give an excellent amount of information because the student presents ah, the whole package, not answers to true and false questions, or fill in the blank. They have to develop what they're gonna talk about and their thought pattern". He also uses assessment as a way of monitoring change in conceptions so that "we see how we've changed our ideas".

In assessing students he uses individual and group presentations, on-line quizzes and a portfolio (strategies). There are no tests or exams. Presentations are the "main assessment tool". He insists that presentations are not only Powerpoint shows, but go beyond and include "a hands on demonstration or hands-on involvement with students". 
On-line pre-quizzes are used to establish what students know prior to starting a section, and these are followed up with post-section quizzes to show what the students have learned (periodicity). The final portfolio piece is turned in at the end of the semester and includes lesson plans, inquiry reports, reflections on learning, "what I thought before, what I now know is true, kind of thing, and what I've learned", as well as a research log of useful Internet sites, books and other resources that will be of value when they become teachers. At the end of each unit, the instructor holds "so what" sessions with the students. In these the students are asked to "write a reflection on what's happened so far in the course, and what they like and don't like". These are done confidentially, if desired, so students are free to express opinions.

By making presentations to their peers and later to schoolchildren, students are provided with a safe environment to make mistakes. Feedback on presentations is provided by the instructor in verbal and written format, as well as by peers. "They're open to peer review immediately. The rest of the students in the class ask them questions and ask them to explain things". Online quizzes are discussed in class and the instructor says, "I kinda hope they mess up sometimes because that's the best way, or one of the best ways to clarify things, to get a misconception out and then clarify it. And, that's good learning." He also provides feedback to students as they are working on projects as he moves around the classroom facilitating discussion and challenging their thinking. He emphasizes that part of their grade is "my observation of whether you're participating or not" (grade implementation). Although generally the group gets the same grade for project presentations, he does take into account effort and participation. Sometimes students will complain to him about other students who do not do enough work to 
warrant the same grade, and this a tension he has not figured out how to resolve successfully.

He uses multimedia presentations and demonstrations in his mini-lectures and "so I've modeled that', to prepare students for the assessment tasks. Similarly, after they have conducted an experiment, he will go through what is required in an inquiry report and do a "mock reflection of it, so that they see ah, what was expected". He does the same for the required portfolio pieces, explaining exactly what is expected in the portfolio (assessment preparation).

Dr. Walton is concerned that the students demonstrate what they have learned, "the depth of their understanding", that they can "relate it to something" and that they "see how we've changed our ideas" (knowledge focus). He believes that "once you've experienced it, you'll remember it so much better'. Thus, application of concepts and monitoring of conceptual change is important for him.

Assessment data were to be used to improve instruction, saying that, "if the students don't understand it, I haven't done a good job of teaching. And I better assess the way I presented the material and maybe change something." He qualified that statement by adding that with a more participatory style of presenting material that he perceives that "more of the students grasp the ideas than just me telling them about it, dumping facts and hoping that they get it." Also, the assessment data should be used to improve student presentations and participation, resulting in better presentations the next time around (relationship to teaching and learning).

The self-survey ratings on the Assessment of Classroom Learning in Science Inventory (ACLSI) for Dr. Walton are relatively high overall. The ACLSI assesses the 
use of a diversity of different strategies and purposes. Five out of seven scores were above $85 \%$ and therefore considered to be expert (Burry-Stock, 1995).

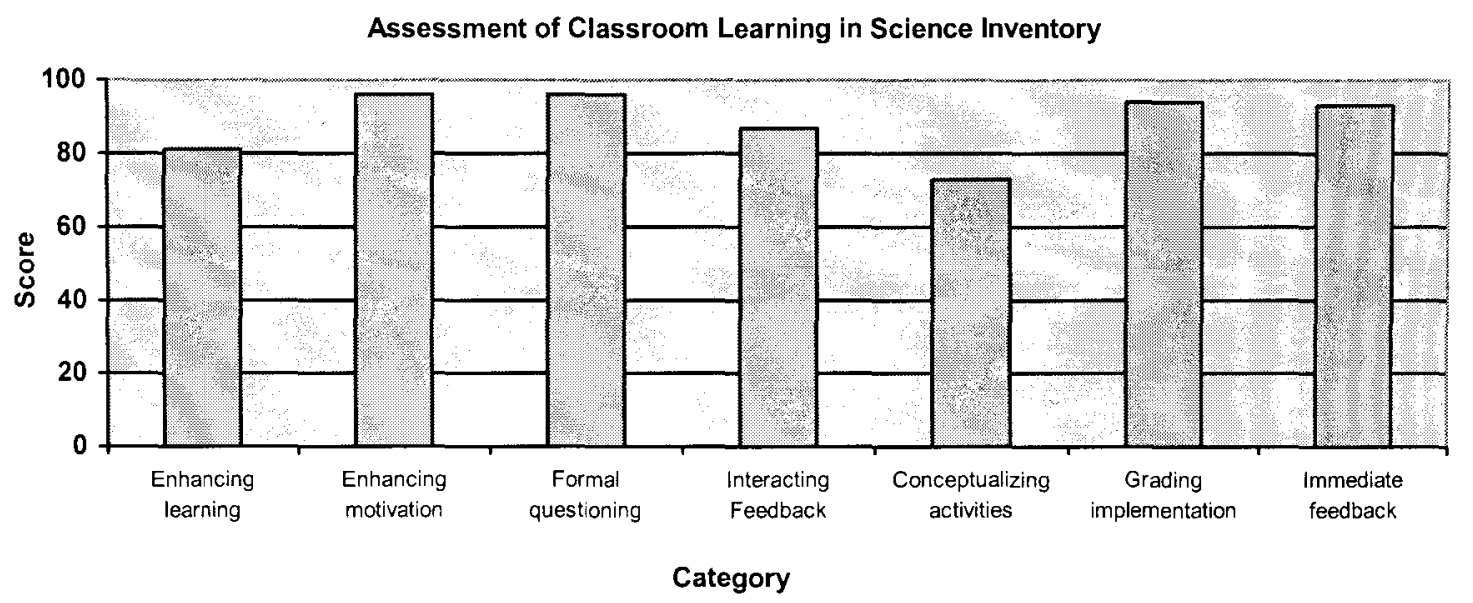

Figure 11. Results of the Assessment of Classroom Learning in Science Inventory for Dr. Walton.

To score high on the different subscales, a teacher would have to be using a variety of different strategies for a range of different purposes. For instance, the formal questioning category focuses on the use of traditional tests, grades and quizzes, and $\mathrm{Dr}$ Walton rated himself at $96 \%$ for this category. Enhancing motivation includes the use of portfolios, science fairs, individual and group presentations, and he scored a 96\%. Grading implementation includes modeling expectations, providing criteria for performance, announcing quizzes, weighting grades, and he scored a 94\%. Similarly, he scored $93 \%$ on the immediate feedback category, which includes the use of hands-on activities for informal feedback. The category where he rated himself the lowest $(73 \%)$ was for conceptualizing activities because he does not use concept maps or formal laboratory reports. Thus, his self-reporting appears to be consistent with his description of his practices. 
The purpose of assessment is not stated in the syllabus, but can be implied as focusing on allocating a grade. However, the course materials, portfolio guidelines and rubrics state that the portfolio is "the story of your growth and development as a scientist and science educator" and will document "your effort, progress and achievements as you participate in science as an individual and in group processes". Guidelines are provided for students to reflect on their own work. So, the focus of assessment is on student growth, reflection and development.

Clear criteria for performance are provided through the use of rubrics and these also provide feedback to the students about the various portfolio pieces. Rubrics and criteria for performance are made available ahead of time, so students are well prepared for the particular assessment task (assessment preparation). The students felt less stressed about the NOVA class, as there was not a heavy emphasis on content knowledge and tests, but on application and portfolio demonstrations of competency (knowledge focus). This is supported by a survey of student opinions where 12 out of 15 students disagreed that getting the correct answer to a problem is more important than investigating the problem (only two disagreed and one was unsure).

The syllabus outlines the grade scheme as follows (a) on-line quizzes, taken before class 15\%,(b) group presentations, written and oral 20\%, (c) multimedia presentations, websites, PowerPoint presentations 15\%, (d) portfolios 40\%, and (e) lab participation, group work, attendance 10\% (strategies). The greatest proportion of the grade is allocated to demonstrating competency through the portfolio, and then for various types of presentations. 
Comparison of Conceptions and Practices: Assessment

In comparing conceptions and practices, it is necessary to contrast the data from the different sources, as outlined in the previous two sections. Table 10 summarizes the properties and associated dimensions for both conceptions and practices of assessment.

Table 10

A Comparison of the Properties and Associated Dimensions of Assessment that are Espoused and Practiced: Dr. Walton

\begin{tabular}{|l|l|l|}
\hline Properties & Conceptions & Practice \\
\hline $\begin{array}{l}\text { Purpose of } \\
\text { assessment }\end{array}$ & $\begin{array}{l}\text { Assimilation and reproduction } \\
\text { of knowledge, changes in } \\
\text { conceptions }\end{array}$ & $\begin{array}{l}\text { Documenting student growth, } \\
\text { reflection and development, } \\
\text { allocating grades }\end{array}$ \\
\hline Strategies & $\begin{array}{l}\text { Individual and group } \\
\text { presentations, on-line quizzes, } \\
\text { portfolios. }\end{array}$ & $\begin{array}{l}\text { Individual and group } \\
\text { presentations, on-line quizzes, } \\
\text { portfolios, rubrics }\end{array}$ \\
\hline Periodicity & $\begin{array}{l}\text { Before a new section, at the } \\
\text { end of a section }\end{array}$ & $\begin{array}{l}\text { Before a new section, at the } \\
\text { end of a section }\end{array}$ \\
\hline Interaction feedback & $\begin{array}{l}\text { Verbal after quizzes, peer } \\
\text { review and written after } \\
\text { presentations, written } \\
\text { comments on portfolios, } \\
\text { challenge ideas during class } \\
\text { projects }\end{array}$ & $\begin{array}{l}\text { Verbal after quizzes, verbal } \\
\text { and written after presentations } \\
\text { and written comments on } \\
\text { portfolios. }\end{array}$ \\
\hline Use of data & $\begin{array}{l}\text { Improving instruction, } \\
\text { improving student } \\
\text { presentations }\end{array}$ & $\begin{array}{l}\text { Improving instruction, } \\
\text { improving student } \\
\text { presentations }\end{array}$ \\
\hline $\begin{array}{l}\text { Assessment } \\
\text { preparation }\end{array}$ & $\begin{array}{l}\text { Modeling, discussion of } \\
\text { requirements }\end{array}$ & $\begin{array}{l}\text { Modeling, discussion, rubrics } \\
\text { with clear criteria for } \\
\text { performance }\end{array}$ \\
\hline Knowledge focus & $\begin{array}{l}\text { Understanding, application, } \\
\text { experiential learning, changing } \\
\text { conceptions }\end{array}$ & $\begin{array}{l}\text { Application of concepts, } \\
\text { competency, changing } \\
\text { conceptions }\end{array}$ \\
\hline $\begin{array}{l}\text { Relationship to } \\
\text { teaching and learning }\end{array}$ & $\begin{array}{l}\text { Improve teaching and student } \\
\text { learning }\end{array}$ & No evidence \\
\hline $\begin{array}{l}\text { Grading } \\
\text { implementation }\end{array}$ & $\begin{array}{l}\text { Individual and group grades } \\
\text { for various tasks }\end{array}$ & $\begin{array}{l}\text { Individual and group grades } \\
\text { for various tasks, final grade }\end{array}$ \\
\hline
\end{tabular}

While there are some subtle differences between conceptions of assessment and Dr. Walton's practices, these to not constitute major contradictions, so that there appears 
to be an overall consistency between personal conception and actual practices in the classroom.

\section{Action Research: Conceptions}

When first asked to explain the purpose of action research, Dr. Walton was not sure what was meant by the term, saying "Ok now, straighten me out on it. Give me another slant on what you're saying" (conceptualizing). He first thought it to be inquiry research by students.

Once he was reminded that it was the process in which the education team member had participated, Dr. Walton expressed that it is crucial to have an outside person conducting the action research in order for it to have merit and for students to feel free to express their opinions. He felt that the outsider prevented any bias and preconceived ideas from him creeping in. He was not involved in conceptualizing the action research project and was comfortable that the education faculty member "did the whole thing" (support). "I certainly believe an independent investigator is a lot better, like Janet was", because "the students are just freer to express to her, knowing that these ah, evaluation sheets that were put out were going to be given to her for totaling up and ah, so on. I just don't think they can get away from the fact that ah, their grade is linked to the guy that is up there in front".

The design of the action research was left to the outside facilitator, and Dr. Walton was happy with the entrance and exit interviews (instrumentation) that were done. He felt that if he were to design his own study that it would be less specific, "just sort of an indirect way of seeing trends and what was said and trying to analyze it that way". For his own study, he might "build some kind of instrument to test that, and then 
have this person interview a cross section of the class, or it it's a small class, the whole class". So, he would still require outside assistance.

For Dr. Walton, the primary focus of the action research project was on whether he was "doing an effective job". While he was not directly involved in conceptualizing the project, he was interested to find out what students thought about his course, what the weaknesses were, what could have been done differently, and what was helpful. "I want them to contribute something to the way I teach" so that he can figure our how best the students learn. "And then from then on, I think I'd break it down into ah, what were the activities of class, and did they, were they pointed towards um, students learning by experience and, and by investigation". To arrive at the position of being able to accept student critique he acknowledges that "it took my mental attitude toward 'I know what's right and you don't', to a frame of mind that says, 'you can contribute something to the way I teach"'. He feels that such a shift is very difficult for university faculty to make because they feel that know the material and the best way to deliver it.

Accordingly, the purpose of the action research is perceived as a way "of measuring what you've done in the classroom". It helps to reinforce methods that work and are effective, and to change approaches where they do not work. It also provides data to argue the value of the innovative course with administrators because "in the eyes of some of the people who were doubtful about this class, it ah, it really established that this is a viable class at the college level".

He primarily has an objective orientation to knowledge, saying, "I think, the more detailed and objective answers you could get the better it would be". While he 
prefers "if you can get hard data, that's always better", he recognizes that "there has to be subjectiveness to it though" because it involves student perceptions and opinions.

In examining student comments he has realized that students have more to offer than he had originally anticipated (results). "My idea was, you don't know anything about this, and you don't even have enough information even to ask a good question about this right now, so just sit there an listen to me and then we'll talk about it. But, ah, I've discovered, that, that these guys have very creative ideas, these students. And, man they come up with some neat things. And, I was suppressing them". As a result he is now willing to say when he does not know the answer to something and that in turn "frees students to do the same". So, his primary concern is for improving his teaching and improving student learning, and engaging students in the reflective process.

While the original action research project has ceased, Dr. Walton sees merit in having students write about his course at the end of particular sections. Thus, he sees that it is necessary to gather data from the students on an ongoing basis (iteration). In this way he is able to consider continuous improvement to the course and his teaching.

Because Dr. Walton is primarily concerned with the need to generate meaning, to understand practice and to interpret reality through reflection and consensus, his orientation is toward a practical interest. This involves the practitioner and researcher cooperating together to identifying problems, causes and interventions Classroom action research, in which "primary concern is given to teachers' self-understanding and judgments," has a practical emphasis (Kemmis \& McTaggart, 2000, p. 569). This clearly is Dr. Walton's intention. 
Dr. Walton relied primarily on the education faculty member in the NOVA team to implement the original action research component (support and conceptualization). There were two research foci, namely (a) "how the methods used in the course influence the forms of inquiry utilized in the lesson plans and capstone experience developed by the students", and (b) whether "the attitude of students toward science, mathematics and science instruction changed". To do so, she (a) analyzed documents used by faculty, documents created by students and also surveyed students, and (b) conducted classroom observations and interviewed the students at the end of the semester (design). She then analyzed common themes that emerged from the data. Results showed that students had a more positive attitude toward taking science classes, did not just see science as a collection of facts and most felt more confident about teaching it in the future.

This research was presented by the education faculty member and the other course team member at a NOVA Leadership Development Conference, but Dr. Walton was not involved in the process, and has not communicated the results of the research to others, other than the NOVA team at his university.

Since then, he has continued his action research on an informal basis, but adopted the same focus on teaching, rather than on student outcomes. He does not have any established research questions, but is concerned to continue to improve his teaching (purpose), and so has students regularly write about the course and aspects with which they have difficulty. These free writes are done confidentially so that students are free to express their opinions without feeling that their grade may be impacted (research design). "I call them 'so what' sessions. And the students get a chance and I try to 
establish in their minds that there's total grade immunity here. Whatever you say isn't going to influence your grade".

Using these 'so what' sessions he gathers data from students at the end of a unit (iteration), although the analysis of this data was more informal, with him looking through the responses for common trends and issues. "And then, read it over and kind of summarize it and ah, this is a constant theme from the students, this is something I have to give attention to".

The results of the action research were "over $90 \%$ positive from the beginning", but students still noted areas for improvement, such as the need for better organization skills when two instructors were involved in teaching. Where negative comments were made, at first he felt hurt, thinking, "Ooh, wait a minute now, that's not right". "But, then I reflect on it and say, OK, perception is reality to these students, and if that's what they're perceiving, I gotta approach it a different way". As a consequence he feels that he will "never teach a class the same way as I used to, ever again".

Discussions about the outcomes of the action research were held with the outside researcher, the other faculty member initially involved in team teaching the course, as well as the students who had results discussed with them. So, his reflective concern was for collaborative engagement, involving the range of stakeholders.

In summary, the star diagram (Rearick \& Feldman, 1999) in Figure 12 shows that the primary foci of the action research conceptions and practices reflect practical interest, collaborative reflection, and professional purposes. 




Figure 12. Star Diagram for Action Research Practices of Dr. Walton

Comparison of Conceptions and Practices: Action Research

In comparing conceptions and practices, it is necessary to contrast the data from different sources. Table 11 summarizes the dimensions for both conceptions and practices of action research. 
Table 11

A Comparison of the Properties and Associated Dimensions of Action Research that are Espoused and Practiced: Dr. Walton

\begin{tabular}{|l|l|l|}
\hline Dimension & Conceptions & Practice \\
\hline $\begin{array}{l}\text { Conceptualization } \\
\text { and support }\end{array}$ & $\begin{array}{l}\text { Externally conceived and } \\
\text { driven }\end{array}$ & External \\
\hline Focus & Improving teaching & Improving teaching \\
\hline Research design & Qualitative & Qualitative \\
\hline Instrumentation & $\begin{array}{l}\text { Entrance and exit interviews, } \\
\text { student perceptions }\end{array}$ & $\begin{array}{l}\text { Documentary analysis, } \\
\text { observation, interviews, } \\
\text { student's written perceptions, } \\
\text { class discussions }\end{array}$ \\
\hline $\begin{array}{l}\text { Knowledge } \\
\text { orientation }\end{array}$ & $\begin{array}{l}\text { Preference for objective, } \\
\text { accepting subjective nature }\end{array}$ & Accepting subjective nature \\
\hline Interest & Practical & Practical \\
\hline Purpose & $\begin{array}{l}\text { Personal purposes, improve } \\
\text { instruction, promote course }\end{array}$ & $\begin{array}{l}\text { Personal purposes, change } \\
\text { teaching practices }\end{array}$ \\
\hline Reflection & Collaborative & Collaborative \\
\hline Use of results & Improve teaching & Improve teaching \\
\hline Iteration & Ongoing informal & $\begin{array}{l}\text { Once-off formal but ongoing } \\
\text { informal }\end{array}$ \\
\hline
\end{tabular}

There is consistency between conceptions and practices, with Dr. Walton using primarily an informal approach to reflection. Formal action research is relegated to the involvement of an outsider to conduct and analyze data.

\section{Conclusion}

In all three areas researched Dr. Walton holds a view that focuses on active student participation in learning. The metaphor that characterizes this instructor is 'teacher as coach and guide, and students as active participants in developing understanding'. Overall, there is a consistency among his conceptions and his practices of teaching and learning, assessment, and action research. 


\section{Bruce Stevenson}

This case was chosen because it reflected a quantitative approach to action research focusing on student outcomes.

Dr. Stevenson teaches an earth science course as an honors class that typically includes education, as well as other majors. The course is offered in a computer lab and uses a website permanently hosted on the university server as the primary source of information. There is no textbook for the course. The syllabus, hosted on the website, contains weekly pre-reading assignments, weekly in class assignments and weekly writing assignments, which requires students to produce a written or visual product to describe their learning for that week. Students are expected to read material from the Internet links listed on the syllabus prior to coming to class, and then in class to work on the weekly Internet assignments and written assignments.

\section{Teaching and learning: Conceptions}

As the instructor he sees his role as that of facilitator. "My job is to serve as the facilitator, by and large, to help direct students towards better understanding". His task is to stimulate the interest of the students and to pique their curiosity. He provides some basic instructions for what is to be achieved for the day and is there "to provide some inputs to the students as they are working through these things". Another role is to stimulate discussion on key points and to "provide leading questions that will promote discussion in various ways". The instructor's job is also to "figure out some way to evaluate the students and provide a grade at the end of the semester".

His primary goal for teaching the course is for students to gain an "understanding of process and not just a bunch of facts". He sees that it is important to get the students 
"to kind of buy into the fact that, you know, we are not going to learn a bunch of answers here, but we are going to learn how to think about what the answers might be". He wants to encourage students to think in terms of processes, and to ask questions as they watch different earth processes. He is particularly concerned for students to hone their observation skills, to illustrate and gain an insight into earth processes, "so they can come to understand how things work". He also encourages them to think metacognitively saying "perhaps it's time for you to start thinking about what you know, how you know it and why you know it, um, what you don't know and try to figure out how you can learn it". He wants students to assimilate information, synthesize and apply that knowledge. He is not interested in simple regurgitation of factual information (use of knowledge), but that they learn to "ask critical questions of themselves and think in terms of what possible answers might come from that" and for students to apply knowledge to illustrate the different earth processes. Basic facts must be related to a process in order to understand a phenomenon. In the syllabus he states that "perhaps you will discover that real data can be ambiguous, contradictory or sufficiently confusing that it defies rational attempts at interpretation" (view of knowledge). Thus, many of the tasks given to students are very open-ended. "I am kind of notorious for giving homework assignments that I don't actually know the answer to and as the students are working through the problem, you know, I start to get a feel for myself what possible answers there might be". Thus, knowledge is seen as provisional and relative and he is concerned that students are engaged in the process of creating their own knowledge. "I mean really creating knowledge, and its not unlike creating art or creating a painting or a poem or anything else. It is a creative process, and I think my mind is wired for those 
kinds of things". He feels that it is important that he is "learning at the same time that the students are learning" because it helps to keep him motivated and enjoying what he is doing.

This instructor also deliberately tries not to be the sole source of knowledge in the classroom, but acknowledges that at times it is necessary for him to serve as the expert to answer questions that might come up. "I really try hard not to be the guy who knows all the answers. Um, although I think I draw from a lot of experience, and certainly students can tap into my knowledge base at some level, but more importantly, I think they need to learn to ask critical questions themselves". While he believes that it is important for an instructor to have a level of competency with the subject matter, he is willing to admit when he does not know an answer to a question, but then follows-up by considering ways to find the answer, and by suggesting what potential answers might be. As a scientist, he is continually "trying to create new tools to better understand and observe the world around us", so that he can enhance his own understanding of phenomena. He accepts that science builds upon prior knowledge, but that sometimes one can go down a dead end, and that it becomes necessary to review one's original point of view. "Scientists don't provide answers, we provide understanding".

In selecting course content Dr. Stevenson considers the purpose of the course. In the earth science course, it is possible to be flexible and to divert from the syllabus as interesting things crop up. "We don't' actually have to get through a finite quantity of material, we can stop and spend extra time as we see fit". However, this luxury does not exist in all courses, where there is an expectation that a certain quantity of material will be covered in a semester because, "you know, you pitch this towards certain standardized 
test kind of things". He keeps up to date with the scientific literature in the field and this, together with his own research, influences the direction he takes in selecting and incorporating material into the earth science course.

Dr. Stevenson's preferred teaching strategy in the class revolves around the use of the Internet as a tool, with students reading information from selected sites, undertaking virtual tours, looking at satellite images, together with discussions using the Socratic type of method. "We have a lot of discussions in the class and we have the hands-on exercises which are taught in the computer lab." He adds that "the real aid that we use in my class is that the students create animations". Students use Windows Movie Maker to produce animations of the different earth systems being studied. They do this by downloading static images off the Internet and then pasting them into Windows Movie Maker to make simple animations to illustrate the various earth systems. Case studies of processes are explored and then related to other instances. He considers this "much better than looking at static images or just lecturing on these things".

Dr. Stevenson hopes to create a classroom atmosphere that is informal, in which students feel free to express ideas, ask questions and "can speak their mind and say whatever they want to say". They are also free to interact with other students, visiting each other during the class to ask questions, discussing amongst themselves, and to engage with the instructor who wanders around to assist as necessary. The relationship between instructor and student is "a two way process", with mutual respect for each other of paramount importance. He perceives that developing a rapport and gaining their confidence and trust is really important because the style of the class is so different that they are distrustful at first. "I think initially, um, what they struggle with is the open- 
ended nature of it. Again, they are accustomed to sort of stand-up lectures where someone recites the three facts that they are supposed to remember". "I think where I get that trust from them is they realize after a while, I am not going to give them a harsh grade because they got the wrong answer" (learning control). Students are expected to take control of their own learning. He states that this is easier to do in a class with 15 to 20 students, which is typical in his earth systems class, but more problematic in the traditional lecture based classroom with up to 100 students. He considers the NOVA course to be "complimentary to the way I teach my graduate level courses", but acknowledges that, "it is pretty unique in terms of the undergraduate things that I have taught".

The major constraint facing effective teaching is that of class size, where large sections are typical in undergraduate courses, making it almost impossible to teach in an interactive way. In teaching a class of 180 , he has resorted to traditional lecture method, although he did not enjoy this approach. Another constraint is the expectations of others in the university, so that faculty are "forced into that mode by the department and other faculty in my department" because doing something different creates tensions and suspicions. "Some of my colleagues in the department don't get it and are never gonna get it, and part of that is a generational thing". This has limited his ability to share teaching ideas with colleagues who are less disposed towards or interested in new ideas. This is the dominant paradigm at the university, where there is the "expectation that there is a certain grade distribution that comes out of the class, and that certain content gets covered and you know, its, those are pretty restrictive". He sees these constraints as limiting effective teaching. 
Factors that have facilitated implementation of the course are: (a) the support of an associate dean, and (b) the fact that the course is an honors course, which means that there is a "pretty open attitude about stimulating students and providing them with kind of open ended types of instruction that kind of piques their curiosity, but also keeps them thinking in broader terms". Thus, Dr. Stevenson feels free to divert from the syllabus as the need arises.

This instructor's teaching style has developed primarily through his own preferred learning style (pedagogical knowledge), saying "I think that's generally the way that I learn myself, so now that translates to the way I teach students too". He sees himself as a curious and creative person who is intellectually stimulated by the scientific process. "The research work I do really kind of satisfies the creative urge in me." In the teaching situation he also perceives himself as a learner, adding that if 'I' $\mathrm{m}$ learning at the same time that the students are learning, that makes it really fun for me". He also has learned from good instructors, particularly his advisor at the masters level, whom he sees as a mentor. Similarly, he has learned from the negative role models saying, "like I don't want to grow up to be this person". Thus, he has avoided approaches from which he personally did not learn. He acknowledges that instructors in many disciplines receive very little training about teaching and learning, and how to be effective instructors, although he adds that, "I think we all want to be good teachers". Teaching the NOVA course has helped to develop some understanding of pedagogy. "I think that the biggest change is that rather than lecturing first, then doing exercises, I have started doing the exercises first, then engaging students in discussion about what it was we did and why we were doing it". 
Evidence of Dr. Stevenson's own teaching effectiveness comes from seeing the students enthusiastic about the class and open and willing to enter into discussion and debate. It is important so see them starting to think in terms of processes and to ask questions, rather than just trying to just give a discrete answer. "Just the fact of even thinking in terms of a process is a really big success". However, he is unsure of how much he impacts student learning in the long term because his course is only one out of a host of other courses that are typically taught in the traditional lecture format, so that students are not supported in developing critical thinking skills and a process orientation in other classes. "You know I don't know how long lasting that effect is".

He believes that students learn (learning styles) "if they can see it for themselves", that is through visualization of processes. He also believes students learn through hands-on activities. He accepts that there are different styles of learning and expects students to make adaptations to their own style accordingly, saying they need "to think about the course content that we're learning and then think about how they're learning it, and try to adapt, um, you know to various types of learning styles or information contents". He does not mention his adaptation to their learning styles. Discussion is another way in which students can learn effectively.

A major constraint to student learning (influences on student learning) is their background and lack of basic knowledge. "I don't think I was always as attuned to their backgrounds and the consequences of that in their preparation". He also attributes the major student difficulties in his class to their experience in other classes, and from their prior educational experiences. "They are prepared to come in and drill on these things, and spit them back out, whether they really understand it or not. But, that's is one thing 
that the students really struggle with, that this is something different that they just don't get much of".

The responsibilities of the student include a willingness to be curious, "and to think about the course content that we're learning and then think about how they're learning it". He expects students to come to class, to participate during class, to do the work allocated before and after class, that is, "do what they need to do to be prepared on a daily basis in the class". He would like students to be motivated to learn by engaging actively, rather than just come to class with the attitude of "what do I need to do to get an A or what's the answer to this question".

On the self-report STEBI B, Dr. Stevenson scored (a) 60 (out of 70) on the personal science teaching efficacy subscale, and (b) 33 (out of 55) on the science teaching outcome expectancy subscale. While his personal science teaching efficacy is relatively high, his teaching outcome expectancy is lower, indicating that he is less confident in his ability to impact student learning. This was reflected in his interview, where he was not sure how much impact his style had on student learning overall during their education at the university. This is a factor of the dominant model of education delivery, the lecture, in other classes.

On the Approaches to Teaching Inventory (ATI) Dr. Stevenson reports himself as having a strong conceptual change focus and student focused orientation (see Figure 13). He considers himself much less concerned with information transmission and less teacher focused. This is consistent with the interview data already presented, where his concern is for students to learn process over facts, and where he states that his preferred method is 
that of hands-on activities and discussion. Evidence from the interview also supports the student-focused categorization.



ITI $=$ Information transmission intention $\mathrm{TFS}=$ teacher focused strategy

$\mathrm{CCI}=$ conceptual change intention $\mathrm{SFS}=$ student focused strategy

ITTF $=$ information transmission and teacher focused $\mathrm{CCSF}=$ conceptual change and student focused

Figure 13. ATI Scores for Dr. Stevenson

However, the orientation towards conceptual change is less easy to support from the interview data. No mention is made of conceptual development or conceptual change processes, other than that students should have "grasped some of the concepts in a general way" and that he was "surprised that the science majors often seem to cling to the preconceptions more than the other students". "Along the way, we expected students would also learn many things or correct misconceptions that they had regarding science and the Earth System". No mention is made of associated strategies for conceptual change, like accommodation, scaffolding, the learning cycle or cognitive restructuring. Essentially, the teaching strategies and goals are oriented to enhancing understanding through assimilation of new knowledge, through procedural reasoning, synthesis and application. So, while conceptual change may be a goal, there is less evidence to support this in practice. 


\section{Teaching and learning: Practices}

The primary teaching tool (teaching strategy) is the website for the course, which contains all reading material, class exercises and assignments. There are 16 weeks in the course, with 16 weeks of reading assignments, 13 weeks of Internet assignments, and 13 weeks of writing assignments. Internet assignments include virtual tours, becoming familiar with software programs and processes, visiting websites with databases of current information and photographs on earth systems, doing simulations, and observing computer models. Internet sites come from a variety of different sources, including "other universities, information outlets of government agencies, published reports of professional organizations and commercial magazines, and personal notes or essays placed online by interested individuals". Sources are international (source of knowledge). The syllabus specifically states that scientists do not know all the answers, and that different scientists may hold competing perspectives on phenomena. He intends for students to engage with this notion and not just search for factual answers, saying in the syllabus, "Indeed, in earth systems science, I would contend that there are relatively few answers at present, but a great many questions" (view of knowledge).

All assignments have questions posed to help direct the student's work. Assignments include creating metaphors, using Windows Movie Maker to produce animations, plotting maps of weather patterns, making a movie of global surface winds over a year (365 frames), creating time-lapsed images, and using original data to create graphs over time. For most of the assignment there are questions to guide the observations and help students reflect on what they have learned. There are also written assignments such as essays on the space program over the last 40 years, and another on 
the possibility of human habitation of Mars. In these, student are expected to be expressive and argue particular view points, rather than just stating facts (use of knowledge). The final assignment for the semester is where students write and perform a poem in "poetry slam" style. The teaching strategies outlined in the syllabus and online materials are consistent with those discussed by the instructor during the interview.

The instructor states in the introduction that much of the reading material is repetitive, but is presented in several different styles in order to reach students with different learning styles. Primarily the assignments are oriented towards spatial, kinesthetic and linguistic learners. All assignments are individual, and while students may "visit" with other students during lab sessions, there are no designated cooperative learning tasks assigned, thus not targeting intrapersonal learning styles. Again, this is consistent with findings from the interview, where he does not mention group work or collaborative tasks.

Using the Esteem observation instrument, Dr. Stevenson was rated by one of the NOVA research fellows and the results are presented in Figure 14.

\section{ESTEEM Observation Scores}



Category

Figure 14. Results of the Esteem Observation Instrument for Dr. Stevenson. 
He scored $100 \%$ for content knowledge and $93.3 \%$ for context pedagogy, which is defined as fluid control of teacher and student interactions. Scores of greater than $85 \%$ are considered "expert" (Burry-Stock, 1995). For content pedagogy, which includes the used of different teaching methods, higher order thinking skills, promoting conceptual understanding and integration of content and processes, he scored $73.3 \%$, which is considered "proficient". This score reflects the lesson structure that is characteristic for the class, with one dominant mode of instruction, that of Internet based assignments and discussion. For facilitating learning (motivating learners, student engagement in activities and experiences) (role of instructor) he scored a 68\%, which is deemed "competent" (Burry-Stock, 1995).

The observer noted that there was little discussion between students and that "questions were asked and answered by the instructor". The instructor moved around among the students to answer individual questions (learning interaction). Several of the students left early when they had completed the day's work. The observer was impressed with the course website and the extensive links to information and data. She added, "each lesson has a reading component, but students have several methods of looking at the material, depending on their individual learning style". This is part of the course design, that students can read the material in different ways.

As regards facilitating learning, there is some disjunction between what the observer saw during one observation, where the instructor was the main initiator of interaction, and what the instructor described in the interview regarding the quantity of student led discussion. This may have been a factor just of that one particular day when 
students were engaged in an Internet assignment and did not have specific questions. This may have accounted for the slightly low ESTEEM score on the first subscale.

Students described the course as "student led and discussion based" with sessions mostly being discussions, with "a little lecture sprinkled in". One student commented that, "I like that he lets us lead the discussion. You don't feel ashamed asking questions you are curious about". These comments support the instructor's claims of frequent student-led discussions (learning control).

Another student added, "This course is quite different. Other courses are mostly lecture. This one incorporates Internet, technology and open discussion. Extensive use is made of hands on activities". The instructor had made the students appreciate science, with comments such as "It is starting to bring together all the science courses I've taken", "This has reaffirmed my love of science", "Yes. I love science and enjoy doing it", and "This course will help me teach because various teaching methods have been modeled successfully". Clearly, the instructor has motivated students' desire to learn (impact on learning).

One student expressed frustration with the technology as s/he experienced difficulty in downloading material. Students stated that the instructor understood that students have different learning styles and that he is knowledgeable about his subject. The student's comments resonate with the instructor's intentions elaborated in the interview.

\section{Comparison of Conceptions and Practices: Teaching and Learning}

In comparing conceptions and practices, it is necessary to contrast the data from the different sources, as outlined in the previous two sections. Here the conceptions of teaching and learning reflect views across classes, while the practices refer specifically to 
the NOVA class. Table 12 summarizes the properties and associated dimensions for both conceptions and practices of teaching and learning.

Table 12

A Comparison of the Properties and Associated Dimensions of Teaching and Learning that are Espoused and Practiced: Dr. Stevenson

\begin{tabular}{|c|c|c|}
\hline Properties & Conceptions & Practice \\
\hline Teaching goals & $\begin{array}{l}\text { Process orientation, assimilate, } \\
\text { synthesize, apply information, } \\
\text { conceptual growth and change }\end{array}$ & $\begin{array}{l}\text { Process orientation, assimilate, } \\
\text { synthesize, apply information }\end{array}$ \\
\hline Role of instructor & $\begin{array}{l}\text { Facilitator, gives guidance and } \\
\text { directions }\end{array}$ & $\begin{array}{l}\text { Discussion leader, provides } \\
\text { input as needed }\end{array}$ \\
\hline Teaching strategy & $\begin{array}{l}\text { Internet based, readings, } \\
\text { creating animations, } \\
\text { discussion, Socratic method }\end{array}$ & $\begin{array}{l}\text { Internet tasks, readings, } \\
\text { animations, discussion, written } \\
\text { responses, a little lecture }\end{array}$ \\
\hline View of knowledge & $\begin{array}{l}\text { Tentative nature, active } \\
\text { knowledge creation. }\end{array}$ & Tentative nature \\
\hline Use of knowledge & $\begin{array}{l}\text { Procedural reasoning, critical } \\
\text { thinking }\end{array}$ & $\begin{array}{l}\text { Procedural reasoning, critical } \\
\text { thinking, arguing views }\end{array}$ \\
\hline Source of knowledge & $\begin{array}{l}\text { Student, teacher and Internet } \\
\text { resource collaboration, } \\
\text { scientific progress }\end{array}$ & $\begin{array}{l}\text { Student, teacher and Internet } \\
\text { resource collaboration, } \\
\text { scientific progress }\end{array}$ \\
\hline Selection of content & $\begin{array}{l}\text { Current scientific theories, } \\
\text { student interest }\end{array}$ & $\begin{array}{l}\text { Current scientific theories, } \\
\text { Internet sites listed on the } \\
\text { syllabus }\end{array}$ \\
\hline $\begin{array}{l}\text { Pedagogical } \\
\text { knowledge } \\
\text { development }\end{array}$ & $\begin{array}{l}\text { Personal learning style, } \\
\text { mentors and prior experiences, } \\
\text { reflection }\end{array}$ & Change based on reflection \\
\hline $\begin{array}{l}\text { Sharing teaching } \\
\text { ideas }\end{array}$ & Informally at university & $\begin{array}{l}\text { Informally and LDC } \\
\text { conference }\end{array}$ \\
\hline $\begin{array}{l}\text { Teaching } \\
\text { effectiveness }\end{array}$ & $\begin{array}{l}\text { Student enthusiasm and } \\
\text { participation }\end{array}$ & No evidence \\
\hline $\begin{array}{l}\text { Constraints to } \\
\text { teaching }\end{array}$ & $\begin{array}{l}\text { Class size, university } \\
\text { philosophy }\end{array}$ & No evidence \\
\hline $\begin{array}{l}\text { Factors facilitating } \\
\text { implementation }\end{array}$ & $\begin{array}{l}\text { Support of immediate } \\
\text { administrator, education team } \\
\text { member }\end{array}$ & $\begin{array}{l}\text { Support of immediate } \\
\text { administrator, education team } \\
\text { member }\end{array}$ \\
\hline Learning interaction & $\begin{array}{l}\text { Whole class, individual, } \\
\text { informal }\end{array}$ & $\begin{array}{l}\text { Whole class, individual, } \\
\text { informal }\end{array}$ \\
\hline
\end{tabular}




\begin{tabular}{|l|l|l|}
\hline Properties & Conceptions & Practice \\
\hline Learning control & Student managed, open ended & Student managed, open ended \\
\hline Learning styles & Spatial, kinesthetic & Spatial, kinesthetic, linguistic \\
\hline $\begin{array}{l}\text { Impact on student } \\
\text { learning }\end{array}$ & One part of a larger process & $\begin{array}{l}\text { More positive view of science } \\
\text { and confidence in ability to } \\
\text { teach }\end{array}$ \\
\hline $\begin{array}{l}\text { Constraints to } \\
\text { student learning }\end{array}$ & $\begin{array}{l}\text { Student background } \\
\text { experiences and knowledge }\end{array}$ & $\begin{array}{l}\text { Frustration with technology } \\
\text { (some students) }\end{array}$ \\
\hline $\begin{array}{l}\text { Student } \\
\text { responsibilities }\end{array}$ & $\begin{array}{l}\text { Curiosity, motivation and } \\
\text { participation, completion of } \\
\text { tasks }\end{array}$ & $\begin{array}{l}\text { Completion of assignments } \\
\text { and tasks }\end{array}$ \\
\hline
\end{tabular}

In the categories for which there is data about conceptions as well as practices, there is an overall consistency and coherence between what is stated, and what is done in practice.

Assessment: Conceptions

For Dr. Stevenson the focus of assessment is on student learning. It is a means (purpose) of determining what students are thinking and understanding about processes. "I think their responses indicate to me how they are learning to observe, how to interpret, how to think in more critical terms". It also shows him how their ideas change over time. "What I really hope to find out is how they are integrating the activities we use with their developing understanding AND how that might be different than the way they understood the topic before taking the class".

In assessing students he is not concerned with students merely getting the correct answer (knowledge focus), but with them generating additional questions and leading the class into additional discussion. The number of questions or tasks that can be answered by memorization are kept to a minimum. 
Dr. Stevenson described his assessment strategies as "somewhat informal and perhaps non-traditional". He has a dislike for traditional exams, but feels compelled to implement them because it is university policy, and he feels bound to comply. However, the final exam is non-traditional in nature, with the students completing a confidential online course assessment. "There is some opportunity to assess the nature of the course itself and for the student to express their personal thoughts about it" and so, the purpose is to determine what students gained from participation in the class.

He is resistant to allocating grades in the traditional way (grading implementation). A preferred method is through informal discussions with students to establish what they are learning and how they are beginning to think about the subject and the different processes being observed. "In my view, assessment is an ongoing process in my class". Weekly written assignments are also an important component although he considers the word assignment "a bit of a misnomer, because the main part of the assignment is for the students to prepare animations and describe their observations". For the final written assignment the students compose a poem and perform it to the group in "slam poetry style".

This instructor states that he provides feedback to students in writing, but primarily he provides feedback through one-on-one or whole group discussion. Often the feedback is in the form of additional questions designed to challenge their thinking. Assessment data are used to make decisions about how much time to spend on topics. If students have difficulties with a particular section, more time is devoted to it, and "by the same token, if their responses are such that they appear to rapidly comprehend or get bored, we move on". Through informal assessment, he feels that, "I think I come to 
better understand how the student is responding to the instruction in the class". He also uses a pre-test and post-test to ascertain if the students' view of the world and of science have shifted by the end of the semester.

Students are prepared for the assessment tasks (assessment preparation) through the interactions that occur in the class and the dialogue between instructor and students. "They begin to ask questions and attempt to answer them among themselves with direction from me."

Assessment: Practices

The syllabus explicitly states that the purpose of assessment is to "give you practical experience assimilating and synthesizing information" and as a "process whereby you may come to realize the power within yourself and the world around us". Students are expected to gather information from the Internet, report findings and to analyze the data gathered.

The primary strategies used to assess students are the weekly assignments, class participation and attendance, and the final "exam". Writing assignments are the "primary mechanism" for evaluation and include writing and explaining metaphors, creating animated visuals and movies, responses to questions, and short written summaries that explain the work for the week, and "its significant to the subject matter". Weekly assignments constitute $50 \%$ of the semester grade, participation and the poetry slam $25 \%$, and the final exam $25 \%$.

The instructor provides feedback to students individually and through whole group discussions. Because of university protocol, he is required to provide students with 
a grade (grading implementation). Students are prepared for the assessment items through Internet activities and classroom discussions.

The self-survey ratings on the Assessment of Classroom Learning in Science Inventory (ACLSI) for Dr. Stevenson are relatively low overall. The ACLSI assesses the use of a diversity of different strategies and purposes. To score a high score on the different subscales, a teacher would have to be using a variety of different strategies for a range of different purposes. Clearly Dr. Stevenson has a more limited range of assessment strategies, and this is indicated in his description of practices. The highest score $(65.6 \%)$ was on interacting feedback through individual and group discussion and written comments and the next highest $(62 \%)$ on formal questioning techniques. Scores above $35 \%$ are considered "competent" and those above $70 \%$ "proficient" (Burry-Stock, 1995). His self-ratings here are consistent with his description of his practices.

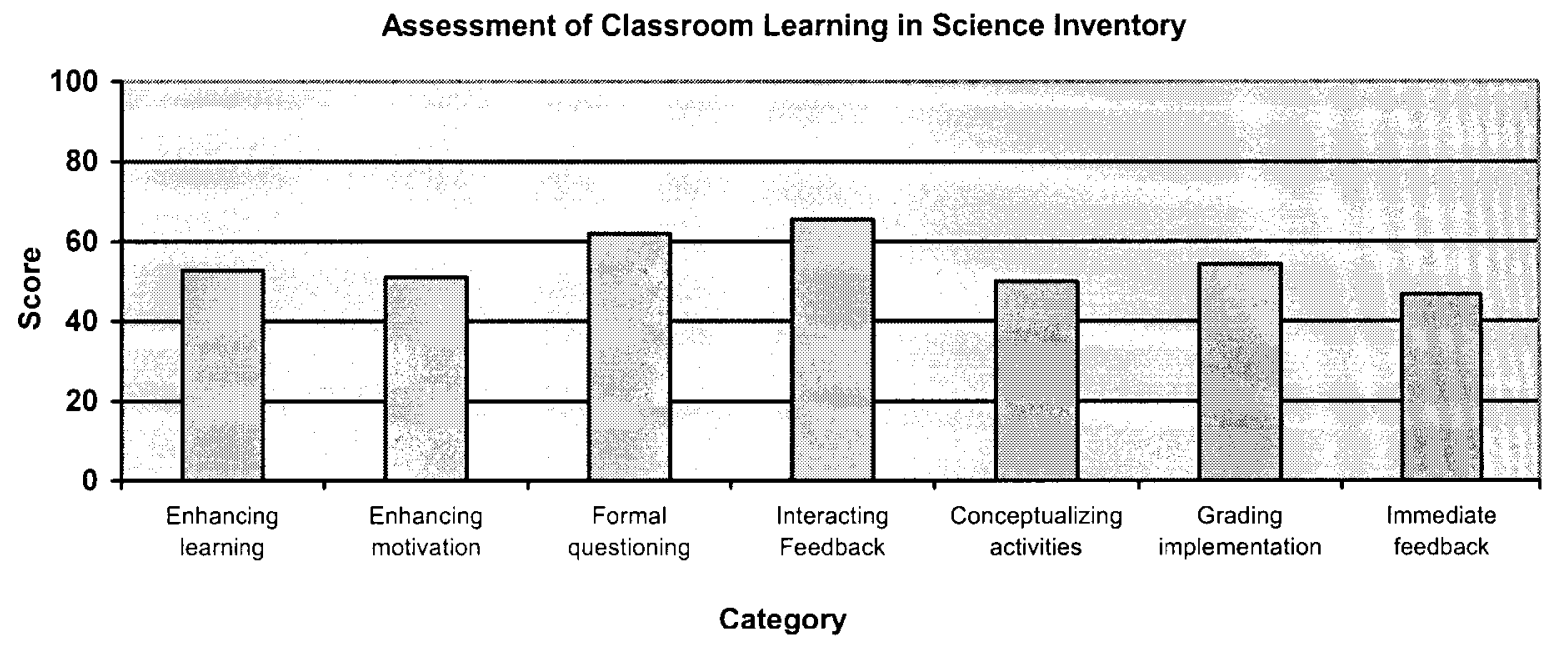

Figure 15. Results of the Assessment of Classroom Learning in Science Inventory for Dr. Stevenson. 
In comparing conceptions and practices, it is necessary to contrast the data from the different sources, as outlined in the previous two sections. Table 13 summarizes the properties and associated dimensions for both conceptions and practices of assessment.

Table 13

A Comparison of the Properties and Associated Dimensions of Assessment that are Espoused and Practiced: Dr. Stevenson

\begin{tabular}{|l|l|l|}
\hline Properties & Conceptions & Practice \\
\hline $\begin{array}{l}\text { Purpose of } \\
\text { assessment }\end{array}$ & $\begin{array}{l}\text { Assess critical thinking, } \\
\text { process understanding, } \\
\text { conceptual growth }\end{array}$ & $\begin{array}{l}\text { Assess assimilation and } \\
\text { synthesis of information }\end{array}$ \\
\hline Strategies & $\begin{array}{l}\text { Informal discussion, weekly } \\
\text { assignments, poetry slam, final } \\
\text { course assessment (exam) }\end{array}$ & $\begin{array}{l}\text { Informal discussion, weekly } \\
\text { assignments, poetry slam, final } \\
\text { course assessment (exam) }\end{array}$ \\
\hline Periodicity & Ongoing, weekly & Ongoing, weekly \\
\hline Interaction feedback & $\begin{array}{l}\text { Oral, individual and group, } \\
\text { challenge thinking, probing } \\
\text { questions }\end{array}$ & Individual and group \\
\hline $\begin{array}{l}\text { Use of data } \\
\text { preparation }\end{array}$ & $\begin{array}{l}\text { Feedback to students, time } \\
\text { allocation to topics, } \\
\text { monitoring progress, assessing } \\
\text { conceptual growth }\end{array}$ & No evidence \\
\hline Knowledge focus & $\begin{array}{l}\text { Conceptual and process } \\
\text { understanding, further inquiry }\end{array}$ & $\begin{array}{l}\text { Conceptual and process } \\
\text { understanding } \\
\text { activities }\end{array}$ \\
\hline $\begin{array}{l}\text { Relationship to } \\
\text { teaching and learning }\end{array}$ & $\begin{array}{l}\text { Monitoring students and time } \\
\text { allocated to particular sections }\end{array}$ & No evidence \\
\hline $\begin{array}{l}\text { Grading } \\
\text { implementation }\end{array}$ & $\begin{array}{l}\text { Resistance to traditional } \\
\text { grading }\end{array}$ & Provides a grade \\
\hline
\end{tabular}

Action research: Conceptions

The process of conceptualizing action research was not easy for Dr. Stevenson and he relied on the education team member to help him learn about the processes involved. "The concept of action research was the most difficult one for me to grasp as I 
became involved in the NOVA program, and I had to rely on my NOVA colleague, Dr. Candy Hatcher, to teach me what it was." It was with assistance from the education team member that a research question was generated. This external support was crucial for the design and implementation of the action research project. Thus, the project was initiated externally.

The purpose of action research is seen as serving the primary purpose of monitoring "students in near-real-time as a means of actively assessing the progress of the course and the how/what the students are learning". A secondary purpose is to provide the instructor with information to modify instructional strategies. "I think it gives me an idea of whether or not the methods I employ in the class are effective, at least effective in the sense that the course accomplishes what I would like it to". He sees action research as a tool for instructors to evaluate their own teaching effectiveness and student's learning strategies. "One could hope to find common or generalizable principles regarding the interaction between teaching and learning".

The focus of the action research project was on students' general knowledge base, perceptions of science, perceptions on earth systems science, and perceptions of pedagogies employed in the class. The focus emerged through discussions with the education team member "regarding the way she thought courses should be taught and students should learn and my impressions about how students viewed science and what they perceived they knew versus what I perceived they knew". The instructor was satisfied with the focus and intended to continue with this research, although he stated he had not "given a great deal of thought to it at this point", but might add other elements later. He plans to continue the action research on his course as long as he teaches it 
(iteration). He notes it is conceivable to use it in other contexts, saying "I suppose one could use it in every course at every level".

Dr. Stevenson sees action research as being essentially qualitative in nature and design, with a desire to quantify these qualitative dimensions and to be empirical, although it "doesn't have an obvious foundation in established "laws" or governed "laws". It is less "discrete" than the usual scientific research he undertakes on physical processes.

Students are the main objects of inquiry and it is important to gather initial data as a base line, and then to compare these to results at the end of the course. A pre-test post-test method was considered the most effective. While his orientation is essentially quantitative, he does acknowledge that "I am not a dispassionate or completely objective observer - I am actually part of the experiment and my behavior clearly influences the outcome to some extent". However, he is unsure what the results mean because they are not "statistical in nature". This is contradictory to the notion of action research as being essentially qualitative in its design, with a subjective observer being part of the process. The technical interest associated with action research (Carr \& Kemmis, 1986) is concerned with improving efficiency and effectiveness in educational practice by gathering empirical data to test hypotheses and make generalizations (see chapter 2, page 76). This is reflected in Dr. Stevenson's description of the action research project where the focus of the research was on gathering baseline and post-test data using quantitative methods. Thus, the interest reflected in his description is essentially technical in nature. In recognizing that action research is qualitative and also more subjective, there is an element of the practical interest emerging. 
Reflection on the action research process has helped him to evaluate his own teaching and to establish if the methods he uses in class are effective. This reflective process is largely autobiographical, with Dr. Stevenson reflecting on his own approach to teaching. "I have become curious about the results, and I want to obtain enough information to see if what I do in this course really makes a difference". So, while the objects of research were the students, his reflections on the results have helped him consider his impact on students. "In a classroom setting, the learning environment is a complex system with many feedbacks - students respond to instruction or activities emanating from the instructor".

Primarily the results of the action research are used to evaluate the teaching process, and because generally results are positive, Dr. Stevenson is unsure what to change. "I'm not sure what I would do differently at this stage. We are dealing with a relatively small sample size (about 30 students over two years), so I am not convinced our results are "real" in the statistical sense at this point". Thus, he plans to continue to gather the same data from different cohorts using the same instruments (iteration).

He has also shared his findings (sharing teaching ideas) at NOVA LDCs and several national meetings, but feels less disposed to do so with his colleagues at his university because he feels the results are not yet conclusive. He thinks it would be difficult to "emulate" his course in the university and adds that, "I may be overly pessimistic about that". Action research: Practices

The proposal describes the purpose of the action research project as being to establish a baseline of information about student "areas of expertise, areas of weakness, and general level of expertise with respect to the ESS course topics". This data would serve 
as both diagnostic data to help guide the instructor's delivery or content, and as a pre test for evaluation purposes. The project was conceptualized together with the education faculty member and likely reflected her ideas in the design.

As described in the action research presentation summary, the research examined the following null hypotheses using a pre and post test research design: "(1) Attitudes, perceptions, knowledge of science education majors are no different than those of the general student populations"; and (2) "attitudes, perceptions, knowledge of science and scientific methods among students are not altered as a result of completing this course" (focus). From the Powerpoint presentation made at the LDC, the overall conclusions from the research are that (a) at the outset of the course, students express similar attitudes, perceptions, knowledge of science irrespective of discipline, and (b) as the course progresses, students' attitudes, perceptions, knowledge of science changed towards a more process-based orientation. Quantitative data are presented for each of these aspects. This quantitative approach reflects a technical interest with an objective knowledge orientation.

In summary, the star diagram (Rearick \& Feldman, 1999) in Figure 16 shows that the primary foci of the action research conceptions and practices reflect a technical interest, autobiographical reflection, and personal purposes. 


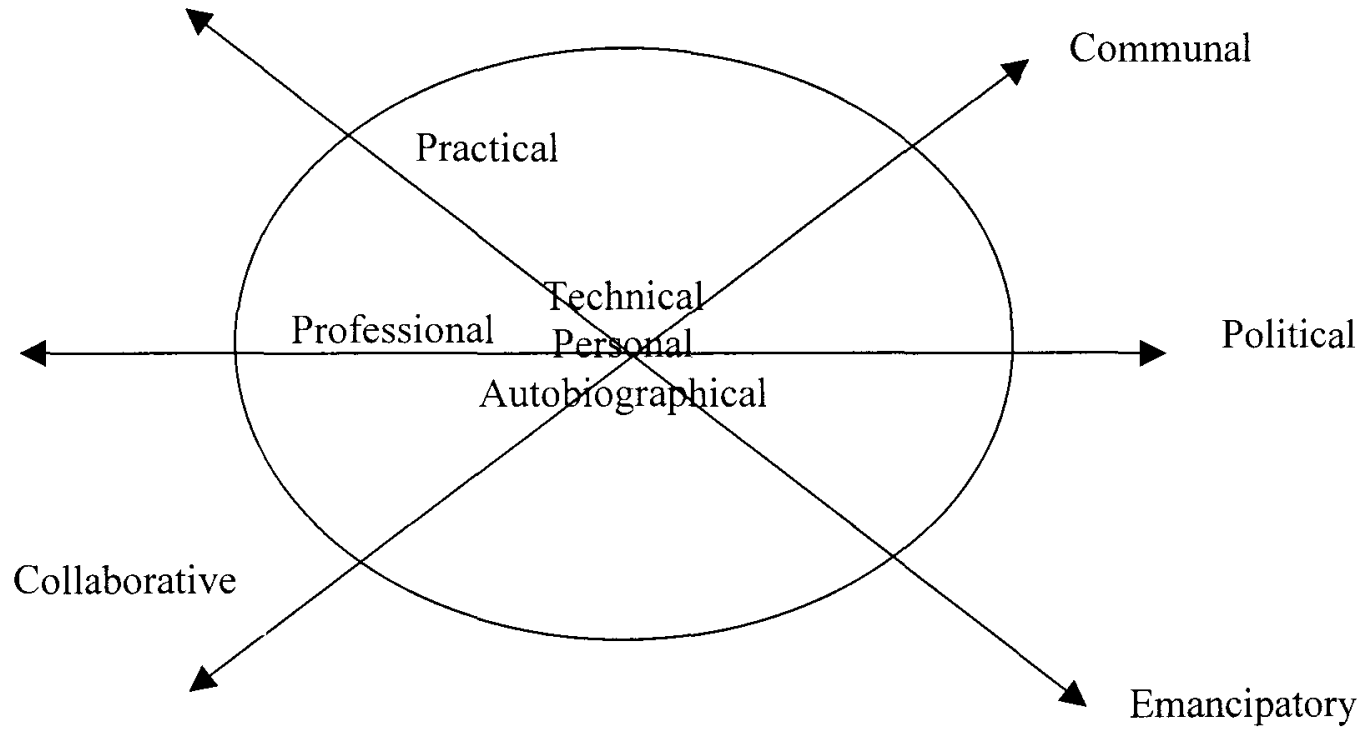

Figure 16. Star Diagram for Action Research Practices of Dr. Stevenson

Comparison of Conceptions and Practices: Action Research

In comparing conceptions and practices, it is necessary to contrast the data from the different sources. Table 14 summarizes the properties and associated dimensions for both conceptions and practices of action research. 
Table 14

A Comparison of the Properties and Associated Dimensions of Action Research that are Espoused and Practiced: Dr. Stevenson

\begin{tabular}{|c|c|c|}
\hline Properties & Conceptions & Practice \\
\hline $\begin{array}{l}\text { Conceptualization } \\
\text { and support }\end{array}$ & Externally conceived and driven & $\begin{array}{l}\text { External with education team } \\
\text { member }\end{array}$ \\
\hline Focus & $\begin{array}{l}\text { Students' knowledge and } \\
\text { perceptions, improving teaching }\end{array}$ & $\begin{array}{l}\text { Students' knowledge and } \\
\text { perceptions }\end{array}$ \\
\hline Research design & $\begin{array}{l}\text { Quantifying the qualitative } \\
\text { dimensions of teaching and } \\
\text { learning }\end{array}$ & $\begin{array}{l}\text { Quantitative, pre test and post } \\
\text { test }\end{array}$ \\
\hline Instrumentation & Self designed survey & Self designed survey \\
\hline $\begin{array}{l}\text { Knowledge } \\
\text { orientation }\end{array}$ & $\begin{array}{l}\text { Subjective but with a desire for } \\
\text { objectivity }\end{array}$ & Objective, statistical \\
\hline Interest & Technical, practical & Technical \\
\hline Purpose & $\begin{array}{l}\text { Personal purposes, monitor } \\
\text { students, improve instruction, } \\
\text { personal growth }\end{array}$ & $\begin{array}{l}\text { Personal purposes, monitor } \\
\text { student changes }\end{array}$ \\
\hline Reflection & Autobiographical & Autobiographical \\
\hline Use of results & $\begin{array}{l}\text { Share results, self evaluation, } \\
\text { change instruction }\end{array}$ & $\begin{array}{l}\text { Share results, self evaluation, } \\
\text { limited change }\end{array}$ \\
\hline Iteration & $\begin{array}{l}\text { Continue same focus in } \\
\text { successive courses }\end{array}$ & $\begin{array}{l}\text { Continue same focus in } \\
\text { successive courses }\end{array}$ \\
\hline
\end{tabular}

There appears to be some contradiction between the expression (conception) of a qualitative design and subjective knowledge orientation for action research, and the actual practice of the research, which is essentially quantitative and objective. Dr. Stevenson recognizes that research on teaching is more qualitative in nature, but in designing the study has not reflected this in the actual implementation. The focus of the research was entirely on the learners and not the teacher or the teaching process, as was noted as possibilities in his description of the purposes of action research.

In his member check of the case study narrative Dr. Stevenson noted that "in particular, I think you very accurately portray the conflict regarding my perception of 
action research as subjective and qualitative, against my research training as an object/quantitative scientist" and added that "I especially like that portion of the case study, and appreciate that you have recognized it".

\section{Conclusion}

Dr. Stevenson holds a subjective view of teaching and learning, and assessment and his views are consistent with his practices. The metaphor that characterizes this instructor's views is 'teacher as facilitator and guide, students as processors of new ideas'. However, his conceptions of action research are more objective, and thus inconsistent with the other views and practices. Additionally, his self-ratings of conceptual change practices were not supported by interview and other data.

\section{Todd Andrews}

This case and the next case were selected to represent a team taught approach, with two professors teaching the class. Also, it reflects a quantitative approach to action research, which focused on teaching rather than student learning.

Dr. Andrews team teaches an integrated science education course together with Dr. Rogers. There is a two-semester sequence of 4 credit hours each semester, with cohorts of students going through both semesters in sequence. Two credit hours each semester are allocated to the natural science component (including physical, chemical, biological and environmental science) and two credit hours to the education component (teaching science). Each year the course revolves around a new theme. In the first year the theme was invasive species, in the second year it was whales, and for the third year it will be turtles. Science and education 'content' are integrated across these themes. The 
course is described as being problem-based with field components, and is standardsdriven.

There are two required textbooks for the course. Class meets twice a week for three-hour sessions. One session meets in a science laboratory and the other in a computer laboratory. Technically, each instructor is only responsible for two credit hours each, that is, one class session per week, but because it is an integrated course, they need to be involved in all sessions. This means that each semester each professor ends up with an overload of 2 credit hours and this is not recognized as part of their teaching load.

\section{Teaching and learning: Conceptions}

Dr. Andrews expressed three goals for teaching: (a) to teach the processes of science, or the scientific methods over "science merely as a collection of facts", (b) for students to "understand the value of the knowledge they have, or that they are gaining", and (c) to teach "the content, the actual content itself" because they need to know certain scientific concepts and principles (view of knowledge). Over the last four years, his goal has shifted away from just disseminating content knowledge to where he now sees himself as modeling behaviors for students and trying to help students see the longer term value of their education. However, moving away from just teaching content has been difficult for him, with him saying that "for a lot of the course [NOVA course] I felt inefficient, and um, students weren't learning as much content as they, as they could".

He sees the role of the instructor as providing directions for student learning, clarifying things that students do not comprehend and creating a supportive learning environment, thereby motivating student engagement. Sometimes the instructor's role is "to simply provide them with information that they couldn't get on their own, or would 
have a difficult time acquiring". A good instructor is seen as one who is able to place himself or herself in the position of the learner, and to realize that "not all people learn the same way". He also sees the teacher as a learner, saying that, "we're learning things as well".

Preferred teaching strategies include open-ended questioning and classroom discussion. "I do some lecturing, but the bulk of my lecturing or my class discussions revolve around questions." He likes to ask "question after question" to keep students involved in the class (learning interaction). Students are expected to use knowledge they have acquired to answer questions and challenge their own thinking about topics.

Dr. Andrews states that he often poses a series of questions for students so that they can research the answers themselves in the computer laboratory and then prepare a few Powerpoint slides with the answers to present to the class. "I make it pretty clear that, that I'm expecting them to learn certain things but that I'm not gonna stand up and talk about them. You know, that's the reason why they have a text book." These research tasks often involve group work, and he feels that he must explain why he is assigning such tasks, because they are more time consuming than if he just lectured. "I feel like I have to explain why I'm doing that because, its, they look at it as being inefficient. Ah, because we could have done that so much more quickly if I had just told them the answers to these questions".

He likes to give guided instruction at the beginning of a topic, providing students with clear examples and directions for tasks they are required to complete. For upper division courses he sometimes sets written research assignments. Thus, he sees the 
source of knowledge as beyond just himself and the textbook, and the control of learning is shifting towards the learners, at least in the upper level classes.

Dr. Andrews describes a strong tension between the need to cover course content and the need to teach students how to access information. When he first started teaching the NOVA class he was very unhappy about the pace of the class because he wanted to provide more content input (view of knowledge), and said it was "a major problem for me throughout the course". But, with time, he has come to accept that "they don't have to learn everything about science in this one class". "They are going to be teaching small kids, you would think that, that, that the concepts are not so technical that they can learn sort of on an as you need it basis." He is satisfied now that it is important for students to learn the process of "inquiry" and inquiry teaching, which he equates with the scientific method.

Content of courses is selected on the basis of what he thinks students need to know to graduate, "I tend to pick and choose what I think are, the, the fundamental concepts, the things they absolutely are going to need to know when they graduate". Then he focuses on "making sure that they understand those core concepts" and will reemphasize them several times during the class because he feels that, like himself, some students need "repetition" to learn new material. To decide what core content he should include, he talks to others who have taught the course before, consults textbooks "because you assume the people who wrote those textbooks have a history of experienced teaching", and considers how it was taught to him when he was a student. If there is time he will add in additional material or "develop something more in depth". Finally, if it is 
"an experimental course, or you know something that's not typically taught, then, then you let yourself be creative and you decide what you think is important and you do it".

Dr. Andrews has developed his pedagogical knowledge on-the-job, noting that he does not have any formal training in education. His first approach to teaching was to deliver as much content as possible because "my experiences showed me that, that in a class you have a textbook and you're going to cover as much of that textbook as you can within the limits of the time that you have in the class". Thus, he sees his personal experiences as an obstacle because "we may choose to teach in a certain way based on the experiences we've had as learners", although at the same time "we may choose to teach differently because of those experiences". While at first he saw his goal as to "convey the content I know, the content that I learned ah, in school", he concedes that over the last four and a half years, the importance of content has "become less".

He acknowledges that working with the NOVA education team member has been enormously beneficial to him as his "intense education in, in ways of teaching, concepts, theories and ideas about teaching. Um, this is my training". As a consequence he is willing to try new ideas and to "experiment" with his teaching in other classes because he has "bought into it to a large degree". He states that he now realizes that he does not have to "teach them everything in a class" and feels less pressure to cover the breadth of content because that is often done at the expense of depth of understanding. "I have changed my philosophy as far as that goes." He is clearly a professor in transition, recognizing that he "hasn't touched the potential of what I can do" and thinks that he is becoming more successful every year that he teaches, but notes that there are always areas that need improvement. "I think in some courses I'm getting much better, and some 
courses I am not getting better". He added that the tenure process has not been particularly valuable in assisting him to become a better teacher.

He primarily shares his teaching ideas informally with other faculty in the university. He also presented the action research results to the NOVA leadership development conference, but was not happy about the experience (see section on action research). Dr. Andrews is keen to learn more about teaching and learning, "and that's something that I have decided that I really want to do more of'. He plans to attend workshops on teaching and to network with other professors, "whose primary mission is teaching, is teaching or pedagogy". He noted that his university does not have a center for teaching and learning to assist faculty with these issues.

To establish if he has been effective in teaching he uses both formal and informal data from the students. Formal information comes from student's exams and tests, "you know when I assess them, how well they did on the assessment", and from class discussions showing that students have understood a topic. Informal data includes the fact that he has a high attendance rate even though he does not have required attendance, that students are attentive and ask questions in class, and "when I have students who come to me and they are excited about something, or they are thinking beyond what we talked about in class, the application of something, then I am successful". He hopes that students would want to take other classes with him after their first experience, that they see him as enthusiastic and as someone who "really enjoys what he was doing".

General constraints to him being effective include teaching 12 credit hours each semester, carrying an overload because of team teaching on the NOVA course, the fact that he does not teach the laboratory sections associated with his other courses, and the 
many other administrative duties at the university. So, time is his main limiting factor. Factors that have facilitated the implementation of the course include the interdisciplinary nature of the courses, and the team-taught dimension.

Dr. Andrews believes that both the teacher and the learner act in reciprocal roles at times, saying, "I think the roles flip flop, we change our roles back and forth". He is excited about being able to learn with the students. "One of the great things of being a teacher for me, it's the learning side of it". He believes that his teaching has an impact on students and that "if I didn't think it had an effect, then I would never change. I'd do what was easiest". So, because he is concerned to make sure that students do learn from and with him, he reflects on his teaching strategies and makes changes accordingly.

Poor student background in science was cited as one of the constraints to teaching the education majors. Associated with this is student anxiety about the content because "there is so much that they think they don't know". These are the only two science classes that the elementary majors will take at the university, so it is impossible to provide the full compliment of content knowledge they will eventually end up teaching. However, because they are education majors, he believes that it is equally important to teach them how to teach at the elementary grade level. In order to deal with this it is important for instructors to recognize that different students have different learning styles, because there are different "ways of knowing or ways of learning for students, that not all students learn the same way". He conceded that some learners are more visual, while others are more aural learners.

In the teaching and learning situation, Dr. Andrews feels that students should be responsible for their own learning and to "put themselves in the best position to learn 
and to um, to motivate themselves". He wants them "to be disciplined, to be inquisitive and you know, and they need to be willing to work hard". This involves being organized and willing to engage in and be excited about learning.

On the self-report STEBI B, Dr. Andrews scored (a) 53 (out of 70) on the personal science teaching efficacy subscale, and (b) 42 (out of 55) on the science teaching outcome expectancy subscale. While his personal science teaching efficacy is relatively low, his teaching outcome expectancy is fairly high, indicating that he is more confident in his ability to impact student learning than he is about his teaching capabilities. This was reflected in his interview, where he is still grappling with deciding on his own instructional approaches.

On the Approaches to Teaching Inventory (ATI) Dr. Andrews reports himself as having a strong conceptual change focus and student focused orientation (see Figure 17). He considers himself much less concerned with information transmission and less teacher focused. This is consistent with the interview data already presented, where his concern has shifted away from just disseminating information, to engaging students in performance tasks to demonstrate competence. He has developed a concern that students demonstrate their own understanding. Evidence from the interview also supports the student-focused categorization, where he sees himself more as an organizer of a facilitative learning environment.

While he sees himself as being concerned with conceptual change, there is less evidence for this from the interview data. He mentions that it is important to find out student's alternative conceptions or misconceptions, but does not state how he might work with these to effect conceptual change. Essentially, the teaching strategies and goals are 
oriented to enhancing understanding through discussion and hands-on activities. So, while conceptual change may be a goal, there is less evidence to support this in practice.

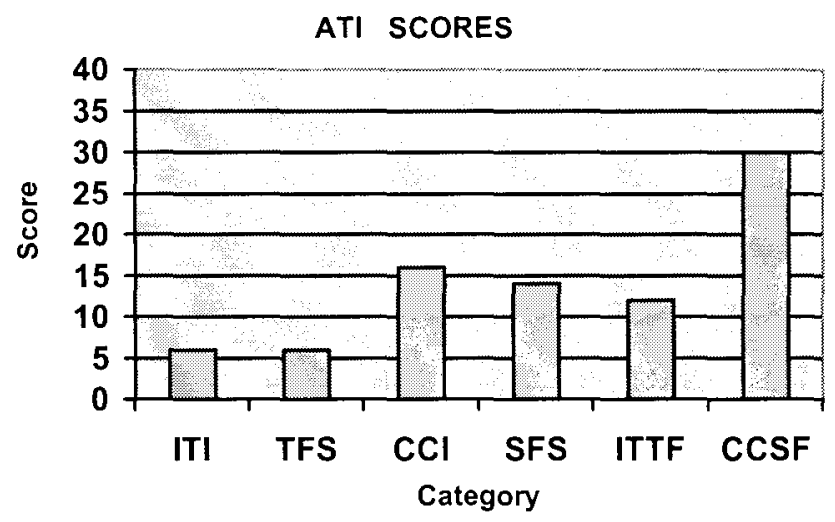

Figure 17. ATI Scores for Dr. Andrews
ITI $=$ Information transmission intention

TFS $=$ teacher focused strategy

$\mathrm{CCI}=$ conceptual change intention

$\mathrm{SFS}=$ student focused strategy

ITTF $=$ information transmission and teacher focused

$\mathrm{CCSF}=$ conceptual change and student focused

\section{Teaching and Learning: Practices}

The goals for the course described in the syllabus are for students to (a) be prepared to teach representative K-6 science content, (b) gain confidence in teaching science, (c) be engaged in standards-based science experiences, (d) engage in research that is field based, authentic and open-ended, and (e) be engaged in effective practices for science instruction. Because students in the NOVA program will be future teachers, an important goal is teaching them "why inquiry is important", so that they will be encouraged to use the processes with their future students. Students described the goals for the course as being to (a) get them to think critically, and (b) to learn both the science and how to teach it. They see the role of the instructor as, "the teacher is a guide, helping the student to learn without telling, but making sure they get something out of it".

Content is drawn from across disciplines and the course is "designed to offer a broad science content knowledge base and to encourage positive attitudes towards science and science teaching", with an emphasis on "inquiry-based learning through 
active participation in environmental research" (view of knowledge). Each year a new theme is found for the course, and these arise on the basis of opportunities that present themselves.

Through participation in original research projects, students are generators of new knowledge (use of knowledge). Students stated that they felt differently and more positively about science because of the way the course was taught through an inquiry based approach. "It shows ways and activities to teach, but also that it's not difficult to gain knowledge to use in the classroom or to learn by themselves" (impact on student learning). They recognized that the course was different to most other courses they had taken and was the first course in which they were required to discover on their own and even challenge the professors. Some students did find this frustrating because it was new to them and they were not always sure what was expected.

The NOVA course is described by Dr. Andrews as being "inquiry-based" by which he means that students engage in conducting investigations and original research in small groups (methods). For instance in the first year some students conducted experiments on the foraging behavior of certain snails, or did descriptive studies on the location of alien invasive species. At the end of the semester students presented the results of their work orally or in poster format.

There is very little direct instruction, "in fact, there's almost no lecture in the class", with students instead typically working on performance-based projects throughout the semester. Another term used was "problem-based" by which Dr. Andrews means that "it involves open ended questions, there are themes to the class. There is a good bit of research, particularly this year we have some main themes, or issues that we are dealing 
with". This year it has involved allocating different ecosystems to groups of students to research. In each group there is a biologist, a chemist, a geologist and a physicist and students must become "expert" on their particular aspect of the ecosystem. The group makes Powerpoint presentations at the end of the semester.

Another activity is the development of a science kit, where students develop a kit and accompanying curriculum materials. During the first semester, students worked through an environmental kit that was locally manufactured, then in the second semester they had to produce a similar one focusing on the theme of the year. Dr. Andrews did not feel satisfied with this process because students were given so much freedom and he would have preferred if the instructors had guided them more. In future he says, "I would probably push for at least one lesson on curriculum development, the formal, the formality of developing a curriculum, so that they, so that they sort of knew where it was going". Because students were uncertain about the outcomes of the process, he felt there was a lot of anxiety and that students became de-motivated. And so, he may have "done it a bit differently" by giving more direct instructions for how to proceed. Other projects include the construction of a WebQuest and keeping a reflective journal. Clearly, students are expected to use the knowledge they have gained to create new products that demonstrate their understanding. The methods of instruction being used are promoting kinesthetic, interpersonal and intrapersonal learning styles. While students are also expected to read text material (linguistic learning style), it is not clear how these are integrated into the course. Using this method of instruction, the role of the instructor becomes that of organizer and creator of an environment in which students can learn, although he would still prefer to provide more directions and clarity on tasks. 
Using the Esteem observation instrument Dr. Andrews, together with Dr.

Williams, were rated by one of the NOVA research fellows and the results are presented in Figure 18. This observation included four student groups of three students per group presenting on their selected ecosystem. Each student evaluated the presentation for the other groups. Each group had a "specialist" in geology, physics, biology, and chemistry who had to instruct the rest of the class on the specialty of the ecosystem.

\section{ESTEEM Observation Scores}

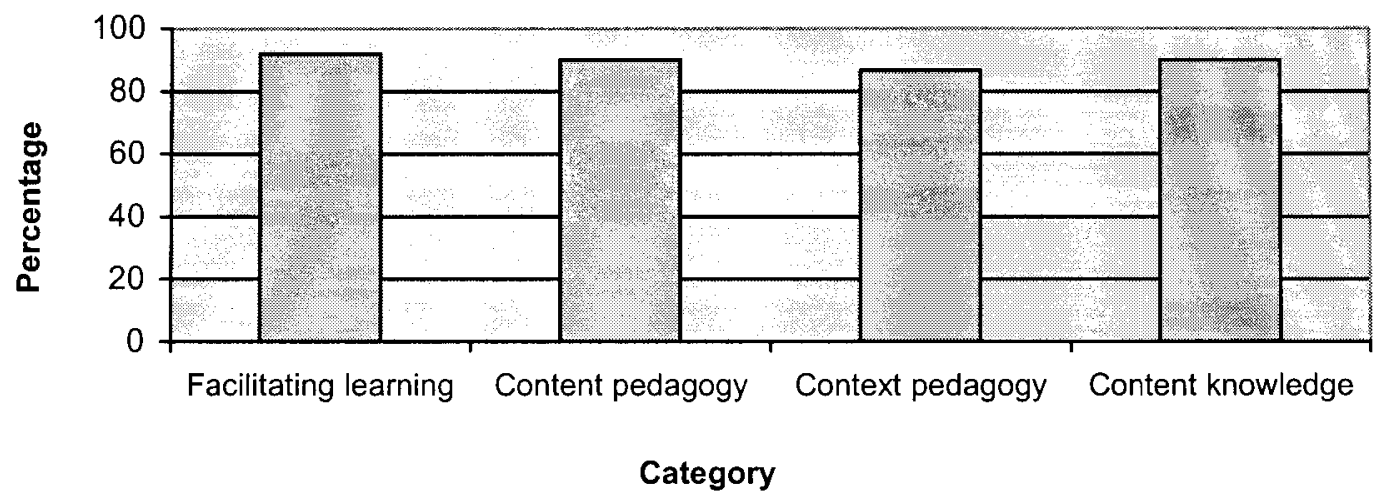

Figure 18. Results of the Esteem Observation Instrument for Dr. Andrews.

In this instance the implementation of the whole class instruction, rather than individual instructors, was rated. They scored more than $85 \%$ on all categories, with scores of greater than $85 \%$ considered "expert" (Burry-Stock, 1995). For facilitating learning (motivating learners, student engagement in activities and experiences) (role of instructor) they scored a $92 \%$, for content pedagogy the score was $90 \%$ (use of different teaching methods, higher order thinking skills, promoting conceptual understanding and integration of content and processes), for context pedagogy they scored $86.7 \%$ (fluid control of teacher and student interactions), and for content knowledge they scored $90 \%$ 
(use of exemplars, balance between depth and comprehensiveness, coherence of science experiences, and accuracy of content).

The administration has been supportive of the new course, allowing for block scheduling and team teaching by the two professors (factors facilitating implementation). However, one administrator noted that, "it might not have happened without outside support and recognition".

Comparison of Conceptions and Practices: Teaching and Learning

In comparing conceptions and practices, it is necessary to contrast the data from the different sources, as outlined in the previous two sections. Here the conceptions of teaching and learning reflect views across classes, while the practices refer specifically to the NOVA class. Table 15 summarizes the properties and associated dimensions for both conceptions and practices of teaching and learning. 
Table 15

A Comparison of the Properties and Associated Dimensions of Teaching and Learning that are Espoused and Practiced: Dr. Andrews

\begin{tabular}{|c|c|c|}
\hline Properties & Conceptions & Practice \\
\hline Teaching goals & $\begin{array}{l}\text { Learn processes of science, } \\
\text { the value of knowledge, } \\
\text { content, learning how to } \\
\text { teach }\end{array}$ & $\begin{array}{l}\text { Learn basic content, how to } \\
\text { teach using a standards- } \\
\text { based approach, gain } \\
\text { confidence, conduct research }\end{array}$ \\
\hline Role of instructor & $\begin{array}{l}\text { Give directions, generate and } \\
\text { answer questions, give input }\end{array}$ & $\begin{array}{l}\text { Organizer, creator of } \\
\text { learning environment }\end{array}$ \\
\hline Teaching strategy & $\begin{array}{l}\text { Discussion, question and } \\
\text { answer, research and written } \\
\text { projects }\end{array}$ & $\begin{array}{l}\text { Assigning students } \\
\text { performance based tasks }\end{array}$ \\
\hline View of knowledge & $\begin{array}{l}\text { Content, concepts, scientific } \\
\text { method and processes }\end{array}$ & $\begin{array}{l}\text { Integrated across disciplines, } \\
\text { scientific method and } \\
\text { processes, student created }\end{array}$ \\
\hline Use of knowledge & Answering questions & $\begin{array}{l}\text { Create new products, } \\
\text { application to performance } \\
\text { tasks }\end{array}$ \\
\hline $\begin{array}{l}\text { Source of } \\
\text { knowledge }\end{array}$ & $\begin{array}{l}\text { Outside resources, textbook, } \\
\text { instructor }\end{array}$ & $\begin{array}{l}\text { Students, outside resources, } \\
\text { textbook, instructor }\end{array}$ \\
\hline Selection of content & Core concepts in the topic & $\begin{array}{l}\text { Thematic, integrated across } \\
\text { disciplines }\end{array}$ \\
\hline $\begin{array}{l}\text { Pedagogical } \\
\text { knowledge } \\
\text { development }\end{array}$ & $\begin{array}{l}\text { On-the-job, involvement } \\
\text { with NOVA team member }\end{array}$ & No evidence \\
\hline $\begin{array}{l}\text { Sharing teaching } \\
\text { ideas }\end{array}$ & $\begin{array}{l}\text { Informal, moving towards } \\
\text { formal }\end{array}$ & Informal and formal \\
\hline $\begin{array}{l}\text { Teaching } \\
\text { effectiveness }\end{array}$ & $\begin{array}{l}\text { Formal test data and informal } \\
\text { information from students }\end{array}$ & $\begin{array}{l}\text { Formal test data and informal } \\
\text { information from students }\end{array}$ \\
\hline $\begin{array}{l}\text { Constraints to } \\
\text { teaching }\end{array}$ & Time and teaching loads & No evidence \\
\hline $\begin{array}{l}\text { Factors facilitating } \\
\text { implementation }\end{array}$ & Interdisciplinary, team taught & $\begin{array}{l}\text { Administrative support for } \\
\text { block scheduling and team } \\
\text { teaching, NASA support }\end{array}$ \\
\hline $\begin{array}{l}\text { Learning } \\
\text { interaction }\end{array}$ & $\begin{array}{l}\text { Teacher initiated discussions, } \\
\text { question and answer }\end{array}$ & $\begin{array}{l}\text { Two way process, students } \\
\text { initiating new ideas }\end{array}$ \\
\hline Learning control & $\begin{array}{l}\text { Teacher initiated, shifting } \\
\text { towards learners }\end{array}$ & Student controlled \\
\hline
\end{tabular}


Table 15 (continued)

\begin{tabular}{|l|l|l|}
\hline Properties & Conceptions & Practice \\
\hline Learning styles & $\begin{array}{l}\text { Students learn in different } \\
\text { ways, including visual and } \\
\text { aural }\end{array}$ & $\begin{array}{l}\text { Kinesthetic, intrapersonal, } \\
\text { interpersonal }\end{array}$ \\
\hline $\begin{array}{l}\text { Impact on student } \\
\text { learning }\end{array}$ & $\begin{array}{l}\text { Teacher and student learn } \\
\text { from each other }\end{array}$ & $\begin{array}{l}\text { More positive view of } \\
\text { science and confidence in } \\
\text { ability to teach }\end{array}$ \\
\hline $\begin{array}{l}\text { Constraints to } \\
\text { student learning }\end{array}$ & $\begin{array}{l}\text { Student background } \\
\text { knowledge }\end{array}$ & $\begin{array}{l}\text { Uncertainty about new } \\
\text { approach and expectations }\end{array}$ \\
\hline $\begin{array}{l}\text { Student } \\
\text { responsibilities }\end{array}$ & $\begin{array}{l}\text { Self motivated, organized } \\
\text { and hard working }\end{array}$ & $\begin{array}{l}\text { Participate in groups, ask } \\
\text { questions, make and present } \\
\text { products }\end{array}$ \\
\hline
\end{tabular}

Dr. Andrews has grappled with the tension between providing content knowledge and allowing students to engage in inquiry based learning and other tasks where they must demonstrate their ability to apply knowledge and generate new products. He has clearly shifted his position away from just wanting to provide students with the facts, but is still grappling with how to align his views with some of the practices in the NOVA course. Particularly, he is finding it hard to resolve the conflict between providing content knowledge and engaging students in inquiry-based learning and tasks where they must demonstrate and apply their knowledge. Thus, several of his espoused ideas about teaching and learning are different to the practices in the NOVA course. This means that his practices are influenced by contextual factors that include having another professor team teaching the course with him.

\section{Assessment Conceptions}

Dr. Andrews believes that the purpose of assessing students is (a) to establish "whether you've met your goal and your objectives in your teaching", and (b) "to determine the ah, effectiveness of the learning, student learning". Assessing students 
provides him with a way of finding out what the students understand and have learned or have not learned (knowledge focus). It is also a way for students to demonstrate their competencies, such as making public presentations and conducting investigations.

His preferred methods to assess students include tests, oral exams and written research projects and Powerpoint presentations. He assesses differently based on the course level, saying, "I probably focus more ah, on, on objective testing in the lower levels than I do with the senior levels." In junior and senior classes he tends to use more research and written projects because students are more mature and more motivated to learn. He sees exams as a necessary mechanism to motivate the lower level classes because "they're so indoctrinated into lecture, test, lecture, test, that if you, if they don't have that test waiting for them, then they tend not to be, in some cases, motivated to, to learn, unfortunately". A preferred method is the use of discussion and oral exams "because I think its real, I mean I think it allows for interaction, it allows, ah, it, it, it simulates the way um, people, you function in society, somebody asks you a question and you respond". Time permitting he would use oral exams in all his courses. By holding classroom discussions with students, he feels that he is able to establish where they are on an ongoing basis.

Since being involved in the NOVA course he has started to "buy into the idea of performance assessments" as a way of allowing students to demonstrate "knowledge and learning". However, he has had to grapple with this new method of assessment because it "was something very foreign to me and I didn't and I still don't have a, a comfort level without having something very, very, something that I'm used to, something more objective" (knowledge focus). "When it comes to the assessment, um, that, for me that 
was ah, that was probably one of the biggest challenges to teaching that course, was it was not a traditional way of assessing learning for me. Or at least not, not what I was accustomed to." He was particularly unhappy about the use of journals because they are personal reflective accounts by students and so he feels it is very hard to allocate a grade

\section{(grading implementation).}

By providing feedback to students he hopes that "it'll help identify those areas that they are, that they need to work on, where they don't have the knowledge, they have not learned to the level I would expect them to, and so, they can address that and go back and remedy that." Feedback is done in different ways, depending on the task. There is daily feedback through discussion and question and answer activities. He usually gives group feedback on exams by discussing general problem areas, but also gives individual comments on written tests. There is always the opportunity for individual or small group feedback if students need it. When commenting on journals, these are usually in written form for each individual. During oral exams, he would summarize the discussion at the end, including strengths and weaknesses, and allow students to counter "if they think that their weaknesses are not really their weaknesses, and to demonstrate that they aren't". Providing feedback is an important way to show the students that he cares about their success.

Assessment data provides (use of data) Dr. Andrews with information about the teaching and learning process by (a) helping him to see whether students are participating in the learning process, to identify their preconceptions and misconceptions, and (b) allows him to "recognize whether what I'm doing, whether I am being effective or not". 
However, he does not elaborate how he would use such information, or how assessment is related to teaching and learning.

\section{Assessment Practices}

In the NOVA class, students are "assessed based on their performance on ah, on journals, on projects, on presentations, and less on examinations" (methods). The final assessment for the semester was done by oral interview with each student meeting the two professors together. Dr. Andrews insisted on calling it an oral exam. "I consistently would call it an exam and the students would get, get, start to worry about it and ask questions", but "it certainly was not a real challenging classic exam (laugh) as I think of exams. But anyway". He thinks that because of that he frequently came across as "the bad guy because I would mention the word exam in class" and that "if we could put a blood pressure monitor on them at any time they ever heard the word exam, you could sense ah, anxiety".

In assessing students in the NOVA course, the purpose was to see the extent to which students were providing correct information, how they communicated that to others, and whether they were conducting quality scientific inquiry investigations. Dr. Andrews also noted that they emphasized the reflective side, because "we wanted them to try to extend that to their, either their current teaching or their future teaching".

Throughout his interview he echoed how he had grappled with the performance assessment process because it was not as objective as he would have liked it to be (knowledge focus) and it was not what he was "accustomed to". The education team member established most of the assessment practices and he was left grappling with these new ideas. However, he indicated that he was starting to incorporate more performance 
tasks and group work into his other classes because of his involvement with the NOVA course.

The syllabus outlines the course grading implementation process and methods of assessment for each of the two sequence courses. "Clear expectations, instructions, scoring guides, and due dates (periodicity) are provided for every assignment." These include (a) textbook and related readings, (b) reflective journal/science notebook, reviewed at midterm and end of semester (15), (c) developing a common language about standards (10), (d) kit-based assessment (15), (e) science summit presentation (20), (f) long term/in depth project, due at end of semester (15), and $(\mathrm{g})$ end-of term comprehensive interview/exam (25).

For the second semester course items (a), (b) and (g) remained but the other items were replaced with developing a WebQuest (25), invasive species science kit self assessment (15) and a science poster presentation (20).

In preparing students for assessment, several strategies were used to orient students to the performance expectations. This included a short talk and interactive discussions about qualities of good oral presentations, discussions about the requirements for good research investigations, and providing journal articles about interactive science notebooks and journals. He acknowledges that in preparing students for creating posters, the instructors were less effective in explaining their expectations. In preparing students for developing kits, they were exposed to and used a number of different kits that are used in local schools, and even visited the state center where school science kits are made and refreshed. To prepare students for creating a WebQuest, they were provided with some "guided instruction" and looked at a number of different relevant websites and also 
had sessions to deal with the technology requirements, using FrontPage. Rubrics were also provided for most of these tasks to clarify performance criteria. To prepare for the end of semester interviews, "we spent time, considerable amount of time talking about the kinds of things that we might ask them in the interview". Because of this preparation, he perceived that students had "felt pretty comfortable talking with us".

The self-survey ratings on the Assessment of Classroom Learning in Science Inventory (ACLSI) for Dr. Andrews are relatively low overall. The ACLSI assesses the use of a diversity of different strategies and purposes. To score a high score on the different subscales, a teacher would have to be using a variety of different strategies for a range of different purposes. The interview data shows how Dr. Andrews is grappling with new ideas and prefers a more limited range of assessment strategies, and this is indicated in his description of preferred practices. The highest score he obtained (73\%) was for immediate feedback via observation, oral feedback and hands on activities, then conceptualizing activities (70\%) which includes the use of concept maps, computer projects and lab reports, followed by enhancing motivation (66.7\%) which involves use of portfolios, science fairs, student experiments, class presentations and hands on activities. The lowest stores were for grading implementation (including modeling expectations, providing criteria for assessment, weighting of grades, incentives enhancing learning) $(45.7 \%)$ and for enhancing learning (47.7.\%), which includes the use of diagnostic instruments, communicating and using performance measures, systematic grading procedures and use of tests. Scores above $35 \%$ are considered "competent" and those above 70\% "proficient" (Burry-Stock, 1995). Dr. Andrews's conceptions of assessment seem to be consistent with his practices. 




Figure 19. Results of the Assessment of Classroom Learning in Science Inventory for Dr.

Andrews

Comparison of Conceptions and Practices: Assessment

In comparing conceptions and practices, it is necessary to contrast the data from the different sources, as outlined in the previous two sections. Table 16 summarizes the properties and associated dimensions for both conceptions and practices of assessment. 
Table 16

A Comparison of the Properties and Associated Dimensions of Assessment that are Espoused and Practiced: Dr. Andrews

\begin{tabular}{|c|c|c|}
\hline Properties & Conceptions & Practice \\
\hline $\begin{array}{l}\text { Purpose of } \\
\text { assessment }\end{array}$ & $\begin{array}{l}\text { Assessing student learning, } \\
\text { understanding, motivate } \\
\text { students to study }\end{array}$ & $\begin{array}{l}\text { Assessing student learning, } \\
\text { communication, inquiry } \\
\text { processes, reflection }\end{array}$ \\
\hline Strategies & $\begin{array}{l}\text { Tests, discussion, oral exams, } \\
\text { tests. Shift towards } \\
\text { performance assessments, with } \\
\text { some resistance }\end{array}$ & $\begin{array}{l}\text { Commitment to exams, but } \\
\text { accepting a range of } \\
\text { performance tasks }\end{array}$ \\
\hline Periodicity & $\begin{array}{l}\text { Ongoing discussions, } \\
\text { according to syllabus }\end{array}$ & $\begin{array}{l}\text { Ongoing, according to } \\
\text { syllabus }\end{array}$ \\
\hline Interaction feedback & $\begin{array}{l}\text { Group, small group or } \\
\text { individual, content areas } \\
\text { needing improvement }\end{array}$ & $\begin{array}{l}\text { Group, small group or } \\
\text { individual }\end{array}$ \\
\hline Use of data & $\begin{array}{l}\text { Provides information on } \\
\text { students and methods }\end{array}$ & No evidence \\
\hline $\begin{array}{l}\text { Assessment } \\
\text { preparation }\end{array}$ & $\begin{array}{l}\text { Discussion, provision of } \\
\text { exemplars and performance } \\
\text { criteria }\end{array}$ & $\begin{array}{l}\text { Discussion, provision of } \\
\text { exemplars and performance } \\
\text { criteria }\end{array}$ \\
\hline Knowledge focus & Objective, content oriented & $\begin{array}{l}\text { Objective, content oriented, } \\
\text { beginning to adopt } \\
\text { performance based tasks }\end{array}$ \\
\hline $\begin{array}{l}\text { Relationship to } \\
\text { teaching and learning }\end{array}$ & Not elaborated & No evidence \\
\hline $\begin{array}{l}\text { Grading } \\
\text { implementation }\end{array}$ & $\begin{array}{l}\text { Difficult to grade some tasks } \\
\text { because of subjectivity }\end{array}$ & $\begin{array}{l}\text { Points allocated for different } \\
\text { tasks, as per syllabus }\end{array}$ \\
\hline
\end{tabular}

Dr. Andrews had some difficulties with performance-based assessment because he perceives it to lack objectivity but acknowledged that he was beginning to accept and use performance-based assessment. Initially the assessment strategies used in the NOVA course were not consistent with his preferred methods of assessment and he was working through how to deal with this because there were aspects with which he was still not comfortable. 


\section{Action Research: Conceptions}

Dr. Andrews was introduced to the concept of action research at the NOVA orientation workshop, but felt that he was not ready for it at that point because they had not yet developed the course. So, he did not feel that he really understood action research, or that other colleagues in the university understand or use it. He had a difficult time distinguishing between informal and formal action research saying, "I have some colleagues that are doing it, but don't even realize that they're doing it. I mean they're doing it, they don't realize it has a name." "Well, I don't know its really action research though, because they are not, I don't think they're really asking the question, am I being effective in what I'm doing here. I mean I think they're asking questions like, you know, what has worked, what, what, so far what have you done that you thought that you learned from". He had primarily learned about action research through his discussions with the education team member, Dr. William Rogers (see next case study), but still felt inadequate in understanding its meaning and purpose.

When asked to identify a focus for a future action research project, he was not willing to attempt to arrive at a research focus or question, saying, "You know I don't know. I can't think. I probably could think about it, but right now I don't, I don't know. I don't know that I understand it well enough to feel comfortable to, to think intelligently about it. About how am I doing, I don't want to propose a way I might do it, if I don't even know what I'm talking about." Thus, he would like to participate in a workshop that that would really show him "how action research fits into teaching and learning".

In describing the purpose of action research, he felt that it was to improve instructional practices. "I think it's a way of assessing the effectiveness of an instructor in 
a course". While student learning is an outcome of effective teaching, "its not looking at how well the students are, are learning, per se, but how effective the teacher is in, in student learning". The purpose is personal with some professional intent, but does not consider broader political issues.

He felt information gathered was of little use unless it showed him what he was doing wrong. Data that was positive and supportive of his teaching was not valuable because it did not show him what needed to change. "I mean its, its no value to me, ah, to know if what's, if what I am doing is working." "I focus on anything that's negative and try to figure out why, as opposed to the strengths."

Dr. Andrews was not able to conceive of an action research design for the future because of his lack of understanding of the purpose and process of action research. $\mathrm{He}$ leaned towards a more informal ongoing process (iteration) of "what I am already doing and don't even know its action research", "in an informal way". He felt that it is a process that should be incorporated at different points during the course to gather information on an ongoing basis, rather than just at the end of semester.

One approach would be to sit down with students, possibly in a focus group and ask them a set of "very objective questions" (knowledge focus). "I, in my mind I have this, this huge table of, of these different questions that you could ask too". He also felt that, "having valid instruments and things that you can compare from year to year or from, from person to person, I think those are um, those are probably good."

The interest reflected in his conceptions are essentially practical in nature, because he is concerned to improve practice through reflection on action. However, his 
reflective process is largely autobiographical because it does not seek to engage others, such as students or the person with whom he team teaches, in the process.

In summary, the star diagram (Rearick \& Feldman, 1999) in Figure 20 shows that the primary foci of the action research conceptions reflect practical interest, collaborative reflection, and professional purposes.



Figure 20. Star Diagram for Action Research Practices of Dr. Andrews Action Research: Practices

The focus of the action research project that was undertaken was on students' perceptions of whether the instructors had effectively used inquiry-based methods to teach science, with the purpose of improving instruction in areas where there were weaknesses. Dr. Andrews expressed frustration about the action research project that was undertaken because it had not been conducted in a way that he conceived as being truly valuable. He claimed it was "a sort of one shot thing" (design, iteration). Maybe if you, 
if you ask William this, maybe there was a lot more going on with action research than I recognized." He also did not perceive that any action research was being conducted during the current course, saying, "I don't think we are doing any formal action research". From his perspective the action research project was not an ongoing endeavor.

He remembers that the action research project was only implemented at the end of the semester, when students completed a rubric (instrumentation), to assess the extent to which the instructors had effectively implemented an inquiry approach. He thought that the rubric had been validated by some "experts" and that "if that's what the experts say is the best way to do it, then that's the way to do it".

He could not remember if students had done this at the end of each semester in the course sequence, or only at the end of one of the courses. Essentially he recalls that the student assessments of the course were positive and that there was little they suggested that needed changing. The only negative perception from students (use or results) that he remembers was that they felt that there needed to be more content included into the course, an issue with which he personally had grappled. "I think that, that the, the data suggested that we were very effective in them, them understanding what inquiry was, understanding why an inquiry is a good way of, of, of learning, helping students to learn". The lack of negative comments did not strike him as particularly useful because he preferred to use results to make changes. He noted that he and the other instructor had modified many aspects of the course since its first implementation, "partly based on what worked and didn't work" and also because they had new opportunities each semester to do different things. However, these modifications did not arise from the basis of action research data. 
Each semester the university assesses faculty teaching by implementing a "course assessment program that the administration runs". He sees these course assessments as important to his reflective processes because "we're given copies of all of those evaluations from all of our courses and we have to reflect on those evaluations for professional purposes. "So, I guess I'm doing it anyway, but it's coming, but its not, it's not coming during the class. It's not coming during the course of a class I'm teaching, it's coming post teaching, for the next year basically". Again, reflection is a post hoc experience rather than an ongoing process.

Dr. Andrews has not disseminated any action research findings in his university context. However, he did make a presentation to one of the NOVA Leadership Development Conferences, only because Dr, Rogers's plane was delayed. He was not happy about that situation saying that "I probably should just, should just have bailed out on it, but I went ahead and explained what I could about the action research". He did not feel confident doing so and felt it was "painful for me, and it was just not what I wanted. But, anyway, I did it, I did it and we met our obligation of, of giving it, so. That was it." Clearly, he did not feel comfortable presenting their findings to an audience.

The results presented, which reviewed student ratings of the course on a 4-point Likert scale using the instructional practices rubric, were generally very positive. Eight dimensions were reported on, namely (a) understanding how scientists work, (b) posing scientifically oriented questions, (c) supporting a climate for inquiry, (d) habits of mind associated with science, (e) designing and constructing investigations, (f) posing explanations, (g) comparing explanations with current scientific knowledge and (h) communicating and justifying results. For all items more than $83 \%$ of students scored 
their instructors with either a 3 or 4 ( 4 bring the highest score possible), with $95 \%$ being the highest score, which was for supporting a climate for inquiry.

\section{Comparison of Conceptions and Practices: Action Research}

In comparing conceptions and practices, it is necessary to contrast the data from different sources. Table 17 summarizes the dimensions for both conceptions and practices of action research.

Table 17

A Comparison of the Properties and Associated Dimensions of Action Research that are Espoused and Practiced: Dr. Andrews

\begin{tabular}{|l|l|l|}
\hline Dimension & Conceptions & Practice \\
\hline $\begin{array}{l}\text { Conceptualization } \\
\text { and support }\end{array}$ & $\begin{array}{l}\text { Not clear about process, } \\
\text { relied on education team } \\
\text { member }\end{array}$ & $\begin{array}{l}\text { Education team member } \\
\text { conceptualized project }\end{array}$ \\
\hline Focus & $\begin{array}{l}\text { Teaching effectiveness, not } \\
\text { sure for the future }\end{array}$ & Student perceptions of class \\
\hline Research design & $\begin{array}{l}\text { Ongoing process, informal, } \\
\text { instrumentation for } \\
\text { comparative purposes }\end{array}$ & $\begin{array}{l}\text { Quantitative, end of semester, } \\
\text { formal }\end{array}$ \\
\hline Instrumentation & $\begin{array}{l}\text { Questions, discussions, focus } \\
\text { groups, valid instruments }\end{array}$ & $\begin{array}{l}\text { Inquiry rubric and university } \\
\text { protocols }\end{array}$ \\
\hline $\begin{array}{l}\text { Knowledge } \\
\text { orientation }\end{array}$ & Objective questions & $\begin{array}{l}\text { Processes of science, inquiry } \\
\text { methods }\end{array}$ \\
\hline Interest & Practical & Technical \\
\hline Purpose & $\begin{array}{l}\text { Personal purposes, improve } \\
\text { teaching and student } \\
\text { learning, }\end{array}$ & $\begin{array}{l}\text { Personal and professional } \\
\text { purposes, improve teaching }\end{array}$ \\
\hline Reflection & Autobiographical & Autobiographical \\
\hline Use of results & To make changes to teaching & $\begin{array}{l}\text { Minimal negative comments, } \\
\text { except to increase amount of } \\
\text { content offered }\end{array}$ \\
\hline Iteration & Ongoing process & $\begin{array}{l}\text { Once off event, not part of } \\
\text { current courses }\end{array}$ \\
\hline
\end{tabular}

There are several tensions exhibited between Dr. Andrews's conceptions of action research and the way in which the action research project was actually undertaken. 
Essentially he was not in control of the design of the project and felt disempowered because he did not fully understand the purpose and processes of action research. He still does not feel comfortable with its intention.

\section{Conclusion}

Dr. Andrews is a professor in transition from holding strongly objective views of teaching, learning and assessment focusing on knowledge presentation by the instructor and replication by students, to a view that is still emergent. This means that there are many conflicts between his personal beliefs and the practices in the NOVA courses, including in the implementation of the action research project. He is struggling to marry his own personal learning experiences with some of the ideas that have presented themselves in implementing the NOVA course, but is engaged in experimenting with new ideas as he expands his own personal teaching philosophy and style. He in concerned to engage students in the learning process through discussion and is keen that there is a two-way learning process. The emerging metaphor characterizing this instructor's views is 'teacher and students as journeymen, with teacher as captain, all learning from their experiences together'.

\section{William Rogers}

This case and the last one were selected to represent a team taught approach, with two professors teaching the class. Also, it reflects a quantitative approach to action research, which focused on teaching rather than student learning.

Because the context of both cases is the same course, the course description and details will not be repeated here. 


\section{Teaching and learning: Conceptions}

Dr. Rogers's principle teaching goal is to prepare future elementary school teachers by showing them how to integrate science content with pedagogy. He also hopes to "remove some of those common obstacles to effective ah science teaching, such as fear of science, and ah, the bad personal experiences that many of them have had when they have been learning science". He aims to do this by having them conduct original research because "I think its reasonable to assume that, that if you've done research you're not going to be daunted by, you know providing instruction on a given topic". He also wants to prepare students to use technology in their teaching.

Because he is "really committed to have students explore ideas", the instructor's role is viewed as creating a "framework" for learning. This includes helping students to clarify ideas after they have thought about them, and providing opportunities "that will address those issue and needs I see them having as future teachers". By structuring the learning environment and modeling instruction for students, he is also able to get them to reflect on "why we teach the way we teach". So, metacognitive processes help to make explicit the pedagogical principles underpinning the way the course is run. "It's sort of like a circle of, of this iterative process, where you, you learn about it, you practice it, then you think about what you've produced". His role is to facilitate that discussion

\section{(learning interaction).}

His preferred teaching strategy is for students to be engaged in producing instructional and curriculum materials relating to science content, through a process he calls "guided discovery". Guided discovery is "sort of a process where the teacher or instructor knows where he wants the students to get, but the student is not told what that 
destination is, but is rather guided through some experiences towards that destination" (learning control). He added that, "when I say guided discovery, you know its, its not open inquiry. You know, we have decided what we want to do, but it's going to be their job to figure out, with our help, how to get there" (use of knowledge).

“There is very little of what I'd call, we don't do much teaching in the traditional sense". Typically, a class session starts with a review of "where we are in our program, you know, kind of ah, catching up" and then a new task is set. "It might involve doing ah, a lab. It might involve um, looking at the standards. It might involve sharing work. It might involve curriculum development. It might involve a field trip. So, it is quite a varied array of experiences they have." He stated that he has always been predisposed towards hands-on, activity-based science, where students are able to "play around with their own ideas" (teaching strategy).

Throughout the course students work on performance-based tasks that include doing original research, working in jigsaw groups and making PowerPoint presentations, designing kits and WebQuests. To be successful in accomplishing the tasks assigned, students must be able to integrate science content and pedagogy. The focus is on application. Thus they must be able to integrate "procedural knowledge, content knowledge, and processing knowledge" (view of knowledge). In selecting content for his courses he says that he thinks about the teaching standards, logic of placement of activities, best use of available time, what students will need to know to be certified as teachers. The sources of information should be diverse, including books, local issues, students and the instructors. He feels that the students should be "operating from a knowledge base, and that is what I try to give them. And then, and then they can layer 
their own beliefs and attitudes and experiences on top of that and formulate their own philosophy. However, it won't be just based on opinion, but on some sound pedagogical evidence and research data.

Students are responsible for engaging in their own learning, thinking about what is going on, keeping a thinking notebook of reflections on their own learning. Students must also be able and willing to engage in the learning process and put in time and effort to their own learning. "I think, you know in terms of performances, um it ultimately boils down as, you know are you willing to do the work. And, some are and some aren't."

Dr. Rogers is "committed" to his teaching approach as his "personal philosophy" and says "I have developed sort of a consistency that, um, that I hold myself to". However, he acknowledges that as a schoolteacher, he was more concerned with "the nature of the discipline". "I mean, I had masters degree in biology when I began teaching, so, um, you know, my, my first inclination was to, you know, create little, little biologists". He tried particularly hard to make the subject matter easier for students to understand, saying that "I know that I spent um, my entire career attempting to be, to be more clear and more linear and more logical in my presentations, so that I could take what was extremely clear in my head and make it, I thought, extremely clear in my student's heads". He now wonders if he did his students a disservice by not creating any dissonance in their minds because "they would leave my class thinking that they understood things because it was presented clearly to them". "I was trying to take my um, distilled understanding over the years and you know eliminate the trouble spots, the thinking spots and present them with a version that they could just ah, absorb". 
Over time, his orientation shifted towards thinking about "those things that students should know or be able to do". He was not able to cite any specific instances or persons that had contributed to the shift in his ideas about pedagogy, but felt that "maturity, having children of my own, watching and listening to my peers, talking with my peers um, and just a growing sense that um, there were some critical things that, that all people should know, and that that's what I really needed to focus on, to focus my teaching on". "Its unfortunate, a lot of that stuff developed later in my career, and I don't really know what influenced that". Today he is committed to students exploring ideas and says that this has become his style of teaching. He added that one of the main obstacles to being an effective teacher is that it "just takes time to get it right" because "teaching effectively is a highly complex activity". Nowadays he does a lot of "post processing, but not a lot of up front, ah information processing" because this helps him and the students to understand the pedagogy behind what he is doing. He also noted that Dr. Andrews, who is a much younger teacher, is more oriented towards the delivery of instruction although "he has really been open and receptive to this, to this approach".

Dr. Rogers shares his teaching ideas with Dr. Andrews and colleagues at meetings and is working to get the team teaching approach expanded to other methods courses. In sharing ideas with Dr. Andrews he tries to do so more "subversively, than you know, than telling him. I sort of share it as, you know, as an insight that I have had". He intends to present his work at conferences in the future, although he notes that most of the people are "like-minded". Other avenues for sharing ideas have been the publication of a book and through professional development workshops for practicing teachers. 
He evaluates his teaching effectiveness through the relationship he establishes with the students. "I mean, those situations in which I have learned the most, I think that there has been that relationship between the teacher and the learner". He strives to find ways to continually enhance his understanding of and relationship with students because for him "how to influence that relationship to the greatest extent possible has always been what I considered to be the most interesting challenge of teaching". This includes being able to take the perspective of the learner. He sees an effective teacher as one who has curiosity and the ability to think on one's feet, aspects over which one has little control, and a solid set of teaching skills and an understanding of the students. "I mean to me that's the ultimate measure of my success, you know that I, I am ready and I am confident to teach science". Good teachers focus on student learning and not teaching.

Constraints that are encountered are that not all students are advised to take the particular sequence of courses, and end up taking a separate science and separate methods course which often means that the methods of teaching science are "decontextualized". For this reason, the university has to continue to offer the stand-alone methods course because some students are selected out of the NOVA course "by situations over which we have no control". He has also experienced some difficult getting administrators to understand the rationale and value of having the content and methods courses integrated. Dr. Rogers did not mention any constraints to his teaching or factors that prevented him from being successful.

One of the barriers to student learning that he perceives is that students are accustomed to structure and want to have material presented in "a logical fashion that makes it easy to understand", just as he used to do. So, they often find the open-ended 
nature of the class hard to cope with, particularly when even the instructors "profess a lot of times that ah, you know we are not quite sure where this is going". "Its not something they hear from too many of their professors." He believes that students have to make the transition from teaching "as the primary activity", to "learning as the primary activity" and "that's the biggest thing that they need to let go of because we are telling them they are entering a profession, and we are telling them its not about teaching, its about learning". Also, some students, particularly older ones, had negative science experiences when they were at school, and that has made them afraid to teach science. However, he feels that the course will impact them in the long term as they grapple with "whether or not these things are significant for their future lives as teachers".

On the self-report STEBI B, Dr. Rogers scored (a) 64 (out of 70) on the personal science teaching efficacy subscale, and (b) 32 (out of 55) on the science teaching outcome expectancy subscale. While his personal science teaching efficacy is high, his teaching outcome expectancy is lower, indicating that he is less confident in his ability to impact student learning than he is about his abilities to teach. This is somewhat inconsistent with his interview data, where he saw the course having an impact on student teaching effectiveness.

On the Approaches to Teaching Inventory (ATI) Dr. Rogers reports himself as having a strong conceptual change focus and student focused orientation (see Figure 21). He considers himself much less concerned with information transmission and less teacher focused. This is consistent with the interview data already presented, where his concern has shifted away from just disseminating information, to engaging students in performance tasks to demonstrate competence. Evidence from the interview also supports the student- 
focused categorization, where he sees himself as creating a framework for student engagement and reflection on practices.

The conceptual change focus is supported by his discussion of learning, where he states that to learn means to either "add to an existing conceptual framework or to alter an existing conceptual framework". He went on to describe the Piagetian notion of assimilation and accommodation of concepts, saying "it just makes a whole lot of sense to me that, that we process information ah, in a way that is either additive or that we wrestle with new ideas, and we have to somehow integrate it into our existing conceptual frameworks". He uses a metaphor of a filing cabinet, where he says students must find a niche to file information. Sometimes, "information fits nicely in an existing folder that we have and sometimes we have to change our filing system".

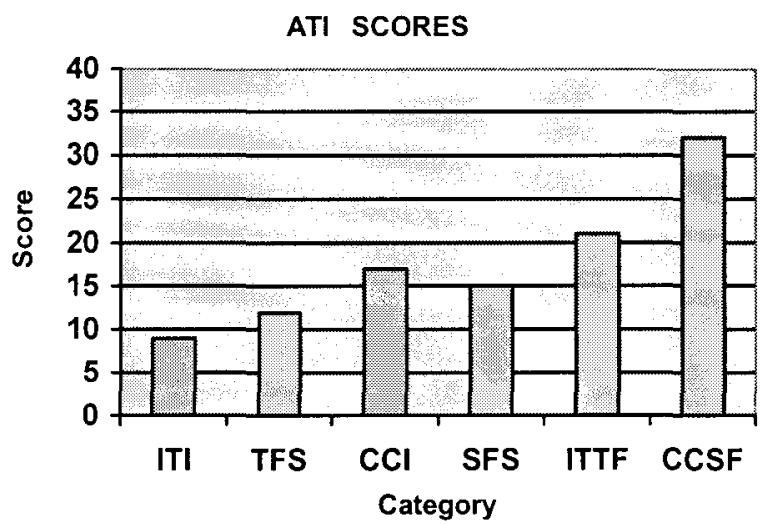

ITI $=$ Information transmission intention TFS $=$ teacher focused strategy $\mathrm{CCI}=$ conceptual change intention SFS $=$ student focused strategy

ITTF $=$ information transmission and teacher focused $\mathrm{CCSF}=$ conceptual change and student focused

Figure 21: ATI Scores for Dr. Rogers

Teaching and Learning: Practices

The practices of this instructor are essentially the same as Dr. Andrews, because they are teaching the same class. In this section only additional emphases to what has already been discussed in Dr. Andrews's case are presented. 
Dr. Rogers is very favorable predisposed to students using kits, and to developing new kits because this approach is one that has been adopted by their state and so students will encounter different kinds of science kits once they start teaching. Dr. Andrews spoke less favorably about the kit development process because he felt it to be too open-ended. Dr. Rogers emphasized that to prepare students for kit development, in the first semester course they use of different types of kits, such as one on ecosystems that can be found in local schools. Thereafter, students engage in developing their own set of kit materials. In the current offering of the course, students were developing a kit based on whales, because there is a large whaling museum close to their city. Recently, a large whale had washed up on the beach and the university had been asked to rearticulate the bones of the whale for display at the museum. Dr. Rogers wanted to build onto this, with students developing a kit for local science teachers to use with their school children when visiting the museum. The assignment for the students was to develop materials for teachers to use prior to a visit, during a visit to the museum, and after the visit. The task was to build "portions of the kit", to field test and "design a professional development piece for the teachers". The process involves students bring together their content and pedagogical knowledge, integrating and applying these to a real world scenario (use of knowledge). The process is very open-ended and evolves as they proceed. Dr. Rogers is very tolerant of this, while Dr. Andrews had found it difficult to accept.

The starting point for developing the course was around the state standards for initial science teacher preparation and these are reflected in the syllabus. The selection of content to meet those standards is opportunistic to local issues and needs that Dr. Rogers identified. The first year this focused on invasive species and the second year on whales, 
as well as a community quilt that depicts local flora and fauna. The quilt was used as the focus for students developing WebQuests. The next time that students take the course, the focus will be on terrapins, because there is a rare, endangered terrapin that the university is helping to save. So, each year there is a new focus, and course materials evolve around the emerging themes. No two years are the same.

Using the Esteem observation instrument Dr. Andrews, together with Dr. Williams, were rated by one of the NOVA research fellows and the results are presented in Figure 22 This observation included four student groups of three students per group presenting on their selected ecosystem. Each student evaluated the presentation for the other groups. Each group had a "specialist" in geology, physics, biology, and chemistry who had to instruct the rest of the class on the specialty of the ecosystem.

\section{ESTEEM Observation Scores}

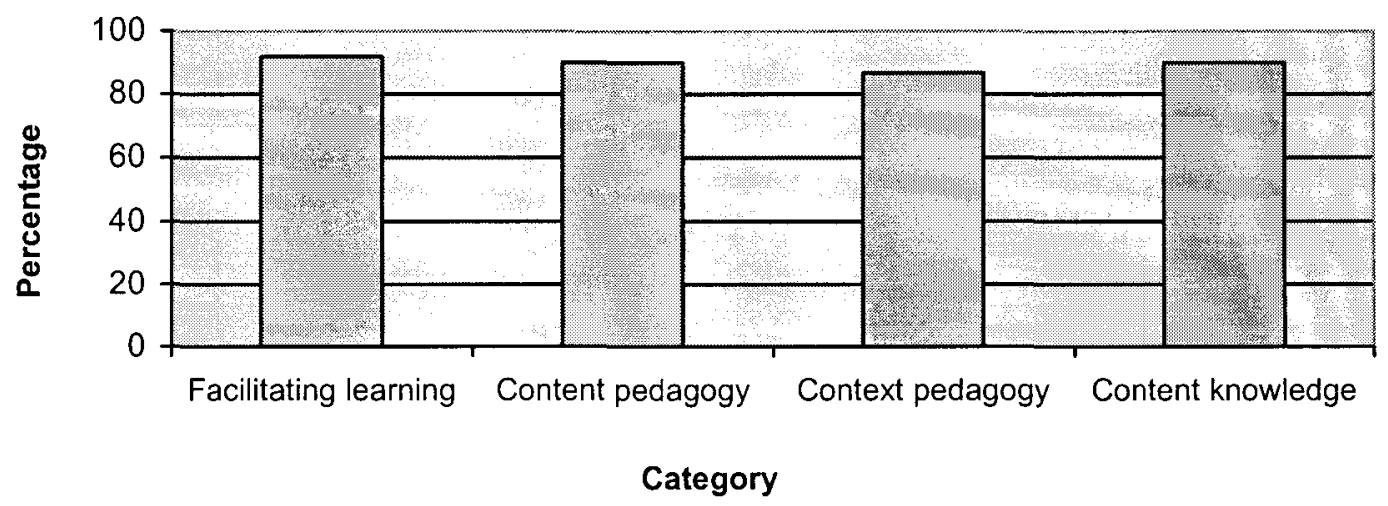

Figure 22. Results of the Esteem Observation Instrument for Dr. Rogers.

In this instance the implementation of the whole class instruction, rather than individual instructors, was rated. They scored more than $85 \%$ on all categories, with scores of greater than $85 \%$ considered "expert" (Burry-Stock, 1995). For facilitating learning (motivating learners, student engagement in activities and experiences) (role of 
instructor) they scored a $92 \%$, for content pedagogy the score was $90 \%$ (use of different teaching methods, higher order thinking skills, promoting conceptual understanding and integration of content and processes), for context pedagogy they scored $86.7 \%$ (fluid control of teacher and student interactions), and for content knowledge they scored $90 \%$ (use of exemplars, balance between depth and comprehensiveness, coherence of science experiences, and accuracy of content).

Comparison of Conceptions and Practices: Teaching and Learning

In comparing conceptions and practices, it is necessary to contrast the data from the different sources, as outlined in the previous two sections. Here the conceptions of teaching and learning reflect views across classes, while the practices refer specifically to the NOVA class. Table 18 summarizes the properties and associated dimensions for both conceptions and practices of teaching and learning. 
Table 18

A Comparison of the Properties and Associated Dimensions of Teaching and Learning that are Espoused and Practiced: Dr. Rogers

\begin{tabular}{|c|c|c|}
\hline Properties & Conceptions & Practice \\
\hline Teaching goals & $\begin{array}{l}\text { Prepare elementary teachers } \\
\text { in content and methodology, } \\
\text { reduce fear of science, } \\
\text { conduct research, technology } \\
\text { use }\end{array}$ & $\begin{array}{l}\text { Learn basic content, how to } \\
\text { teach using a standards- } \\
\text { based approach, conduct } \\
\text { research }\end{array}$ \\
\hline Role of instructor & $\begin{array}{l}\text { Creating a framework, } \\
\text { modeling instruction, } \\
\text { facilitating reflection }\end{array}$ & $\begin{array}{l}\text { Organizer, creator of } \\
\text { learning environment }\end{array}$ \\
\hline Teaching strategy & $\begin{array}{l}\text { Guided discovery, materials } \\
\text { and curriculum development } \\
\text { by students }\end{array}$ & $\begin{array}{l}\text { Assigning students } \\
\text { performance based tasks }\end{array}$ \\
\hline View of knowledge & $\begin{array}{l}\text { Procedural knowledge, } \\
\text { content knowledge, and } \\
\text { processing knowledge, } \\
\text { students construct own } \\
\text { knowledge and products }\end{array}$ & $\begin{array}{l}\text { Integrated across disciplines, } \\
\text { scientific method and } \\
\text { processes, students construct } \\
\text { own knowledge and } \\
\text { products }\end{array}$ \\
\hline Use of knowledge & $\begin{array}{l}\text { Create new products, } \\
\text { integrate content and } \\
\text { pedagogy, apply to real } \\
\text { world contexts }\end{array}$ & $\begin{array}{l}\text { Create new products, } \\
\text { integrate content and } \\
\text { pedagogy, apply to real } \\
\text { world contexts }\end{array}$ \\
\hline Source of knowledge & $\begin{array}{l}\text { Students, outside resources, } \\
\text { textbook, instructor }\end{array}$ & $\begin{array}{l}\text { Students, outside resources, } \\
\text { textbook, instructor }\end{array}$ \\
\hline Selection of content & $\begin{array}{l}\text { State standards, what } \\
\text { students need to know, time, } \\
\text { sequencing of activities }\end{array}$ & $\begin{array}{l}\text { State standards, thematic, } \\
\text { integrated across disciplines, } \\
\text { opportunistic }\end{array}$ \\
\hline $\begin{array}{l}\text { Pedagogical } \\
\text { knowledge } \\
\text { development } \\
\end{array}$ & $\begin{array}{l}\text { Developed over time, trial } \\
\text { and error, reflection }\end{array}$ & No evidence \\
\hline $\begin{array}{l}\text { Sharing teaching } \\
\text { ideas }\end{array}$ & Informal and formal & Informal and formal \\
\hline $\begin{array}{l}\text { Teaching } \\
\text { effectiveness }\end{array}$ & $\begin{array}{l}\text { Relationship with students, } \\
\text { ability to teach }\end{array}$ & No evidence \\
\hline $\begin{array}{l}\text { Constraints to } \\
\text { teaching }\end{array}$ & No evidence & No evidence \\
\hline $\begin{array}{l}\text { Factors facilitating } \\
\text { implementation }\end{array}$ & $\begin{array}{l}\text { Administrative support for } \\
\text { block scheduling and team } \\
\text { teaching, NASA support }\end{array}$ & $\begin{array}{l}\text { Administrative support for } \\
\text { block scheduling and team } \\
\text { teaching, NASA support }\end{array}$ \\
\hline
\end{tabular}


Table 18 (continued)

\begin{tabular}{|l|l|l|}
\hline Properties & Conceptions & Practice \\
\hline Learning interaction & $\begin{array}{l}\text { Instructor initiated, two way } \\
\text { process }\end{array}$ & $\begin{array}{l}\text { Two way process, students } \\
\text { initiating new ideas }\end{array}$ \\
\hline Learning control & $\begin{array}{l}\text { Instructor guided, student } \\
\text { managed }\end{array}$ & $\begin{array}{l}\text { Instructor guided, student } \\
\text { managed }\end{array}$ \\
\hline Learning styles & Not mentioned & $\begin{array}{l}\text { Kinesthetic, intrapersonal, } \\
\text { interpersonal }\end{array}$ \\
\hline $\begin{array}{l}\text { Impact on student } \\
\text { learning }\end{array}$ & Improve ability to teach & $\begin{array}{l}\text { More positive view of } \\
\text { science and confidence in } \\
\text { ability to teach }\end{array}$ \\
\hline Constraints to & $\begin{array}{l}\text { Coping with open-ended } \\
\text { situations, shifting from } \\
\text { being teaching focused to } \\
\text { learner focused }\end{array}$ & $\begin{array}{l}\text { Uncertainty about new } \\
\text { approach and performance } \\
\text { expectations }\end{array}$ \\
\hline $\begin{array}{l}\text { Student } \\
\text { responsibilities }\end{array}$ & $\begin{array}{l}\text { Engage and reflect on } \\
\text { learning, do work }\end{array}$ & $\begin{array}{l}\text { Participate in groups, ask } \\
\text { questions, make and present } \\
\text { products }\end{array}$ \\
\hline
\end{tabular}

Dr. Rogers is the driving force behind the pedagogical practices in the NOVA course and his views about teaching and learning are consistent with his practices. Assessment Conceptions

The purpose of assessment for Dr. Rogers is (a) to provide feedback to students as to whether or not they are meeting the goals and standards that have been established, (b) to inform the instructor of student progress, and (c) to inform instruction, "because we're typically building our assessments before our planning at this point, which is something sort of new to the practice". In designing the assessment tasks and performance criteria before instruction occurs, assessment is seen to drive the instructional process, with the instructor making sure that students are adequately prepared to complete the assigned tasks. Assessment data gathered from students can also be used to adapt and revise future instruction (link between teaching and learning). 
Dr. Rogers's preferred strategy for assessment is through the use of performance tasks and rubrics that make clear, "up front", the criteria needed for successful completion of the task (assessment preparation). "We've come to, to rely exclusively on performance based assessments in our program, and, so, we seldom um, do anything that's not performance based." Performance tasks allow students to apply knowledge and skills they have acquired, thus showing what they have learned. This is somewhat inconsistent with his earlier statement about guided learning as being the process in which the student "does not know what the destination is" but is guided towards that end point. Providing a rubric implies knowledge of that final product. He may mean that while students do have a rubric to score the final product, they have no notion, initially, of what that might look like.

He stated that he has not given a final exam for eight years and that this is because in education "we have a performance based system, we have a standards based system, and in a standards based system you're really much more curious about what students know or are able to do". These standards include both content and process standards (knowledge focus). He acknowledges that as a schoolteacher he did not always think about assessment in this way, but that in teacher education it really makes the most sense because of national and state standards for initial teacher preparation. $\mathrm{He}$ noted that the state requirement for teachers to pass a set of standardized tests before being given a teaching certification is contradictory to the standards-based approach because such tests do not consider performance on complex tasks.

He sees the value of performance-based assessment as providing clear guidelines to students so that they "know what their grades are going to be based on" (grading 
implementation) and this allows students "to decide what kind of level of response they want to prepare". So, students are in control of the amount of effort they wish to put into each assessment task and their own grade.

Dr. Rogers believes that the use of performance-based tasks and associated rubrics means that students are able to monitor themselves, thus obtaining ongoing feedback. It is also important to provide students with feedback at the end of each assignment both individually and in a group setting. He believes that the feedback from "this type of assessment is much more informative than the feedback that would be provided through a more traditional form of assessment", both for the student and the instructor.

Assessment data should be used to get feedback about student learning and to make modifications to the tasks and assessment criteria, if necessary. For instance, he says about the assessment rubric for the WebQuest that, "clearly this particular assessment does need to be modified because it has some points of confusion and those need to be ironed out um, before the next time we do this". He is concerned to improve the assessment criteria so that students understand the expectations of them.

\section{Assessment Practices}

According to the syllabus, the purposes of assessment are to provide "a comprehensive suite of measures will be used to assess the content and methods gained by students" (knowledge focus). "Clear expectations, instructions, scoring guides, and due dates are provided for every assignment".

The types of performance tasks (strategies) used have already been described in the Dr. Andrews's case and include the following: (a) textbook and related readings, (b) 
interactive and reflective journal/science notebook, (c) developing a common language about standards, (d) kit development, (e) science summit presentation, (f) WebQuests, and $(\mathrm{g})$ discovery center and poster, and $(\mathrm{h})$ end-of term comprehensive interview/exam (25). All of these have associated rubrics and assessment criteria for that particular task. "It tells us what we are looking for and it really helps to clarify, um, our expectations for students". These performance tasks and rubrics are implemented according to the syllabus (periodicity).

Dr. Rogers prefers to call the mid-term and final assessment an interview, steering away from the term exam, while Dr. Andrews insisted on it being called an exam. $\mathrm{He}$ sees it as an alternative to the final exam and an opportunity to find out how much students have learned through open discussion. Topics covered during the interview with each student include "attitudinal questions, it was factual questions, it would be, it would be ah, related to the topics that they, that they studied, the invasive species, the ecosystems that we looked at. So, it could be from a range of different types of questions" (knowledge focus).

In preparing students for the assessment tasks he provides students with rubrics so that performance criteria are clear ahead of time, allocates articles to read on different issues, provides exemplars, gives instructions on how to undertake the task, engages them in similar experiences (such as science kits) and conducts field trips. If necessary, he will also provide content knowledge, like for the science discover center, but feels that they should not "need too much because they're relatively simple things they will be looking at", like how a fax machine works. 
Feedback is also provided verbally after students have presented their various projects in front of their peers. This comes from both the instructors and other students. In addition, each student is given "a completed scoring guide and on the scoring guide we'll have feedback, specific feedback". Apart from feedback to students, the process also provided feedback to the instructors about the nature of the assignment itself, whether or not it needs to be modified". Thus, he has used the assessment data to change the tasks assigned or to improve existing tasks. For instance, he decided not to use the long term/in depth project that he typically uses with other classes and replaced it with other projects, like group presentations, in which each student is responsible for researching and presenting one aspect of an ecosystem.

The self-survey ratings on the Assessment of Classroom Learning in Science Inventory (ACLSI) for Dr. Rogers reflect a spectrum of scores from $65.7 \%$ to $93 \%$. The ACLSI assesses the use of a diversity of different strategies and purposes. To score a high score on the different subscales, a teacher would have to be using a variety of different strategies for a range of different purposes. The highest score $(93 \%)$ was for immediate feedback through hands on activities, observations and oral feedback, and this is consistent with the interview data. The next highest score of $86 \%$ was for formal questioning that includes use of teacher made tests, multiple choice, matching questions, true/false questions, and assigning letter grades. It is surprising that he rated himself so highly on this aspect as he claimed not to use tests and exams any longer. However, the instructions for the instrument were that "this inventory addresses the degree to which you feel that you are skilled in using various classroom learning assessment practices". So, he may have been rating his previous experiences and skills from those practices. 
Scores above $35 \%$ are considered "competent" and those above $70 \%$ "proficient" (Burry-Stock, 1995). For the other categories (enhancing learning, enhancing motivation, interacting feedback, conceptualizing activities and grading implementation) he scored between $65.7 \%$ and $73.3 \%$ falling within the "competent" range. Clearly, he sees himself as still developing the skills in these categories.

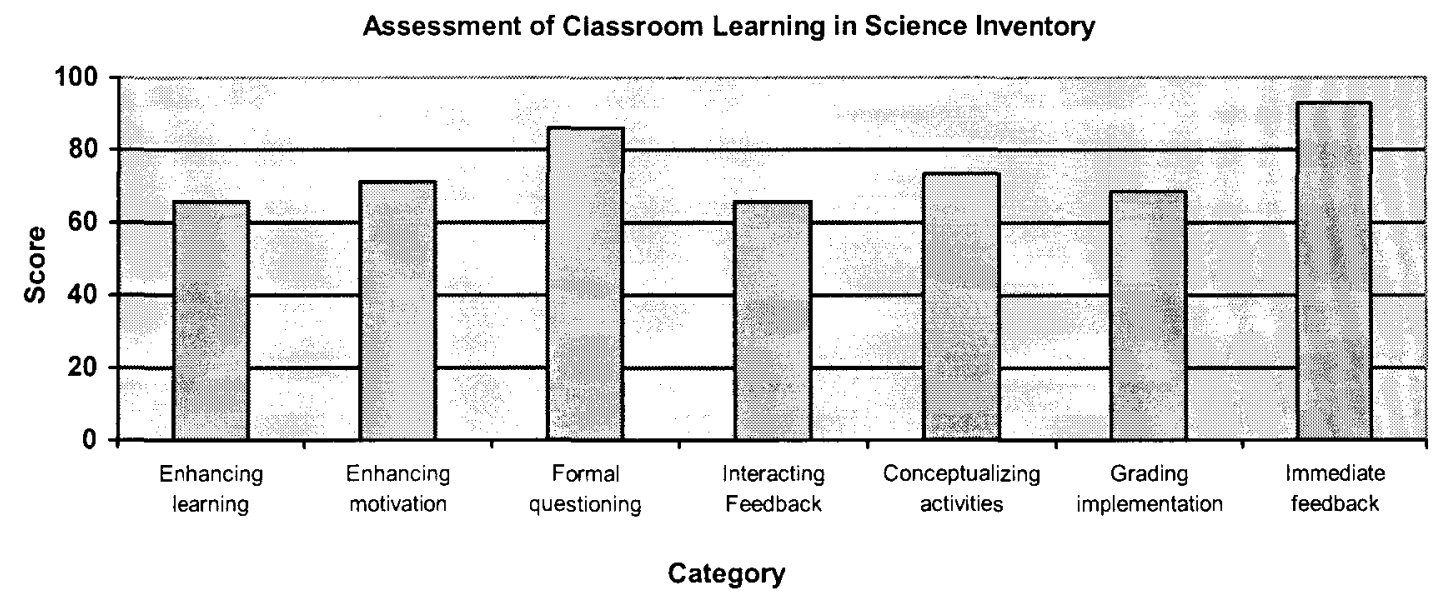

Figure 23: Results of the Assessment of Classroom Learning in Science Inventory for Dr.

Rogers.

Comparison of Conceptions and Practices: Assessment

In comparing conceptions and practices, it is necessary to contrast the data from the different sources, as outlined in the previous two sections. Table 19 summarizes the properties and associated dimensions for both conceptions and practices of assessment. 
Table 19

A Comparison of the Properties and Associated Dimensions of Assessment that are Espoused and Practiced: Dr. Rogers

\begin{tabular}{|l|l|l|}
\hline Properties & Conceptions & Practice \\
\hline $\begin{array}{l}\text { Purpose of } \\
\text { assessment }\end{array}$ & $\begin{array}{l}\text { Feedback, monitor progress, } \\
\text { improve instruction }\end{array}$ & $\begin{array}{l}\text { Assessing student learning } \\
\text { including content and } \\
\text { processes of science }\end{array}$ \\
\hline Strategies & $\begin{array}{l}\text { Performance-based tasks and } \\
\text { rubrics }\end{array}$ & $\begin{array}{l}\text { Range of performance tasks } \\
\text { and rubrics }\end{array}$ \\
\hline Periodicity & $\begin{array}{l}\text { Periodic, according to } \\
\text { syllabus }\end{array}$ & $\begin{array}{l}\text { Periodic, according to } \\
\text { syllabus }\end{array}$ \\
\hline Interaction feedback & $\begin{array}{l}\text { Group and individual, } \\
\text { ongoing and at end of task, } \\
\text { self-assessment for students, } \\
\text { feedback to instructors }\end{array}$ & $\begin{array}{l}\text { Group and individual, } \\
\text { ongoing, and at end of task, } \\
\text { for students and instructors }\end{array}$ \\
\hline $\begin{array}{l}\text { Assessment } \\
\text { preparation }\end{array}$ & $\begin{array}{l}\text { Improve or change } \\
\text { assessment tasks, improve } \\
\text { instruction }\end{array}$ & $\begin{array}{l}\text { Improve or change } \\
\text { assessment tasks, }\end{array}$ \\
\hline Knowledge focus & $\begin{array}{l}\text { Provide criteria up front } \\
\text { and processes of science }\end{array}$ & $\begin{array}{l}\text { Exemplars, readings, } \\
\text { appropriate experiences and } \\
\text { performance criteria }\end{array}$ \\
\hline $\begin{array}{l}\text { Relationship to } \\
\text { teaching and } \\
\text { learning }\end{array}$ & $\begin{array}{l}\text { Direct the instructional } \\
\text { attitudes, content and } \\
\text { process, use to improve } \\
\text { teaching }\end{array}$ & $\begin{array}{l}\text { Feedback to improve } \\
\text { instruction }\end{array}$ \\
\hline $\begin{array}{l}\text { Grading } \\
\text { implementation }\end{array}$ & $\begin{array}{l}\text { Use of rubrics, students } \\
\text { decide level of performance }\end{array}$ & $\begin{array}{l}\text { Rubrics, points allocated for } \\
\text { different tasks, as per } \\
\text { syllabus }\end{array}$ \\
\hline
\end{tabular}

Overall, there is consistency between the conception of assessment and associated practices.

Action Research: Conceptions

Dr. Rogers sees action research as important to inform practice, and not to "inform ah, the body of knowledge" (purpose). "I mean its, its more of a, um, private focused exploration and not intended to be reported, um the data" (knowledge 
orientation). "I think that it gives you a lens for looking at what you do and then for making ah, adjustments to what you do so that, so that the outcomes that, that ah, are produced are more in keeping with what your intensions are". It is geared to identifying a concern about teaching and gathering information for making decisions about what to change, "sort of a continuous improvement model or um, being a professional" (use of results). He also noted that one of the things that he thought Dr. Andrews had learned from the process was that you do not always have to give student "the right piece of information, but ah, guide them rather than providing them with the information".

The focus of the research should be on student perceptions of "our instruction through the lens of inquiry" and of the interaction between the two teachers. He sees that working with a colleague (support) and eliciting student input are essential ingredients to a successful action research project.

He draws the distinction between action research and reflection saying that, "reflection is less systematic and more random", but adds that, "reflective practitioners always do action research" (iteration). This suggests that he sees the two as synonymous", with the possible distinction that action research is a "systematic" process that is specific to the context in which it is undertaken (design). "When they do it more systematically then I think it sort of rises to the appropriate, reflection becomes more, ah, more research oriented. So, its sort of like a higher, more formal, more, more well thought out level of reflection". However, he was not sure what they would have done without the rubric they used to assess their instruction, saying, "had we not had that tool, it might have been more difficult. Or, we might have just said, well, you know, let's just 
take some notes, or" (instrumentation). He did not articulate other possible designs for the research.

He does not think that the concept of action research is in the "lexicon of people generally" at the university and sees this as a limitation to implementation. There are some efforts to engage in co-planning of curricula by faculty, but "I don't think that that, that the collaboration went beyond the planning stage. And I don't they were checking in on each other, on their, their effectiveness". So, he feels that there is a lot more support needed to encourage action research more broadly across his campus.

The interest reflected in his conceptions is essentially practical in nature, because he is concerned to improve practice through reflection on action. Students are sources of information, rather than participants in the reflective process, so his reflective processes are largely autobiographical because it does not seek to engage others in deliberating and arriving at consensus.

In summary, the star diagram (Rearick \& Feldman, 1999) in Figure 24 shows that the primary foci of the action research conceptions reflect practical interest, autobiographical reflection, and personal and professional purposes. 


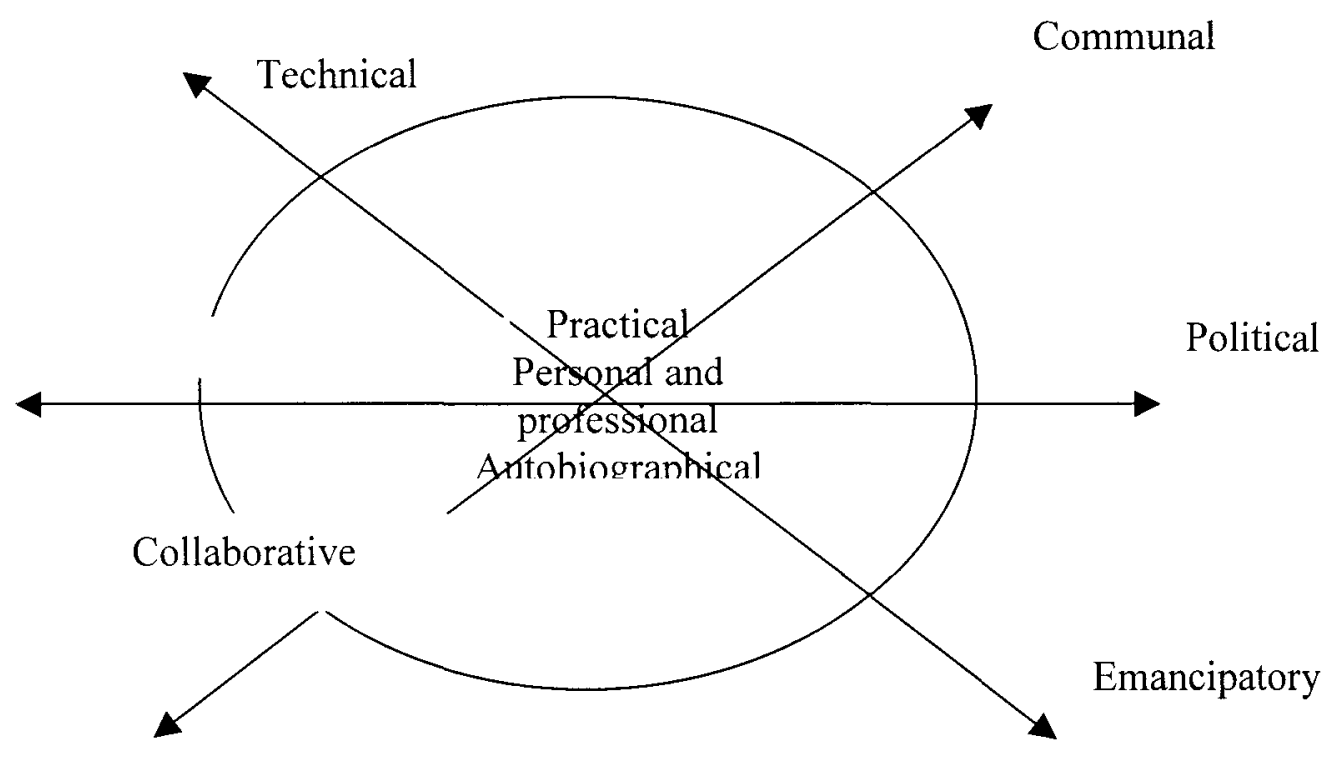

Figure 24. Star Diagram for Action Research Practices of Dr. Rogers

Action Research: Practices

Dr. Rogers took principal responsibility for implementing the action research component of the NOVA project, identifying a rubric to use to evaluate the teaching of the course at the end of semester (conceptualization and design). This left Dr. Andrews somewhat disempowered because he did not fully understand the purposes and processes associated with the action research project. The rubric they used, called the instructional practices rubric (instrumentation), had been developed by a project on which Dr. Rogers had served as a consultant and seemed an appropriate instrument to assess effectiveness regarding the implementation of inquiry-based teaching. This was Dr. Rogers's first action research project ever undertaken.

For the NOVA class, the initial focus of the action research was on student perceptions of the course (see previous case), but no data were generated on perceptions 
about the interaction between the two teachers, as was stated they desired. Identifying a rubric that looked at inquiry-based instructional practices "gave us a focus" and was easy to implement. "Having the instrument really um, helped us a lot."

Dr. Rogers said they did not spend "a whole lot of time" analyzing the data because the "the deficits sort of jumped out and the points where we were doing well stood out, and I think, um, overall we were pretty pleased with the way the students reacted to um, the way we were teaching through inquiry". Thus, there was little evidence of aspect that needed changing from the data gathered using the rubric (use of results) (see results presented by Dr. Andrews). However, based on informal student comments, not from the action research rubric, the instructors "found that we were shortchanging the physical sciences". Because of this, they "revamped the curriculum for the second semester to include more topics from the physical sciences", with students producing materials from physical science that included developing a discover center consisting of a poster and activities for school children.

He also noted that other informal data showed that students "felt that they should see more laboratory type activities that would be more typical of a um, of a science class", but that by the end of the year, they realized that they were guiding them "towards reaching their own conclusions, and not being the ones who provided those conclusions for them". He felt that while students were initially accustomed to being told all the answers based on prior experiences in other courses, that at the end of the NOVA courses they "see the value of it, of for including that type of instruction in their repertoire". Informal results also showed that there was very little use of mathematics by students to 
interpret or explain results of their investigations. He did not state how these findings would be used in future.

Dr. Rogers stated that for the current courses the action research focus was "aimed at generating data that we can use to say that this approach is making a difference". Thus, the research focus for this year was "aimed more at looking at um, outcomes for students" so that he could have data to argue the benefit of the team teaching approach with administrators (use of results). "We hope that this method is, is having, ah, more positive outcomes on students who go through our program because we want to expand it". His intention is to motivate for the mathematics methods course to be integrated in the same way with the mathematics content course. He was gathering pretest and post-test information about science content knowledge, attitudes to science, and views on the nature or science (knowledge orientation), and planned to use this to promote the approach more broadly. From the previous case analysis, Dr. Andrews claimed that no action research was being done in the current cycle of the course. This indicates a lack of communication between the two instructors about this ongoing dimension.

Dr. Rogers will be going on sabbatical in the next academic year and plans to analyze all the data that has been obtained, in order to write papers for publication and presentation at national conferences, like AETS or NARST. He also plans to write up the whale restoration project and student involvement in kit development. He has not done this yet because of a lack of time (dissemination). 
Comparison of Conceptions and Practices: Action Research

In comparing conceptions and practices, it is necessary to contrast the data from different sources. Table 20 summarizes the dimensions for both conceptions and practices of action research.

Table 20

A Comparison of the Properties and Associated Dimensions of Action Research that are Espoused and Practiced: Dr. Rogers

\begin{tabular}{|l|l|l|}
\hline Dimension & Conceptions & Practice \\
\hline $\begin{array}{l}\text { Conceptualization } \\
\text { and support }\end{array}$ & $\begin{array}{l}\text { Generally not well } \\
\text { understood, needs support } \\
\text { structures }\end{array}$ & $\begin{array}{l}\text { Education team member } \\
\text { conceptualized project }\end{array}$ \\
\hline Focus & Inquiry-based instruction & $\begin{array}{l}\text { Student perceptions of class, } \\
\text { student knowledge, attitudes } \\
\text { and views about science }\end{array}$ \\
\hline Research design & Systematic process & $\begin{array}{l}\text { Quantitative, end of semester, } \\
\text { pre- and post-tests }\end{array}$ \\
\hline Instrumentation & Take notes & $\begin{array}{l}\text { Inquiry practices rubric, VNOS, } \\
\text { surveys }\end{array}$ \\
\hline $\begin{array}{l}\text { Knowledge } \\
\text { orientation }\end{array}$ & $\begin{array}{l}\text { Personal versus public } \\
\text { knowledge }\end{array}$ & $\begin{array}{l}\text { Content and processes of } \\
\text { science }\end{array}$ \\
\hline Interest & Practical & Technical \\
\hline Purpose & $\begin{array}{l}\text { Improve teaching, personal } \\
\text { purposes }\end{array}$ & $\begin{array}{l}\text { Personal and professional } \\
\text { purposes, improve teaching }\end{array}$ \\
\hline Reflection & Autobiographical & Autobiographical \\
\hline Use of results & Improve instruction & $\begin{array}{l}\text { Make curricular changes, } \\
\text { promote course in university, } \\
\text { modify other courses }\end{array}$ \\
\hline Iteration & Ongoing reflective processes & Beginning and end of semester \\
\hline
\end{tabular}

While Dr. Rogers' conception of action research was to gather qualitative data to improve teaching, he had moved towards gathering quantitative data about student outcomes, because he perceived this was necessary to motivate for expansion of the instructional methods and course structure to other classes. Thus, he shifted his focus to the students because of contextual demands. 
He conceptualized action research as an ongoing, formal and systematic process, but his practices were more informal and reflective, with the formal component only coming at the end of the semester. Clearly he is a reflective practitioner looking at his practice on an ongoing basis, but methods of formalizing this process on an ongoing basis were not evident. This may have been because he found it difficult to describe what an action research design might look like had they not had the instructional practices rubric to use. So, there are some clear contradictions between Dr. Rogers's conceptions and his practices of action research that relate to an apparent inability to formalize qualitative data collection and analysis strategies.

\section{Conclusion}

Dr. Rogers's views are characterized by the desire to engage students in real world performance tasks, particularly in developing curriculum materials. The metaphor that characterizes this instructor is 'teacher as the creator of a learning framework, with students as active participants in developing curriculum'. Overall, there is a consistency among his conceptions and his practices of teaching, learning and assessment, although his views about action research are not always carried out in practice.

\section{Summary}

Five case studies were presented in this chapter, with the purpose of describing and analyzing the conceptions and practices of these five professors teaching science courses for non-science majors. All of the professors provided deep insights into their thoughts and practices during the interviews, opening themselves to the interviewer for some challenging questions. Only Dr. Andrews stated that the interview process was somewhat difficult, feeling more like a job interview in which he felt he had to justify his teaching 
philosophy. They all stated that the process had helped them by raising questions they had not thought of and encouraging them to think about their teaching more deeply. In the member check of his case study Dr. Stevenson noted that he didn't "fully comprehend the implications" of the case study and would like to read the complete dissertation or have a personal conversation with the author about the implications.

The results showed that each of the professors has their own set of assumptions on which his teaching and assessment practices are based. Thus, there is a range of different perspectives and practices across the spectrum of cases. It is clear that all of the instructors want to be good teachers and are concerned about their students' learning processes. However, the ways in which they engage in teaching and assessing students show clear differences. Similarly, the ways in which the professors think about and undertake action research differ from case to case.

Because there are variations across cases, the purpose of the next chapter is to perform cross-cases analysis. Themes and trends across cases will be explored in order to move towards generating answers to the research questions posed in chapter one, and to move towards explanation building (Yin, 2003). 


\section{CHAPTER 5}

\section{CROSS-CASE ANALYSIS}

The purpose of conducting cross-case analysis is to (a) move towards "understanding and explanation" in which the researcher explores the conditions under which the findings occur, and (b) to enhance generalizabilty or the relevance of the findings beyond just one specific case (Miles \& Huberman, 1994). Miles and Huberman (1994) further noticed that there is a "tension between the particular and the universal: reconciling an individual case's uniqueness with the need for more general understanding of generic processes that occur across cases" (p. 173). Cross-case analysis must preserve the uniqueness of each case, while building a more holistic understanding of that case within its own context, and in its relationship to other contexts.

In this chapter, the results of the cross-case analysis of the five cases discussed in chapter four are presented. The research questions established in chapter one were used to guide this process, forming the framework around which cross-case analysis was undertaken. The process included both case-oriented analysis and variable oriented analysis (Miles \& Huberman, 1994). Case-oriented analysis looks for "specific, concrete, historically-grounded patterns common to small sets of cases" (p. 174), while variable oriented analysis involves the search for "themes that cut across cases" (p. 175). This involved the comparison of the codes and matrices established in chapter four, as well as the development of new matrices, with common trends, themes and differences emerging in the process. The HyperResearch cross case search and report feature facilitated this. 
The research questions established in chapter one are reviewed below.

- How do science faculty involved in NOVA courses conceptualize teaching, learning, assessment and action research?

- What approaches to teaching, assessment and action research do these faculty employ?

- How do theories of action (conceptions) relate to theories-in-use (practices)?

- Does practice constitute the scholarship of teaching and learning, in relationship to the literature definitions?

\section{Faculty conceptions and practices}

This section aims to address the first two research questions:

- How do science faculty involved in NOVA courses conceptualize teaching, learning, assessment and action research?

- What approaches to teaching, assessment and action research do these faculty employ?

In the ensuing sections, each of the research interests of teaching and learning, assessment and action research are discussed separately. For each of these, the structure is as follows: (a) cross-case analysis and discussion of conceptions, (b) cross-case analysis and discussion of practices, (c) comparison of conceptions and practices.

The cases described in chapter four represent a complex set of data that could be analyzed in different ways. One technique used here was to examine the properties around which the cases were written and to collapse these into two dominant themes for each of teaching and learning, assessment, and action research. Each of these dominant themes has associated dimensions around which the categories vary on a continuum and 
these can be shown as intersecting lines on a grid (Strauss \& Corbin, 1998). This consolidation into dominant themes was done in order to make possible comparisons of conceptions and practices across cases using a scoring method described below.

\section{Conceptions: Teaching and learning}

For this part of the research, a modified version of the dominant themes established by Trigwell and Prosser (1996) were used to analyze the five professor's case narratives. These themes were (a) teaching intention, with the variants ranging from an information transmission intention (ITI) to a knowledge utilization and production intention (KUPI), and (b) teaching strategy, where the variants ranged from a teacherfocused strategy (TFS) to a student-focused strategy (SFS). These might be seen as intersecting lines on a grid. These criteria also relate to the approaches to teaching inventory completed by all study participants.

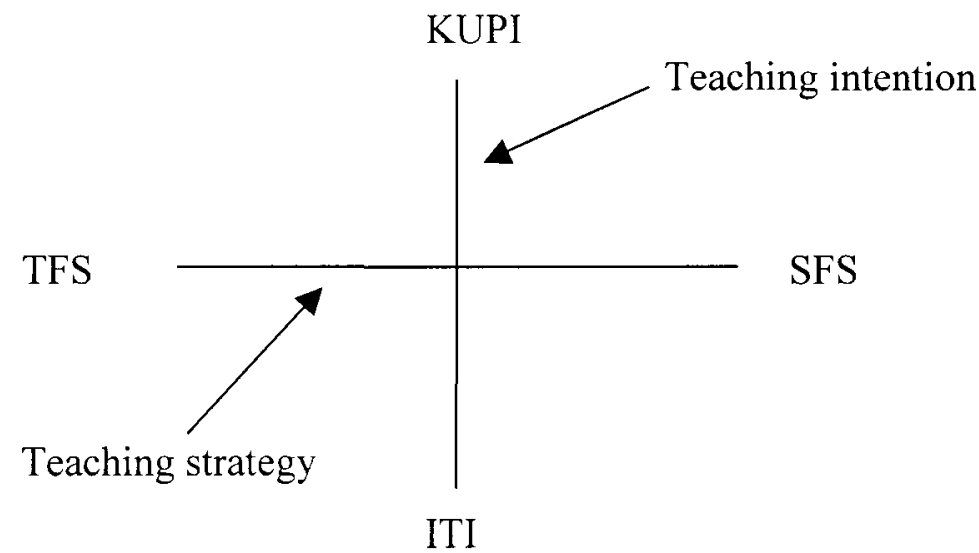

Figure 25. Intersection of Teaching Strategy and Teaching Intention

Using the technique established by Samuelowicz and Bain (2001) each professor was coded with an $\mathrm{A}, \mathrm{A} / \mathrm{b}, \mathrm{B} / \mathrm{a}$ or $\mathrm{B}$ on each of the properties associated with teaching and learning. For this study, (a) the A represents a teacher-focused strategy with an information transmission intention, (b) the $\mathrm{A} / \mathrm{b}$ a teacher-focused strategy and 
information transmission intention but with aspects of a student-focused strategy or knowledge utilization and production intention, (c) the B/a reflects a student focused strategy and knowledge utilization and production intention but with aspects of an information transmission intention or teacher-focused strategy, and (d) the B consists of a student-focused strategy with knowledge utilization and production intention. This showed the dimensions (variations) across which the properties were distributed (Strauss \& Corbin, 1998) and resulted in a matrix representing each professor's orientation towards teaching and learning. If scores of 1,2,3 and 4 are allocated respectively, it is possible to compare the approaches to teaching on a continuum of teacher-focused strategies with an information transmission intention to student-focused strategies with a knowledge utilization and production intention. The possible scores would range from 9 through 36 and results are presented in Table 21.

Table 21

A comparison of the Properties of Teaching Espoused by Different Professors

\begin{tabular}{|l|l|l|l|l|l|}
\hline Properties & Lane & Walton & Stevenson & Andrews & Rogers \\
\hline Teaching goals & $\mathrm{A}$ & $\mathrm{B} / \mathrm{a}$ & $\mathrm{B}$ & $\mathrm{B} / \mathrm{a}$ & $\mathrm{B}$ \\
\hline Role of instructor & $\mathrm{A} / \mathrm{b}$ & $\mathrm{B} / \mathrm{a}$ & $\mathrm{B} / \mathrm{a}$ & $\mathrm{A} / \mathrm{b}$ & $\mathrm{B} / \mathrm{a}$ \\
\hline Teaching strategy & $\mathrm{A} / \mathrm{b}$ & $\mathrm{B}$ & $\mathrm{B}$ & $\mathrm{A} / \mathrm{b}$ & $\mathrm{B}$ \\
\hline View of knowledge & $\mathrm{A}$ & $\mathrm{B} / \mathrm{a}$ & $\mathrm{B}$ & $\mathrm{A} / \mathrm{b}$ & $\mathrm{B}$ \\
\hline Use of knowledge & $\mathrm{A} / \mathrm{b}$ & $\mathrm{B}$ & $\mathrm{B} / \mathrm{a}$ & $\mathrm{A} / \mathrm{b}$ & $\mathrm{B}$ \\
\hline $\begin{array}{l}\text { Source of } \\
\text { knowledge }\end{array}$ & $\mathrm{A} / \mathrm{b}$ & $\mathrm{B}$ & $\mathrm{B}$ & $\mathrm{A} / \mathrm{b}$ & $\mathrm{B}$ \\
\hline $\begin{array}{l}\text { Selection of } \\
\text { content }\end{array}$ & $\mathrm{A} / \mathrm{b}$ & $\mathrm{B} / \mathrm{a}$ & $\mathrm{B} / \mathrm{a}$ & $\mathrm{A}$ & $\mathrm{B} / \mathrm{a}$ \\
\hline $\begin{array}{l}\text { Learning } \\
\text { interaction }\end{array}$ & $\mathrm{A} / \mathrm{b}$ & $\mathrm{B} / \mathrm{a}$ & $\mathrm{B} / \mathrm{a}$ & $\mathrm{A} / \mathrm{b}$ & $\mathrm{B} / \mathrm{a}$ \\
\hline Learning control & $\mathrm{A}$ & $\mathrm{B} / \mathrm{a}$ & $\mathrm{B}$ & $\mathrm{A} / \mathrm{b}$ & $\mathrm{B}$ \\
\hline Total & 15 & 30 & 32 & 18 & 33 \\
\hline
\end{tabular}


Table 21 shows that conceptions are structured around properties and that the faculty in this study hold different conceptions about teaching, spread across the continuum from $\mathrm{A} / \mathrm{b}$ through $\mathrm{B}$. In general, there is consistency in conceptions among the properties for each of the professors. Dr. Lane and Dr. Andrews essentially fit into category $\mathrm{A} / \mathrm{b}$, while Dr. Walton is closer to $\mathrm{B} / \mathrm{a}$ with elements of $\mathrm{B}$, and the other two professors are closer to category $\mathrm{B}$, with elements of $\mathrm{B} / \mathrm{a}$.

Dr. Lane's conceptions can be categorized as being more student directing than purely teacher-centered. Rather than just lecturing to students in what would be considered a teacher-centered approach, he sees himself as directing student learning in an attempt for them to learn new content. Similarly, Dr. Andrews is oriented towards guiding student learning so that they may learn new material, but his conceptions reflect strategies that are more student-focused, such as engaging them in discussion, hands-on activities and mini-research projects.

Dr. Andrews is also concerned to learn with and from students, saying that learning with students is one of the benefits of being a teacher. Similarly, Dr. Walton, Dr. Rogers and Dr. Stevenson see themselves as partners in a process of discovery that allows the students to grow and develop, through which they also learn. But, there are also elements of a student-directing conception evident in their positions, with Dr. Walton saying that part of his role is to "help direct students towards better understanding" and all of them providing students with tasks to direct their learning. However, the latter three professors show more student-focused strategies, engaging learners in authentic tasks with students making choices about assignment topics and how to complete these. In this case they see their role being to assist as necessary. This 
suggests that while it is useful to use the labels teacher-centered and student centered, these are not immutable bounded systems. Instead, there may be other categories that overlap with or extend from these two dominant categories in a continuum, with a "student-directing category" and "partners in learning category" being two additional possibilities or extensions that fit in between the two extremes.

All of the professors in this study stated that they have changed their conceptions over time, with all of them starting out early in their careers as being teacher-focused, with an information transmission intention. Over time they have recognized that students need to be more engaged in their own learning and have tried to implement more studentfocused strategies. For Dr. Lane, this shift was made possible by the provision of new materials (i.e. calculators) that could be used by students to solve and graph equations. Together with students doing pre-readings and question and answer sessions, he considered these as new student-oriented teaching innovations. For the others, there have been other stimuli that encouraged the shift in their conceptions. For both Dr. Walton and Dr. Rogers, who have been teaching for more than 30 years, this was a slow evolutionary process in which they gradually came to think differently. Dr. Rogers could not think of one key event that stimulated the shift, while Dr. Walton cited the case of teaching a summer graduate course in which he had the courage to try out some new ideas. The feedback was so positive that he began integrating hands-on activities into all of his classes, and particularly in doing experiments and principle generating activities prior to talking about the content and underpinning concepts. For Dr. Andrews and Dr. Stevenson the stimulus to change came with the NOVA course, although Dr. Stevenson had already 
begun thinking along these lines and NOVA just gave him the opportunity to try something different.

There were two perspectives on teaching innovation, one that saw innovation as the provision of new materials and one that viewed it as a process of curriculum development. For Dr. Lane, major constraints to good teaching were the lack of equipment and time. The only way in which he was able to make the changes towards his view of being more student-centered was through the provision of calculators, bought with the NOVA grant. However, his course was still bound by the textbook, following its themes rigidly, chapter by chapter, throughout the semester. For the others, the process of innovation involved radically reconceptualizing the curriculum, including content and methods of delivery. Together with the other NOVA team member, these professors had produced a completely new course. Dr. Walton's course was integrated around four themes involving the International Space Station. In this way students integrated content knowledge across a range of disciplines, while having good instruction modeled for them. They also had to apply their content and pedagogical knowledge to delivering conceptual understanding to peers and to elementary education children. Dr. Andrews and Dr. Rogers had created a team-taught, integrated course for which student received both science and education credit over a two semester sequence. This meant that students learned science while learning how to develop curriculum materials, through conducting original investigations, and by peer teaching others in the class. For Dr. Stevenson, there was no emphasis on students being able to teach science but on learning about scientific processes, integrating knowledge obtained from a variety of sources and applying it to the creation of animations, graphics and poetry. His emphasis was on using the Internet and 
other technological tools for learning. So, all of these professors engaged in thinking about curriculum in innovative ways that moved beyond the textbook and integrated knowledge from different sources and disciplines.

Conceptions of teaching are also related to an instructor's own prior experiences as a learner, with conceptions about teaching being based on the role models encountered during their own education. Poor role models may be a limiting factor because of the lack of exposure to alternatives or might be an incentive to consider other possibilities. For Dr. Walton, Dr. Stevenson, and Dr. Andrews, there were instructors that they knew they did not want to emulate and had tried different approaches to teaching that were different to the ways in which they had been taught. However, while that dissatisfaction existed, Dr. Andrews felt that not having been exposed to good instructional models made it difficult to consider other possibilities. Dr. Lane claimed that one instructor had encouraged him to be more interactive during a graduate course and that she had impacted his ability to think differently about teaching. Similarly, Dr. Stevenson was fortunate in that he had one mentor teacher who had made a significant impact on his own ideas about teaching. He also turned to his own learning style as a visual, hands-on learner to draw ideas for his instruction.

Only one of the professors had any background in educational theory, being Dr. Rogers who was a certified high school teacher for many years. His doctorate was also in education. Of all the instructors, he was the only one who spoke clearly and freely about educational theorists and principles, for instance citing the importance of Piaget in conceptual development and describing the processes of accommodation and assimilation. For the others, all their pedagogical knowledge had developed through trial 
and error, from student feedback on new teaching approaches attempted, from prior experiences as learners, and through their personal learning preferences.

The comparison of Dr. Andrews and Dr. Rogers, who team-teach a course, make for interesting analysis. Their conceptions about teaching are very different, with Dr. Andrews being more teacher-centered and oriented towards content transmission, and Dr. Rogers towards students using information to create new products and knowledge. Dr. Andrews articulated many concerns about the way in which the NOVA course was run, particularly that he often did not think it was as efficient as it might have been had the instructors provided more direct instruction. Dr. Andrews is a much younger teacher who has only been teaching for a few years, and Dr. Rogers attributed the difference to this. While it is clear that there are differences in conceptions, Dr. Andrews noted that his experience in team teaching the course with an education faculty member had been his "personal training" and had made him reexamine his own thoughts about teaching. The process has been and continues to be a major learning curve for him regarding educational principles. He is grappling with deciding which ideas he agrees with, which he might adapt, and which he would prefer to discard. Clearly, he is a professor in transition.

These instructors assess their teaching effectiveness in various ways, including the use of formal test data (Lane and Andrews), student participation and enthusiasm, formal or anecdotal student feedback, and the ability of students to teach (Walton and Rogers). Drs. Lane and Andrews' preferences for using student performance on tests reflects their concern for content knowledge, while Drs. Walton and Rogers' consideration of student's ability to teach reflects the concern for application and use of 
knowledge and skills acquired. Dr. Walton and Dr. Rogers also saw modeling of good instruction for future teachers as an important component. This is consistent with their other conceptions about teaching.

While Dr. Lane and Dr. Andrews are more focused on teaching content, all of the professors considered their role to be more than just delivering content matter. Dr. Andrews wants to be able to help students make appropriate career decisions by being a good role model and showing them that he cares about their development. While Dr. Lane was not able to articulate what possible impact he might have on student outcomes, suggesting that students should be asked instead, he claimed that he wanted to show students that knowledge is relevant to real world situations and may be useful at some unknown point in the future. In contrast Dr. Walton and Rogers saw themselves as contributing meaningfully to students becoming life long learners, critical of the teaching approaches encountered during the rest of their education, able to apply and use the knowledge and skills acquired in their classes. Dr. Stevenson also saw himself as impacting student learning as one part of a larger process, although contextual constraints meant that his efforts were often watered down by the student's other experiences.

Using the STEBI self report instrument, all of the professors had relatively high scores for the personal science teaching efficacy suggesting that they were relatively confident in their teaching abilities. The lowest score was for Dr. Andrews and this may be a reflection of his grappling with considering the role of new methods for his practice.

Drs. Lane, Walton and Andrews had fairly high teaching expectancy outcomes, indicating that they believed they had a good impact on student learning. In the case of Dr. Lane, this was not reflected in other aspects of his interview, where he was not able to 
articulate the anticipated impact he would have on students. The lowest scores were for Drs. Stevenson and Rogers and this is consistent with the other interview data, where Dr. Stevenson was concerned that students did not generally experience a good model of education. So, his course was only a small component of their total experience and might not be reinforced by any other university experiences they had. Similarly, Dr. Rogers felt that students were conditioned into believing that they had to be passive learners and that the teacher was central to their learning. One of the hardest tasks was to get them to make the shift to realizing that 'learning' is the primary responsibility of a teacher, and not teaching. Drs. Walton and Stevenson agreed with this analysis.

There were several contextual constraints identified in developing innovative courses. For Dr. Andrews, student's existing content knowledge was a problem because there were so many gaps in their scientific understanding. However, he felt that in teaching courses specifically for education majors it was easier to integrate innovative teaching methods because students did not need as much content knowledge in the discipline as someone graduating with a science degree. While this was a tension initially for Dr. Walton, he stated that he had realized that even future doctors and engineers blossomed when exposed to an activity-based approach that generated discussion and conceptual understanding. Thus, he had increasingly used innovative teaching methods in all his classes, irrespective of the audience, moving away from a content transmission mode of instruction. For Dr. Stevenson, he was only able to be innovative because the class he teaches is an honors course and not a prerequisite for any major, so this provided him with the freedom to experiment. He was not sure how to integrate more studentcentered approaches into traditional courses because the university philosophy promoted 
very large classes that were easier done with didactic instructional strategies. He was glad that most of his other courses were graduate classes in which he was more able to promote student-teacher discussion and interaction because the class sizes were smaller. Time, resources and teaching loads were also factors, particularly for those teaching in smaller universities or colleges such as Dr. Lane and Dr. Andrews.

A major constraint to student learning identified by Drs. Walton, Stevenson and Rogers was student's prior experience of teaching and learning in other classes that tended to be more didactic and content oriented. This meant that students did not have a strong background of understanding scientific principles. This was a trend that had started during their schooling and typically continued at the university level, with a dominant university philosophy promoting quantity of content over process and understanding of concepts. So, they felt that students had a hard time coping with the more open-ended nature of their courses and in shifting from being "teaching focused" to being "learning focused". This meant that they had to spend a lot of time gaining the student's trust and confidence because they were "initially suspicious and did not know how to respond". While they felt they had moved significantly in this direction by the end of a semester, they still felt that they never lost the stigma of being the person who gives out grades. Dr. Stevenson noted that the lack of exposure to expressing their opinions meant that they did not "know how discuss particularly well".

Four of the professors also identified poor mathematical skills as a limiting factor for students. Dr. Lane added that for him student motivation and interest were often factors that prevented students from learning, because "some have some, you know, interest to learn and some don't'. He felt that this was related to student's academic 
abilities, that, "poor students really don't care. If they don't care, we try hard to try to ah, bring them in the fold", but he added that his efforts were not always successful. He acknowledged that this might be that those students just did not like science, but might be capable in some other academic area

All five professors saw students as responsible for participating in the learning process in and outside of class, so as to maximize their own learning. Only Dr. Stevenson and Dr. Andrews articulated a concern that different students learn in different ways and said they attempted to provide opportunities to address the different styles that students have.

\section{Practices: Teaching and learning}

The same method was used to allocate practices with an $\mathrm{A}, \mathrm{A} / \mathrm{b}, \mathrm{B} / \mathrm{a}$ or $\mathrm{B}$ as was used to score the conceptions of faculty, scoring these respectively with a $1,2,3$, or 4 . The findings are presented in this section. Thereafter, emerging trends and issues are discussed. The possible scores would range 9 through 36 and results are presented in Table 22

A Comparison of the Properties of Teaching Practiced by Different Professors

\begin{tabular}{|l|l|l|l|l|l|}
\hline Properties & Lane & Walton & Stevenson & Andrews & Rogers \\
\hline Teaching goals & $\mathrm{A} / \mathrm{b}$ & $\mathrm{B}$ & $\mathrm{B}$ & $\mathrm{B} / \mathrm{a}$ & $\mathrm{B} / \mathrm{a}$ \\
\hline Role of instructor & $\mathrm{A} / \mathrm{b}$ & $\mathrm{B}$ & $\mathrm{B} / \mathrm{a}$ & $\mathrm{B}$ & $\mathrm{B}$ \\
\hline Teaching strategy & $\mathrm{A} / \mathrm{b}$ & $\mathrm{B}$ & $\mathrm{B} / \mathrm{a}$ & $\mathrm{B}$ & $\mathrm{B}$ \\
\hline View of knowledge & $\mathrm{A}$ & $\mathrm{B} / \mathrm{a}$ & $\mathrm{B}$ & $\mathrm{B}$ & $\mathrm{B}$ \\
\hline Use of knowledge & $\mathrm{A} / \mathrm{b}$ & $\mathrm{B}$ & $\mathrm{B}$ & $\mathrm{B}$ & $\mathrm{B}$ \\
\hline $\begin{array}{l}\text { Source of } \\
\text { knowledge }\end{array}$ & $\mathrm{A}$ & $\mathrm{B}$ & $\mathrm{B}$ & $\mathrm{B}$ & $\mathrm{B}$ \\
\hline $\begin{array}{l}\text { Selection of } \\
\text { content }\end{array}$ & $\mathrm{A}$ & $\mathrm{B}$ & $\mathrm{B}$ & $\mathrm{B}$ & $\mathrm{B}$ \\
\hline $\begin{array}{l}\text { Learning } \\
\text { interaction }\end{array}$ & $\mathrm{A} / \mathrm{b}$ & $\mathrm{B}$ & $\mathrm{B}$ & $\mathrm{B}$ & $\mathrm{B}$ \\
\hline Learning control & $\mathrm{A}$ & $\mathrm{B} / \mathrm{a}$ & $\mathrm{B}$ & $\mathrm{B}$ & $\mathrm{B}$ \\
\hline Total & $\mathrm{l}$ & 34 & 34 & 35 & 35 \\
\hline
\end{tabular}


Table 22 shows that the faculty in this study engage in teaching practices that are at either end of the continuum from A through B. Dr. Lane fits more into category $\mathrm{A} / \mathrm{b}$, while the other professors are closer to category B. From this it appears that while Dr. Andrews's conceptions reflect a more content-oriented intention, his practices in the NOVA course are more student-oriented with a knowledge utilization and production intention. This is commensurate with the discussion in the previous section, where because he is teaching a course together with another instructor he has been 'coerced' into using alternative teaching methods. This is further discussed in the next section. For the other professors, their practices reflect their conceptual intentions.

Using the Approaches to Teaching Inventory, all professors claimed to have a conceptual change intention. This was strongest in Dr. Stevenson's completed survey. However, in practice, there was little evidence for this reflected in the discussions about pedagogical practices or during teaching observations. While Dr. Stevenson claimed to monitor student's conceptions on an ongoing basis, there was no other discussion of methods for engaging students in conceptual change. Dr. Rogers presented an eloquent account of how concepts are created and developed through assimilation and accommodation. Using the metaphor of a filing cabinet he described how students could file new information into an appropriate drawer (assimilation), but that sometimes they found it necessary to rearrange the filing cabinet into new folders and drawers (accommodation). Despite this clear understanding of how conceptual change might occur, he did not articulate how he engaged in facilitating this in the classroom context. Only Dr. Walton presented a strategy for bringing out student's existing preconceptions and he did this through the use of on-line quizzes that challenged the students to think 
about phenomena, conducted before he started a new section. Then, in class there would be a class discussion about the different student's ideas and he hoped that "they mess up sometimes because that's the best way, or one of the best ways to clarify things, to get a misconception out and then clarify it. And, that's good learning." So, while a conceptual change intention was evident in their conceptions, it was less evident in practice.

Students in all classes stated that they had benefited from being in the class and that their professors tried hard to give them a good education. Dr. Lane's students admitted to having a poor attitude towards the subject, but that they were becoming more positive as they matured. In part this was because they had had a poor foundation at school. They felt that they were becoming more confident by being given things that they were able to do. Students in the classes of all the other professors stated that they had a much more positive attitude towards science because they were taught in a way that was different to most other classes they took, meaning that they engaged in more hands-on processes, open discussions and presentations of their own work. The education majors in these classes felt that they were more prepared and confident to teach elementary school children. The student comments further served to confirm the practices espoused by the instructor and observed on one occasion by an outsider.

Comparison of conceptions and practices: Teaching

This section compares the differences between participant's conceptions and practices of teaching (see 23). 
Table 23

A Comparison of the Properties of Teaching Espoused and Practiced by Different

Professors

\begin{tabular}{|l|l|l|l|l|l|}
\hline Properties & Lane & Walton & Stevenson & Andrews & Rogers \\
\hline $\begin{array}{l}\text { Teaching } \\
\text { conceptions } \\
\text { (total =36) }\end{array}$ & 15 & 30 & 32 & 18 & 33 \\
\hline $\begin{array}{l}\text { Teaching } \\
\text { practices } \\
\text { (total }=36)\end{array}$ & 14 & 34 & 34 & 35 & 35 \\
\hline
\end{tabular}

Table 23 shows that for Drs. Lane, Walton, Stevenson, and Rogers there is generally a high level of consistency between conceptions of teaching and learning and associated practices. Dr. Lane reflects a teacher-directed approach with a contenttransmission intension for both his conceptions and practices. Drs. Walton, Stevenson and Rogers exhibit student-centered conceptions and practices.

Only for Dr. Andrews is there a major difference between scores, with his conceptions falling within the $\mathrm{A} / \mathrm{b}$ category, while his practices in the NOVA course fall within the B category. As, already discussed, the course is team-taught, with Dr. Rogers being the leader in terms of pedagogy. While the two instructors team plan the course and individual sessions, it appears that Dr. Roger's philosophy is dominant, accounting for the difference between conceptual scores and score of practice for Dr. Andrews. This has left Dr. Andrews grappling with some internal conflict regarding the relationship between his own personal ideas and what happens in practice in the NOVA course. While he stated in the interview that he had "bought into it to a large degree" much of his interview revealed him grappling with the new ideas as he tried to integrate them with existing ones. He was clearly still engaging in this process. 
Summary of cross-case themes

In summary, the cross-case themes relating to teaching and learning are as follows:

- Conceptions about teaching and learning vary around a set of properties, and are fairly consistent across those properties for each professor.

- The teaching conceptions of these professors can be categorized as "teacherdirected", "student-centered" and a "partners in learning" category in which both teacher and learner are active participants. Categories may overlap.

- There was more of a focus on knowledge utilization and production for those professors with a "student centered" or "partners in learning" conception of teaching.

- Teaching conceptions changed over time, in all of these cases, from a teachercentered, didactic approach towards being more student-centered.

- There were two perspectives on teaching innovation, one that saw innovation as the provision of new materials and one that viewed it as a process of curriculum development.

- An instructor's prior experiences as a learner impacts ideas about teaching, either by providing positive or negative role models, or by being the only available model of instruction to draw from experientially.

- Science professors do not have a background in education and their ability to talk about educational theories and the impact on practice is limited. 
- Professors assess their own effectiveness in the same way in which they think about teaching. Conceptions about assessing their effectiveness relate to other conceptions about teaching and learning.

- A conflict between teaching ideas and practices may emerge when a professor is exposed to alternative approaches with which he is not familiar.

- All professors saw their roles as more than delivering content.

- Results from the STEBI self-report survey are consistent with other data gathered about conceptions of teaching and learning.

- Student's prior experiences of didactic instruction were considered a limitation to introducing innovative, participative approaches to teaching.

- The dominant paradigm in universities makes it difficult to introduce innovation because of the inherent barriers to change.

- Students are seen as ultimately responsible for their own learning in and outside of class.

- Student attitudes to science have changed as a result of the NOVA courses and education majors were more confident to teach.

- Most professors claimed to be oriented towards a conceptual change intention, but they generally did not demonstrate associated pedagogical practices that supported this claim.

- Teaching conceptions in general are related to teaching practices, except where a faculty member is teaching a course that he was not totally in control of designing. This may result in a conflict between conceptions and new practices. 


\section{Conceptions: Assessment}

The dominant themes identified were (a) knowledge focus, with the variants ranging from a content-oriented focus (COF) to a knowledge utilization and production focus (KUPF), and (b) assessment strategy, where the variants ranged from a traditional assessment strategy (TAS) to an authentic assessment strategy (AAS). The knowledge utilization and production focus (KUPF) means that students are able to apply knowledge to new contexts, produce new knowledge and change existing conceptions. These themes might be seen as intersecting lines on a grid (see Figure 26).

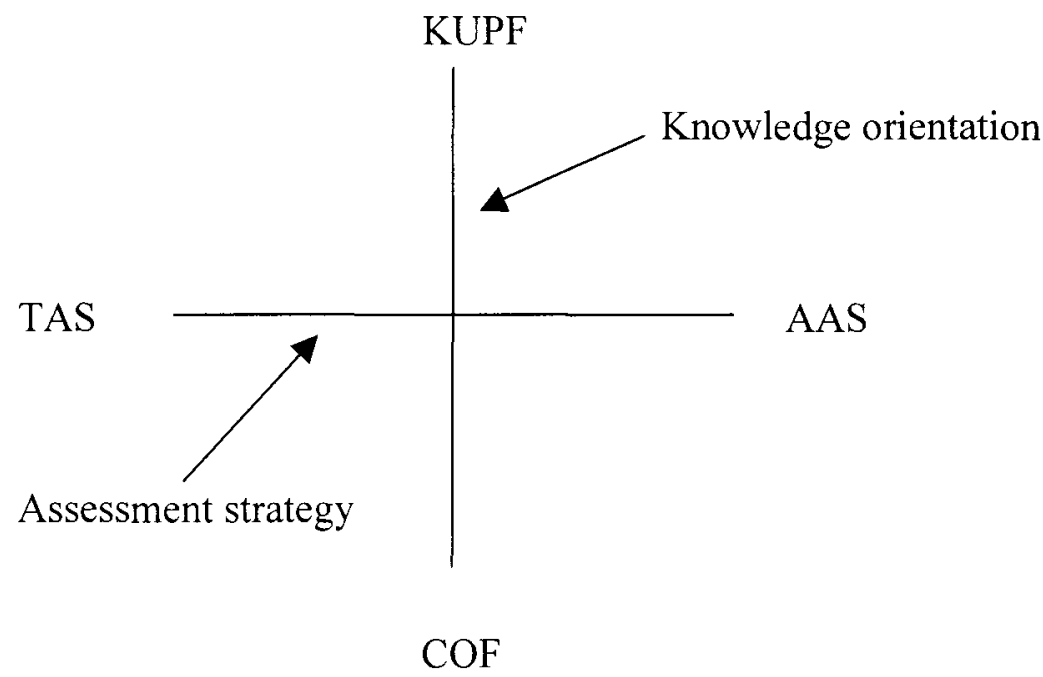

Figure 26. Intersection of Knowledge Orientation and Assessment Strategy

A matrix comparing the five professor's orientations to assessment was created (Samuelowicz \& Bain, 2001) to show the dimensions (variations) across which the properties were distributed (Strauss \& Corbin, 1998).

For this study, (a) the A represents a content-oriented focus using traditional assessment strategies, (b) the $\mathrm{A} / \mathrm{b}$ reflects a content-oriented focus and traditional assessment strategy but with elements of knowledge utilization and production or the use of authentic assessment strategies, (c) the B/a represents the concern for the knowledge 
utilization and production and authentic assessment but may use traditional methods or has elements of a content-oriented focus, and (d) the B reflects the concern knowledge utilization and production focus using authentic assessment strategies. Again, if scores of $1,2,3$ and 4 are allocated, it is possible to compare the orientations on a continuum from an orientation concerned with the reproduction of knowledge assessed using traditional strategies, to an orientation focusing on the generation of new knowledge and products, using authentic methods of assessment. The possible scores would range from 8 through 32 and results are presented in Table 24.

Table 24

A Comparison of the Properties of Assessment Espoused by Different Professors

\begin{tabular}{|l|l|l|l|l|l|}
\hline Properties & Lane & Walton & Stevenson & Andrews & Rogers \\
\hline $\begin{array}{l}\text { Purpose of } \\
\text { assessment }\end{array}$ & $\mathrm{A} / \mathrm{b}$ & $\mathrm{B} / \mathrm{a}$ & $\mathrm{B}$ & $\mathrm{A} / \mathrm{b}$ & $\mathrm{B}$ \\
\hline Strategies & $\mathrm{A}$ & $\mathrm{B}$ & $\mathrm{B}$ & $\mathrm{A} / \mathrm{b}$ & $\mathrm{B}$ \\
\hline Periodicity & $\mathrm{A}$ & $\mathrm{B}$ & $\mathrm{B}$ & $\mathrm{B} / \mathrm{a}$ & $\mathrm{B}$ \\
\hline Interaction feedback & $\mathrm{A} / \mathrm{b}$ & $\mathrm{B}$ & $\mathrm{B}$ & $\mathrm{B} / \mathrm{a}$ & $\mathrm{B}$ \\
\hline $\begin{array}{l}\text { Assessment } \\
\text { preparation }\end{array}$ & $\mathrm{A} / \mathrm{b}$ & $\mathrm{B}$ & $\mathrm{B} / \mathrm{a}$ & $\mathrm{B}$ & $\mathrm{B}$ \\
\hline Use of data & $\mathrm{B} / \mathrm{a}$ & $\mathrm{B}$ & $\mathrm{B}$ & $\mathrm{A} / \mathrm{b}$ & $\mathrm{B}$ \\
\hline Knowledge focus & $\mathrm{A} / \mathrm{b}$ & $\mathrm{B}$ & $\mathrm{B}$ & $\mathrm{A}$ & $\mathrm{B}$ \\
\hline $\begin{array}{l}\text { Grading } \\
\text { implementation }\end{array}$ & $\mathrm{A} / \mathrm{b}$ & $\mathrm{B}$ & $\mathrm{B}$ & $\mathrm{A} / \mathrm{b}$ & $\mathrm{B}$ \\
\hline Total & 15 & 31 & 31 & 19 & 32 \\
\hline
\end{tabular}

Table 24 shows that conceptions about assessment are structured around properties and that the faculty in this study hold different conceptions spread across the continuum from $\mathrm{A} / \mathrm{b}$ through $\mathrm{B}$. In general, there is consistency in conceptions among the properties associated with each professor. Dr. Lane and Dr. Andrews essentially fit into category $\mathrm{A} / \mathrm{b}$, while the other three professors fit into category $\mathrm{B}$. Dr. Lane and Dr. Andrews can be categorized as content-oriented using traditional assessment strategies 
but with elements of knowledge utilization. The other three professors can be categorized as oriented towards knowledge utilization and production, using authentic methods of assessment.

The instructors use a range of different methods of assessment and these relate to their knowledge focus, whether objective and content-oriented or more subjective and oriented to creating new knowledge and products. Dr. Lane and Dr. Andrews prefer to use objective quizzes, tests and exams to assess students. This reflects their concern for teaching content knowledge, as discussed earlier. Dr. Walton uses student presentations, on-line self quizzes designed to challenge existing scientific conceptions, as well as portfolios with associated rubrics. Dr. Rogers prefers to use performance tasks and rubrics that give students a "heads-up" on the criteria for successful performance. In this way, students become responsible for their own grade by the amount of effort they put into completing the associated performance task. Dr. Walton and Dr. Rogers's preferred assessment strategies relate to a desire for students to utilize and create new knowledge and products. Similarly, Dr. Stevenson likes to use a range of alternative assessment processes, where students gather and apply knowledge to a range of problems involving the generation of new products. However, he says he does not provide students with rubrics to guide them or for use as criteria for self-assessment.

While different purposes were elaborated for assessment, all were ultimately focused on monitoring student progress in the class. For Dr. Lane, Andrews and Walton assessment was seen as important to monitor whether students had acquired content knowledge and could apply it to some designated task like solving equations or making presentations. Dr. Stevenson was particularly concerned in monitoring student's critical 
thinking processes and their understanding of geological processes as they engaged in applying what they had learned. For Dr. Rogers, the purpose of assessment was seen as monitoring student progress against specified criteria, and making changes to instruction, as necessary. Both Drs. Walton and Stevenson also felt that assessment data provided information about conceptual growth and used it to monitor changes in student's ideas over time. Dr. Walton did this with diagnostic tests before and after each section in the syllabus, while Dr. Stevenson did it through informal discussion on an ongoing basis. Both said they used these processes to monitor student thinking and to direct future teaching about topics not understood.

Four of the professors (Lane, Walton, Andrews and Rogers) stated that assessment data provides feedback to the instructor about their own effectiveness. Dr. Andrews did not articulate how he would use this data, but the other three noted that they would use assessment data to improve their teaching if they identified an area with which the students were having difficulty. For Dr. Lane, this meant explaining the content in a different way, while for Dr. Walton and Dr. Rogers it meant rethinking assigned tasks and the way in which they were introduced, for example by providing exemplars and models of what was expected. Dr. Rogers added that he thought it important to modify the assessment criteria when problems were identified because these criteria direct the instructional process and student learning. While Dr. Stevenson did not specifically state that assessment data was used to monitor his effectiveness, he did state that he used it to determine how to pace the class and how much time to allocate to different sections. In essence, this is an attempt to guide instruction using assessment information. 
In preparing students for assessment tasks Drs. Walton, Stevenson, Andrews and Rogers agreed that it was important to discuss the requirements and criteria for successful performance with students ahead of time. This included the provision of models and exemplars by Drs. Walton, Andrews and Rogers, with a focus on applying knowledge and generating new products. Dr. Lane preferred to prepare students for the assessment tasks by discussing content with which the students were having difficulty. He preferred students to identify the areas over which they felt they needed a review of material by him. Again, his focus was on the content matter covered during the course.

All instructors provided feedback to students with the intention of improving student learning. Although different strategies were used, they all provided some form of group and individual feedback, either written or verbal. Dr. Lane focused on providing the correct answers to students and discussing errors in solving calculations, so that they could improve for the next time around. Dr. Andrews's feedback focused on the areas of student weakness, including poor content knowledge, so that students could work on those aspects and improve. Dr. Walton and Dr. Stevenson preferred to give feedback on an ongoing basis by challenging student's thinking and asking probing questions as the students worked on their assigned tasks. For Dr. Rogers, the use of rubrics meant that students could monitor their own progress, although he also gave additional feedback while students were working on projects, as well as after students completed tasks. Again, the latter cases reflected a concern for knowledge utilization and production. Ultimately all the professors recognized that they must provide a grade for students at the end of the semester and most of them accepted this without critique. For those using rubrics this is relatively easy because the criteria are known ahead of time 
and can easily be applied to allocate a grade. Similarly, grading of correct content knowledge is easy, although Dr. Lane encouraged his students to present all their calculations and work so that he can allocate a partial grade for work done if students don't get the correct answer. Only Dr. Stevenson stated that he is very resistant to traditional grading, but noted that at the end of semester he is compelled by university policy to allocate a grade, although he would prefer an alternative process. He was grappling with the best way to allocate grades because he preferred more interactive and informal processes of learning that were hard to quantify. He noted that his weekly assignments and end of semester exam were "misnomers" because the weekly assignments generally involved producing animations, graphics and poetry, while the exam engaged students in evaluating the course. So, while he was compelled to provide a grade, it was done in a way that did not compromise his attempts at innovation.

Practices: Assessment

The same method was used to allocate practices with an $\mathrm{A}, \mathrm{A} / \mathrm{b}, \mathrm{B} / \mathrm{a}$ or $\mathrm{B}$ as was used to score the conceptions of faculty, scoring these respectively with a $1,2,3$, or 4 . The findings are presented in this section. Thereafter, emerging trends and issues are discussed. The possible scores would range from 8 through 32 and results are presented in Table 25. 
Table 25

A Comparison of the Properties of Assessment Practiced by Different Professors

\begin{tabular}{|l|l|l|l|l|l|}
\hline Properties & Lane & Walton & Stevenson & Andrews & Rogers \\
\hline $\begin{array}{l}\text { Purpose of } \\
\text { assessment }\end{array}$ & $\mathrm{A}$ & $\mathrm{B} / \mathrm{a}$ & $\mathrm{B} / \mathrm{a}$ & $\mathrm{B}$ & $\mathrm{B}$ \\
\hline Strategies & $\mathrm{A}$ & $\mathrm{B}$ & $\mathrm{B}$ & $\mathrm{A} / \mathrm{b}$ & $\mathrm{B}$ \\
\hline Periodicity & $\mathrm{A}$ & $\mathrm{B}$ & $\mathrm{B}$ & $\mathrm{B}$ & $\mathrm{B}$ \\
\hline Interaction feedback & $\mathrm{A} / \mathrm{b}$ & $\mathrm{B}$ & $\mathrm{B}$ & $\mathrm{B}$ & $\mathrm{B}$ \\
\hline $\begin{array}{l}\text { Assessment } \\
\text { preparation }\end{array}$ & $\mathrm{A} / \mathrm{b}$ & $\mathrm{B}$ & $\mathrm{B}$ & $\mathrm{B}$ & $\mathrm{B}$ \\
\hline Use of data & $\mathrm{B} / \mathrm{a}$ & $\mathrm{B}$ & $\mathrm{B}$ & $\mathrm{B} / \mathrm{a}$ & $\mathrm{B}$ \\
\hline Knowledge focus & $\mathrm{A} / \mathrm{b}$ & $\mathrm{B}$ & $\mathrm{B}$ & $\mathrm{A} / \mathrm{b}$ & $\mathrm{B} / \mathrm{a}$ \\
\hline $\begin{array}{l}\text { Grading } \\
\text { implementation }\end{array}$ & $\mathrm{A} / \mathrm{b}$ & $\mathrm{B} / \mathrm{a}$ & $\mathrm{B} / \mathrm{a}$ & $\mathrm{B}$ & $\mathrm{B}$ \\
\hline Total & 14 & 30 & 30 & 27 & 31 \\
\hline
\end{tabular}

Table 25 shows that the faculty in this study engage in assessment practices that are at either end of the continuum from A through B. Dr. Lane fits more into category A/b, while Drs. Walton, Stevenson and Rogers are closer to category B. Overall, there is consistency among the properties associated with each professors.

Dr. Andrews is an interesting case because he displays $\mathrm{A} / \mathrm{b}$ through $\mathrm{B}$ properties for his practices. The education team member primarily established the assessment procedures for the class. Because his knowledge focus is content oriented, he found it particularly hard to accept the performance based assessment because it was not as "objective" as he would have preferred or was used to. He found it difficult to move away from the concept of a traditional exam, and insisted on calling the final oral interview, the final exam. "I interpreted that as a final oral exam", but even so was not totally happy with this because "it was less of an exam, I mean it was partially an exam, but it was more reflective". He also noted that it was not as rigorous as he would have liked, saying, "it was, it certainly was not a real challenging classic exam". Clearly, Dr. 
Andrews was placed in a conflict situation where he had to reappraise his own ideas about assessment. This is akin to conceptual accommodation required to incorporate new ideas into an existing schema $(\mathrm{Ho}, 2000)$. In the end, Dr. Andrews acknowledged that he is now beginning to incorporate more performance tasks and rubrics into his other classes and that he has begun to see their value

Comparison of conceptions and practices: Assessment

This section compares the differences between participant's conceptions and practices of assessment (see Table 26).

Table 26

A Comparison of the Conceptions and Practices of Assessment of Different Professors

\begin{tabular}{|l|l|l|l|l|l|}
\hline Properties & Lane & Walton & Stevenson & Andrews & Rogers \\
\hline $\begin{array}{l}\text { Assessment } \\
\text { conceptions } \\
\text { (total = 32) }\end{array}$ & 15 & 31 & 32 & 19 & 32 \\
\hline $\begin{array}{l}\text { Assessment } \\
\text { practices } \\
\text { (total = 32) }\end{array}$ & 14 & 30 & 30 & 27 & 31 \\
\hline
\end{tabular}

Table 26 shows that for Drs. Lane, Walton, Stevenson, and Rogers there is generally a high level of consistency between conceptions of assessment and associated practices. Only for Dr. Andrews is there a major difference between these scores because many of the decisions about assessment practices were outside of his control. His reliance on traditional assessment methods and his resistance to new approaches show that he has had to grapple with the conflict between an objective view of reality and a more subjective view.

Using the Assessment of Classroom Learning in Science Inventory to rate their practices, there was a general consistency between espoused beliefs and self-reported 
practices. Only in the case of Dr. Lane was there an apparent contradiction where he rated himself much higher than interview evidence than evidence from actual practices suggested. This shows the value of triangulating data gathering methods because this makes data available in multiple forms for interpretation.

Summary of cross-case themes

In summary, the cross-case themes relating to assessment are as follows:

- Conceptions about assessment are structured around a set of properties, and are fairly consistent across those properties for an individual.

- Content-oriented instructors use traditional methods of assessment, while those that are concerned with knowledge utilization and production use authentic assessment strategies. The COF and KUPF orientation was also synonymous with their teaching intentions.

- All professors considered the ultimate purpose of assessment being to monitor student progress.

- Feedback to students was considered important to enhance learning.

- Another purpose articulated was for assessment data to be used to provide feedback to the instructors about teaching effectiveness so as to improve instruction.

- All cases stated that students should be prepared for assessment tasks through discussion of criteria and review of material.

- Allocating a grade is an administrative requirement that most professors accept. 
- In general the ACLSI was useful for measuring faculty assessment practices, although the one contradictory case suggests its should not be used exclusively as a source of data.

- Conceptions about assessment are related to teaching practices, except where a faculty member is teaching a course in which a team member decides the pedagogical principles. This may result in a conflict between conceptions and new practices.

\section{Conceptions: Action research}

The dominant themes identified were (a) outcomes focus, with the variants ranging from learning outcomes focus (LOF) to a teaching outcomes focus (TOF), and (b) research strategy, where the variants ranged from a qualitative factual strategy (QFS) to a qualitative reflective strategy (QRS). These themes might be seen as intersecting lines on a grid (see Figure 27.

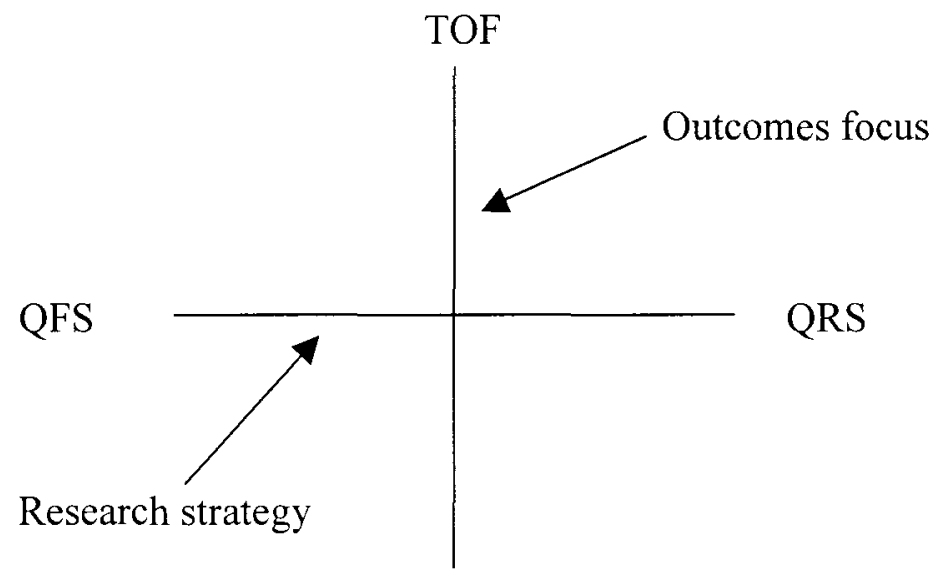

LOF

Figure 27. Intersection of Outcome Focus and Research Strategy 
A matrix comparing the five professor's orientations to action research was created (Samuelowicz \& Bain, 2001) to show the dimensions (variations) across which the properties were distributed (Strauss \& Corbin, 1998).

For this study, (a) the A represents concern for a learning outcomes focus using a quantitative factual strategy, (b) the $\mathrm{A} / \mathrm{b}$ reflects a learning outcomes focus using a quantitative factual strategy, but with elements of a teaching outcomes focus or qualitative reflective strategy, (c) the B/a indicates a teaching outcomes focus using a qualitative reflective strategy with elements of a learning outcomes focus or quantitative factual strategy, and (d) the B shows a teaching outcomes focus using a qualitative reflective strategy. Again, if scores of 1, 2, 3 and 4 are allocated, it is possible to compare the orientations on a continuum from an orientation concerned with the student outcomes using quantitative methods to one concerned with teaching outcomes using qualitative methods. The possible scores would range from 9 through 36 and results are presented in Table 27.

Table 27

A Comparison of the Properties of Action Research Espoused by Different Professors

\begin{tabular}{|l|l|l|l|l|l|}
\hline Properties & Lane & Walton & Stevenson & Andrews & Rogers \\
\hline Focus & $\mathrm{A}$ & $\mathrm{B}$ & $\mathrm{A} / \mathrm{b}$ & $\mathrm{B} / \mathrm{a}$ & $\mathrm{B}$ \\
\hline Research design & $\mathrm{A}$ & $\mathrm{B}$ & $\mathrm{A} / \mathrm{b}$ & $\mathrm{B} / \mathrm{a}$ & $\mathrm{B} / \mathrm{a}$ \\
\hline Instrumentation & $\mathrm{A}$ & $\mathrm{B}$ & $\mathrm{A}$ & $\mathrm{B} / \mathrm{a}$ & $\mathrm{B} / \mathrm{a}$ \\
\hline $\begin{array}{l}\text { Knowledge } \\
\text { orientation }\end{array}$ & $\mathrm{A}$ & $\mathrm{B} / \mathrm{a}$ & $\mathrm{B} / \mathrm{a}$ & $\mathrm{A} / \mathrm{b}$ & $\mathrm{B}$ \\
\hline Interest & $\mathrm{A}$ & $\mathrm{B}$ & $\mathrm{A} / \mathrm{b}$ & $\mathrm{B} / \mathrm{a}$ & $\mathrm{B}$ \\
\hline Purpose & $\mathrm{A} / \mathrm{b}$ & $\mathrm{B}$ & $\mathrm{B} / \mathrm{a}$ & $\mathrm{B} / \mathrm{a}$ & $\mathrm{B}$ \\
\hline Reflection & $\mathrm{A} / \mathrm{b}$ & $\mathrm{B}$ & $\mathrm{B} / \mathrm{a}$ & $\mathrm{B} / \mathrm{a}$ & $\mathrm{B} / \mathrm{a}$ \\
\hline Use of results & $\mathrm{A} / \mathrm{b}$ & $\mathrm{B}$ & $\mathrm{B}$ & $\mathrm{B}$ & $\mathrm{B}$ \\
\hline Iteration & $\mathrm{A}$ & $\mathrm{B}$ & $\mathrm{A} / \mathrm{b}$ & $\mathrm{B}$ & $\mathrm{B}$ \\
\hline Total & 12 & 35 & 22 & 28 & 33 \\
\hline
\end{tabular}


Table 27 shows that conceptions about action research are structured around properties and that the faculty in this study hold different conceptions spread across the continuum from A through B. In most cases, with the exception of Dr. Stevenson, there is consistency in conceptions among the properties associated with each professor. Dr. Lane essentially fits into category A with a focus on students, using a quantitative research approach, while the conceptions of Drs. Walton, Rogers fit into category B with a focus on teaching using a qualitative approach, and Dr. Andrews into a B/a category with a focus on teaching, but a need for more quantitative and "objective" methods of data gathering. Dr. Stevenson showed a blend of properties from A through B, being interested in finding ways to quantify the teaching and learning process, but also interested in improving instruction, as well as in monitoring student development.

The design of the action research was conceived of as either quantitative or qualitative in nature. Dr. Stevenson and Dr. Lane planned to focus specifically on student outcomes using quantitative techniques. Dr. Lane planned to use a quasi-experimental design and to compare two groups of students using a test. One group of students would be taught using the new chemistry procedures (green chemistry) and the other group in the traditional way. Comparison of student's test results was seen as the only way to assess student learning. Dr. Stevenson was interested in doing pre- and post-test surveys of student attitudes, content knowledge and understanding of processes. While his knowledge orientation was more subjective, he was concerned with finding ways to quantify teaching and learning, but did not state how the data generated could be used to improve instruction. Similarly, Dr Andrews wanted to use "valid instruments" for "comparative purposes", but did not articulate his own research design and instead relied 
on the education team member. Dr. Walton also had a preference for "objective" data and hence had a preference for an outsider to conduct the action research component, but was accepting of the qualitative nature of teaching. So, he said he also used written comments and open discussions with students to identify their shifting concerns about the teaching and learning process, and to give him feedback on what was effective in the classroom. Both Dr. Andrews and Walton saw the primary focus of action research as being on instruction. So, all of these professors had a leaning towards objective, quantitative data, although the latter three recognized the subjective nature of teaching.

Dr. Rogers had a more subjective view of action research, seeing it as a personal process that should be carried out systematically involving the instructor, an outside observer and the students. He did not envision the data being made available publicly because it was geared to improving instruction in context. However, he found it hard to articulate possible research questions or an appropriate design for this private, classroombased endeavor. Possibly this was because he had never undertaken an action research project in the past.

Four of the professors felt that action research had a role to play in higher education, while Dr. Lane stated that he did not think so at this stage. His views seemed to be tied to his own research interest on "green chemistry" which did not yet have a lot of support. The others felt that action research is not generally well understood within the wider university context and that they too had needed assistance in thinking about and engaging with the processes. Dr. Andrews would like to see more valid instruments that could be used from year to year for comparative purposes and also wanted more training as he did not fully understand the concept and practices associated with action research. 
Dr. Walton wanted something more specific for each class delivered because so much evaluation happens at the end of the semester with traditional evaluation sheets that all instructors have their students complete. He wanted something more specific to his own classes. Dr. Stevenson saw action research as a valuable self-evaluation instrument that could be used within departments, but because he had little training in education wanted more exposure to action research methods. Dr. Rogers was familiar with action research because of his education background, but thought that it needed more support from administrators before it could take root in the university context. He felt that its use became less as one moved up the K-12 education system, and was least accepted in the post-secondary sector. Clearly, they felt they needed more support personally or from administrators to implement the processes in a way that was meaningful.

The notion of action research was something that these science faculty members found hard to engage with because this was the first experience of it for all of them. For this reason, Drs. Walton, Stevenson and Andrews had turned to the education team member to assist with conceptualization, design and implementation of the project. Dr. Walton stated that the action research needed an outsider so that students could feel free to express their true opinions. He was satisfied that the education team member had conducted the entire study with minimal involvement from himself. Dr. Lane planned to emulate the study that had originally been planned but that had not actually been implemented because the original science team member had left the college. Dr. Andrews had left the design up to Dr. Rogers and was not sure what any future action research cycle might involve. Dr. Stevenson relied on the education team member to "teach me what it was". So, for the science faculty in this study, they recognized that they did not 
have enough exposure to exemplars and other models to assist with their own development of action research projects. They needed more exposure and training in this qualitative research methodology to make them take ownership of the process.

None of the science professors had any experience with action research prior to the NOVA project, except for Dr. Rogers who had been a science teacher and had encountered its theoretical considerations during his tenure as a teacher. Thus, it is noteworthy that for most of them their conceptions of action research are only likely to have developed through their involvement in NOVA, through interactions with the education team member, and through what they experienced during the process of implementation. This is different to the way in which conceptions about teaching and assessment have developed, because everyone has had multiple years of personal experience of the latter two phenomena, either as learners or as teachers, and have developed personal beliefs over time. Action research is not in the lexicon of the general public and so conceptions are likely to be newer and specific to the NOVA context.

All of the study participants considered the results of action research as useful to improving instruction. Dr. Lane would use the results as the basis on which to change his other courses and to advocate to others the use of his new approach to teaching chemistry. Dr Walton and Dr. Rogers saw it as a mechanism for the continuous improvement of teaching. They viewed students as important participants contributing necessary information to improve teaching on an ongoing basis. Dr. Stevenson and Dr. Andrews wanted to use the results to improve instruction, but because there were no really negative results from their particular studies they did not know what to change. 
Practices: Action research

The same method was used to allocate practices with an $\mathrm{A}, \mathrm{A} / \mathrm{b}, \mathrm{B} / \mathrm{a}$ or $\mathrm{B}$ as was used to score the conceptions of faculty, scoring these respectively with a 1,2,3, or 4 . The findings are presented in this section. Thereafter, emerging trends and issues are discussed. The possible scores would range from 9 through 36 and results are presented in Table 28.

Table 28

A Comparison of the Properties of Action Research Practiced by Different Professors

\begin{tabular}{|l|l|l|l|l|l|}
\hline Properties & Lane & Walton & Stevenson & Andrews & Rogers \\
\hline Focus & & $\mathrm{B}$ & $\mathrm{A} / \mathrm{b}$ & $\mathrm{B} / \mathrm{a}$ & $\mathrm{A} / \mathrm{b}$ \\
\hline Research design & & $\mathrm{B} / \mathrm{a}$ & $\mathrm{A}$ & $\mathrm{A}$ & $\mathrm{A}$ \\
\hline Instrumentation & & $\mathrm{B}$ & $\mathrm{A}$ & $\mathrm{B} / \mathrm{a}$ & $\mathrm{A} / \mathrm{b}$ \\
\hline $\begin{array}{l}\text { Knowledge } \\
\text { orientation }\end{array}$ & & $\mathrm{B}$ & $\mathrm{A}$ & $\mathrm{B} / \mathrm{a}$ & $\mathrm{A} / \mathrm{b}$ \\
\hline Interest & & $\mathrm{B}$ & $\mathrm{A}$ & $\mathrm{A}$ & $\mathrm{A}$ \\
\hline Purpose & & $\mathrm{B}$ & $\mathrm{A} / \mathrm{b}$ & $\mathrm{B}$ & $\mathrm{B}$ \\
\hline Reflection & & $\mathrm{B}$ & $\mathrm{B} / \mathrm{a}$ & $\mathrm{B} / \mathrm{a}$ & $\mathrm{B} / \mathrm{a}$ \\
\hline Use of results & & $\mathrm{B}$ & $\mathrm{B} / \mathrm{a}$ & $\mathrm{B} / \mathrm{a}$ & $\mathrm{B}$ \\
\hline Iteration & & $\mathrm{B} / \mathrm{a}$ & $\mathrm{A} / \mathrm{b}$ & $\mathrm{A}$ & $\mathrm{A}$ \\
\hline Total & 0 & 34 & 16 & 22 & 20 \\
\hline
\end{tabular}

Dr. Lane had not yet conducted an action research project, so his conceptions

remain unchallenged in practice. Dr Walton can be categorized as a B, with a focus on teaching using qualitative reflective processes. Dr. Stevenson focused on student outcomes using quantitative methods, fitting closer into category A/b. Drs. Andrews and Rogers reflect elements ranging from $\mathrm{A}$ through $\mathrm{B}$, not directly fitting into any particular category, although overall being closer to $\mathrm{A} / \mathrm{b}$.

Formal action research tended to be blurred with ongoing reflective processes. Dr. Stevenson and Dr. Walton used informal class discussion to monitor progress and make changes as they felt necessary and referred to this as part of action research. Even Dr. 
Rogers who stated that action research was a systematic process had found it difficult to develop a formal plan, saying that he did not know what they would have done without the research instrument he had discovered, which is a rubric geared to assessing whether instructors were using inquiry-based instruction. Without this instrument, he would have reverted to "taking some notes". Most of the changes that he had made in the course since its first implementation cycle were a result of his informal reflections on what worked and what needed improvement. Dr. Andrews articulated a difficulty in distinguishing between informal reflection and formal action research, saying that he had some colleagues that are doing it, but didn't know it was action research. By this engagement, he was meaning informal reflection on their teaching. In the end he said that he probably was engaged in action research because he used informal reflective processes to make changes on an ongoing basis and because he paid particular attention to student evaluations to make improvements. However, he noted that the student evaluations were a post hoc process, rather than occurring during the teaching process, and thus only applied to the subsequent year he taught that particular course again.

The professors found it difficult to articulate research questions for future investigation. Dr. Lane was not able to generate a question beyond his focus on teaching chemistry using a particular method, and Dr. Andrews was not engaging in any action research for the current course cycle and could not think of one for the future, saying, "You know I don't know. I can't think. I probably could think about it, but right now I don't, I don't know, I don't know that I understand it well enough to feel comfortable to, to think intelligently about it". It is apparent that they do not have sufficient insights and experiences to draw from to raise new and meaningful questions. Similarly, Dr. 
Stevenson was content to continue with the same focus, and was not able to think of any possible new questions for investigation. Dr. Walton stated that, " the basic question would be, is, am I doing an effective job. And then from then on, I think I'd break it down into ah, what were the activities of class, and did they, were they pointed towards um, students learning by experience and, and by investigation". However, he was not entirely sure how he would gather and analyze data, saying that he would have students write comments and then use "just sort of a indirect way of seeing trends and what was said and trying to analyze it that way. I certainly believe an independent investigator is a lot better, like Janet was". His preference was still to be reliant on the outside facilitator. Dr. Roger's intention for the action research project he implemented was on providing quantitative information to administrators to argue for the implementation of team teaching in other classes. So, his research is geared to gathering data to argue for a particular methodology and for "quality control". He added that an ongoing research focus could be on the team approach, but could not describe what this research process might look like. So, overall, the professors could not think of and generate researchable questions relating to teaching.

In formalizing their action research designs, most professors leaned towards a traditional scientific research process, even though they recognized that teaching is a qualitative process. They had a preference for quantitative procedures or "quantifying the qualitative dimensions of teaching". This is reflected in Dr. Lane's planned quasiexperimental design and in the use of pre- and post-test surveys used by Drs. Stevenson, Andrews and Rogers. Dr. Stevenson focused on student attitudes and knowledge, while Dr. Andrews and Rogers focused on student opinions of the class at the end of semester. 
The results of these studies were quantified and presented in graphical form. Only Dr. Walton moved towards formalizing qualitative processes as part of his ongoing reflection on his teaching by engaging students in 'so what sessions' at intervals during the semester in which students write comments about the class. He then analyzes this information for common trends that emerge to inform the future design and delivery of the class. However, even in this case, the process tended to be more informal than formal, without a clear research agenda. The formal action research component in the class taught by Dr. Walton was conducted by an outsider, but was also a qualitative design that used interviews with students to establish their perceptions of the class and examined student portfolios for evidence of appropriate instructional strategies being used by students. So, the model of action research he was exposed to may have facilitated his orientation towards a more qualitative approach because his conceptions were more objective and quantitative in nature.

Of particular interest is that Dr. Rogers stated that action research should focus on teaching and be part of an ongoing cycle of professional development, but did not reflect this in practice. In the first cycle the action research was only done at the end of the semester, with students completing a rubric evaluating their professors' orientation to inquiry-based learning. In the second cycle he turned his attention to student outcomes, rather than instruction, focusing instead on student attitudes towards science, content knowledge, and views on the nature of science. His design was quantitative in nature, employing pre-and post-test surveys of the NOVA course and another comparative science course, in a quasi-experimental design. Thus, his practices were completely at odds with his espoused views of the role, focus and design for action research. 
Comparison of conceptions and practices: Action research

This section compares the differences between participant's conceptions and practices of action research (see Table 29).

Table 29

A Comparison of the Conceptions and Practices of Action Research of Different

Professors

\begin{tabular}{|l|l|l|l|l|l|}
\hline Properties & Lane & Walton & Stevenson & Andrews & Rogers \\
\hline $\begin{array}{l}\text { Action research } \\
\text { conceptions } \\
\text { (total = 36) }\end{array}$ & 12 & 35 & 22 & 28 & 33 \\
\hline $\begin{array}{l}\text { Action research } \\
\text { practices } \\
\text { total =36) }\end{array}$ & 0 & 34 & 16 & 22 & 20 \\
\hline
\end{tabular}

Dr. Lane's had not continued with the original NOVA research because he had not been part of developing that proposal and did not feel committed to its implementation, although two sections of the course were still being taught by him for comparative purposes. This suggests that he did not know how to compare those two sections or what data should be collected. Also, his own reconceptualized action research project had not been implemented, again suggesting that he did not know how to do this, saying that "I have not basically put down the questions yet".

Dr. Walton's conceptions and practices show a comparable level, indicating overall consistency between conceptions and practices. One contradiction that existed was that he believed that action research was best conducted by an outsider, but then suggested that he was engaged in action research throughout the semester, through feedback from students and reflective processes. He also had preference for more 
objective methods of data collection, but in practice used informal discussion sessions with students.

For the other three, there is a bigger difference between their conceptions of action research and their actual practices, indicating a conflict between what they would like to do and what they actually did.

Dr. Stevenson's conceptions included using action research as a tool to improve teaching, favoring quantitative methods to gather data, what he called "quantifying the qualitative dimensions of teaching", while being acceptant of the subjective nature of teaching. In his implementation of his action research project he focused exclusively on student content knowledge, attitudes and perceptions of the course using quantitative methods to collect and analyze data. He was not able to suggest what aspects of teaching might be changed or improved based on the data collected. He exhibits what he called the "schizophrenia" of being a faculty member concerned with the qualitative dimension of teaching, while also being a research scientist concerned with quantitative and objective data. He was not sure how to integrate these two different research paradigms into a meaningful activity.

Dr. Andrews conceived of action research as an ongoing process geared to examining teaching effectiveness. Having relied on the education team member to learn about action research, it is likely that he developed his conceptions based on the information he was given. He had a dilemma as to whether it should be an informal or a formal process, considering faculty who were engaged in reflection about their teaching as engaging in action research. Later in the interview he called for valid instruments that could be used for comparative purposes over time, and also saw his teaching evaluations 
as part of action research, shifting towards a more formalized view of action research.

He claimed that he did not fully understood the process and wanted further information or to attend a workshop on the topic. Despite this, he displayed a fairly high level of conceptual understanding of its role and purpose, particularly as being geared to the improvement of instructional practices and conduced on an ongoing basis. In this regard he exhibited a much stronger subjective orientation to how knowledge about teaching is generated than he exhibited about discipline knowledge.

In practice though Dr. Andrews was not able to implement his own action research project and had relied on the education team member to identify a focus, the research instruments and the implementation strategy. So, his scores reflect that practice. The focus of the project was on teaching, but he was unhappy that the rubric that students used to score their practice had only been implemented at the end of the semester and would have preferred a process that was ongoing. He did not view the findings as particularly helpful because they were generally positive and therefore did not identify areas that needed change. He felt very inadequate about presenting the findings at the NOVA Leadership Development Conference, saying that the education team member should have performed that role because he was not an educationalist. This was further evidence that he considered himself a novice action researcher. In his other classes, he sees the annual faculty surveys done by students as being very helpful for his reflection on his teaching effectiveness, but again was critical because it was "not coming during the course of the class". So, he is grappling for ways to implement ongoing reflection in a more formalized manner. 
Dr. Rogers articulated a coherent view of action research as geared towards improving teaching practice in a systematic manner. For him, a systematic approach overcame the weaknesses of just reflection on action by being more "research oriented", or a "more well thought out level of reflection". His focus was on instruction and gathering of qualitative data from students and through observations of teaching by a participant observer. This implies an ongoing, cyclical process of gathering data and reflecting on its meaning. However, he found it difficult to suggest how this might be done, other than by keeping some notes of the process.

In practice Dr. Rogers adopted a quantitative approach using a rubric that was implemented only once at the end of the semester and focused on assessing the two professor's instruction. In his second iteration, he had moved away from a focus on teaching to a focus on student outcomes, which was contradictory to his views that action research be personal, contextual, geared to improving instruction and that the results not be made public. In this second cycle of action research he aimed to use the results to show administrators that the new teaching approaches had made an impact on student learning. This is at odds with his espoused purpose of it being geared towards personal reflection on teaching practice.

Summary of cross-case themes

In summary, the cross-case themes relating to action research are as follows:

- Conceptions about action research are structured around a set of properties, with different faculty holding different conceptions .

- Designs conceived were either quantitative or qualitative, with no mixed method designs reflected in the cases examined. 
- Most faculty members had a preference for objective data and quantitative methods. In implementing action research projects, most professors adopted a traditional quasi-scientific design using quantitative pre-and post-test surveys.

- Action research may have a role to play in higher education, but it is generally not well understood and these professors found it hard to engage with. They needed support structures to facilitate their efforts because most of them had never been exposed to the concept prior to NOVA.

- All believed that the results of action research should be valuable in improving instruction, but in practice were not sure how to use that data.

- Formal action research tended to be blurred with ongoing, informal reflective processes.

- The professors were not able to articulate new research questions and accompanying designs for future investigation.

- In the cases examined, there are contradictions between the beliefs and practices of three of the professors and one professor had not implemented any action research project.

\section{Theories of action and theories-in use}

This section aims to answer the third research question: How do theories of action (conceptions) relate to theories-in-use (practices)?

This section discusses the findings presented here in the light of the concepts of theories of action and theories-in-use. Theories of action are the espoused theories that people say drives their behavior. Theories-in-use are the actual theories that drive practice (Argyris \& Schon, 1974). 
In the cases examined, four of the professorsdisplay consistency between their theories of practice and their theories-in-use regarding teaching and learning, and assessment. Dr. Lane is committed to a content-oriented approach in which he is responsible for directing student learning. This is reflected in conceptions and practices of both phenomena. In contrast, Drs. Walton, Stevenson and Rogers adopted a studentfocused orientation focusing on knowledge utilization and production by students. For all these professors, the theories of action about teaching and learning were also comparable to their the theories of action about assessment. This was also true of their theories-inuse. In other word, there was consistency in theories of action and theories-in-use within and among conceptions and practices of teaching and learning, and assessment.

In regard to teaching and learning and assessment, the case that did not exhibit this congruence between theories of action and theories-in-use was that of Dr. Andrews. There was evidence of consistency among his theories of action regarding teaching and learning, and assessment, which tended towards an objective view of reality, with teacher-directed instruction through the delivery of content knowledge. However, these conceptions did not match the theories-in-use evident in the NOVA class that he teamtaught with another professor. Even though they planned together, he felt that the other professor had more responsibility for the pedagogy because this was his area of expertise. Thus, he felt obliged to accept the other professor's theories-in-use as far as implementing the class and this in turn presented a number of conflicts for him. Particularly, he was concerned about students not getting enough content knowledge in the NOVA course and that the teaching process was often too open-ended and inefficient. 
These were matters that Dr. Andrews was still working through, although he had come to the opinion that he did not have to teach "everything about science in this one class", indicating a shift away from his original stance. Similarly, although initially resistant to using performance tasks and assessment rubrics, he had begun to integrate these into his other classes. He was also doing more group work and student led projects in the other courses he teaches, although he still felt he had to justify to the students why alternative approaches were important because it was more time consuming than if he had "just told them the answers to these questions". It is clear that as a consequence of being involved with Dr. Rogers and being exposed to new ways of doing things, that his theories of action had begun to change, and these in turn were impacting his theories-inuse in other contexts.

The conceptions and practices of action research reveal some interesting aspects to the relationship between theories of action and theories-in-use. These are discussed next for each professor.

During the interview, Dr. Lane had a difficult time explaining what he understood by action research and drew his information from the one example he knew of, that of the process outlined in the NOVA proposal. He viewed action research as a traditional research process in which quantifiable data was to be gathered through test data that compared control and "experimental groups" because this was what had been planned in the NOVA proposal. This became his theory of action. However, it was not well developed enough to be transformed into a theory-in-use because he had not engaged in any data collection processes either for the NOVA course or for the other classes he had 
identified for gathering data about a new chemical procedure. So, he did not truly have confidence about the value of his theories of action.

When first asked, Dr. Walton did not know what was meant by action research and this researcher had to remind him that it was part of the process in which the education team member had been involved. After that, he articulated a clear view of action research as a process for teaching improvement. His theory of action was that it should be done by an outsider, using qualitative methods, such as interviews with students, observations of classes and materials produced by students, with information provided to the instructor to improve practice. He did qualify this by saying that he would prefer more objective methods and answers, but accepted that teaching is a subjective process. This theory of action appears to be driven by what had actually happened in the process of implementing the NOVA action research project. In practice, his theory-in-use was more personal, informal and reflective, based on what he has been doing as an instructor for many years. He saw action research as an ongoing process that he was engaged with at regular intervals over the course of a semester. However, he did not have any clearly articulated research questions or research focus, other than finding out what students thought of the course, and was not sure how to analyze the data other than summarizing student comments, adding that if "this is a constant theme from the students, this is something I have to give attention to". So, his theory-in-use was more informal than his theory of action.

Dr. Stevenson represents a case in which his theory of action is less similar to his theory-in-use. The major difference is that his theory of action reflected a tolerance for the subjective, qualitative nature of teaching, combined with a desire for objectivity in 
assessing student outcomes. In implementing his theory-in-use he reverted to the traditional research paradigm within which he was trained as a research scientist, emphasizing pre-and post-test scores, quantitative data, and neglecting the relevance of the data for teaching. Thus, his research training and experience heavily influenced his theory-in-use.

The theory of action described by Dr. Andrews reflects a desire for both informal and formal processes with a focus on improving teaching. He saw action research as an ongoing process that should provide information to the instructor about instructional effectiveness over the course of a semester. In practice he allowed Dr. Rogers to decide how to implement the action research project and this affected his scores. However, he was critical of the approach used because it was only done at the end of the semester and had not provided data that he thought was useful for improving instruction. At the end of this process, it seems that his theory-in-use was still evolving because he had not implemented any formal action research project on his own and could not articulate a research question, but had started to think of ways in which to elicit student participation. For this reason he valued the input of students at the end of semester and wanted other strategies to involve them on an ongoing basis, but he did not have any practical examples to draw on to consolidate his own evolving theory-in-use. While there is some difference in his scores for his theory of action and theory-in-use, he seems to be working towards aligning these and making them more coherent and consistent.

Dr. Rogers presents an interesting case because his theory of action regarding action research reflects a classical 'textbook' description of the process as being contextual, qualitative, directed at improving instruction, and involving a participant 
observer and students in the triangulation of data sources. It appears driven by a theoretical understanding of the process. In reality, his theory-in-use was completely the opposite, adopting a quasi-experimental, quantitative, comparative design that focused specifically on student outcomes for purposes of advocating a new approach across campus, rather than focusing on the specifics of one context. It seems that the environmental context was a major influence in this decision, as may have been his prior training in traditional scientific research and the fact that this was the first attempt at doing such research. Also, he was not able to generate a future action research question or design, which might be a reflection of never having undertaken the process in reality. His articulated conceptions just reflected a theoretical description. He did not show any evidence of trying to make his theories-in-use compatible to his theory of action.

Overall, theories of action relating to action research were often driven by examples of what was possible, such as the NOVA research proposal, the actual NOVA action research project implemented, input from a teacher educator or theoretical knowledge of action research. In practice, it tended to be driven by prior experiences of reflective teaching, or the dominant, traditional research paradigm.

\section{Scholarship of teaching and learning in practice}

This section aims to address the fourth research question: Does practice constitute the scholarship of teaching and learning, in relationship to the literature definitions?

The model for the scholarship of teaching and learning established by Trigwell, Martin, Benjamin and Prosser (2000) was used to analyze the scholarship of teaching and learning of each of the faculty members involved in the study. To do so, their model was converted into a 4-point rubric for each of their four sets of criteria, with a resulting total 
score of 16. Each instructor was given a score according to this rubric based on the evidence presented in chapter 4 . This model is reviewed in Table 30 and the results of that analysis presented in Table 31 .

Table 30

Multidimensional Model of Scholarship of Teaching

\begin{tabular}{|c|c|c|c|c|}
\hline & \begin{tabular}{|l|} 
Informed \\
dimension
\end{tabular} & $\begin{array}{l}\text { Reflection } \\
\text { dimension }\end{array}$ & $\begin{array}{l}\text { Communication } \\
\text { dimension }\end{array}$ & $\begin{array}{l}\text { Conception } \\
\text { dimension }\end{array}$ \\
\hline 1 & $\begin{array}{l}\text { Uses informal } \\
\text { theories of } \\
\text { teaching and } \\
\text { learning }\end{array}$ & $\begin{array}{l}\text { Effectively } \\
\text { none or } \\
\text { unfocused } \\
\text { reflection }\end{array}$ & None & $\begin{array}{l}\text { Sees teaching in a } \\
\text { teacher-focused } \\
\text { way }\end{array}$ \\
\hline 2 & $\begin{array}{l}\text { Engages with the } \\
\text { literature of } \\
\text { teaching and } \\
\text { learning generally }\end{array}$ & $\begin{array}{l}\text { Limited } \\
\text { reflection on } \\
\text { teaching }\end{array}$ & $\begin{array}{l}\text { Communicates with } \\
\text { departmental/faculty } \\
\text { peers (tea room, } \\
\text { conversations, } \\
\text { department seminars) }\end{array}$ & $\begin{array}{l}\text { Sees teaching in a } \\
\text { teacher-directed } \\
\text { way }\end{array}$ \\
\hline 3 & $\begin{array}{l}\text { Engages with the } \\
\text { literature, } \\
\text { particularly the } \\
\text { discipline } \\
\text { literature }\end{array}$ & $\begin{array}{l}\text { Reflection-in- } \\
\text { action }\end{array}$ & $\begin{array}{l}\text { Reports work at local } \\
\text { and national } \\
\text { conferences }\end{array}$ & $\begin{array}{l}\text { Sees some } \\
\text { teaching in a } \\
\text { student-focused } \\
\text { way }\end{array}$ \\
\hline 4 & $\begin{array}{l}\text { Conducts action } \\
\text { research, has } \\
\text { synoptic capacity, } \\
\text { and pedagogic } \\
\text { content } \\
\text { knowledge }\end{array}$ & $\begin{array}{l}\text { Reflection } \\
\text { focused on } \\
\text { asking what } \\
\text { do I need to } \\
\text { know about } \\
\text { here, and how } \\
\text { will I find out } \\
\text { about it? }\end{array}$ & $\begin{array}{l}\text { Publishes in } \\
\text { international } \\
\text { scholarly journals }\end{array}$ & $\begin{array}{l}\text { Sees teaching in a } \\
\text { student-focused } \\
\text { way }\end{array}$ \\
\hline
\end{tabular}

Note. - Descriptions have been created for some cells. From "Scholarship of teaching: A model," by K. Trigwell, E. Martin, J. Benjamin \& M. Prosser, 2000, Higher Education Research and Development, 19, p. 163. 
Table 31

Analysis of the Scholarship of Teaching of Five Professors

\begin{tabular}{|l|l|l|l|l|l|}
\hline & $\begin{array}{l}\text { Informed } \\
\text { dimension }\end{array}$ & $\begin{array}{l}\text { Reflection } \\
\text { dimension }\end{array}$ & $\begin{array}{l}\text { Communication } \\
\text { dimension }\end{array}$ & $\begin{array}{l}\text { Conception } \\
\text { dimension }\end{array}$ & Total \\
\hline Dr. Lane & 1 & 1 & 2 & 2 & 6 \\
\hline Dr. Walton & 2 & 4 & 2 & 4 & 12 \\
\hline $\begin{array}{l}\text { Dr. } \\
\text { Stevenson }\end{array}$ & 2 & 3 & 2 & 4 & 11 \\
\hline Dr. Andrews & 1 & 3 & 2 & 3 & 9 \\
\hline Dr. Rogers & 4 & 3 & 4 & 4 & 15 \\
\hline
\end{tabular}

Based on this analysis, Dr. Lane reflects the least engaged in the scholarship of teaching and learning, followed by Dr. Andrews. Accordingly, only Dr. Rogers can be considered as engaging fully in the scholarship of teaching and learning, with Drs.

Stevenson and Walton moving in that direction. While Dr. Stevenson and Dr. Andrews had presented their action research project findings at a NOVA Leadership Development Conference this was a one-off event and only Dr. Rogers was involved in presenting papers on an ongoing basis at national conferences and in writing research articles/books about teaching and learning.

\section{Summary}

In this chapter the results of cross-case analysis were presented and related to the research questions established in chapter one. Faculty conceptions and practices about teaching and learning, assessment and action research have been described and analyzed. The relationship to theories of action and theories-in-use have been addressed and finally a decision made as to whether faculty practices meet the criteria for the scholarship of teaching and learning established by Trigwell, Martin, Benjamin and Prosser (2000). 


\section{CHAPTER 6}

\section{DISCUSSION AND CONCLUSIONS}

Creating a new theory is not like destroying an old barn and erecting a skyscraper in its place. It is rather like climbing a mountain, gaining new and wider views, discovering unexpected connections between our starting point and its rich environment. But, the point from which we started out still exists and can be seen, although it appears much smaller and forms a tiny part of our broad view gained by mastery of the obstacles on our adventurous way up. Albert Einstein (cited in Zukav, 1979, p. 45)

The results of this study were presented in chapters four and five, with detailed case study analysis of five professor's conceptions and practices provided in chapter four, and cross-case analysis provided in chapter five. The case narratives and cross-case analysis represent a crystallization of sets of complex data, ideas and practices and thus reflect one way of telling these professor's stories. Their tales were made valid by having each of the participants engage in a member check of his individual story, to ratify it.

The purpose of this chapter is to draw together the findings and relate them to the relevant literature in the field, and then to move towards building a general theory that fits all of the cases, in reference to relevant literature. The implications of the 
study are discussed, particularly in the context of the NOVA program and recommendations for faculty development initiatives and for future research are also made.

\section{Faculty conceptions and practices: Teaching and learning}

Entwistle, Skinner, Entwistle and Orr (2000) placed faculty conceptions of teaching and learning into two dominant groupings, those that are teacher-focused and content-oriented; and those that are student-focused and learner oriented. Broadly speaking, this is also true of this research, with Dr. Lane and Andrews falling within the first category, and with the other three professors falling within the latter category. However, this research suggests that this classification is too limiting because there are so many different properties around which conceptions about teaching and learning are structured, so that faculty may exhibit some characteristics of another category. For instance, Dr. Lane and Dr. Andrews were content-oriented, but were not just teacher-centered, preferring instead to find ways to engage students, in some way, in the learning process. Thus, they fall more within the student-directing category, identified by van Driel, Verloop, van Werven and Dekkers (1997) who described a category where students were engaged in a variety of activities orchestrated and controlled by the teacher.

Dr. Andrews also displays elements of an additional possible category, one of being 'partners in learning' with students, where he considers himself learning from and with the students as he teaches. This might parallel the "student-teacher interaction" category coined by Kember (1997), where the instructor places an emphasis on student understanding and discovery. Similarly, Dr. Walton, Dr. Rogers 
and Dr. Stevenson see themselves as partners in a learning process through which they also learn. Their role is to provide leadership, so that students grow and develop under their guidance. There is an element of a student-directing category for these professors too because all of them assign tasks for students to complete. However, the latter three are more student-focused, engaging learners in original tasks in which there is some choice over content and methods used to complete those tasks, with the instructor's role being to challenge and assist as necessary. This is reminiscent of the "facilitating understanding" category described by Kember (1997) where the instructor recognizes that students are individuals, with differing needs and so caters to these needs by allowing open-ended discussions, by asking probing questions and challenging student's thinking. None of the professors in this study had students select the material to be covered, or allowed completely open-ended, studentregulated processes. This means that none were completely student-centered. As proposed by Kember (1997) this evidence suggests a continuum of conceptual categories, from teacher-centered to student-centered approaches, rather than hermetically sealed, discrete entities. The 'student-directing' and 'partners in learning' categories appear to be transitions along this continuum.

Kember (1997) also identified a category termed "conceptual change/intellectual development". While the scores for the Approaches to Teaching Inventory revealed that promoting student conceptual change and growth was a goal for all of the professors, their discussion of practices did not support this intention. Only Dr. Walton described a strategy aimed at addressing misconceptions, by having students take an online quiz prior to the topic being introduced in class. In this way he 
hoped that any misconceptions would be raised so that he could address these through hands-on activities and discussion. This is a clear instance in which conceptions did not match practices for four of the professors, possibly because they were not aware of specific instructional strategies that could be used to deal with student's alternative conceptions.

In this research, the epistemological assumptions of the professors were linked to their beliefs as was found by Entwistle, Skinner, Entwistle and Orr (2000). Drs. Lane and Andrews who were student-directing were also concerned with seeking objectivity and the delivery of content matter. The other three were more studentfocused, held more subjective opinions about the nature of reality and were focused on what students could do to demonstrate their knowledge and skills. However, even here, Dr. Andrews did not fit neatly into this categorization because he recognized the subjective nature of teaching and was keen to find ways to engage students in providing feedback about this dynamic process.

The professor's have developed their ideas about teaching primarily through trial and error, initially based on their experience as learners, but evolving over time through practice to a more sophisticated understanding of the teaching process, rejecting approaches that did not work and keeping those that do. Kreber (2002b) noted that while this is generally the accepted view of how faculty develop their teaching ideas and practices, that "empirical evidence is scarce" (p. 12) and so this study has provided validation to support this. That much of their pedagogical knowledge has been drawn from role models in their own education, either good or bad ones, indicates that they have learned through observation and modeling 
(Bandura, 1986), and this in turn has influenced their conceptions of teaching. Reflection on practice and feedback from students has also facilitated the development of their personal theories about teaching and learning. This is what Hativa and Goodyear (2001) call practical or craft knowledge, that is, knowledge that has developed through experience. Only Dr. Rogers had any formal education training and he was the only participant to refer to any educational theory or theorists during the interviews. This means that while they are able to articulate reasons for doing what they do, these are personal theories that are not necessarily supported by educational research. University faculty clearly need to provided with exposure to educational models and theories to support their practices.

All of the professors claimed that they have undergone some transformation over time towards more student-focused categories. Again, this suggests that change occurs along a continuum, as proposed by Kember (1998). The stimulus for such change was different for the each of the professors. For Dr. Lane it was the provision of resource materials that enabled him to use calculators with students. For Dr. Rogers it was a slow evolving process that did not have any particular cause, just a growing sense of realization that students needed to be integrally involved in the learning process. Similarly, for Dr. Walton, the process had been slow and occurred over many years. He cited the case of trying an innovative approach and receiving positive reinforcement from students for his efforts. In the case of Dr. Stevenson, changes in his views were emerging, but he had not had the opportunity to implement new ideas until the NOVA course, which provided him with the supportive context needed to experiment with new approaches. For these professors, change was 
evolutionary, requiring time and the right set of environmental conditions for it to occur. Because there has been a change in both conceptions and practices, this implies that double-loop learning (Argyris \& Schon, 1974), which requires a reexamination of beliefs and values, had taken place but at a slow pace.

This research shows that there is a clear relationship between conception of teaching and associated practices as was identified by Samuleowicz and Bain (2001). Because both conceptions and practices changed together over time, this suggests that these are reciprocal processes, providing feedback to each other through what Bandura (1986) calls reciprocal determinism, the interaction of different factors where each is a determinant of the other. In this manner the contradictions between theories of action and theories-in-use interacted reciprocally towards coherence. Only in the case of Dr. Andrews was there a conflict between conceptions and practices in the NOVA course that was team taught with another professor, and he was working to redress this situation. Because there has been a dearth of research that establishes the relationship between conceptions and practices (Samuleowicz \& Bain, 2001), the findings from this study that show a clear link are particularly important and are discussed in more detail later, in the light of Bandura' social cognitive theory.

The process of change for Dr. Andrews might be described as one of immersion, where his team member, through the implementation of the NOVA course, exposed him to new ideas. This process had been very challenging for him because he had to confront many of the assumptions he held about teaching and learning. Argyris and Schon (1974) would call this a dilemma of incongruity, in which there is an increasing incongruity between the espoused theory and the 
theories-in-use and has resulted in Dr. Andrews beginning to make a shift in his conceptions, and parallel to this, to employ some of the new methods in his other classes, that is to change his practices. This is double-loop learning involving confrontation to achieve transformation (Argyris \& Schon, 1974). So, for him, facing the contradiction between the espoused theories for his other classes and the theoriesin-use for the NOVA class, have led him to try to integrate his conceptions and practice for all contexts, in an attempt to resolve the conflict.

Faculty noted that there were several contextual factors that impacted the way in which they engaged in teaching. These specifically related to material conditions present in the university, such as time and resources, a dominant philosophy of content-based instruction, and in some cases administrative resistance to new ideas. For Dr. Lane an additional limitation presented by students was student interest and motivation. For most of the study participants working with non-science majors, the major constraints identified were student's prior learning experiences in which they expected teacher-centered instruction, their lack of exposure to associated alternative teaching approaches and poor student background knowledge in the sciences. Despite these limitations, the new teaching methods used by these professors have proved successful in enabling future science teachers to be more positive about the subject and more confident in their abilities to teach it. Contextual factors are also discussed more fully in a later section. 
As with conceptions of teaching, conceptions about assessment broadly fell into two categories, those that were focused on assessing content knowledge through the use of traditional forms of assessment, like exams and quizzes, and those that were concerned with assessing knowledge utilization and production though the use of authentic forms of assessment like performance tasks and rubrics. Samuelowicz and Bain (2002) identified three dominant categories around which conceptions about assessment were grouped, namely, (a) "reproduction of knowledge", (b) "application of knowledge, and (c) "transformational value of knowledge". Dr. Lane and Dr. Andrews can be placed into the reproduction of knowledge category although they both also displayed some elements of the application of knowledge category, Dr. Lane through applying knowledge to solving calculation based problems, and Dr. Andrews through questioning and discussion.

The other three professors were oriented towards the application of knowledge category, but were also concerned that student's learning should have long term benefits for them, thus indicating an orientation towards the transformational value of knowledge category. Again, this suggests that categories are not bounded systems, and that it is possible to have elements of more than one category, in an eclectic blend, represented within one individual, depending on the context or purposes for which the conceptions are used. Indeed Popekewitz's (1991) warns of the hegemony associated with being firmly embedded in one particular paradigm such that it restricts one's understanding and concomitant courses of action. He advocated paradigm blending. The important thing is for instructors to articulate their ideas, so 
that views are not just tacit structures, but are made public for critique and modification (Ho, 2000).

As with conceptions of teaching, the assessment conceptions were related to assessment practices. Only with Dr. Andrews was there a difference between conceptions and practices and this has already been discussed in the previous section where he was immersed into a new way of doing things and had to resolve the tensions between his ideas and the new concepts and behaviors he encountered in a team-taught class.

Conceptions of teaching were parallel to conceptions of assessment, with the two instructors that were more content oriented and teacher focused adopting traditional styles of assessment, while those that were student focused were concerned with assessing knowledge utilization and production via authentic assessment methods. This was consistent with the findings of Samuelowicz and Bain (2002) who also found that conceptions of teaching were linked to ideas about assessment.

Assessment was viewed as an important tool to provide feedback to students to enhance their learning. This varied from one-on-one approaches to group and whole class feedback. However, this assessment feedback related specifically to instructor's providing feedback on student outcomes and activities, rather than learner reactions to instruction as suggested by Angelo and Cross (1993). Only Dr. Walton used a formal form of assessment to assess his instruction, that of 'so what sessions', while the others tended towards informal reflective processes in which students were not formally involved. 


\section{Faculty conceptions: Action research}

Conceptions about action research broadly reflected two categories, those that were focused on student outcomes using quantitative methods, and those that focused on teaching using qualitative methods. There were no mixed method designs represented by the cases. Most of the faculty had a preference for objective data and quantitative methods of inquiry, consistent with the dominant paradigm of research in science (Kezar, 2000a).

Using the framework established by Kemmis and McTaggart (2000, see p. 77), the data show that their action research efforts are primarily technical in nature, with only one, Dr. Walton, reflecting practical concerns in which there is dialogue with others and an intention to generate consensus. Technical research orientations in action research are considered the least developed of orientations (Carr \& Kemmis, 1986). Overall, there is no evidence for emancipatory research agendas that would work on dealing with issues of power and competing views of reality, such as the constraint on student learning that was identified where students expect didactic instruction. There is also little evidence on the extent to which action research has been used to examine the effectiveness of particular approaches to teaching, to reflect on classroom relationships, to consider issues relating to classroom climate, to examine personal mental constructs and their impact on teaching, or even the impact of different assessment techniques. Such agendas could reflect practical or transformation concerns. Research was primarily reserved for examining the impact on student learning, with technical goals, and it might be argued that this was done to justify the introduction of a new course and to counter any negative perceptions about 
innovation from other faculty or administrators. Only Dr. Walton was successfully finding ways to use the information from students, on an ongoing basis, to impact his future teaching of sections of the course. The others had not yet found ways to use the data collected from action research to make changes to their instruction. It is possible that these faculty members did not see themselves as producers of educational knowledge through action research, as was found by Walker (1993) working with school teachers. Practical and emancipatory research agendas are possible but apparently have not been considered in the case of the professors in this study.

The professors did call for instruments that could be used to assess their instruction, indicating that they lack familiarity with the general field of educational inquiry because there are numerous readily available assessment instruments that can be used to assess the quality of instruction (Cross \& Angelo, 1993). These instruments called classroom assessment techniques (CATs) include a range of strategies can be used to in higher education to assess (a) course-related knowledge and skills, (b) learner attitudes, values and self-awareness, and (c) learner reactions to instruction. So, there is a need to provide more input on instrumentation for data gathering and on data analysis, particularly with respect to qualitative techniques.

Evidence presented also shows that successful implementation of a qualitative approach to teaching was dependent on the successful functioning of interdisciplinary faculty teams, where the education team member served as an important resource and participant observer in the action research process. This process had also served to inform Dr. Walton's views towards thinking about a qualitative, participative approach to assessing his own teaching, rather than the more objective approach he 
preferred. But, in general faculty were comfortable with quantitative approaches because these are part of their disciplinary repertoire (Huber, 1999), but less familiar with techniques for gathering and analyzing qualitative data. For instance, Kember and McKay (1997) noted that the use of control groups is unusual in action research groups, but this was the conception of research design articulated by Dr. Lane and Dr. Stevenson and demonstrated in the practices of Dr. Stevenson. Similarly, Dr. Rogers turned to a quantitative design for both iterations of his research, even though his conceptions did not reflect this view. That faculty are more prone to using quantitative techniques suggests that it may be difficult to move faculty in science disciplines out to the research paradigm with which they are most familiar and comfortable. The use of a broader range of methodological approaches, as promoted by Keller (1998) is likely to provide a richer and more in depth platform for examining teaching and learning, but may be difficult to promote among science faculty.

In the cases examined there were contradictions between beliefs and practices of three of the professors and one had not implemented any action research project. For Dr. Stevenson it was because of his conflicting orientations to teaching and to research, with research being seen as more objective than teaching. Dr. Rogers shifted to a quasi-experimental design because he wanted to gather information to show that the new method benefited students, despite espousing different ideas and Dr. Andrews followed along and felt disempowered by his lack of understanding about research tools and alternative designs. Similarly, Dr. Lane was also not empowered because he had not implemented any research project. So, it appears that as a 
consequence of the limited exposure to its processes, the conceptions of action research were not well developed and this resulted in practices that reflected the traditional research paradigm in which they were all trained. They had not acquired new ideas about the phenomenon through observation and modeling, as was the case for conceptions of teaching, learning and assessment, processes in which they themselves had participated as learners. This shows that by-and-large these professors are oriented towards the empirical-analytical paradigm (Popkewitz, 1984) and that their research training has framed their thinking about educational research too. These contradictions are discussed more fully in the section on conceptual change.

Action research is an iterative process that involves cycles of planning, acting, observing and reflecting (Hopkins, 1993). Reflection necessitates the origination of new hypotheses and research questions for ongoing planning, action, observation and reflection. However, faculty found it hard to conceive of questions that focused on teaching or ones that were different to the first cycle of research. Schon (1995) concluded that introducing and legitimizing action research would to prove difficult with scholars in the disciplines undertaking the research, and these cases confirm his suspicions. More work is needed in developing the type of professional development to encourage faculty to move towards examining their own teaching practices within an action research mode that utilizes the pluralistic research methods suggested by Keller (1998).

The lack of familiarity with action research in higher education is a major challenge that confronts its usefulness as a strategy for bringing about educational change (Bondy \& Ross, 1998; Ross \& Bondy, 1996). This current research confirms 
that even the faculty who had been through seminar training and were teamed with an educationist still have difficulty conceptualizing and implementing action research processes. It is clear that action research has not been fully and formally embraced by any of these professors as a mechanism for improving instruction on an ongoing basis. Instead, they have reverted to informal reflective process to inform their teaching. Also, as noted by the research participants, action research is not a generally well-known concept in the disciplines in higher education, although some faculty may be engaging in informal processes, such as through personal reflection on teaching. While reflection on action is one part of action research, by itself it does not constitute action research, but reflects the initial stages on a continuum from reflection towards more formalized action research processes (Walker, 1993). For action research to be meaningful for instructional development and to meet the criteria for the scholarship of teaching and learning (Trigwell, Martin, Benjamin, \& Prosser, 2000), it needs to be formalized and informed by educational and pedagogical theory. Unless there is a broad scale movement in higher education to promote action research as a method for improving instruction, associated with incentives for change like promotion and tenure, it is likely to remain better represented in the K-12 system.

\section{Conceptual change}

As a reminder to the reader and as discussed in chapter 2 , there are two main theories that were identified as relevant to the discussion about change within individuals, (a) theories of action and theories-in-use (Aryris \& Schon, 1974) and (b) the theory of conceptual change (Posner, Strike, Hewson \& Gertzog, 1982). 
Change in behavior often requires a fundamental re-examination of the underlying beliefs, values and assumptions that underpin action. Argyris and Schon (1974) called this double-loop learning because it necessitates the examination of old ways of thinking and doing, and the building of new theories of action, and new theories-in-use. It is different to first loop learning, in which new ideas are added onto the old accumulatively without any conflict occurring. In contrast, double-loop learning usually occurs through dilemmas that arise and present contradictions to assumed beliefs. They identified four types of dilemma, (a) dilemmas of incongruity, which arise because on an increasing incongruity between espoused theory and theories-in-use, (b) dilemmas of inconsistency when coexisting beliefs and values within the theory-in-use become incompatible, (c) dilemmas of effectiveness, when it becomes increasingly hard to achieve established goals, and (d) dilemmas of value when an individual begins to dislike the behaviors that the theories-in-use created (Argyris \& Schon, 1974). As people are exposed to such dilemmas, they are forced to reconsider their assumptions and their thinking.

Kember (1997) believed that change from one conception to another was likely to be slow and difficult to effect. Indeed, for Drs. Walton, Rogers, Stevenson their shift away from teacher-centered approaches took many years to effect. Even for Dr. Lane who has shifted his conceptions from being purely teacher-centered to a student-directing orientation, this had taken years. This process can be described as evolutionary change involving slow processes with both first and double-loop learning likely to have taken place. 
For Dr. Andrews, however, the change in his thinking about teaching and assessment processes was much quicker, foisted upon him by the introduction of the NOVA course. This had placed him into a situation where he was forced to confront his existing conceptions and to make changes. This is akin to the conceptual change process described by Posner, Strike, Hewson and Gertzog (1982) for scientific concepts. They noted that there are four conditions necessary for conceptual change to occur, (a) that there must be "dissatisfaction with existing conceptions" (p. 220) leading the learner to considering alternatives, (b) that a new conception must be intelligible, (c) that a new conception must appear plausible by making sense, and (d) that the new conception should be fruitful, explaining more than the old conception was able to do. Clearly, these conditions have been met in the case of Dr. Andrews as he is working to clarify the mismatch between his espoused theories, and the theoriesin-use evident in the NOVA course. This an example of second-loop learning. It is particularly important to note that he is apparently uncomfortable with holding different conceptions for different courses, but is concerned to arrive at one common set of conceptions around which all of his teaching practices revolve. This process might be called change by immersion because it has occurred over a relatively short period of time. It likely has also included change through observational learning and modeling (Bandura, 1986) of some of Dr. Rogers's practices, such as the use of cooperative groups, performance tasks and rubrics. The NOVA course provided him with the opportunity to observe new behaviors in a social context and to begin to modify his conceptions accordingly. 
Because the concept of action research was new to the science practitioners in this study they had to learn about it from the earlier NOVA workshop and the education team member. They engaged in this process in different ways. For Dr. Stevenson, this took the form of being told about it by the education team member, rather like model one or single-loop learning where new ideas are layered upon the old ideas without any reconceptualization or challenge occurring (Aryris \& Schon, 1974). This style of learning about action research is reflected in his conceptions and practices where he adopted a quantitative approach focusing on student learning, despite his strong orientation towards the subjective nature of teaching. This suggests that he resorted to using the traditional model of research practice that derive from his discipline and with which he is familiar (Huber, 1999). Dr. Stevenson described a dilemma of values, when he referred to the "schizophrenia" of being a faculty member concerned with the qualitative dimension of teaching, while also being a research scientist concerned with quantitative and objective data. Dilemmas of value occur when an individual begins to dislike the behaviors that the theories-in-use created, as indicated by his desire to use the data to improve teaching, but not knowing how to do so. In this way he is beginning to engage in double-loop learning as he begins to reexamine his assumptions and practices. In time, this may lead to a reconsideration of his conceptions about action research, but he is not yet at that point.

Dr. Lane was not exposed to the NOVA workshop and only experienced single-loop learning about action research by reading the NOVA proposal, where a quasi-experimental project had been planned This did not raise any dilemmas for him 
because it neatly fit his existing ideas about research within the discipline. Indeed, it served to reinforce his ideas about a possible future research project design. It appears that he has not been posed with any major dilemmas to challenge his existing conceptions.

A second way to learn about action research was to see good practice being modeled by the education team member, as in the case of Dr. Walton, where a qualitative research design that included interviews with students and faculty, and documentary analysis of student portfolios, was undertaken. While this reinforced his notion that an outside observer provided more objectivity, he had also seen the value of a qualitative approach that involved students and the instructor in reflection and dialogue. So, he learned through observation and seeing good practice modeled in a social context (Bandura, 1986), and in the process had revised some of his conceptions about action research. This reflects double-loop learning as a dilemma of inconsistency, where there are competing values within the theory of action or theoryin-use, leading to a reconsideration of his original ideas in which he had a high regard for external objectivity and became more tolerant of subjective processes. His practices had also shifted towards more qualitative approaches for which he was responsible and in which students were engaged.

Dr. Andrews stated that he had first heard the term action research at the NOVA LDC, but was not ready for the concept at that stage because they had not yet conceptualized their course. So, for him, the first-loop learning did not make a lot of sense. His involvement with Dr. Rogers presented an opportunity for modeling and observational learning to occur but this did not happen in practice because the action 
research was done as a post hoc, end of semester, one-off event. This led him to be frustrated with the process, not valuing the intention or outcomes because of the method of implementation. While he did not learn what good action research was, it made him critical of what did happen and keen to learn more about it in future. Again, this reflects double-loop learning, where he experienced a dilemma of effectiveness because the goals he wanted to achieve, that is, improved instruction, were not met (Argyris \& Schon, 1974). In time, through additional single and double-loop learning, his conceptions and practices had consolidated.

In considering the dilemma of how to effect conceptual change it is useful to consider potential barriers to change that might inhibit the shift. Dalin (1978) defined four barriers to change, namely practical, psychological, power and value barriers, which work against change. Practical barriers include any type of structural barrier, like time, finances or equipment and often are the easiest to overcome. In the case of the NOVA program this barrier was overcome through the provision of a grant that allowed for the purchase of materials and payment of stipends for participating faculty.

Psychological barriers exist because people would rather stay with what they know because they feel deskilled by new ideas and approaches. Thus, it is likely that the psychological barriers present a strong resistance to change because conceptual change requires intense introspection and movement away from that which is familiar. This is associated with values barriers, where existing, underlying values could be in conflict with the new set of values associated with change. An individual is vulnerable during this period of re-examining their underpinning values and modes 
of thinking. Hence, the provision of support structures and processes will provide a strong psychological cushion during the period of transition. In the NOVA course, the education faculty member helped with this process although this was not their specific task and their time allocated to NOVA was limited. It would be preferable to have a support person who is dedicated to this role, such as the 'critical friend' described by Kember (1998).

Supportive structures are particularly important where the power barriers, which include vested interests and power relations associated with hierarchies, are opposed to change. Dr. Rogers found that the lack of understanding by the dean about the team teaching approach had put a damper on the interest displayed by other faculty. In contrast, Dr. Stevenson and Dr. Walton noted that the support of their deans had been vital for implementing their courses, despite resistance from some other faculty members in the department. This suggests that it might be best to start any change strategy by analyzing the power relations in an organization to identify the power barriers, and to build alliances of persons with similar interests

Other values barriers that were cited by participants in the study were (a) the dominant paradigm that promotes large classes, a content orientation and lecture-style delivery of instruction, and (b) student's expectations of didactic instruction that made them uncertain of the expectations and purposes associated with studentfocused instruction. This suggests that students are geared towards surface learning and find it hard to adapt to a deeper approach to learning when their instructor adopts a deep approach to teaching (Prosser \& Trigwell, 1999). This presents a barrier to their own learning and conceptual development. It can also be a power barrier, 
because students find it hard to adapt to the new style, still seeing the instructor as the one who gives out grades, so that it is hard for the instructors to win student trust and confidence. This barrier is associated with the practical barrier of general poor student preparation in the sciences, particularly in the case of teaching non-science majors, thatwas the focus of this research. So, there are barriers within any particular context that make change more difficult to implement and these may be practical, psychological, value or power barriers. It appears that conceptual change does not just rely upon the shift in personal values, but is impacted by a multitude of external, environmental conditions.

Social learning theory as a model for changing concepts and practices

While the conceptual change model proposed by Ho $(1998,2000)$ have yielded results in bringing about change in faculty beliefs and practices of teaching, as has the notion of double-loop learning (Argyris \& Schon, 1974), there are elements in both these models that are missing. First, they do not take into account the environmental or contextual conditions necessary for these changes to take place, such as those that relate to the practical, values and power barriers described in the previous section. Environment should be taken to include the social environment that involves students, class interactions and dynamics, as well as the broader administrative context. Second, the conceptual change model and double-loop learning model suggest that change in conceptions must precede a change in behavior and yet there is some evidence that these are reciprocal processes, or indeed that a change in practice may actually create a shift in a person's personal paradigm (Raubenheimer, 1994). For this reason, Bandura's social cognitive theory provides a 
more embracing model that can be used to explain a broader range of factors associated with changes in conceptions and practices.

Social cognitive theory states that there are reciprocal relationships between three factors, behavior (B), cognitive and other personal factors (P), and environmental influences (E), which "all operate interactively as determinants of each other" in a process called reciprocal determinism (Bandura, 1986, p. 23). This is represented diagrammatically in Figure 28.

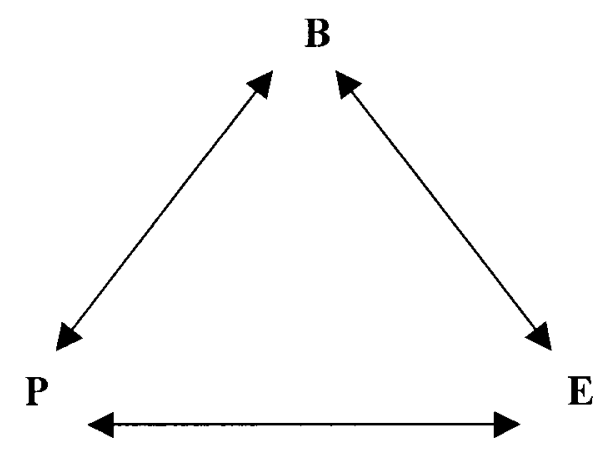

Figure 28. Schematization of the Relations between Three Classes Df determinants in Triadic Reciprocal Causation.

From Social foundations of thought and action: A social cognitive theory, by A. Bandura, 1986, p 23, Englewood Cliffs, NJ: Prentice-Hall.

In the cases examined there are several examples of interesting reciprocal processes. The fact that personal constructs about teaching and learning have evolved over time for several of the professors to be consistent with their theories of action indicates that personal factors and behavior interacted with each other in a reciprocal relationship to develop a coherence between conceptions and practices. 
Bandura noted that, "in most instances, the development and activation of the three sets of interacting factors are all highly interdependent" (p. 24). Using this notion of social cognitive theory, it is likely that the development of coherence between theories of action and theories of practice required a conducive environment for this to occur. For instance, Dr. Walton noted that the changes he made in his practices began to gain momentum after he had implemented a graduate in-service course for science teachers. He had created a set of environmental conditions that provided him with positive feedback from the participants (social environment), further reinforcing his concepts and future behaviors. This reciprocity between factors grew as he tried new ideas in different contexts and continued to receive positive reinforcement. Dr. Rogers experimented with new approaches to teaching in his school classroom, restructuring the environment and his behaviors to reflect a more inquiry-based approach to teaching. This was a nurturing, supportive environment in which change and new teaching methods were encouraged. His emerging philosophy took time to develop, but is one he is deeply committed to. In the case of Dr. Stevenson, the NOVA honors course provided a safe environment for him to experiment with new ideas, with the support of his administrators, but without the constraints present in teaching large classes. He received positive feedback for his actions from those in his social environment (students and immediate superiors). So, again, the three determinants reciprocally reinforced one another. For these professors the environmental factors were central to them making changes in practices and conceptions because the feedback from the social environment provided positive reinforcement and aided in shifting their personal beliefs, which in turn 
reinforced their behaviors and their restructuring of the environment. Bandura noted that "the production of a reciprocal effect takes time" (p. 25), explaining why the evolutionary transition to new approaches took years for these professors.

For Dr. Lane, the environment he has worked in has also reinforced his teaching approaches. When he made a shift from being teacher-centered and lecture dominated, towards a student-directing approach, the social environment positively reinforced this. In his context students and administrators have been satisfied with this student-directing approach to teaching, further reinforcing his behaviors and his conceptions. Similarly, Dr. Lane's beliefs about action research were informed by his prior experiences (behaviors) of scientific research methods. This reciprocally reinforced his beliefs in a social context, where the status quo was accepted.

The case of Dr. Andrews is particularly interesting because he was put into an environment that did not match his personal constructs or his preferred teaching practices when he began teaching the NOVA course with a team member. At first he was resistant to many of the ideas because they were different to what he was used to or what he conceived to be important. But, over time the alternative behaviors and the new context he was exposed to in the NOVA course have acted to change his conceptions. "Environmental influences can affect persons apart from their behavior, as when thoughts and feelings are modified through modeling, tuition or social persuasion" (Bandura, 1986, p. 25). Indeed, Dr. Andrews noted that the NOVA course had been his "training" in how to teach, such that the new behaviors and environmental feedback in turn began to change the way in which he conceives of and constructs other teaching environments to reflect the NOVA course 'philosophy' 
and the way in which practices his teaching and assessment functions. So, for him, the stimuli for change were observing new behaviors in a supportive environment, which acted reciprocally to change his conceptions, as well as his future behaviors and the way he structures his other teaching environments.

While, the three factors play important roles in reinforcing one another in a reciprocal manner, Bandura (1996) wrote that,

Reciprocity does not mean symmetry in the strength of bi-directional influences. Nor is the patterning and strength of mutual influences fixed in reciprocal causation. The relative influence exerted by the three sets of interacting factors will vary for different activities, different individuals, and different circumstances. When environmental conditions exercise powerful constraints on behavior, they emerge as the overriding determinants. (Bandura, 1986, p. 24)

Bandura also states that, "the triadic factors do not operate in the manner of a simultaneous wholistic intersection. Reciprocity does not mean simultaneity of influence" (p. 25). So, it is possible for one factor to exert a stronger influence over the others, for the differences to be felt over time, and even for one determinant to be shunned. This may result in maladaptive behavior, inconsistent thinking or inappropriate environmental conditions because one factor in the triad is dominant and at least one is ignored or circumvented.

These concepts may help explain the scenario where Dr. Rogers engaged in an action research project that did not meet his personal constructs about what constitutes action research. Because of contextual administrative pressures, he 
resorted to a process that would help explain to administrators the benefits for students of the NOVA course and the team teaching approach. Power barriers in the environment were in operation. Thus, he adopted a quasi-experimental, quantitative process that reflected a rational paradigm typical of administrators and applicable to traditional scientific research. It appears that he set aside his personal ideas about action research and was driven by contextual demands to adopt strategies (behaviors) that were not consistent with his espoused ideas. So, the "relative influence" of environment appears to have overridden his espoused ideas, with him just being concerned with environment and behavior.

It is also possible that because Dr. Rogers had not previously undertaken an action research project that reflected his espoused beliefs, that these ideas, which reflect the typical textbook definitions, had never been reinforced by practices or by a supportive environment. Zuber-Skerritt (1992b) noted that while academics may publicly commit themselves to more progressive ideas, "in practice they often retreat to a traditional approach" (p. 30). She could not offer any explanation for this, but one explanation might be that environmental conditions, as well as prior experience of certain behaviors, in this case those associated with a traditional research paradigm, could override the espoused beliefs (theories of action). And because the environmental and behavioral influences were strongly mutually supporting each other, they circumvented the reciprocal relationship with his espoused conceptions. It would be interesting to establish if, in time, Dr. Rogers begins to address this inconsistency by either reflecting more quantitative approaches to his views about action research or by adopting more qualitative approaches in his attempts to 
advocate the value of the course. Alternatively, it is also possible that there are two different triads operating, one for the classroom context, and one for the context of administrators and external evaluators. This area needs further research by interviewing Dr. Rogers. It is the intention to do so.

If indeed there are different triads for different contexts, then this might explain why faculty will engage in didactical teaching when confronted by large classes, because they have not had other approaches modeled for them in similar environments. In this study Dr. Stevenson was the only participant to cite large class size as a limitation to effective teaching because he teaches in a large, state university. He added that when teaching such classes he was forced into adopting a lecture-based style. In such cases, even though their conceptions might reflect a preference for participative and experiential approaches to teaching and learning, professors have not learned to change their behaviors through observational learning of other ways to deal with large classes.

The differences between Dr. Stevenson's espoused conceptions about teaching and his espoused beliefs about action research represent another interesting case that can be explained by social cognitive theory. In this case, it appears that there are two separate reciprocal triads operating, one for the phenomenon of teaching, learning and assessment; and the other that operates for the phenomenon of research. Dr. Stevenson acknowledged "schizophrenia" between his more subjective views about teaching, learning and assessment, and those associated with research. He attributed his views about action research to his training as a research scientist. Thus, this 'research' triad has been reciprocally reinforced over time by his successes as a 
research scientist. Similarly, the triad for 'teaching, learning and assessment' has been reciprocally reinforced over time by his successes as an instructor. That these two triads exhibit an inconsistency between each other only presented a problem when Dr. Stevenson began to consider how he might use the results of the action research to improve his instruction, that is, when he began to think about the relationship between these two triads. Again, it will be interesting to find out if he resolves this dilemma and this is another area for future research.

While cognitive social theory has assisted in explaining the cases examined in this study, Bandura noted that,

Intricate analysis of triadic reciprocality still awaits the tools for gauging how multiple reciprocal links of influence operate together and the time course in which they operate. This is a formidable task not only because the triadic systems are interactive, but because each subsystem itself contains multiple reciprocal processes. (Bandura, 1986, p. 28)

So, the cases examined by this research have contributed to an understanding of how reciprocal processes may impact how faculty engage in their work functions.

However, it has also left several areas for future investigation.

\section{Implications for faculty development initiatives}

Several of the professors in this study adopted approaches to teaching that were student-centered. Elementary education students in these classes stated that they had a more positive attitude to science and felt more confident to teach it in the future. It appears that the negative cycle of experience that results in poor classroom science teaching in schools has been broken through inquiry-based approaches to 
teaching college science. This process appears to be assisted when faculty have student-centered theories of action that are consistent with their theories-in-use.

Clearly there is a need to expose science faculty to new teaching and assessment methodologies and to move towards integrating theories of action with theories-in-use, where there are inconsistencies between these. Much faculty development has tended to adopt a single loop approach, simply teaching about new ideas without challenging the old. The conceptual change model proposed by Ho $(1999,2000)$ has challenged this notion and shown that bringing about conceptual conflict can result in new teaching approaches being adopted, concomitant to new ideas about teaching and learning. However, she noted that this was not successful in all cases.

Similarly, Borko and Putnam described professional development as extending faculty (a) "general pedagogical knowledge", (b) "subject-matter knowledge", and (c) "pedagogical content knowledge" (p. 60), although their subjectmatter knowledge is likely to be the most developed. It appears that changing conceptions, and changing knowledge about pedagogy are not sufficient in all instances. The findings of this research suggest that it is important to consider more than just knowledge, conceptions and behavior in shifting practices and to engage in faculty development initiatives in which the social cognitive triad is clearly represented. This means it becomes necessary to examine the context in which such changes are being made and to facilitate the creation of a supportive, enabling environment (Chopp, Frost \& Jean, 2001). Successful faculty development programs can only occur with adequate institutional support (Camblin \& Steger, 2000). 
Kreber (2001b) made five recommendations for faculty development. These are discussed here in the light of the findings from this study and the implications for the NOVA program are highlighted. First, Kreber suggested that there is a need to, "introduce faculty wide collaborative action research programs in which professors and faculty developers explore teaching and learning in the discipline" (Kreber, 2001b, p. 81). Action research can be an effective mechanism for faculty development as has been established in other contexts (Kember, 1998, 2000; Kember \& Gow, 1992; Kember, 1998, 2000; Zuber-Skerritt, 1992a, 1992b). However, this research has shown that action research is generally not well understood by science faculty, who tend towards informal reflection rather than ongoing cycles of planning, acting, observing and reflecting on the results of observation. The faculty in this study were not able to articulate new research questions or designs and clearly needed much more support to move beyond the first iteration of research that was done to satisfy NOVA requirements. This is where the "critical friend" described by Kember (1998) becomes very important. It is often not possible for faculty to arrive at new conceptions and practices, without seeing those modeled for them in an unthreatening context, or without having someone else be their 'eyes and ears' and to provide a critical perspective on their practices. The "critical friend" would play the role of participant observer and educational theorist. However, this should not be a part-time person with their own teaching commitments, as was the case in the NOVA, but a person who is available to work with faculty on an ongoing basis, through successive iterations of action research, for instance through a faculty center for teaching and learning. The faculty also need have additional training in action research methods 
and to be encouraged to take ownership of the process, rather than seeing it as something that the education team member was responsible for. Clearly, this will require institutional funding and support.

Interdisciplinary teams, peer mentoring and collaboration amongst various stakeholders can be important ingredients for faculty change (Harnish \& Wild, 1994; Quinlan \& Åkerlind, 2000; Wilhelm, Craig, Glover, Allen \& Huffman, 2000). In the NOVA project, the interdisciplinary team that included a science and education team member, as well as an administrator was consistently cited as a strong benefit during the evaluation of the program (Sunal, Kallam, McKinnon, Raubenheimer, Gardner, MacAllistair, et al., 2003). The case of Dr. Andrews and Dr. Rogers team teaching a course showed the power of learning by observing, acting alongside an experienced teacher, with Dr. Andrews learning new approaches to teaching, while at the same time changing his conceptions. However, team teaching is difficult to arrange in a university context because of the allocation of teaching credit hours. In this case, both ended up teaching an overload, without getting credit for this. Kreber (2001b) also suggested team teaching as a way to stimulate discussion and reflection to improve practice. Kezar (2001), however, noted that there is a paucity of research in this area because most universities are not learning organizations and also because the shift is mostly a "philosophical change" within individuals and so is difficult to research empirically. Dr. Rogers noted that he planned to implement research on team teaching in future, but was not sure how to design the study. This would be a valuable research effort for NOVA to support. 
So, for team teaching and mentoring to be a viable proposition would require restructuring of teaching loads and this in turn requires administrative support and funding. These are obviously not roles the NOVA can take on as goals, although it could play an advocacy role in this regard.

For NOVA, it is clear that there is a need to continue funding the development of new science courses because it is only through those grants that interdisciplinary teams have been able to work together and initiate these innovative classes, shown to impact students in many different ways (Sunal, Kallam, McKinnon, Raubenheimer, Gardner, MacAllistair, et al., 2003). NOVA does make available further grants for research, but few of the NOVA participants have applied for these. A workshop providing further action research training, for instance during a future Leadership Development Conferences (LDCs) might facilitate more interest in this aspect. Specifically, consideration should be given to making additional grants available to support future iterations of the action research cycle with a focus on teaching.

There are many different definitions for the scholarship of teaching and learning. One of the common criteria established is that the results of research on teaching effectiveness be made public (Hutchings \& Schulman, 1999; Richlin, 2001; Trigwell, Martin, Benjamin, \& Prosser, 2000) and "become part of the knowledge base of teaching and learning in higher education" (Richlin, 2001m p. 58). Using this definition, three of the professors had communicated results at NOVA LDCs, but only Dr. Rogers had presented papers about teaching on an ongoing basis at national conferences and in writing research articles/books. Dr. Walton and Dr. Stevenson might be considered as being engaged in scholarly teaching (Richlin, 2001), in which 
professors undertake some formal research, but the results of which are not widely communicated to the public. So, most of the science professors in this study were not yet engaged in the scholarship of teaching because they were not yet fully engaged in formal research about practice and in communicating those results.

While the NOVA program has broadly publicized the results of the NOVA evaluation at national conferences (e.g. Sunal, Sunal, Whitaker, Odell, \& McKinnon, 2003) and through other publications (Sunal, Wright, Bland, 2004), this has primarily only involved the research fellows, and not the general NOVA participants. The NOVA program could promote a move towards the scholarship of teaching by providing more opportunities for faculty to present the findings of their action research. While this is done at LDCs in the form of presentations to other NOVA participants, this needs to be formalized to include written products available to the broader educational community. This might take the form of single publications, or a NOVA journal focusing on action research projects and their results.

Second, Kreber (200lb) suggested that faculty "contract for and focus on the scholarship of teaching for a given number of years" and that institutions "allow for sabbaticals to be dedicated to the scholarship of teaching" (p. 83). Aleamoni (1997) added that faculty development should be linked to faculty assessment, with institutional commitment to "a comprehensive instructional evaluation scheme and a subsequent comprehensive instructional development program" (p. 36). This means that institutions would need to commit time and resources to restructuring the way in which faculty development occurs, and for it to be linked to promotion and tenure processes. As already discussed in chapter 2 , this is part of a current national debate 
that started with Boyer's seminal work on the scholarship of teaching. Shifting the focus towards the scholarship of teaching will require the implementation of new methods for assessing faculty effectiveness based on new standards (Glassick, Huber and Maeeroff, 1997). This is beginning to gain momentum across the country through the work of different organizations such as the American Association for Higher Education and Carnegie Foundation for the Advancement of Teaching and Learning. These organizations can lobby and advocate the shifts that are necessary.

The third recommendation by Kreber (2001b) was that faculty development be based on educational theory and research. Teaching practices should be examined through a combination of reflection and an articulated theory and knowledge base (Entwistle, Skinner, Entwistle, \& Odd, 2000). As had already been discussed, the conceptual change process used by Ho $(1999,2000)$ has yielded results. This research has suggested that an additional theoretical perspective, that of reciprocal determinism, is important to the study of how people change behaviors and conceptions. These are not one-way processes, but are reciprocal relationships in a triad of personal factors, behaviors and environmental influences. In the context of the NOVA program, environmental influences have been acknowledged as important and this is why an administrator is required on participating NOVA teams. NOVA might use these administrators to greater effect as change agents if they provided additional support to them through further small research grants to examine the impact of contextual constraints on implementing innovation. Also, there might be specific sessions for this audience at LDCs to build alliances of change agents. 
Furthermore, faculty development initiatives in universities need to utilize the theoretical perspective presented in this study as the basis of their development programs. To date, only Ho $(1999,2000)$ has shown the results of using a coherent theoretical model, that of cognitive restructuring, for faculty change. There is much more research needed in this area, including on the role of reciprocal determinism in faculty development initiatives.

Kreber's fourth recommendation is that faculty be encouraged to read discipline specific articles on teaching, and form reading circles to discuss these. This would include research on student learning, effective teaching, and the implementation of classroom research (Paulsen, 1999). For instance, the professors in this study would benefit from being exposed to methods that can be used to challenge and change student's alternative conceptions about science as this was an intention reflected in their ATI survey, but not evident in their practices. They would also benefit from greater exposure to general educational theories. NOVA could facilitate this process by creating special interest groups among participants, possibly around discipline specific interests, and appointing a facilitator who would encourage sharing of literature, creating on-line discussion forums and providing general support for those interested in innovative teaching. Similarly, faculty development centers need to provide more input on educational theories to faculty across campuses.

Kreber's fifth suggestion was that courses on learning to teach in higher education should be developed that model the scholarship of teaching (Kreber, 2001b). Such courses that model the scholarship of teaching can be effective at increasing the scholarship of teaching of participants, namely current and future 
educators in higher education (Kreber, 1999). This is consistent with the call by the Association for Education of Teachers in Science (AETS, 1991) for the improved preparation of teacher educators, including higher education faculty, through the use of standards. It is unlikely that NOVA has a role to play in this arena because it works specifically with professors who are already teaching, rather than future professors. However, universities might consider developing and then requiring new faculty to take a number of education courses aimed specifically at how to teach in the disciplines in higher education. This has been done in countries such as New Zealand and Australia.

In summary, professional development is not a one-time event but involves (a) a clear focus on learning and learners, (b) an emphasis on the individual and organizational change, (c) small changes guided by a grand vision, and (d) ongoing professional development that is procedurally embedded (Guskey, 2000). It is clear that for the ideas presented here to take effect, a new vision that values the scholarship of teaching and learning will be needed. Action research is one mechanism to achieve this, but if it is to become a valuable tool for instructional change, it will need to become more visible and valued in higher education circles. Presently it does not have the credibility attached to it in the $\mathrm{K}-12$ sector.

\section{Recommendations for future study}

This study has identified several areas that will assist faculty developers and instructional designers in working to change faculty teaching practices. However, there are many areas in which additional research is needed to help complete the 'jigsaw puzzle'. 
Some suggestions have already been made for following-up with specific professors about particular aspects raised. A particularly fruitful area will be to examine how concepts of new phenomena, like action research, develop over time in reciprocal relationships. For instance, to hold further interviews with Dr. Stevenson might yield deeper insights into the nature of his perceived 'schizophrenia' between subjective views of teaching and highly objective views of research. Similarly, to pursue with Dr. Rogers, the effect that environmental influences play on his espoused views of action research. Also, Dr. Andrews's dissatisfaction with action research needs to be further monitored as he develops new ways to assess his teaching. This researcher plans to continue with this process.

There is space for researching particular reciprocal relationships in the triad as related to teaching in higher education. For instance Bandura noted that the methods for examining reciprocal relationships are still emerging, and that it is possible and acceptable to select and examine only certain factors in any triad. "The study of initial and reciprocal effects are separable" and is "best advanced through the microanalysis of interactive processes" (Bandura, 1986, p. 28). A closer examination of the impact of social and environmental factors, such as beliefs about students, class size, type of teaching space used, nature of student-teacher interactions, and frequency of student feedback, on teaching practices and/or conceptions is one area that is open for further investigation. Much more work is needed to understand how the complexity of factors in the environment interact and make their impact on conceptions and practices. 
A longitudinal study examining how conceptions and practices change over time would also be valuable. For instance, this might be done in a future professor's program in which future professors experience exemplary teaching. A counter area for investigation would be the impact of poor role models on future professor's behaviors and ideas about teaching. All of the professors in this study alluded to this, but there is room for more exploration on the way in which these experiences played out in their lives as instructors.

There is a need to provide additional training on action research methods and designs and to work with professors to articulate new action research questions and appropriate designs. Monitoring how well designed action research projects, with a focus on teaching, impacts faculty conceptions and practices would help to give action research greater status in the higher education context. Examining how the answers to research questions about teaching in turn affects conceptions and practices will be an interesting area of engagement.

There is also much more research needed on supporting the implementation of effective action research projects in the context of universities and colleges. Specifically, it is necessary to understand how best to engage in supporting qualitative action research projects that focus on teaching. This requires moving science faculty away from the research paradigm with which they are the most familiar, and there does not appear to have been any research done on this aspect.

\section{Summary}

Because there have been few case studies in higher education that considered the link between conceptual frameworks and associated practices (Samuelowicz, 
1999, Quinlan, 1996, 1999a, 1999b), this research has contributed to the field by telling the stories of five academics and by examining the diversity of factors that have impacted their conceptions and their practices. Also, while most of the research on faculty conceptions has focused specifically on identifying and categorizing their conceptions, there is little research on the relationship to practices, or on the relationship among different conceptions. This research has contributed to that aspect too.

The case study approach has revealed deep insights into the professional lives of five professors as they showed how they conceive of and practice their tasks as instructors in their discipline, particularly in relation to teaching non-science majors. The thick, holistic descriptions have resulted in complex accounts of each professor's conceptions and practices. Each of them has unique and individual perceptions and ways of carrying out their tasks. The research has shown that they care deeply about their effectiveness as instructors, wanting to improve their teaching to benefit students and for their own self-efficacy and enjoyment. However, they achieve their goals in different and interesting ways.

The use of multiple sources of data allowed for triangulation of data for confirmatory purposes and also for highlighting contradictions between different aspects of study. For instance, while the Approaches to Teaching Inventory revealed that all professors held a conceptual change intention, there was less evidence to support this through observation of practice, or from the interview data. So, multiple data sources, and multiple methods of collecting data helped with establishing the validity of the study and in enhancing reliability of the findings. 
Case studies by definition are contextual accounts of particular aspects of people's lives and are concerned with generating understanding and not with causal relationships (Marton \& Svensson, 1979). However, through cross-case analysis and the common themes and contrasting issues that emerged, it was possible to move the relevance of the case study approach to a broader audience, particularly others involved in the NOVA program. Cross case analysis also aimed to move towards explanation by establishing a general theory, using Bandura's model of reciprocal determinism, that fit and could be used to explain all of the cases (Miles \& Huberman, 1994). 


\section{REFERENCES}

Adams, J., Brissenden, G., Lindell, R., Slater, T., \& Wallace, J. (2002). Observations of student behavior in collaborative learning groups. Astronomy Education Review, 1, 18.

Aleamoni, L. M. (1997). Issues in linking instructional-improvement research to faculty development in higher education. Journal of Personnel Evaluation, 11, 31-37.

American Association for Employment in Education (2001). Educator supply and demand in the United States. Columbus, OH; American Association for Employment in Education.

American Association for Higher Education. (2002a). American Association for Higher Education. Retrieved 1 July, 2002, from http://www.aahe.org/teaching/Teaching Initiative Home.htm

American Association for Higher Education. (2002b). Origin of SOTL. Retrieved 30 June, 2002, from http://aahe.ital.utexas.edu/sotl tutorial/home.html

Angelo, T.A., \& Cross, K. P. (1993). Classroom assessment techniques: A handbook for college teachers ( $2^{\text {nd }}$ ed.). San Francisco: Jossey Bass Publishers.

Areola, R. A., Theall, M., \& Aleamoni, L. M. (2003, April). Beyond Scholarship: Recognizing the multiple roles of the professoriate. Paper presented at the 2003 annual meeting of the American Educational Research Association, Chicago, IL.

Argyris C., \& Schon, D.A. (1974). Theory in practice: Increasing professional effectiveness. San Francisco: Jossey-Bass Publishers.

Arhar, J. M., Holly, M. L., \& Kasten, W. C. (2001). Action research for teachers: Traveling the yellow brick road. Upper Saddle River, NJ: Merrill Prentice Hall.

Association for the Education of Teachers of Science (1999). Position statement: Professional knowledge standards for science teacher educators. Retrieved 5 June, 1999, from http://aets.chem.pitt.edu/

Atkin, J. M., \& Helm, J. (1993). Getting serious about priorities in science education. Studies in Science Education, 21, 1-20.

Atkinson, M. P. (1991). The scholarship of teaching and learning: Reconceptualizing scholarship and transforming the academy. Social Forces, 79, 217-230. 
Bain, J.D. (2000). Celebrating good teaching in higher education: Putting beliefs into practice. In C. Bowie (Ed.), Improving the quality of teaching for learning. Brisbane: HERDSA Queensland.

Ballantyne, R., Bain, J., \& Packer, J. (1997). Reflecting on university teaching: Academics' stories. Canberra, Australia: Australian Government Publishing Service.

Bandura, A. (1986). Social foundations of thought and action: A social cognitive theory. Englewood Cliffs, NJ: Prentice-Hall.

Bass, R. (1999). The scholarship of teaching: What's the problem? Inventio, 1, Retrieved June 20, 2002 from http://www.doiiit.gmu.edu/Archives/feb98/randybass.htm

Bell, R.L., Toto, D., McNall, R., \& Tai, R. (2004, January) Beliefs into action: Beginning teachers' implementation of nature of science instruction. Paper presented at the 2004 annual meeting of the Association for the Education of Teachers in Science, Nashville, TN.

Bernard, H. R., \& Ryan, G. W. (1998). Text analysis: Qualitative and quantitative methods. In H. R. Bernard (Ed.), Handbook of Methods in Cultural Anthropology (pp. 595-629). Walnut Creek, CA: AltaMira Press.

Bertram, C.B., \& Easley, J. A. (2000). Emerging communities of practice: Collaboration and communication in action research. Educational Action Research, 8, 243-259.

Bogdan, R. C., \& Biklen, S. K. (2003). Qualitative research fro education: An introduction to theories and methods ( $\left.3^{\text {rd }} \mathrm{ed}\right)$. Boston: Allyn and Bacon.

Boileau, D. M. (1993, April). "Scholarship Reconsidered" A Challenge to Use Teaching Portfolios to Document the Scholarship of Teaching. Paper presented at the Annual Meeting of the Eastern Communication Association, New Haven, CT.

Bondy, E., \& Ross, D. (1998). Teaching teams: Creating the context for faculty action research. Innovative Higher Education, 22, 231-249.

Boyer, E. L. (1990). Scholarship Reconsidered: Priorities of the Professoriate. New Jersey: Carnegie Foundation for the Advancement of Teaching.

Boyer, E. L. (1996). From Scholarship reconsidered to scholarship assessed. Quest, 48, 129-139.

Borko, H., \& Putnam, R. T. (1995). Expanding a teacher's knowledge base: A cognitive psychological perspective on professional development. In T.R. Guskey \& M. Huberman (Eds.), Professional development in education: New paradigms and practices (pp. 35 -65). New York: Teachers College Press. 
Brandt, R. (1993). On teaching for understanding: A conversation with Howard Gardner. Educational Leadership, 50, 4-7.

Brew, A. (1999a). The value of scholarship. Paper presented at the HERDSA Annual International Conference, Melbourne, Australia. Retrieved September 18, 2002 from http://www.herdsa.org.au/vic/cornerstones/authorframeset.html

Brew, A. (1999b). Research and teaching: Changing relationships in a changing context. Studies in Higher Education, 24, 291-301.

Brew, A. (2001). Conceptions of research: A phenomenographic study. Studies in Higher Education, 26, 271-285.

Brew, A., \& Boud, D. (1995). Teaching and research: Establishing the vital link with learning. Higher Education, 29, 261-273.

Brickhouse, N. W. (1990). Teacher's beliefs about the nature of science and their relationship to classroom practice. Journal of Teacher Education, 41, 53-62.

Bruner, J. (1996). The culture of education. Cambridge, MA: Harward Uuniversity Press.

Burchell, H. (2000). Facilitating action research for curriculum development in higher education. Innovations in Education and Training International, 37, 263-269.

Burke, K. (1999). How to assess authentic learning (3rd ed.). Arlington Heights, IL: SkyLight Professional Development.

Burroughs-Lange, S. G. (1996) University lecturers' concept of their role. Higher Education Research and Development, 15, 29-48.

Burry-Stock, J. A. (1995) The ESTEEM Instruments. University of Alabama, Tuscaloosa, AL: University of Alabama Academic Publishing Services.

Burry-Stock, J. A., \& Oxford, R. L. (1994). Expert Science Teaching Educational Evaluation Model (ESTEEM): Measuring Excellence in Science Teaching for Professional Development. Journal of Personnel Evaluation in Education, 8, 267.

Calderhead, J. (1996). Teachers: Beliefs and knowledge. In D. C Berliner \& R. C. Calfee (Eds.), Handbook of educational psychology (pp. 709-725). New York: Macmillan Library Reference USA.

Camblin, L. D., \& Steger, J. A. (2000). Rethinking faculty development. Higher Education, 39, 1-18.

Carlson, P.A. (2002). A community of practice: Web portals and faculty development. Journal of Computing in Higher Education, 13(2), 4- 24. 
Carr, K. (2002). Building bridges and crossing borders: Overcoming cultural barriers to collaboration between science and education departments through service learning. Paper presented at the first Northwest NOVA cyber-conference. Retrieved March 25, 2002 from http://nova.georgefox.edu/nwcc/index.html

Carr, W., \& Kemmis, S. (1986). Becoming critical: Education, knowledge and action Research. London: The Falmer Press.

Carter, C. E. (2001). Going beyond the disciplines: Creating spaces for "in-between" teaching and learning. Invention, 3, Retrieved June 20, 2002 from http://www.doiiit.gmu.edu/inventio/main.asp?pID=spring01\&sID=carter

Centra, J.A. (1993). Reflective faculty evaluation: Enhancing teaching and determining faculty effectiveness. San Francisco: Jossey-Bass.

Charmaz, K. (2000). Grounded theory: Objectivist and constructivist methods. In N. K. Denzin \& Y. Lincoln (Eds.), Handbook of qualitative research (509-535). Thousand Oaks, CA: Sage Publications.

Chopp, R. S., Frost, S. H., \& Jean, P. M. (2001). What is old is new again. Change, 33, 43-46.

Cochran-Smith, M., \& Lytle, S. L. (1992). Communities for teacher research: Fringe or forefront. American Journal of Education, 100, 298-323.

Cochran-Smith, M., \& Lytle, S. L. (1999). Relationship of knowledge and practice: Teacher learning in communities. Review of Research in Education, 24, 249-305.

Colbeck, C. L., Cabrera, A.F., \& Marine, R. J. (2000). Faculty Motivation to Use Alternative Teaching Methods. East Lansing, MI: National Center for Research on Teacher Learning. (ERIC Document Reproduction Service No. ED 465342)

Conway, R., Kember, D., Sivan, A., \& Wu, M. (1994). Making departmental changes through action research, based on adult learning principles. Higher Education, 28, 265-282.

Creswell, J. W. (1998). Qualitative inquiry and research design. Thousand Oaks, CA: Sage Publications.

Cross, K.P. (1996). Classroom research: Implementing the scholarship of teaching. American Journal of Pharmaceutical Education, 60, 402-407.

Cross, K.P. (1998). Classroom research: Implementing the scholarship of teaching. New Directions for Teaching and Learning, 75, 5-12. 
Cross, K.P., \& Angelo, T.A. (1989). Faculty members as classroom researchers. Community Technical and Junior College Journal, 59(5), 23-25.

Cross, K.P., \& Steadman, M.H. (1996). Classroom research: Implementing the scholarship of teaching. San Francisco: Jossey-Bass.

Dalin, P. (1978). Limits to educational change. London: MacMillan.

Daly, W.T. (1994). Teaching and scholarship: Adapting American higher education to hard times. Journal of Higher Education, 65, 45-57.

Dinham, S. (2000). Use of multiple methods in research on college teachers. In N. Hativa and P. Goodyear (Eds.), Teacher thinking, beliefs and knowledge in higher education (pp321-334). Dordrecht, Netherlands: Kluwer Academic Publishers.

Denzin, N. K., \& Lincoln, Y. (Eds.) (2000). Handbook of qualitative research. Thousand Oaks, CA: Sage Publications.

Driver, R., \& Oldham, V. (1986). A constructivist approach to curriculum development in science. Studies in Science Education, 13, 105-122.

Driver, R. (1992, April). Constructivism in primary science education. Paper presented at the training course on International Trends in Primary Science Education, Liverpool, United Kingdom..

Edgerton, R. (1997). Education White Paper. Retrieved 5 October, 2002 from http://www.pewundergradforum.org/wp3.html

Eisenbach, R., Golich, V., \& Curry, R. (1998). Classroom assessment across the disciplines. New Directions for Teaching and Learning, 75, 59-66.

Enochs, L. G., \& Riggs, I. M. (1990). Further development of an elementary Science Teaching Efficacy Belief Instrument: A pre-service elementary scale. East Lansing, MI: National Center for Research on Teacher Learning. (ERIC Document Reproduction Service No. ED 319601)

Entwistle, N., Skinner, D., Entwistle, D., \& Odd, S. (2000). Conceptions and beliefs about "good teaching": An integration of contrasting research areas Higher Education Research and Development, 19, 5-26.

Entwistle, N., \& Walker, P. (2002). Strategic alertness and expanded awareness within sophisticated conceptions of teaching. In N. Hativa and P. Goodyear (Eds.), Teacher thinking, beliefs and knowledge in higher education (pp.15-39). Dordrecht, Netherlands: Kluwer Academic Publishers. 
Fedock, P. M., Zambo, R., \& Cobern, W. W. (1996). The professional development of college science professors as science teacher educators. Science Education, 80, 5-19.

Feldman, A., \& Capobianco, B. (2000). Action Research in Science Education. East Lansing, MI: National Center for Research on Teacher Learning. (ERIC Document Reproduction Service No. ED 463944)

Fernandez-Balboa, J-M., \& Stiehl, J. (1995). The generic nature of pedagogical content knowledge among college professors. Teaching and Teacher Education, 11, 293-306.

Fox, D. (1983). Personal theories of teaching. Studies in Higher Education, 8, 151-163.

Gall, M. D., Gall, J. P., \& Borg, W. R. (2003) Educational research: An introduction. Boston: Allyn and Bacon.

Glaser, B.G., \& Strauss, A. L. (1967). The discovery of grounded theory: Strategies for qualitative research. Chicago: Aldine Pubublishing.

Glassick, C., Huber, M.T., \& Mayeroff, G. I. (1997). Scholarship assessed: Evaluation of the Professoriate. San Franscisco: Jossey-Bass.

Gow, L., \& Kember, D. (1993). Conceptions of teaching and their relationship to student learning. British Journal of Educational Psychology, 63, 20-33.

Guskey, T. R. (2000). Evaluating professional development. Thousand Oaks, CA: Corwin Press.

Guziec, M.K, \& Lawson, H. (2004). Science for Elementary Educators: Modeling Science Instruction for Childhood Education Majors. Journal of college science teaching. 33, $38-41$

Hadfield, M., \& Bennett, S. (1995). The action researcher as chameleon. Educational Action Research, 3, 323-335.

Hammrich, P. L. (1994) Learning to teach: Teaching assistants conception changes about science teaching. East Lansing, MI: National Center for Research on Teacher Learning. (ERIC Document Reproduction Service No. ED 401 154)

Harnish, D., \& Wild, L. A. (1994). Mentoring strategies for faculty development. Studies in Higher Education, 19, 191-201.

Harwood, W.S., Reiff, R., \& Phillipson, T. (2002). Scientists. Conceptions of Scientifir Inquiry: Voices from the Front. East Lansing, MI: National Center for Research on Teacher Learning. (ERIC Document Reproduction Service No. ED 465632)

Hativa, N. (1998). Lack of clarity in university teaching: A case study. Higher Education, $36,353-381$. 
Hativa, N. (2001). Exemplary university teachers: Knowledge and beliefs regarding effective teaching dimensions and strategies. The Journal of Higher Education, 72, 699-729.

Hativa, N. (2002). Becoming a better teacher: A case of changing pedagogical knowledge and beliefs of law professors. In N. Hativa and P. Goodyear (Eds.), Teacher thinking, beliefs and knowledge in higher education (pp. 289-320). Dordrecht, Netherlands: Kluwer Academic Publishers.

Hativa, N., \& Goodyear, P. (2002). Research on teacher thinking, beliefs, and knowledge in higher education: Foundations, status and prospects. In N. Hativa and P. Goodyear (Eds.), Teacher thinking, beliefs and knowledge in higher education (pp. 335-359). Dordrecht, Netherlands: Kluwer Academic Publishers.

Hattie, L., \& Marsh, H. W. (1996). The relationship between research and teaching: A meta-analysis. Review of Educational Research, 66, 507-542.

Hassard, J. (1993). Sociology and organisational theory: Positivism, paradigms and postmodernity. Cambridge, United Kingdom: Cambridge University Press.

Healey, M. (2000). Developing the scholarship of teaching in higher education: A discipline-based approach. Higher Education Research \& Development, 19, 169-189.

Hermes, L. (1999). Learner assessment through subjective theories and action research . Assessment and Evaluation in Higher Education, 24, 197-204.

Hirsch, D. (2000). Practitioners as researchers: Bridging theory and practice. New Directions for Higher Education, 110, 99-106.

Ho, A.S.P. (1998). A conceptual change staff development programme: Effects as perceived by the participants. International Journal for Academic Development, 3, 24-38.

Ho, A.S.P. (2000). A conceptual change approach to staff development: A model for programme design. International Journal for Academic Development, 5, 30-41.

Hofer, B. K., \& Pintrich, P.R. (1997). The development of epistemological theories: Beliefs about knowledge and knowing and there relation to learning. Review of Educational Research, 67, 88-140.

Hopkins, D. (1993). A teacher's guide to classroom research (2 $2^{\text {nd }}$ ed.). Buckingham, United Kingdom: Open University Press.

Huber, M. T. (1999, September). Disciplinary styles in the scholarship of teaching: Reflections on the Carnegie Academy for the Scholarship of Teaching and Leaning. 
Paper presented at the $7^{\text {th }}$ International Improving Student Learning Symposium, University of York, UK.

Huber, M. T., \& Morreale, S.P. (2001). Situating the scholarship of teaching and learning: A cross-disciplinary conversation. Retrieved 11 March, 2002 from http://www.carnegiefoundation.org/eLibrary/docs/situating.htm

Hutchings, P., \& Schulman, L.S. (1999). The scholarship of teaching: New elaborations, new developments. Change, 31, 10-15.

Hutchings, P. (Ed.). (2000). Opening Lines: Approaches to the scholarship of teaching and learning. Menlo Park: CA: The Carnegie Foundation for the Advancement of Teaching.

Jacobs, D. (2001). A chemical mixture of methods. In P. Hutchins (Ed.), Opening Lines: Approaches to the scholarship of teaching and learning ( $\mathrm{p}$ 41-52). Menlo Park: CA: The Carnegie Foundation for the Advancement of Teaching.

Janesick, V. J. (2000). The choreography of qualitative research design. In N. K. Denzin \& Y. Lincoln (Eds.) Handbook of qualitative research (pp. 379-399). Thousand Oaks, CA: Sage Publications.

Johnston, R. (1999, May). Alternative assessment. Paper Presented at the NOVA Workshop, Western Kentucky University, Bowling Green, Kentucky.

Karplus, R. (1977). Science teaching and the development of reasoning. Journal of Research in Science Teaching, 14, 169-175.

Keller, G. (1998). Does higher education research need revisions? The review of higher education, 21, 267-278.

Kember, D. (1997). A reconceptualisation of the research into university academics' conceptions of teaching. Learning and Instruction, 7, 225-275.

Kember, D, (1998). Action research: Towards an alternative framework for educational development. Distance Education, 19, 43-64.

Kember, D. (2000). Action learning and action research. London: Kogan Page.

Kember, D., Charlesworth, M., Davies, H., McKay, J., \& Stott, V. (1997). Evaluating the effectiveness of educational innovations: Using the study process questionnaire to show that meaningful learning occurs. Studies in Educational Evaluation, 23, 141-157.

Kember, D., \& Gow, L. (1992). Action research as a form of staff development in higher educaiton. Higher Education, 23, 297-310. 
Kember, D., \& Gow, L. (1994). Orientations to teaching and their effect on the quality of student learning. Journal of Higher Education, 65, 58-74.

Kember, D., \& McKay, J. (1996). Action research into the quality of student learning: A paradigm for faculty development. The Journal of Higher Education, 67, 528-554.

Kember, D., Kwan, K., \& Ledesma, J. (2001). Conceptions of good teaching and how they influence the way adults and school leavers are taught. International Journal of Lifelong Education, 20, 393-404.

Kember, D., Lam, B., Yan, L., Yum, J., \& Liu, S. B. (1999). Case studies of improving teaching and learning from the Action Learning Project. Downloaded on 16 September 2002, from http://celt.ust.hk/ideas/ar/pdf files/alp1999.index.htm

Kemmis, S., \& Mc'Taggart, R. (2000). Participatory Action Research. In N.K. Denzin \& Y. Lincoln (Eds.), A Handbook of qualitative research (pp. 567-605). Thousand Oaks, CA: Sage Publications.

Kezar, A. J. (2001). Understanding and facilitating organizational change in the $21^{\text {st }}$ century: Recent research and conceptualizations. ASHE-ERIC Higher Education Report, 28, 1-183.

Kezar, A. J. (2002a). Teaching and Learning. In ERIC Clearinghouse on higher education: ERIC trends. Retrieved 29 June 2002, from http://www.eriche.org/trends/teaching.html

Kezar, A. J. (2002b). Faculty. In ERIC Clearing house on higher education: ERIC trends. Retrieved 29 June 2002, from http://www.eriche.org/trends/faculty.html

Kreber, K. (1999). A course-based approach to the development of teaching scholarship: A case study. Teaching in Higher Education, 4, 309-325.

Kreber, C. (2000a). Exploring the scholarship of teaching. Journal of Higher Education, $71,476-495$.

Kreber, C. (2000b). How university teaching award winders conceptualize academic work: Some further thoughts on the meaning of scholarship. Teaching in Higher Education, 5, 61-76.

Kreber, C. (2000c). Integrating teaching with other aspects of professorial work: A comparison of experienced and inexperienced faculty role conceptualizations. The Canadian Journal of Higher Education, 30, 79-111.

Kreber (2001a). Conceptualizing the scholarship of teaching and identifying unresolved issues: The framework for this volume. New Directions for Teaching and Learning, $86,1-18$. 
Kreber (2001b). The scholarship of teaching and its implementation in faculty development and graduate education. New Directions for Teaching and Learning, 86, 79-88.

Kreber C. (2002a). Controversy and consensus on the scholarship of teaching. Studies in Higher Education, 27, 151-167.

Kreber, C. (2002b). Teaching excellence, teaching expertise, and the scholarship of teaching. Innovative Higher Education, 27, 5-23.

Kreber, C. (in press). Challenging the dogma: Towards a more inclusive conceptualization of the scholarship of teaching. Journal on Excellence in College Teaching.

Kreber, C., \& Cranton, P. A. (2000). Exploring the scholarship of teaching. Journal of Higher Education, 71, 476-495.

Krockover, G., Adams, P., Eichinger, D., Nakhleh, M., \& Shepardson, D. (2001). Actionbased research teams: Collaborating to improve science education. Journal of College Science Teaching, 30, 313-17.

Kuhn, T. S. (1970). The structure of scientific revolutions, $\left(2^{\text {nd }}\right.$ ed). Chicago: University of Chicago Press.

Larson, C. L. (2000). Commentary: Creating scholarly practice through communities of inquiry. International Journal of Leadership in Education, 3, 307-314.

Levin, J., \& Nolan, J. F. (2000). Principles of Classroom Management: A Professional Decision-Making Model. Boston: Allyn \& Bacon.

Lincoln, Y. S., \& Guba, E. (1986). But is it rigorous? Trustworthiness and authenticity in naturalistic evaluation. New Directions for Program Evaluation, 30, 73-84.

Lincoln, Y. S., \& Guba, E. (1990). Judging the quality of case study reports. Qualitative Studies in Education, 3, 53-59.

Martin, E., Prosser, M., Trigwell, K., Ramsden, P., \& Benjamin, J. (2000). What university teachers teach and how they teach it. Instructional Science, 28, 387-412.

Marton, F. (1981). Phenomenography - describing conceptions of the world around us. Instructional Science, 10, 177-200.

Marton, F. (1988). Phenomenography: Exploring different conceptions of reality. In D. Fetterman (Ed.), Qualitative approaches to evaluation in education: The silent revolution (pp. 176-205). New York: Praeger. 
Marton, F., \& Booth, S. (1997). Learning and awareness. New Jersey: Lawrence Erlbaum Associates.

Marton, F., \& Saljo, R. (1997). Approaches to learning. In F. Marton, D. Housell and N.J. Entwistle (Es). The experience of learning: Implications for teaching and studying in higher education, $2^{\text {nd }}$ ed. Edinburgh: Scottish Academic Press.

Marton, F., \& Svensson, L. (1979). Conceptions of research on student learning. Higher Education, 8, 471-486.

Mathison, S. (1988). Why triangulate? Educational Researcher, 17, 13-17.

McAlpine, L., \& Weston, C. (2002). Reflection: Issues related to improving professor's teaching and students' learning. In N. Hativa and P. Goodyear (Eds.), Teacher thinking, beliefs and knowledge in higher education (pp. 59-78).Netherlands: Kluwer Academic Publishers.

Merriam, S. B. (1998). Qualitative research and case study applications in education. New York: Jossey-Bass.

Miles, M. B., \& Huberman, A. M. (1994). Qualitative data analysis: An expanded source book. Thousand Oaks, CA: Sage Publications

Mills, G. E. (2000). Action research: A guide for the teacher researcher. Upper Saddle River, NJ: Merrill Prentice Hall.

Moallem, M., \& Earle, R.S. (1998). Instructional design models and teacher thinking: Towards a new conceptual model for research and development. Educational Technology, 38, 5-20.

Mulholland, J., \& Wallace, J. (1996). Breaking the Cycle: Preparing Elementary Teachers to Teach Science. Journal of Elementary Science Education, 8, 17-38.

Mulholland, J., \& Wallace, J. (1996). Beginning Elementary Science Teaching: Entryways to Different Worlds. East Lansing, MI: National Center for Research on Teacher Learning. (ERIC Document Reproduction Service No. ED 435547)

Murray, K., \& MacDonald, R. (1997). The disjunction between lecturers' conceptions of teaching and their claimed educational practice. Higher Education, 33, 331-349.

National Commission on Mathematics and Science Teaching for the $21^{\text {st }}$ Century (2001). Before it's too late: A report to the nation from the national commission on mathematics and science teaching for the $2 I^{\text {st }}$ century. Washington: US Department of Education. 
National Council for Accreditation of Teacher Education (2002). Professional standards for the accreditation of schools, colleges and departments of education. Washington DC: NCATE.

National Council for Teachers of Mathematics. (1991). Professional standards for teaching mathematics. Reston, VA: National Council for Teachers of Mathematics.

National Research Council (1996). National science education standards. Washington, DC: National Academy Press.

National Research Council (1997). Science teaching reconsidered: A handbook. Washington, DC: National Academy Press.

National Research Council (1999). Transforming undergraduate education in science mathematics, engineering and technology. Washington, DC: National Academy Press.

National Research Council (2000). Inquiry and the national science education standards: A guide for teaching and learning. Washington, DC: National Academy Press.

National Research Council (2001). Educating teachers of science, mathematics and technology: New practices for the new millennium. Washington, DC: National Academy Press.

National Science Foundation (1996). Shaping the future: New expectations for undergraduate education in science, mathematics, engineering and technology. Arlington, VA: National Science Foundation.

National Science Teachers Association (2000). NSTA releases nationwide survey on science teacher credentials, assignments, and job satisfaction. Retrieved 2 October, 2002, from http://www.nsta.org/369

National Survey of Student Engagement (2000). The NSSE 2000 report: National benchmarks of effective educational practice. Bloomington, IN: National Survey of Student Engagement.

Nespor, J. (1987). The role of beliefs in the practice of teaching. Journal of Curriculum Studies, 19, 317-328.

NOVA (2002). NOVA evaluation report 1996-2002. University of Alabama, Tuscaloosa, AL: NOVA.

Pajares, M. F. (1992). Teachers' beliefs and educational research: Cleaning up a messy construct. Review of Educational Research, 62, 307-332. 
Patton, M. Q. (1987). How to use qualitative methods in evaluation. Newbury Park, CA: Sage Publications.

Patton, M. Q. (1990). Qualitative evaluation and research methods (2 ${ }^{\text {nd }}$ ed.). Newbury Park, CA: Sage Publications

Patton, M. Q. (2002). Qualitative research and evaluation methods ( $3^{\text {rd }} \mathrm{ed}$.). Thousand Oaks, CA: Sage Publications.

Paulsen, M. P. (1999). How College Students Learn: Linking Traditional Educational Research and Contextual Classroom Research. Journal of Staff, Program \& Organizational Development, 16, 63-71.

Paulsen, M. P. (2001). The relation between research and the scholarship of teaching. New Directions for Teaching and Learning, 86, $19-29$.

Persichitte, K. A., Young, S., \& Tharp, D. D. (1996). Conducting research on the Internet: Strategies for electronic interviewing. East Lansing, MI: National Center for Research on Teacher Learning. (ERIC Document Reproduction Service No. ED 409860)

Popkewitz, T. S. (1984). Paradigm and ideology in educational research. London: Falmer Press.

Posner, G. J., Strike, K. A., Hewson, P. W., \& Gertzog, W. A. (1982). Accommodation of a scientific conception: Towards a theory of conceptual change. Science Education, 66, 211-227.

Prosser, M., \& Trigwell, K. (1999). Understanding and learning in teaching: The experience in higher education. Philadelphia, PA: Society for Research into Higher Education \& Open University Press.

Prosser, M., Trigwell, K., Hazel, E., \& Waterhouse, F. (2000). Students' experiences of studying physics concepts: The effect of disintegrated perceptions and approaches. European Journal of Psychology of Education, 15, 61-74.

Prosser, M., Walker, P., \& Millar, R. (1996). Differences in students' perceptions of learning physics. Physics Education, 31, 43-48.

Quinlan, K. M. (1996). Collaboration and cultures of teaching in university departments: Faculty beliefs about teaching and learning in history and engineering. Unpublished doctoral dissertation, Stanford University.

Quinlan, K. M. (1999a). Building Bridges: The Scholarly Dimensions of Faculty Beliefs about Engineering Education. East Lansing, MI: National Center for Research on Teacher Learning. (ERIC Document Reproduction Service No. ED 440565) 
Quinlan, K. M. (1999b). Commonalities and controversy in context: A study of academic historians' educational beliefs. Teaching and Higher Education, 15, 447-463.

Quinlan, K. M., \& Åkerlind, G. S. (2000). Factors affecting departmental peer collaboration for faculty development: Two cases in context. Higher Education, 40, 23-52.

Radloff, A. (2002). Learning to teach: Changes in technical college teachers' beliefs about learning and teaching over a two-year teacher education program. In N. Hativa and P. Goodyear (Eds.), Teacher thinking, beliefs and knowledge in higher education (pp. 265-288). Dordrecht, Netherlands: Kluwer Academic Publishers.

Ramsden, P. (1992). Learning to teach in higher education. London: Kogan Page.

Raubenheimer, C. D. (1994). Shift in practice, shift in paradigm? Southern African Journal of Science and Mathematics Education, 1, 1-16.

Raubenheimer. C. D. (2003, April). Faculty conceptions and practices of action research in the NOVA program. Paper presented at the 2003 annual meeting of the American Educational Research Association, Chicago, IL.

Raubenheimer. C. D. (2004). Lessons from Research: Professional Development of University Science Faculty Through Action Research. In D. W. Sunal, E. Wright \& J. Bland (Eds.), Research in Science Education: Reform in Undergraduate Science Teaching for the $21^{\text {st }}$ Century. Greenwich, CT: Information Age Publishing, Inc.

Rearick, M. L., \& Feldman, A. (1999). Orientations, purposes and reflection: A framework for understanding action research. Teaching and Teacher Education, 15, 333-349.

Reiff, R. (2002). If Inquiry is so Great, Why isn't Everyone Doing It? East Lansing, MI: National Center for Research on Teacher Learning. (ERIC Document Reproduction Service No. ED 465642)

Reynolds, R.J., McCullough, J.D., Bendixen-Roe, M., \& Morrow, L. (1994). The need for knowledge about teacher educators. East Lansing, MI: National Center for Research on Teacher Learning. (ERIC Document Reproduction Service No. ED 372 041)

Richlin, L. (1998). Using CATs to help new instructors develop as teachers. New Directions for Teaching and Learning, 75, 79-86.

Richlin, L. (2001). Scholarly teaching and the scholarship of teaching. New Directions for Teaching and Learning, 86, 57-68.

Robinson, J., \& Leamon, J. (1999). A documentary analysis of educational programmes leading to the award of degree in nursing at pre and post registration level. London, United Kingdom: English National Board for Nursing, Midwifery and Health Visiting. 
Ross, D., \& Bondy, E. (1996). The evolution of a college course through teacher educator action research. Action in Teacher Education, 18, 44-55.

Rowland, S. (1996). Relationships between teaching and research. Teaching in Higher Education, 1, 7-20.

Rubin, H. J., \& Rubin, I. S. (1995). Qualitative interviewing: The art of hearing data. Newbury Park, CA: Sage Publications.

Ryan, G. W., \& Bernard, H. R. (2000). Data management and analysis methods. In N. K. Denzin \& Y. Lincoln (Eds.) Handbook of qualitative research (pp. 769-801). Thousand Oaks, CA: Sage Publications.

Sambell, J.K., \& McDowell, L. (1998). The construction of the hidden curriculum: Messages and meanings in the assessment of student learning. Assessment \& Evaluation in Higher Education, 23, 391-402.

Samuelowicz, K. (1999). Academics' educational beliefs and teaching practices. Unpublished doctoral dissertation, Griffith University, Australia.

Samuelowicz, K., \& Bain, J. D. (1992). Conceptions of teaching held by academic teachers. Higher Education, 24, 93-112.

Samuelowicz, K., \& Bain, J. D. (2001). Revisiting academics' beliefs about teaching and learning. Higher Education, 41, 299-325.

Samuelowicz, K., \& Bain, J. D. (2002). Identifying academics' orientation to assessment practice. Higher Education, 43, 172-201.

Saroyan, A., \& Amundsen, C. (2001). Evaluating university teaching: Time to take stock. Assessment and Evaluation in Higher Education, 20, 341-353.

Sawyer, S. M. B. (1999). Professors' beliefs about their subject matter knowledge in relation to their practice of learner-centered instruction. Unpublished doctoral dissertation, University of Georgia, Athens, Georgia.

Schon, D. A. (1983). The reflective practitioner: How professionals think in action. New York: Basic Books.

Schon, D. A. (1995). The new scholarship requires a new epistemology. Change, 27, 2634.

Schulman, L. (1986). Knowledge and teaching: Foundation of the new reform. Harvard Educational Review, 57, 1-24. 
Schulman, L. (1999). Visions of the possible: Models for campus support of the scholarship of teaching and learning. Downloaded on 11 April 2002 from www.carnegiefoundation.org/eLibrary/docs/Visions.htm

Seidman, I. (1998). Interviewing as qualitative research. New York: Teachers College Press.

Seymour, E. (1995). The loss of women from science, mathematics and engineering undergraduate majors: An explanatory account. Science Education, 79, 437-473.

Shepard, L.A. (2000). The role of assessment in a learning culture. Educational Researcher, 29, 4-14.

Sheppard, C., \& Gilbert, J. (1991). Course design, teaching method and student epistemology. Higher Education, 22, 229-249.

Silva, M. C. (1999). The scholarship of teaching as science and as art. Inventio: Creative thinking about learning and teaching, 1. Retrieved June 20, 2002 from http://www.doiiit.gmu.edu/Archives/feb98/silva_1.htm

Smaling, A. (2000). What kind of dialogue should paradigm-dialogues be? Quality and Quantity, 34, 53-63.

Smelcer, P. (2002). Effectiveness of content and pedagogy change in SC 100: Integrated Science. Paper presented at the first Northwest NOVA cyber-conference. Retrieved March 25, 2002 from http://nova.georgefox.edu/nwcc/index.html

Smith, D. C., \& Neale, D. C. (1989). The construction of subject matter knowledge in primary science teaching. Teaching and Teacher Education, 5, 1-20.

Stake, R. E. (2000). Case studies. In N. K. Denzin \& Y. Lincoln (Eds.) (2000). Handbook of qualitative research (pp. 435-454). Thousand Oaks, CA: Sage Publications.

Steadman, M. (1998). Using classroom assessment to change both teaching and learning. New Directions for Teaching and Learning, 75, 23-35.

Stenhouse, L. (1975). An introduction to curriculum research and development. Lopndon: Heinemann.

Stenhouse, L. (1987). The conduct, analysis and reporting of case study in educational research and evaluation. In R. Murphy \& H. Torrance (Eds.) Evaluating Education: Issues and Methods. London: Harper Row.

Strauss, A., \& Corbin, J. (1990). Basics of qualitative research: Grounded theory procedures and techniques. Newbury Park, CA: Sage Publications. 
Strauss, A., \& Corbin, J. (1998). Basics of qualitative research: Techniques and procedures for developing grounded theory. Thousand Oaks, CA: Sage Publications.

Sunal, D. W. (1999, May). A strategy for meaningful learning in college science, mathematics and engineering courses. Paper Presented at the NOVA Workshop, Western Kentucky University, Bowling Green, Kentucky.

Sunal, D. W., Hodges, J., Sunal, C. S., Whitaker, K. W., Freeman, L. M., \& Edwards, L. (2001). Teaching science in higher education: Faculty professional development and barriers to change. School Science and Mathematics, 101, 246-257.

Sunal, D., Kallam, L., McKinnon, L., Raubenheimer, C. D., Gardner, F., MacAlistair, D., et al. (2003). NOVA Evaluation Report 1996 - 2003. Tuscaloosa, AL: University of Alabama.

Sunal, D., Sunal, C., Whitaker, K., Odell, M., \& McKinnon, C. (2003, April). The Effect of Standards-Based Reform in University Courses on Undergraduates' Science Knowledge. Paper presented at the 2003 American Educational Research Association, Chicago, IL.

Sunal, D., Wright, E., \& Bland Day, J. (Eds.). Reform in Undergraduate Science Teaching for the $21^{\text {st }}$ Century. Greenwich, CT: Information Age Publishing, Inc

Taggart, G. L., Phifer, S. J., Nixon, J. A., \& Wood, M. (2001). Rubrics: A handbook for construction and use. Lanham, Maryland: Scarecrow Press.

Theall, M., \& Centra, J. A. (2001). Assessing the scholarship of teaching: Valid decisions from valid evidence. New Directions for Teaching and Learning, 86, 31-43.

Tobias, S. (1991a). Science education reform. The Scientist, 5, 12.

Tobias, S. (1991b). What makes science hard? American Journal of Pharmaceutical Education, 55, 378-382.

Trigwell, K., Martin, E., Benjamin, J., \& Prosser, M. (2000). Scholarship of teaching: A model. Higher Education Research and Development, 19, 155-168.

Trigwell, K., \& Prosser, M. (1996a). Congruence between intention and strategy in university science teachers' approaches to teaching. Higher Education, 32, 77-87.

Trigwell, K., \& Prosser, M. (1996b). Changing approaches to teaching: A relational perspective. Studies in Higher Education, 21, 275-284.

Trigwell, K., \& Prosser, M. (In press). Development and use of the approaches to teaching inventory. Personal communication with author. 
Trigwell, K., Prosser, M., \& Taylor, P. (1994). Qualitative differences in approaches to teaching first year university science. Higher Education, 27, 75-84.

Trigwell, K., Prosser, M., \& Waterhouse, F. (1999). Relations between teachers' approaches to teaching and students' approaches to learning. Higher Education, 37, $57-70$.

US Department of Education (2000). The initial report of the secretary on the quality of teacher preparation. Washington, DC: Department of Education.

US Department of Education (2002). Meeting the highly qualified teacher challenge: The secretary's annual report on teacher quality. Washington, DC: Department of Education.

van Driel, J.H., Verloop, N., van Werven, H.I., \& Dekkers, H. (1997). Teachers' craft knowledge and curriculum innovation in higher engineering education. Higher Education, 34, 105-122.

Walker, M. (1993) Developing the theory and practice of action research: A South African case. Educational Action Research, 1, 1-15.

Webb, G. (1992). On pretexts for higher education development activities. Higher Education, 24, 351-361.

Webb, G. (1997a). Deconstructing deep and surface: Towards a critique of Phenomenography. Higher Education, 33, 195-213.

Webb, G. (1997b). Contesting learning theory: A response to Entwistle and Ekeblad. Higher Education, 33, 225-230.

Weston, C.B., \& McAlpine, L. (2000). Making explicit the development towards the scholarship of teaching. New Directions for Teaching and Learning,, 86, 89-97.

Wilhelm, R. W., Craig, M. T., Glover, R. J., Allen, D. D., \& Huffman, J. B. (2000). Becoming qualitative researchers: A collaborative approach to faculty development. Innovative Higher Education, 24, 265-278.

Wilson, S. M., \& Wineburg, S. S. (1993). Wrinkles in time and place: Using performance assessments to understand the knowledge of history teachers. American Educational Research Journal, 30, 729-769.

Yager, R.E. (1992). Viewpoint: What we did not learn from the 60s about science curriculum reform. Journal of Research in Science Teaching, 29, 905-910.

Yin, R. K. (1994). Case study research: Design and methods. Thousand Oaks, CA: Sage Publications. 
Zoller, U. (1999). Scaling-up of higher-order cognitive skills-oriented college chemistry teaching: An action-oriented research. Journal of Research in Science Teaching, 36, 583-596.

Zuber-Skerritt, O. (1992a). Professional development in higher education: A theoretical framework for action research. London: Kogan Page Limited.

Zuber-Skerritt, O. (1992b). Action research in higher education: Examples and reflections. London: Kogan Page Limited.

Zukav, G. (1979). The dancing Wu-Li masters: An overview of the new physics. London: Fontana Paperbacks. 


\section{APPENDICES}

\section{Appendix A}

\section{Introductory email}

Dear Professor .......,

I am a Ph.D. student in the Department of Leadership, Foundations and Human Resource Education in the College of Education and Human Development at the University of Louisville, Kentucky. I have been a participant in the NOVA program since 1999 and am also currently a research fellow for NOVA assisting with data collection and analysis for the evaluation of NOVA. While this particular research will utilize data that is already housed in the database at the Science Teaching and Learning Center, University of Alabama, and is funded in part by NOVA, it is a separate initiative that will constitute my doctoral dissertation.

The focus of this doctoral research is on NOVA faculty conceptions and practices of teaching, assessment and action research. I am conducting case study research on interesting NOVA courses, and I would like to invite you to participate in this study. The research data that is needed in addition to that already available will be collected through interviews and some survey items. I am attaching a table that outlines all the data that will be used to construct the case studies, indicating in red the data that still needs to be collected.

I would need to schedule three electronic interviews (or telephonic interviews) with you over a period of a month that will last approximately one hour each, in real time (i.e. both of us working at the same time to pose and answer questions). You will complete the Approaches to Teaching Inventory (ATI) and the Assessment of Classroom 
Learning in Science Inventory (ACLSI) at your own convenience. I would also ask to receive copies of your NOVA course syllabus and the assessment items used with students. When I have transcribed interviews, and written the initial case record, I will return these to you for your comments. To assure confidentiality, I would ask you to select your own pseudonym for the case study.

I understand that this research project will make demands upon your time, but it is intended to add to the research on science and mathematics teacher education in NOVA and contribute to understanding how faculty development projects might better serve the needs of math and science faculty in the future. I would like to arrange a time to call you within the next week to discuss the research in more detail and to answer any questions you may have about the project. If you are interested, please could you indicate suitable times on .....day or ....day for me to call you.

Sincerely

C. Dianne Raubenheimer 
Sources and method of data collection and analysis

\begin{tabular}{|l|l|l|}
\hline Topic & $\begin{array}{l}\text { Source and method of data } \\
\text { collection }\end{array}$ & Analysis \\
\hline $\begin{array}{l}\text { Teaching and } \\
\text { learning }\end{array}$ & $\begin{array}{l}\text { Conceptions } \\
\text { Interviews (science/math faculty) } \\
\text { STEBI (Science teacher efficacy } \\
\text { belief instrument) } \\
\text { ATI (Approach to teaching inventory) }\end{array}$ & $\begin{array}{l}\text { Conceptions } \\
\text { Data coding, explanation } \\
\text { building } \\
\text { Quantification of subscales } \\
\text { Quantification of subscales }\end{array}$ \\
& $\begin{array}{l}\text { Practices } \\
\text { ESTEEM - observation instrument } \\
\text { Syllabuses } \\
\text { Field notes } \\
\text { Student interview transcripts }\end{array}$ & $\begin{array}{l}\text { Practices } \\
\text { Quantification of subscales } \\
\text { Data coding, explanation } \\
\text { building } \\
\text { Data coding }\end{array}$ \\
\hline Assessment & $\begin{array}{l}\text { Conceptions } \\
\text { Interviews (science/math faculty) }\end{array}$ & $\begin{array}{l}\text { Conceptions } \\
\text { Data coding, explanation } \\
\text { building }\end{array}$ \\
& $\begin{array}{l}\text { Practices } \\
\text { Syllabuses } \\
\text { Test items } \\
\text { ACLSI (Assessment of classroom } \\
\text { learning in science inventory) }\end{array}$ & $\begin{array}{l}\text { Practices } \\
\text { Data coding, explanation } \\
\text { building } \\
\text { Quantification of subscales }\end{array}$ \\
& $\begin{array}{l}\text { Conceptions } \\
\text { Interviews (science/math faculty) }\end{array}$ & $\begin{array}{l}\text { Conceptions } \\
\text { Data coding, explanation } \\
\text { building }\end{array}$ \\
& $\begin{array}{l}\text { Practices } \\
\text { Action research proposals } \\
\text { AR reports and presentations }\end{array}$ & $\begin{array}{l}\text { Practices } \\
\text { Data coding, explanation } \\
\text { building; "Star diagrams" }\end{array}$ \\
\hline $\begin{array}{l}\text { Action } \\
\text { research }\end{array}$ & & \\
& &
\end{tabular}




\section{Appendix B}

Faculty Interview Questions

\begin{tabular}{|c|c|c|}
\hline \multicolumn{3}{|c|}{ Questions relating to teaching and learning } \\
\hline Focus & Main questions & Supplementary questions \\
\hline $\begin{array}{l}\text { Questions } \\
\text { related to } \\
\text { teaching }\end{array}$ & $\begin{array}{l}\text { Q3. What do you see as your } \\
\text { role and as your students' role in } \\
\text { the teaching and learning } \\
\text { process? } \\
\text { Q4. What makes somebody a } \\
\text { good teacher? } \\
\text { Q5. How has your approach to } \\
\text { teaching developed? }\end{array}$ & $\begin{array}{l}\text { Do you think you achieve your } \\
\text { aims? If so, what helps you? } \\
\text { - What, if anything, prevents you } \\
\text { from achieving your aims? } \\
\text { - What do you do when teaching? } \\
\text { - What approaches do you prefer? } \\
\text { not work? Why didn't they work? } \\
\text { - Do you think about teaching in this } \\
\text { way in all situations? If not, what } \\
\text { are other ways in which you think } \\
\text { about teaching in other contexts? } \\
\text { - What are your and the students' } \\
\text { main responsibilities? } \\
\text { - How do you include them in what } \\
\text { you do? } \\
\text { - How do you know when you are } \\
\text { being a successful teacher? } \\
\text { What, if anything, do you see as } \\
\text { main obstacles to good teaching? } \\
\text { - What is poor teaching? } \\
\text { - What has influenced your } \\
\text { professional development? } \\
\text { What are some important factors, } \\
\text { persons or incidents that have } \\
\text { brought you to where you are now? } \\
\text { and methods with colleagues? }\end{array}$ \\
\hline
\end{tabular}




\begin{tabular}{|c|c|c|}
\hline $\begin{array}{l}\text { Questions } \\
\text { related to } \\
\text { learning }\end{array}$ & $\begin{array}{l}\text { Q7.What is learning? } \\
\text { Q8. How do you know when } \\
\text { students have learned } \\
\text { something? }\end{array}$ & $\begin{array}{l}\text { What does it mean to learn? } \\
\text { - What do students bring to the } \\
\text { learning process? } \\
\text { - What makes a good student? And } \\
\text { what makes a poor student? } \\
\text { If you ask students what they have } \\
\text { learned at the end of the course, } \\
\text { what do you hope they would say? } \\
\text { - Do you communicate to students } \\
\text { the kind of learning you value? If } \\
\text { so, how? } \\
\text { What makes these difficult for } \\
\text { students? }\end{array}$ \\
\hline $\begin{array}{l}\text { Questions } \\
\text { related to } \\
\text { knowledge }\end{array}$ & $\begin{array}{l}\text { Q10. What is knowledge in your } \\
\text { discipline? }\end{array}$ & $\begin{array}{l}\text { Where does knowledge come from? } \\
\text { How does it advance? } \\
\text { - What, if anything distinguishes an } \\
\text { academic teacher from a } \\
\text { practitioner in the same field? } \\
\text { - Are there different types of } \\
\text { knowledge? } \\
\text { How do you deal with the } \\
\text { relationship between theory and } \\
\text { practice? } \\
\text { When teaching a course for the first } \\
\text { time, how do you decide what to } \\
\text { include or leave out? } \\
\text { When you modify your course, } \\
\text { what influences you to make } \\
\text { changes? }\end{array}$ \\
\hline $\begin{array}{l}\text { Questions } \\
\text { linking } \\
\text { teaching } \\
\text { and } \\
\text { students' } \\
\text { learning }\end{array}$ & $\begin{array}{l}\text { Q11. We have talked about } \\
\text { teaching and learning. Does your } \\
\text { teaching influence the way } \\
\text { students learn? If so, how? }\end{array}$ & $\begin{array}{l}\text { What do you think it the biggest } \\
\text { influence on student learning? } \\
\text { What is the most important thing } \\
\text { you do in your teaching that } \\
\text { influences the ways in which } \\
\text { students learn? }\end{array}$ \\
\hline
\end{tabular}




\begin{tabular}{|l|l|}
\hline \multicolumn{2}{|c|}{ Questions relating to student assessment } \\
\hline \multicolumn{1}{|c|}{ Focus } & \multicolumn{1}{c|}{ Main questions } \\
\hline $\begin{array}{l}\text { General } \\
\text { questions } \\
\text { about } \\
\text { assessment }\end{array}$ & $\begin{array}{l}\text { Q1. What is the role of assessment? } \\
\text { Q2. What do you hope to find out by assessing students? } \\
\text { Q3. What types of assessment tasks to you prefer to use and why? } \\
\text { Q4. What do you learn from student's responses, projects, and } \\
\text { assignments? } \\
\text { Q5. What do their responses tell you about their learning? } \\
\text { Q6. What is the difference between a good answer and a bad one? } \\
\text { Q7. How does the information you get from students affect your } \\
\text { teaching? } \\
\text { Q8. Do you provide feedback to students? If so how, and what do you } \\
\text { hope this will achieve? }\end{array}$ \\
\hline $\begin{array}{l}\text { Questions } \\
\text { about } \\
\text { specific } \\
\text { assessment } \\
\text { tasks }\end{array}$ & $\begin{array}{l}\text { Referring to specific assessment items } \\
\text { Q9. Why did you ask this question/task? What were you hoping to } \\
\text { assess? } \\
\text { Q10. Is it possible to answer the question/task by memorization of } \\
\text { information or do they need to integrate information from different } \\
\text { sources? } \\
\text { Q11. What is the difference between a good answer and a bad one? } \\
\text { Q12. What happens in the teaching process that prepares students to } \\
\text { answer this question/task? } \\
\text { Q 13. Do you think about assessment in this way in all contexts? }\end{array}$ \\
\hline
\end{tabular}




\begin{tabular}{|c|c|c|}
\hline \multicolumn{3}{|c|}{ Questions relating to action research } \\
\hline Focus & \multicolumn{2}{|c|}{ Main questions } \\
\hline $\begin{array}{l}\text { General } \\
\text { questions } \\
\text { about action } \\
\text { research }\end{array}$ & \multicolumn{2}{|c|}{$\begin{array}{l}\text { Q1. What is the purpose of action research? } \\
\text { Q2. What might be some of the anticipate outcomes of action research? } \\
\text { Q3. What makes good action research? What makes poor action } \\
\text { research? } \\
\text { Q4. When would you use action research? } \\
\text { Q5. Whom would you involve in the process? Why? } \\
\text { Q6. How would you use the findings? } \\
\text { Q7. Does action research have a role in the disciplines in higher } \\
\text { education? } \\
\text { Q8. How is action research different from other research? }\end{array}$} \\
\hline & Main questions & Supplementary Questions \\
\hline $\begin{array}{l}\text { Questions } \\
\text { about } \\
\text { specific } \\
\text { action } \\
\text { research } \\
\text { undertaken }\end{array}$ & $\begin{array}{l}\text { Q12. What factors facilitated } \\
\text { implementation of the action } \\
\text { research? } \\
\text { Q13. Do you plan to conduct action } \\
\text { research in the future? } \\
\text { Q14. Have you shared your research } \\
\text { with others at your university or } \\
\text { elsewhere? } \\
\text { Q15. What advice would you give to } \\
\text { others interested in initiating action } \\
\text { research? }\end{array}$ & $\begin{array}{l}\text { - How did you choose a focus? } \\
\text { - What did you hope to } \\
\text { achieve? } \\
\text { - How did you decide on } \\
\text { these? } \\
\text { - Were they effective? What } \\
\text { would you do differently? } \\
\text { What have you learned about } \\
\text { students? } \\
\text { What have you learned about } \\
\text { teaching? } \\
\text { - What have you learned about } \\
\text { yourself? } \\
\text { Did you do anything } \\
\text { differently after the research? } \\
\text { What were some of the } \\
\text { constraints? How would you } \\
\text { overcome these? } \\
\text { - Why or why not? } \\
\text { If yes, can you suggest a } \\
\text { possible focus? } \\
\text { If yes, how was this } \\
\text { received? }\end{array}$ \\
\hline
\end{tabular}




\section{Appendix C \\ ESTEEM CLASSROOM OBSERVATION RUBRIC}

\section{Directions:}

The Science Classroom Observation Rubric is used to assess expert science teaching from a constructivist perspective. A rubric is an analytical scoring guide. In order to administer the rubric, documentation is needed. Documentation may be in the form of a written record (script of all classroom activities, presentations, interactions, etc.), a video tape, or an audio tape. An administrator of this rubric should spend time learning the practices described on the rubric.

A Pre-observation discussion/interview should be completed before the classroom observation. This discussion helps to clarify the lesson purpose, procedures, and outcomes.

Classroom behaviors from the record are to be compared with the descriptions in the rubric (scoring guide). If the classroom behavior is best described by the " 5 " level description, then the rating should be a " 5 ." If the classroom behavior is best described by a " 3 " level description, then the rating should be a " 3 ." However, if the classroom behavior would be best described somewhere between a " 5 " and a " 3 ," then a " 4 " rating should be used. A " 2 " rating would fall between a "3" and a " 1 ." Teaching practices are described at a " 5 ," " 3 ," and " 1 " level. Ratings of " 4 " and " 2 " should be used when the behavior would be best described between " 5 " and " 3 " and " 3 " and " 1 " respectively. Ratings should be recorded on the accompanying scoring sheet.

The ESTEEM Instruments, Copyright, 1995

Judith A. Burry-Stock 


\section{ESTEEM}

\section{Pre-observation Interview}

An observation form should be completed before a classroom observation is done. Instructor Date

Observer (if there is one)

Institution

Course \# \& title

Topic of Lesson

Length of the Lesson (Circle One)

Placement of lesson within the Course

Purpose of the lesson

Intended Outcome

Materials and/or text used (Copies should be given to the observer ahead of the classroom observation.)

Other Comments

The ESTEEM Instruments, Copyright, 1995

Judith A. Burry-Stock 


\section{ESTEEM \\ SCIENCE CLASSROOM OBSERVATION RUBRIC \\ (Teaching Practices)}

\section{Category I: Facilitating the Learning Process from a Constructivist Perspective}

\section{A. Teacher as a Facilitator}

$5 \quad$ Students are responsible for their own learning experience.

Teacher facilitates the learning process. Teacher-student learning experience is a partnership.

3 Students are not always responsible for their own learning experience. Teacher directs the students more than facilitates the learning process. (Teacher-student learning experience is more teacher-centered than student-centered.)

1 Students are not responsible for their own learning experience. Teacher directs the learning process. (Teacher-student learning experience is completely teacher-centered, i.e. teacher lectures or demonstrates and never interacts with students.)

\section{B. Student Engagement in Activities}

5 Students are actively engaged in initiating examples, asking questions, and suggesting and implementing activities throughout the lesson.

3 Students are partially engaged in initiating examples and asking questions at times during the lesson.

1 Students are almost never engaged in initiating examples and asking questions during the lesson.

C. Student Engagement in Experience

5 Students are actively engaged in experiences (physically and/or mentally.)

3 Students are moderately engaged in experiences.

1 Students are seldom engaged in experiences.

D. Novelty

5 Novelty, newness, discrepancy, or curiosity are used consistently to motivate learning. 
3 Novelty, newness, discrepancy, or curiosity are used sometimes to motivate learning.

1 Novelty, newness, discrepancy, or curiosity are used occasionally or not at all $t$ motivate learning.

\section{E. Textbook Dependency}

5 Teacher does not depend on the text to present the lesson. Teacher and students adapt or develop own content materials for their needs.

3 Teacher does depend somewhat on the text to present the lesson. Teacher and students make some modifications.

1 Teacher does depend solely on the text to present the lesson. Teacher makes no modifications with students.

\section{Category II: Content-Specific Pedagogy (Pedagogy Related to Student Understanding)}

\section{F. Student Conceptual Understanding}

5 The lesson focuses on activities that relate to student understanding of concepts.

3 Most of the time the lesson focuses on activities that relate to student understanding of concepts.

1 Much of the time the lesson focuses on activities that do not relate to student understanding of concepts.

G. Student Relevance

5 Student relevance is always a focus and the lesson relates to student experiences outside the classroom.

3 Student relevance is always a focus.

1 Student relevance is not a focus

H. Variation of Teaching Methods

5 During the lesson the teacher appropriately varies methods to facilitate student conceptual understanding; i.e., discussion, questions, brainstorming, experiments, log reports, student presentation, lecture, demonstration, etc. 
3 During the lesson the teacher sometimes varies methods to demonstrate the content; i.e., discussion, questions, brainstorming, experiments, log reports, student presentations, lecture, demonstration, etc.

1 During the lesson the teacher uses only one method to demonstrate the content; i.e., discussion, questions, brainstorming, experiments, $\log$ reports, student presentation, lecture, demonstration, etc.

\section{Higher-Order-Thinking Skills}

5 Teacher consistently moves students through different cognitive levels to reach higher order thinking skills.

3 Teacher sometimes moves students through different cognitive levels to reach higher order student thinking skills.

1 Teacher does not move students through different cognitive levels to reach higher order thinking skills.

J. Integration of Content and Process Skills

5 Content and process skills are integrated.

3 Content and process skills are not integrated.

1 Content is taught without process or process without content.

K. Connection of Content and Evidence

5 Concepts are connected to the evidence.

3 Concepts are partially connected to evidence.

1 Concepts are not connected to evidence.

\section{Category III: Context-specific Pedagogy (Fluid Control with Teacher and Student Interaction)}

\section{Resolution of Misperceptions}

5 As student misperceptions become apparent, the teacher facilitates student efforts to resolve them by gathering evidence, partipating in discussion with students, or fostering discussion among students.

3 As student misperceptions become apparent, the teacher usually facilitates student efforts to resolve them by gathering evidence, 
participating in discussion with students, or fostering discussion among students.

1 As student misperceptions become apparent, the teacher does not facilitate student efforts to resolve them by gathering evidence, participating in discussion with students, or fostering discussion among students.

\section{Teacher-Student Relationships}

5 Teacher consistently demonstrates good interpersonal relations with students. No differentiation is made regarding: ethnicity, gender, multi-cultural diversity, and special education classifications.

3 Teacher does not consistently demonstrate good interpersonal relations with students most of the time. On occasion, some differentiation is made regarding: ethnicity, gender, multi-cultural diversity, and special education classifications.

1 Teacher does not demonstrate good interpersonal relations with students. Differentiation is made regarding: ethnicity, gender, multi-cultural diversity, and special education classifications.

N. Modifications for Student - Understanding

5 Teacher has continuous awareness of his/her student understanding and modifies the lesson when necessary.

3 Teacher has a general awareness of student understanding and occasionally modifies the lesson when necessary.

1 Teacher has little or no awareness of student understanding and does not modify the lesson when it is appropriate.

\section{Category IV: Content-Knowledge (Teacher Demonstrates Excellent Knowledge of Subject Matter)}

\section{O. Use of Exemplars}

$5 \quad$ Exemplars and metaphors (verbal, visual, and physical) are frequently used and are accurate and relevant throughout the lesson.

3 Exemplars and metaphors (verbal, visual, and physical) are sometimes used and are accurate and relevant some of the time.

1 Exemplars and metaphors are rarely used and are not accurte and relevant. 
P. Coherent Science Experience (Lesson)

5 Concepts, generalizations, and skills are integrated coherently throughout the experiences (lesson).

3 Concepts, generalizations, and skills are not always integrated as a coherent organization of events throughout the experience (lesson).

1 Concepts, generalizations, and skills are not integrated and lack coherency throughout the experience (lesson).

Q. Balance Between Depth and Comprehensiveness

5 content has an appropriate balance between in-depth and comprehensive coverage.

3 Lesson does not have an appropriate balance between depth and comprehensive much of the time. (Lesson has too much depth for the topic and too little coverage, or lesson has too much coverage and too little depth.)

1 Content is shallow, incomplete, or lacking. (Lesson has neither depth or breadth.)

R. Accurate Content

5 Content is always evident and always accurate.

3 Content is usually evident and mostly accurate.

1 Content is missing or inaccurate.

Revised March, 1995

Originally written by the committee of: Kathleen Bolland, Judy Burry-Stock, David Hedgepath, Kathleen Pittman, Jeanie Rice Seprenant, Dennis Sunal, Melanie Turner, and Zhicheng Zhang. Contributing editors are lead teachers and staff (special credit to Gary Varrella) from Iowa's Scope, Sequence, \& Cooordination and Chatauqua Programs coordinated by the University of Iowa's Science Education Center.

The ESTEEM Instruments, Copyright, 1995

Judith A. Burry-Stock 


\section{CLASSROOM OBSERVATION RUBRIC SCORING SHEET}

Teacher's Name: Date:

Category I: Facilitating the Learning Process
A.
B.
C.
D.
E.

Subtotal $125=$ $\%$

Category II: Content-specific Pedagogy

F.
G.
H.
I.
J.
K.

Subtotal $130=$ $\%$

Category III: Context-specific Pedagogy

L.

M.

N.

Subtotal $115=$ $\%$

Category IV: Content-Knowledge

o.

P.

Q.

R.

Subtotal $120=$ $\%$

Instrument Total $190=$ $\%$ 


\section{ESTEEM}

CLASSROOM OBSERVATION RUBRIC PROFILE

Name: Date:

\begin{tabular}{|c|c|c|c|c|c|c|}
\hline $\begin{array}{c}\text { Competency } \\
\text { Level }\end{array}$ & $\begin{array}{l}100 \\
90 \\
80 \\
70 \\
60 \\
50 \\
40 \\
30 \\
20 \\
10 \\
0\end{array}$ & $\begin{array}{l}\bullet \\
\qquad \\
\qquad \\
\qquad \\
\bullet \\
\qquad \\
\qquad \\
\text { Category } 1 \\
\text { Facilitating } \\
\text { the } \\
\text { Learning } \\
\text { Process }\end{array}$ & 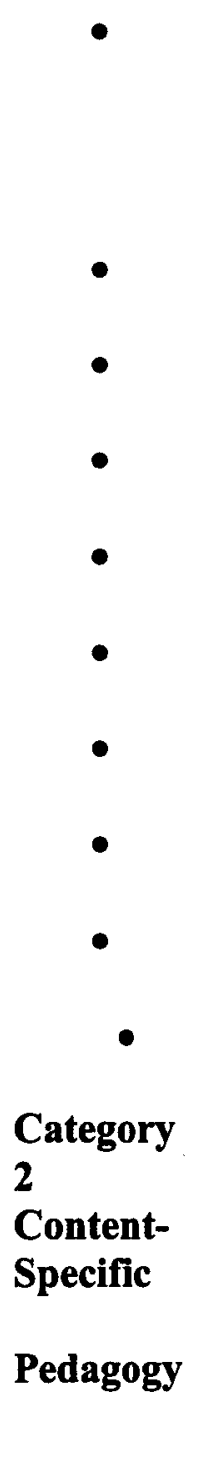 & $\begin{array}{c}\bullet \\
\bullet \\
\bullet \\
\bullet \\
\bullet \\
\bullet \\
\bullet \\
\bullet \\
\bullet \\
\text { Category } \\
\text { 3 } \\
\text { Content- } \\
\text { Specific } \\
\text { Pedagogy }\end{array}$ & $\begin{array}{l}\bullet \\
\bullet \\
\bullet \\
\bullet \\
\bullet \\
\bullet \\
\text { Category } 4 \\
\text { Content - } \\
\text { Knowledge }\end{array}$ & $\begin{array}{r}\bullet \\
\bullet \\
\bullet \\
\bullet \\
\bullet \\
\bullet \\
\bullet \\
\bullet \\
\bullet \\
\bullet \\
\text { TOTAL }\end{array}$ \\
\hline
\end{tabular}




\section{Appendix D}

\section{Students Interview Questions}

Describe the course.

How do you feel about this course?

How does this course compare to other courses you have taken at the undergraduate level in science (mathematics)? What makes it different?

What are the characteristics of an effective teacher in a science (mathematics) course?

How do you feel about the teaching methods used in this course? Have your ideas of teaching science (mathematics) changed as a result of taking this course?

Do you feel differently toward science (mathematics) as a result of your experience in this course? What in this course has led you to reaffirm or change your views?

For education majors only:

Do you think that you can become an effective teacher of science (mathematics)? Why?

Do you think that you can teach science (mathematics) to students with low motivation?

Why? 


\section{Appendix E}

\section{APPROACHES TO TEACHING INVENTORY}

This inventory is designed to explore the way that academics go about teaching in a specific context or subject or course. This may mean that your responses to these items in one context may be different to the responses you might make on your teaching in other contexts or subjects. For this reason we ask you to describe your context.

Please describe the subject/year of your response here:

For each item please circle one of the numbers (1-5). The numbers stand for the following responses:

1 - this item was only rarely true for me in this subject.

2 - this item was sometimes true for me in this subject.

3 - this item was true for me about half the time in this subject.

4 - this item was frequently true for me in this subject.

5 - this item was almost always true for me in this subject.

Please answer each item. Do not spend a long time on each: your first reaction is probably the best one.

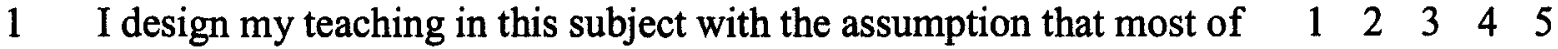
the students have very little useful knowledge of the topics to be covered.

$\begin{array}{lllllll}2 & \text { I feel it is important that this subject should be completely described } & 1 & 2 & 3 & 4 & 5\end{array}$ in terms of specific objectives relating to what students have to know for formal assessment items.

3 In my interactions with students in this subject I try to develop a conversation with them about the topics we are studying.

4 I feel it is important to present a lot of facts to students so that they know what they have to learn for this subject.

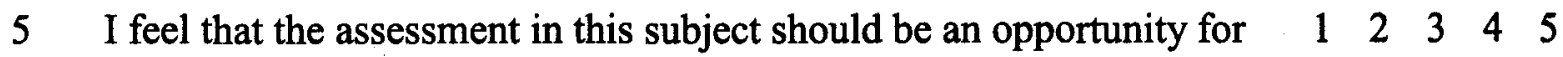
students to reveal their changed conceptual understanding of the subject.

$\begin{array}{lllllll}6 & \text { I set aside some teaching time so that the students can discuss, among } & 1 & 2 & 3 & 4 & 5\end{array}$ themselves, the difficulties that they encounter studying this subject.

$\begin{array}{lllllll}7 & \text { In this subject I concentrate on covering the information that might be } & 1 & 2 & 3 & 4 & 5\end{array}$ available from a good textbook.

$\begin{array}{lllllll}8 & \text { I encourage students to restructure their existing knowledge in terms } & 1 & 2 & 3 & 4 & 5\end{array}$ of the new way of thinking about the subject that they will develop.

9 In teaching sessions for this subject, I use difficult or undefined

$\begin{array}{lllll}1 & 2 & 3 & 4 & 5\end{array}$ 
examples to provoke debate.

10 I structure this subject to help students to pass the formal assessment $\begin{array}{lllll}1 & 2 & 3 & 4 & 5\end{array}$ items.

11 I think an important reason for running teaching sessions in this subject is to give students a good set of notes.

12 In this subject, I only provide the students with the information they $\begin{array}{lllll}1 & 2 & 3 & 4 & 5\end{array}$ will need to pass the formal assessments.

13 I feel that I should know the answers to any questions that students $\quad \begin{array}{lllll}1 & 2 & 3 & 4 & 5\end{array}$ may put to me during this subject.

14 I make available opportunities for students in this subject to discuss $\quad \begin{array}{lllll}1 & 2 & 3 & 4 & 5\end{array}$ their changing understanding of the subject.

15 I feel that it is better for students in this subject to generate their own $\begin{array}{lllll}1 & 2 & 3 & 4 & 5\end{array}$ notes rather than always copy mine.

16 I feel a lot of teaching time in this subject should be used to question $\begin{array}{lllll}1 & 2 & 3 & 4 & 5\end{array}$ students' ideas. 


\section{Appendix F}

\section{Modified STEBI B (NOVA Team Members)}

Name

Please indicate the degree to which you agree or disagree with each statement below by circling the appropriate letters to the right of each statement.

$$
\begin{aligned}
\text { SA } & =\text { STRONGLY AGREE } \\
\mathbf{A} & =\text { AGREE } \\
\mathbf{U N} & =\text { UNCERTAIN } \\
\mathbf{D} & =\text { DISAGREE } \\
\mathbf{S D} & =\text { STRONGLY DISAGREE }
\end{aligned}
$$

The questions below refer to undergraduate students in courses you teach.

1. When an undergraduate student does better than usual, SA A UN D SD it is often because the instructor exerted extra effort.

2. I am continually finding better ways to teach. SA A UN D SD

3. Even if I try very hard, I do not teach students $\quad$ SA A UN D SD as well as other instructors.

4. When the grades of students improve it is often SA A UN D SD due to their instructor having found a more effective teaching approach.

5. I know the steps necessary to teach science or

SA A UN D SD mathematics concepts effectively.

6. I am not very effective in helping my students

SA A UN D SD in their assignments.

7. If students are underachieving, it is

SA A UN D SD most likely due to ineffective teaching.

8. I generally teach ineffectively.

SA A UN D SD

9. The inadequacy of a student's background can be

SA A UN D SD overcome by good teaching.

10. The low achievement of students cannot generally

SA A UN D SD be blamed on their instructors.

11. When a low-achieving student progresses in science

SA A UN D SD 
or mathematics, it is usually due to extra attention given by the instructor.

12. I understand pedagogy well enough to be effective SA A UN D SD in teaching.

13. Increased effort in teaching produces little change in students' achievement.

SA A UN D SD

14. The instructor is generally responsible for the SA A UN D SD achievement of students in science or mathematics.

15. Students' achievement in science or mathematics is directly related to their instructor's effectiveness in teaching.

16. If a student is showing more interest in learning, SA A UN D SD it is probably due to the teaching performance of the student's instructor.

17. I find it difficult to explain to students why science SA A UN D SD or mathematics ideas make sense.

18. I am able to answer students' questions.

SA A UN D SD

19. I have the necessary skills to teach effectively.

SA A UN D SD

20. Given a choice, I would not invite a peer to evaluate my teaching.

SA A UN D SD

21. I do not know what to do to turn students on to SA A UN D SD science or mathematics.

SA A UN D SD

22. When a student has difficulty understanding a concept,

SA A UN D SD I am usually at a loss as to how to help the student understand it better.

23. Even instructors with good teaching abilities cannot help SA A UN D SD some students to learn science or mathematics.

24. When teaching, I usually welcome student SA A UN D SD questions.

25. Effectiveness in teaching has little influence SA A UN D SD on the achievement of students with low motivation. 


\section{Appendix G}

\section{ESTEEM ASSESSMENT OF CLASSROOM LEARNING IN SCIENCE INVENTORY}

Directions: Science teachers are continuously involved in assessment of student learning. This inventory addresses the degree to which you feel that you are skilled in using various classroom learning assessment practices. There are no right or wrong answers.

Scoring: Record your responses on the answer sheet designed for this inventory For each of the following statements, rate the degree to which you feel that you are skilled in implementing each of the following activities for assessing classroom learning in science. A " 1 indicates that you feel that you are "NOT AT ALL SKILLED" in using the statement as an assessment of classroom learning activity. A " 5 " indicates that you feel that you are "HIGHLY SKILLED" in using the statement as an assessment of classroom learning activity. You may also choose any of the numbers in between " 1 " and " 5 " that best describe you. Read each statement and record the number that best represents how skilled you feel you are about using the assessment of classroom learning activity. 


\section{ASSESSMENT OF CLASSRO $6 \mathrm{M}$ LEARNING IN SCIENCE INVENTORY}

NOT AT ALL SKILLED

$n / 2 / 3 / 4 / 5$

HIGHLY SKILLED

1. Using teacher-made paper-pencil tests.

2. Using multiple-choice questions.

3. Using matching questions.

4. Using true/false questions.

5. Using short answer questions.

6. Assigning letter grades.

7. Assigning number grades.

8. Obtaining diagnostic information from standardized norm-referenced tests for enhancing instruction.

9. Obtaining diagnostic information from standardized criterion-referenced tests for enhancing instruction.

10. Using performance measures.

11. Using concept mapping for informal assessment

12. Using concept mapping for grading purposes.

13. Using portfolios for grading purposes.

14. Implementing systematic grading procedures.

15. Implementing a grading model.

16. Developing a grading philosophy.

17. Communicating criteria to students.

18. Weighing differently projects, exams, homework, etc. when assigning semester grades.

19. Developing classroom incentive systems to enhance achievement.

20. Developing assessments that are based on clearly defined objectives.

2 1. Establishing student expectations for determining grades.

22. Using announced quizzes for informed feedback.

23. Incorporating homework in the grading model.

24. Using individual science reports for grading purposes.

25. Using science fair projects.

26. Using individual laboratory reports for grading purposes.

27. Using group laboratory reports for grading purposes.

28. Using systematic procedures for determining borderline grades.

29. Using group oral discussion for informal assessment.

30. Using teacher student oral discussion for informal assessment.

31 . Using group or participation for informal assessment.

32. Enhancing student motivation for learning.

33. Providing timely written feedback.

34. Providing immediate oral feedback.

35. Incorporating extra credit activities in the calculation of grades.

36. Using oral questions from, students for informal. assessment.

37. Using laboratory/activity worksheets for grading purposes.

38. Using individual hands-on activities for informal assessment.

39. Using group hands-on activities for informal assessment.

40. Using individual class presentations for grading purposes.

The ESTEEM Instruments, Copyright, 1995 Judith A. Burry-Stock 


\section{ASSESSMENT OF CLASSROOM LEARNING IN SCIENCE INVENTORY}

NOT AT ALL SKILLED

$/ \mathbf{2} / \mathbf{3 / 4 / 5}$

HIGHLY

\section{SKILLED}

41. Using group class presentations for grading purposes.

42. Using the end-of-chapter questions for enhancing student understanding.

43. Using teacher observations for informal evaluation.

44. Incorporating hands-on activities for enhancing student understanding.

45. Incorporating computer projects for enhancing student understanding.

46. Incorporating computer exercises for grading purposes.

47. Using class review questions for enhancing student understanding.

48. Choosing appropriate assessment methods for grading purposes.

49. Using assessment results when making decisions (instructional, placement, and promotion) about individual students.

50. Using assessment results when planning teaching.

51 . Using assessment results in curriculum development.

52. Using formal assessment results when evaluating class improvement.

53. Communicating assessment results to students.

54. Communicating assessment results to parents.

55. Recognizing unethical, illegal, and otherwise inappropriate assessment methods.

56. Recognizing unethical, illegal, and otherwise inappropriate assessment uses of assessment information.

57. Communicating grading expectations?

'Revised 1994. Judith Burry-Stock. The forerunner of this instrument was the Grading Practice Assessment Inventory written by Rosalyn Malcolm-Payne and Judith Burry. 


\section{ESTEEM}

\section{ASSESSMENT OF CLASSROOM LEARNING IN SCIENCE INVENTORY}

\section{ANSWER SHEET}

Pseudonym:

1.

2.

3.

4.

5.

6.

7.

8.

9.

10.

11.

12.

13.

14.

15.

16.

17.

18.

19.

20.

21.

22.

23.

24.

25.

26.

27.

28.

29.

30.

31.

32.
Date:

33.

34.

35.

36.

37.

38.

39.

40.

41.

42.

43.

44.

45.

46.

47.

48.

49.

50.

51.

52.

53.

54.

55.

56.

57.

The ESTEEM Instruments, Copyright, 1995 Judith A. Burry-Stock 


\section{Appendix H}

\section{Subject Informed Consent Form}

\section{CASES OF FACULTY CONCEPTIONS AND PRACTICES OF TEACHING, ASSESSMENT AND ACTION RESEARCH}

\section{Introduction and Background Information}

You are invited to participate in a research study. The study is being conducted by Mrs Dianne Raubenheimer, a Ph.D. student in the Department of Leadership, Foundations and Human Resource Education in the College of Education and Human Development at the University of Louisville, Kentucky, under the supervision of Professor Sandra Mathison. The study will take place at several NOVA funded sites. Approximately nine subjects will be invited to participate. It is anticipated that the study will be completed by May 2004, and your participation will be requested various at points during that time.

\section{Purpose}

The purpose of this research is:

- To examine conceptions of teaching and learning, assessment and action research held by science and mathematics faculty involved in NOVA funded courses.

- To explore the relationship among these conceptions and actual practices of teaching and learning, assessment and action research.

- To consider the role of action research in faculty development and conceptual change in the context of the NOVA program.

- To consider whether such practices constitute the scholarship of teaching and learning (SOTL).

\section{Procedures}

Your involvement will include approximately three and a half hours of interviews, and completion of two survey instruments, namely (a) the Approaches to Teaching Inventory, and (b) the Grading Practice Assessment Inventory, each taking approximately half an hour. The surveys will be sent to you to complete at your convenience, to be returned by mail to the sub-investigator. You will also be asked to make available copies of your NOVA course syllabus and the assessment items used with students. You may refuse to answer any questions that make you feel uncomfortable or refuse to supply any documentation requested. You will also be requested to read transcripts and full case records to verify the content.

You have my permission to use the existing data about myself and my NOVA course housed in the database at the Science Teaching and Learning Center, University of Alabama, Tuscaloosa.



$\overline{\text { Subject's initials }} \quad \overline{\text { Date }}$




\section{Potential Risks}

There are no foreseeable risks associated with this study, although unforeseeable risks may arise.

\section{Benefits}

The information collected may not benefit you directly, although it will be made available to you as a final case record. The information learned in this study may be helpful to others, particularly in planning future faculty development initiatives.

\section{Confidentiality}

Although absolute confidentiality cannot be guaranteed, confidentiality will be protected to the extent permitted by law. It must be noted that email is not always a secure means of communication and that confidentiality cannot be assured. Email programs are often not private and may even be monitored by employers. If you are concerned about this you may opt for telephonic interviews. I would prefer the interviews to be conducted by



$$
\overline{\text { Subject's initials }} \quad \overline{\text { Date }}
$$

You will be asked to create your own pseudonym to protect your name. The Human Studies Committees, or other appropriate agencies may inspect your research records. Should the data collected in this research study be published, your identity will not be revealed.

\section{Voluntary Participation}

Your participation in this research study is voluntary. You are free to withdraw your consent at any time without penalty or losing benefit to which you are otherwise entitled.

\section{Research Subject's Rights and Contact Persons}

You acknowledge that all your present questions have been answered in language you can understand and all future questions will be treated in the same manner. If you have any questions about the study, please contact Mrs. Dianne Raubenheimer (subinvestigator) at 270-686 6415) or Dr. Sandra Mathison (principal investigator) at 502852-0616.

If you have any questions about your rights as a research subject, you may call the Human Studies Committees office (502) 852-5188. You will be given the opportunity to discuss any questions about your rights as a research subject, in confidence, with a member of the committees. These are independent committees composed of members of the University community, staff of the institutions, as well as lay members of the community not connected with these institutions. The Committee has reviewed this study. 


\section{Consent}

You have discussed the above information and hereby consent to voluntarily participate in this study. You signed and been given a copy of the consent.

Signature of Subject

Date Signed

Signature of Person Explaining Consent if other than Investigator

Date Signed

Signature of Investigator

Date Signed

Revised 09/26/03 


\section{CURRICULUM VITAE}

NAME: Carol Dianne Raubenheimer

ADDRESS: 74 Sleepy Creek Drive

Clayton

NC 27520

DOB: $\quad$ Ladysmith, South Africa, 29 January, 1959

\section{EDUCATION}

\& TRAINING: $\quad$ B. Sc. Cell Biology, Environmental Biology

University of Natal, Durban, South Africa

1977-1979

B. Sc. Honors, Cell Biology, Animal Behavior

University of Natal, Durban, South Africa

1980

M. Sc, Environmental Biology

University of Natal, Durban, South Africa

Completed 1986

Advanced Diploma in Adult Education

University of Natal, Durban, South Africa

1990-1991

M. Ed., Curriculum development and evaluation

University of Natal, Durban, South Africa

1993-1996

\section{PUBLICATIONS:}

Raubenheimer. C. D. (2004). Lessons from Research: Professional Development of University Science Faculty Through Action Research. In D. W. Sunal, E. Wright \& J. Bland (Eds.), Research in Science Education: Reform in Undergraduate Science Teaching for the $21^{\text {st }}$ Century. Greenwich, CT: Information Age Publishing, Inc.

Raubenheimer. C. D. (2003). Faculty conceptions and practices of action research in the NOVA program. Paper presented at the 2003 AERA Convention, Chicago, IL. 
McKinnon, K., \& Raubenheimer, C. D. (2003). Professional development of university faculty in pedagogical content knowledge and student learning. Paper presented at the 2003 AERA Convention, Chicago, IL

Raubenheimer, C. D. (2003). A formative evaluation of the Center for Improvement in Mathematics, Science and Technology Education (CIMSTE) at the University of South Africa. . Pretoria, South Africa: CIMSTE, UNISA.

Sunal, D., Gardener, F., Kallam, L., McAllister, D., McKinnon, C., Raubenheimer, C.D., \& Staples, K. (2002). NASA Opportunities for Visionary Academics (NOVA) evaluation report. Tuscaloosa, AL: University of Alabama.

Raubenheimer, C. D. (1999). A case study evaluation of five schools in the Toyota Teach Primary School Project. Durban, South Africa: The Toyota Teach Primary School Project

Raubenheimer, C. D. et al (1999). Science Today: Grade 7. Cape Town, South Africa: Maskew Millar Longman

Raubenheimer, C. D. (1998). An evaluation of the curriculum development processes and products at the Mathematics, Science and Technology Education College (MASTEC). Pietersburg, South Africa: MASTEC.

Raubenheimer, C. D. (1998). What do educators learn by examining technological systems? Proceedings of the sixth annual meeting of the Southern African Association for Mathematics and Science Education (SAARMSE), 14-17 January 1998. Pretoria: University of South Africa.

Raubenheimer, C. D. (1998). Issues arising from an evaluation of the Gencor Science Foundation Programme, University of Natal, Pietermaritzburg. Proceedings of the sixth annual meeting of the SAARMSE. 14-17 January 1998. Pretoria: University of South Africa.

Raubenheimer, C. D. (1997). An evaluation of the Gencor Science Foundation programme, University of Natal, Pietermaritzburg. Durban: IPEB

Raubenheimer, C. D., Lange, R. V., \& Mfeka, S. (1997). Children and adults learning in an interactive setting, Proceedings of the fifth annual meeting of SAARMSE, 22-26 January 1997. Johannesburg: University of the Witwatersrand.

Russell, E., \& Raubenheimer, C. D. (1997). Camp to classroom... lessons about gender for interactive learning. Proceedings of the fifth annual meeting of 
SAARMSE, 22-26 January 1997. Johannesburg: University of the Witwatersrand.

Majara, K., \& Raubenheimer, C. D. (1997). Reflections on teachers as researchers. Proceeding of the fifth annual meeting of SAARMSE, 22-26 January 1997. Johannesburg: University of the Witwatersrand.

Hardman, S., \& Raubenheimer C. D. (1996). Why business education partnerships? An International perspective and the South African contextual framework. Durban: Institute for Partnerships between Education and Business.

Hardman, S., Raubenheimer, C. D., \& Mtshonthsi, V. (1996). Systemic education reform through education business partnerships. Durban: IPEB

Raubenheimer, C. D. (1994). Trends in assessment in primary science education. Forum on Assessment, 2.

Raubenheimer, C. D . (1994). Shift in practice, shift in paradigm? Southern African Journal of Mathematics and Science Education, 1,(1), p 3 - 19.

Webb, P., \& Raubenheimer, C. D. (1994). Strengthening and upgrading practical work in schools: A primary science response. In P. Lynch (Ed), Upgrading and strengthening practical work in South African schools. Johannesburg: University of the Witwatersrand.

Raubenheimer, C. D. (Ed) (1994). Proceedings of the second curriculum conference of the Primary Science Conference. Durban: The Primary Science Programme.

Raubenheimer, C.D. (1993) A holistic model to teacher development: Who drives the bus? Perspectives in Education, 14,(2) p 67 - 80.

McNaught, C., Raubenheimer, C.D., Keogh, M., Donoghue, R. \& Taylor, J. (1992). Developing networks of grass-roots science curriculum action. Research in Science Education, 22, p 291 - 298.

Raubenheimer, C. D. (1992). Mrs Khumalo's Garden: An instrument for assessing process skills. Durban: Primary Science Programme.

Raubenheimer, C. D. (1992). Some assessment issues in primary science education. Forum on Assessment, 1, pp 1.

Raubenheimer, C. D., \& Keogh, M. I. (1992). Workshops can they work? Report of a workshop held at the Natal Science Education Convention, July 1992. SCISA Occasional Paper, 1, p1 - 8. 
Raubenheimer, C. D. (1992). Proceedings of the first PSP curriculum conference. Durban: The Urban Foundation

Raubenheimer, C.D. (1992). Some issues in curriculum development in South Africa. Proceedings of one-day seminars presented by Professor Paul Black during September 1992. Johannesburg: University of the Witwatersrand.

McNaught, C., \& Raubenheimer. C. D. (Eds) (1991). Critical reflections on teachers in action: An evaluation report of the Natal Primary Science Project. Durban: The urban Foundation.

Raubenheimer, C.D. (1991). Issues in Inset. Proceedings of the Inset Policy Initiative Workshop, 29 May, 1991, Durban: The Urban Foundation.

McNaught, C., Raubenheimer, C. D., Keogh, M., Taylor, J., \& O'Donoghue, R. (1990). Science Curriculum Initiative in South Africa: A Model for participatory curriculum development. Proceedings of the National Subject Didactics Symposium, p 310 - 322. Stellenbosch: University of Stellenbosch.

Raubenheimer, C .D. (1990). A holistic model to teacher development.

Proceedings of the South African Association for Learning and Education Disabilities (SAALED) Conference (12 -14 September). Cape Town: University of Cape Town.

McNaught, C., Raubenheimer, C. D., \& Keogh, M. (1989). A general science syllabus for standards 3 to 7: A report of a workshop held at Michaelhouse, 11 - 12 January, 1989. Durban: Science Curriculum Initiative in South Africa.

Raubenheimer, C. D. (1988). The Role of the primary school science teacher. SAATPS - SAATB Newsletter, 2. 